UNIVERSIDADE DE BRASÍLIA

FACULDADE DE TECNOLOGIA

DEPARTAMENTO DE ENGENHARIA FLORESTAL

\title{
AVALIAÇÃO DA QUALIDADE DE BRIQUETES PRODUZIDOS COM SEIS BIOMASSAS AGROFLORESTAIS POR MÉTODOS NÃO DESTRUTIVOS
}

FREDERICO DE SOUZA

ORIENTADOR: AILTON TEIXEIRA DO VALE CO-ORIENTADOR: WALDIR FERREIRA QUIRINO

TESE DE DOUTORADO EM CIÊNCIAS FLORESTAIS

PUBLICAÇÃO: PPGEFL.TD - 48/2014

BRASÍLIA/DF: DEZEMBRO - 2014 


\section{FICHA CATALOGRÁFICA}

SOUZA, FREDERICO.

Avaliação da qualidade de briquetes produzidos com seis biomassas agroflorestais por métodos não destrutivos. 2014.

x. 142p., 210-297 mm (EFL/FT/UnB), Doutor, Tese de Doutorado - Universidade de Brasília. Faculdade de Tecnologia. Departamento de Engenharia Florestal.
1. Briquetes
4. Biomassas Agroflorestais
2. Avaliação Não Destrutiva
5. Densidade Energética
3. Qualidade de briquetes
6. Raios-X
I. EFL/FT/UnB
II. Título (série)

\section{REFERÊNCIA BIBLIOGRÁFICA}

SOUZA, F. (2014) Avaliação da qualidade de briquetes produzidos com seis biomassas agroflorestais por métodos não destrutivos. Tese de Doutorado em Ciências Florestais, Publicação PPGEFL.TD - 48/2014, Departamento de Engenharia Florestal, Universidade de Brasília, Brasília, DF, 142p.

\section{CESSÃO DE DIREITOS}

AUTOR: Frederico de Souza

TÍTULO: Avaliação da qualidade de briquetes produzidos com seis biomassas agroflorestais por métodos não destrutivos.

GRAU: Doutor

ANO: 2014

É concedida a Universidade de Brasília e quem mais interessar, a reprodução e divulgação total ou parcial deste trabalho, por qualquer meio convencional ou eletrônico, para fins de estudo e pesquisa, desde que citada a fonte.

\section{Frederico de Souza}

Instituto Federal de Educação, Ciência e Tec. de Brasília, Campus Samambaia.

Subcentro Leste, Complexo Boca da Mata, Lote 01, CEP.: 72.304-300

Samambaia - DF - Brasil. 


\section{UNIVERSIDADE DE BRASÍLIA}

FACULDADE DE TECNOLOGIA

DEPARTAMENTO DE ENGENHARIA FLORESTAL

\section{AVALIAÇÃO DA QUALIDADE DE BRIQUETES PRODUZIDOS COM SEIS BIOMASSAS AGROFLORESTAIS POR MÉTODOS NÃO DESTRUTIVOS}

\section{FREDERICO DE SOUZA}

TESE DE DOUTORADO SUBMETIDA AO PROGRAMA DE PÓSGRADUAÇÃO EM CIÊNCIAS FLORESTAIS DA UNIVERSIDADE DE BRASÍLIA, COMO PARTE DOS REQUISITOS NECESSÁRIOS PARA A OBTENÇÃO DO GRAU DE DOUTOR.

\section{APROVADA POR:}

Prof. Dr. Ailton Teixeira do Vale (Departamento de Engenharia Florestal - UnB)

(Orientador)

Prof. Dr. Joaquim Carlos Gonçalez (Departamento de Engenharia Florestal - UnB)

(Examinador Interno)

Dr. Thiago Oliveira Rodrigues (Fundação de Tecnologia Florestal e Geoprocessamento - FUNTEC)

(Examinador Interno)

Prof. Dr. Paulo José Prudente Fontes (Laboratório de Produtos Florestais - Serviço Florestal Brasileiro LPF/SFB)

(Examinador Externo)

Prof. Dr. José Dílcio Rocha (Embrapa Agroenergia)

(Examinador Externo)

Prof. Dr. Ildeu Soares Martins (Departamento de Engenharia Florestal - UnB)

(Examinador Suplente)

Brasília, 19 de dezembro de 2014. 


\section{BIOGRAFIA}

FREDERICO DE SOUZA, filho de Luiz Alberto de Souza (in memorian) e Vera Lúcia Lima Heggdorne, nasceu em 01 de setembro de 1982 na cidade de Brasília, Distrito Federal.

Estudou o primeiro grau (1990-1997) no Centro Educacional Objetivo Júnior (1 a a $4^{\text {a }}$ séries) e no Centro Educacional Objetivo ( $5^{\mathrm{a}}$ a $8^{\mathrm{a}}$ séries), ambos situados em BrasíliaDF. Entre os anos de 1998 e 2000 concluiu o segundo grau também no Centro Educacional Objetivo.

Em agosto de 2002 ingressou por meio de concurso vestibular à Universidade de Brasília (UnB) para o curso de graduação em Engenharia Florestal, concluindo com louvor, no sétimo mês do ano de 2007. Durante seu percurso ao longo dos cinco anos da graduação, participou de vários eventos científicos para estudantes e pesquisadores na área de Ciências Agrárias. Atuou por diversas vezes em monitorias nas áreas de Anatomia Vegetal, Tecnologia da Madeira e Estruturas de Madeiras; assim como atuou em estágios voluntários e remunerados.

Durante a graduação, em 2004 ingressou para o primeiro Projeto de Pesquisa em Iniciação Científica no Laboratório de Produtos Florestais (LPF) do Serviço Florestal Brasileiro, atualmente desmembrado do Instituto Brasileiro do Meio Ambiente e dos Recursos Naturais Renováveis (IBAMA). Em 2005 participou do segundo projeto de pesquisa em iniciação científica pelo LPF/SFB e em 2006 iniciou o terceiro e último projeto de iniciação científica, agora vinculado à Universidade de Brasília. Nos dois primeiros projetos de pesquisa, foi premiado em $2^{\circ}$ lugar no Seminário de Iniciação Científica, categoria apresentação oral.

Em agosto de 2009 ingressou no curso de Mestrado do Programa de Pós-Graduação em Ciências Florestais da Universidade de Brasília, na área de concentração de Tecnologia e Utilização de Produtos Florestais, concluindo em março de 2009. Concomitantemente ao mestrado, ministrou aulas de tecnologia da madeira na 
FIMES - Faculdades Integradas de Mineiros, situada em Mineiros/GO, para o curso de graduação em Engenharia Florestal.

Já em 2010, iniciou o doutoramento em ciências agrárias, também na área de concentração de Tecnologia e Utilização de Produtos Florestais, no Departamento de Engenharia Florestal da Universidade de Brasília.

Em julho de 2010 foi aprovado no concurso público de provas e títulos para Professor Efetivo do quadro da educação básica, técnica e tecnológica do Instituto Federal de Educação, Ciência e Tecnologia de Brasília (IFB), Brasília/DF, onde permanece atualmente ministrando aulas de produção de móveis. 


\section{AGRADECIMENTOS}

À toda minha família pelo apoio e incentivo para atingir um nível cada vez mais alto de aprendizado e escolaridade;

Á minha esposa Alessandra Rocha Metzner pelo amor e companheirismo durante toda esta jornada e por me proporcionar felicidades eternas pela chegada de nossa primeira filha, Júlia Rocha de Souza, que vem me fortalecendo dia após dia;

Ao meu orientador, o professor Dr. Ailton Teixeira do Vale por toda a compreensão ao longo do doutoramento, pela amizade e ensinamentos;

Ao professor coorientador, Ph.D Waldir Ferreira Quirino por todo os ensinamentos sobre a briquetagem e produção de energia da biomassa;

Ao amigo Analista Ambiental do setor de Energia da Biomassa (LPF/SFB) Alessandro pelos ensinamentos e conversas ao longo dos ensaios com as biomassas e a briquetagem;

À analista ambiental Lucélia e pesquisador Dr. Patrick pelo incentivo e direcionamento dos ensaios químicos e briquetagem;

À estagiária do laboratório de produção moveleira do IFB, Anne Kimberlly pelo apoio na trituração e classificação da biomassa, assim como pela confecção dos tubos de madeira no torno manual;

À estagiária do setor de Energia da Biomassa, Isadora Pinha, pela ajuda nos ensaios preliminares de briquetagem e raio-X;

Ao Programa de Pós-Graduação em Ciências Florestais da Universidade de Brasília (PPGCF-UnB) pelo aceite e apoio;

Aos professores da tecnologia da madeira da UnB Joaquim, Alexandre e Cláudio, assim como outros professores do departamento de engenharia florestal que ajudaram na elaboração desta tese;

Ao Programa de Apoio a Planos de Reestruturação e Expansão das Universidades Federais - REUNI (CAPES/CNPq) pelo fornecimento da bolsa de doutorado durante praticamente todo o período do doutorado;

Ao Setor de Anatomia da Madeira da Escola Superior de Agricultura Luiz de Queiroz (ESALQ-USP) da Universidade de São Paulo, pela disponibilidade de uso das instalações e equipamentos; 
Ao professor Dr. Mário Tomazello Filho pelos ensinamentos na área de densitometria por raios-X;

Às empresas Biojan Agroindustrial pelo fornecimento da torta de pinhão manso e à Usina Barra Grande de Lençóis pelo fornecimento do bagaço de cana, por intermediação do pesquisador Dr. Divino Eterno Teixeira do LPF/SFB;

Ao Técnico de Laboratório, Juraci, pela ajuda nos ensaios de compressão diametral no Laboratório de Tecnologia da Madeira da UnB;

Aos servidores da Carpintaria do LPF/SFB Ricardo e Fernando, pela transformação das pranchas de madeira em maravalha, assim como no lixamento dos briquetes para os ensaios com o raio-x;

Aos técnicos em química do setor de Química, Adesivos e Borracha Natural do LPF/SFB, Lopes e Lula, pela ajuda e liberação do moinho de facas;

À Madeireira Casa Nova situada no município de Mineiros-GO pelo fornecimento da biomassa para a realização dos ensaios preliminares;

Aos amigos Igor, Patrícia, Leiliane, Míriam e Alex pelo apoio durante toda a trajetória;

A todos aqueles que contribuíram de alguma forma para a realização de um sonho e conclusão desta tese de doutorado.

Obrigado! 


\section{Aos meus pais,}

Vera Lúcia Lima Heggdorne e

Luiz Alberto de Souza (in memoriam);

aos meus irmãos,

Luiz Alberto Arantes de Souza e

Luany Cristina de Souza Galvão;

à minha esposa,

Alessandra Rocha Metzner;

À minha filha e meus afilhados,

Júlia Rocha de Souza,

Lucas Rocha Yungh e

Arthur Almeida Arantes de Souza

Dedico este trabalho. 


\title{
RESUMO
}

\section{AVALIAÇÃO DA QUALIDADE DE BRIQUETES PRODUZIDOS COM SEIS BIOMASSAS AGROFLORESTAIS POR MÉTODOS NÃO DESTRUTIVOS}

\author{
Autor: Frederico de Souza \\ Orientador: Ailton Teixeira do Vale \\ Programa de Pós-Graduação em Ciências Florestais \\ Brasília, dezembro de 2014.
}

O presente estudo teve como objetivo avaliar os parâmetros de qualidade dos briquetes produzidos a partir das biomassas de cupiúba, pinus, tauari, cumaru, casca de arroz, bagaço de cana e torta de pinhão manso. Para tanto, analisou-se a influência no processo de briquetagem, da biomassa, temperatura e pressão de compactação e tamanho das partículas, determinando as densidades aparentes estereométrica (DA), por imersão em mercúrio (DAHG) e por densitometria de raio $\mathrm{X}$ (DARX); a densidade energética (DE, DEHG e DERX, respectivamente), a resistência mecânica e a velocidade de propagação das ondas de tensão $\left(\mathrm{V}_{0} \mathrm{~S}\right)$ e ultrassônicas $\left(\mathrm{V}_{0} \mathrm{U}\right)$. Também foi avaliada a aplicabilidade da avaliação não destrutiva para a predição de propriedades físicas, mecânicas e energéticas. As biomassas foram aptas à briquetagem nas condições consideradas, com exceção do cumaru e torta de pinhão manso sob altas temperaturas e pressão, combinada à partícula fina. De uma forma geral, a temperatura alta foi o fator que mais influenciou positivamente na briquetagem resultando em maiores densidades aparentes, densidades energéticas e velocidades de propagação na maior parte dos tratamentos. A partícula fina favoreceu em muitos tratamentos, a resistência mecânica. As médias das densidades aparentes e energéticas foram inferiores quando obtidas pelo raio $\mathrm{X}$ em função da precisão do método, retratando melhor a qualidade dos briquetes, com exceção da casca de arroz. A predição da resistência mecânica de briquetes não foi satisfatória. Foi possível predizer satisfatoriamente a DA e DE para os briquetes com tauari e bagaço de cana, com destaque para o equipamento de ultrassom.

Palavras-chave: briquetagem, propriedades energéticas, ondas de tensão e ultrassom. 


\title{
ABSTRACT
}

\section{QUALITY EVALUATION OF BRIQUETTES PRODUCED WITH SIX AGROFORESTRY BIOMASS BY NON-DESTRUCTIVE METHODS}

\author{
Author: Frederico de Souza \\ Advisor: Ailton Teixeira do Vale \\ Doctor's Degree Program in Forest Science \\ Brasília, December, $19^{\text {th }} 2014$.
}

This study aimed to evaluate the briquette's quality parameters produced from cupiuba, pine, tauari, cumaru, rice husk, sugarcane bagasse and jatropha seed cake biomass. Therefore, were analyzed the influence on the briquetting process, biomass, temperature and compaction pressure and particle size, determining the apparent stereometric density (DA), by immersion in mercury (DAHG) and X-ray densitometry (DARX); energy density (DE, and DEHG DERX, respectively), mechanical strength and stress wave $\left(\mathrm{V}_{0} \mathrm{~S}\right)$ and ultrasound velocities $\left(\mathrm{V}_{0} \mathrm{U}\right)$. Were evaluated the applicability of nondestructive evaluation for the prediction of physical, mechanical and energetic properties. The biomass was suitable for briquetting under the conditions deemed, except for cumaru and jatropha seed cake under high temperature and pressure, combined with the fine particle. The high temperature is a factor that positively influences the briquetting resulting in higher apparent densities, energetic densities and wave velocities in most treatments. The fine particle favored in many treatments, the mechanical strength. The mean of apparent densities and energetic densities were lower when the X-ray obtained according to the method's accuracy, better depicting the quality of the briquette, with the exception of rice husk. The briquett's mechanical strength prediction was not satisfactory. It was possible to satisfactorily predict the DA and DE for the briquettes with tauari and sugar cane bagasse, especially with the ultrasound equipment.

Keywords: briquetting, energetic properties, stress wave and ultrasound. 


\section{SUMÁRIO}

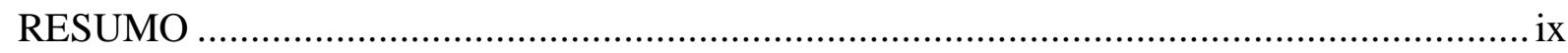

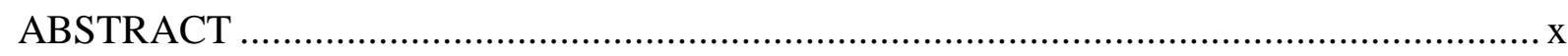

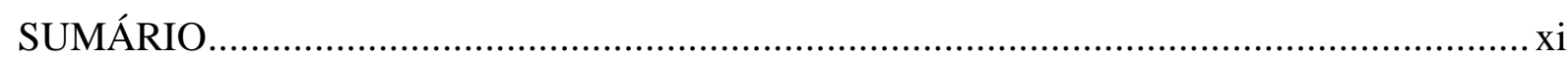

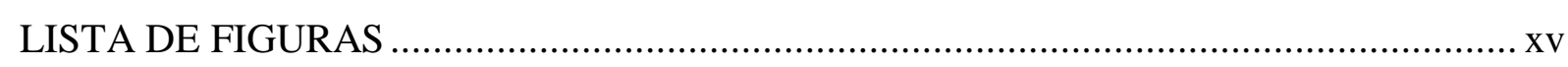

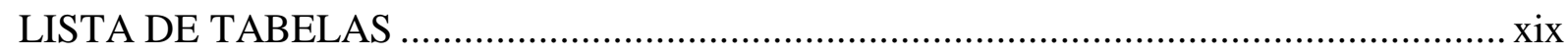

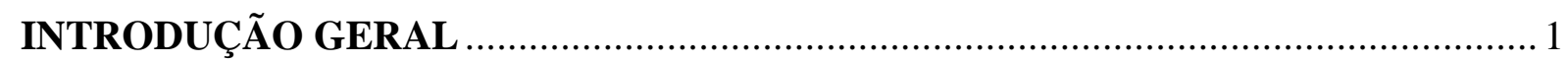

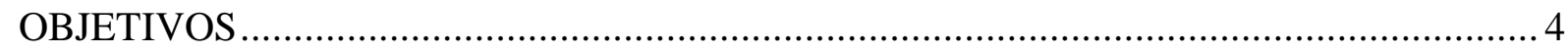

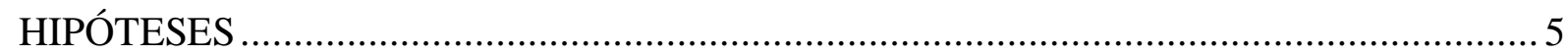

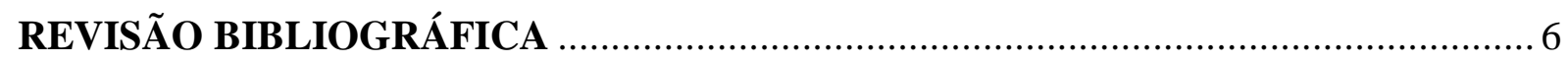

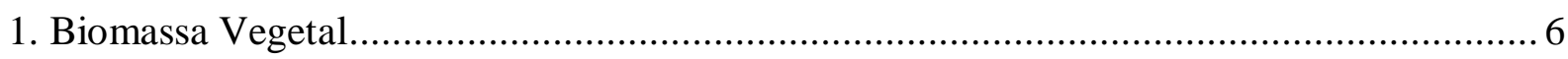

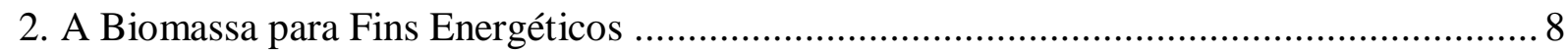

3. Composição Química e a Degradação pelo Efeito do Calor .............................................. 12

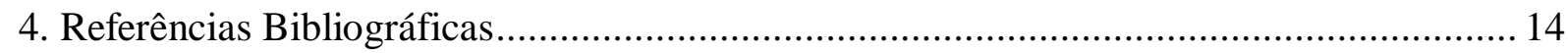

CAPÍTULO I: INFLUÊNCIA DO TAMANHO DAS PARTÍCULAS NA RESISTÊNCIA MECÂNICA DE BRIQUETES CONFECCIONADOS COM SERRAGEM DE Goupia glabra Aubl.

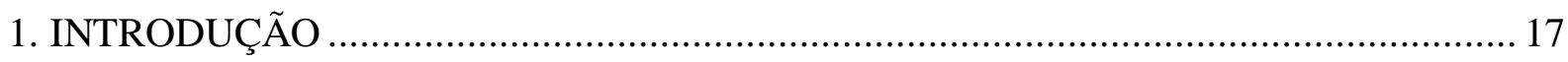

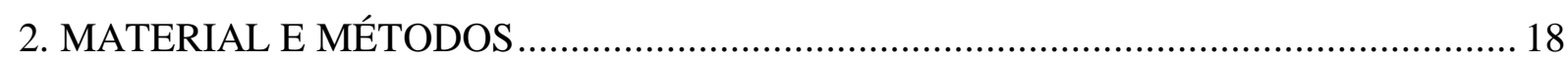

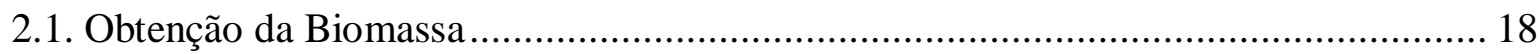

2.2. Distribuiçãa Granulométrica da Serragem......................................................... 19

2.3. Classificaçãa das Partículas ................................................................................. 19

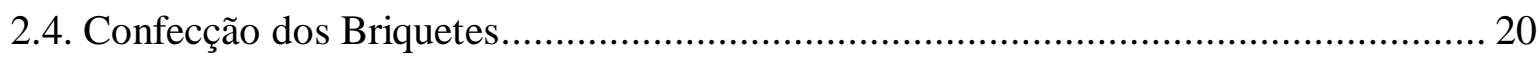

2.5. Determinação da Densidade Aparente ............................................................... 21

2.6. Determinação da Resistência Mecânica.................................................................. 22

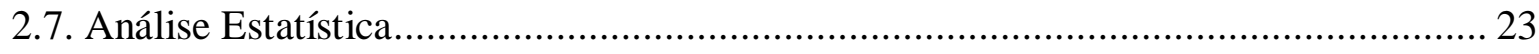

3. RESULTADOS E DISCUSSÃO ....................................................................... 23 
CAPÍTULO II: ANÁLISE DA CARGA MÁXIMA E DA RESISTÊNCIA À TRAÇÃO PARA A CARACTERIZAÇÃO MECÂNICA DE BRIQUETES

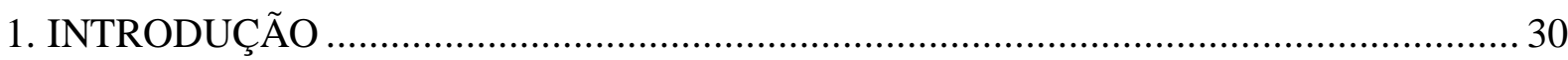

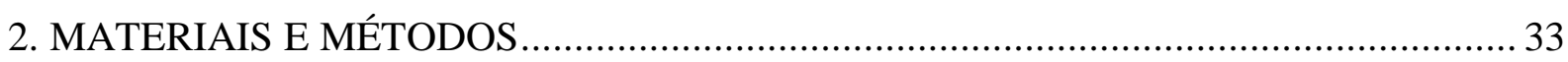

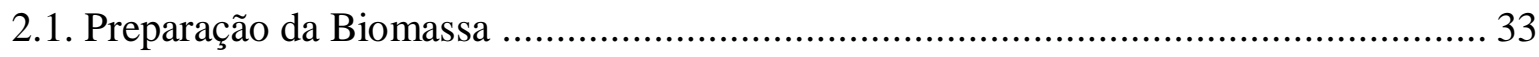

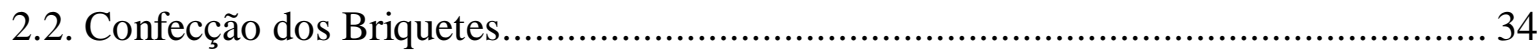

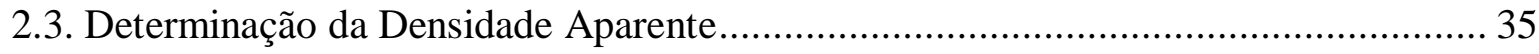

2.4. Determinação da Resistência Mecânica................................................................... 36

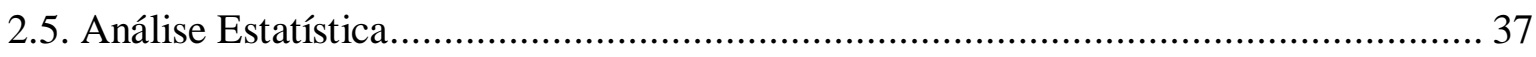

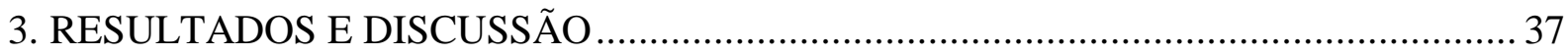

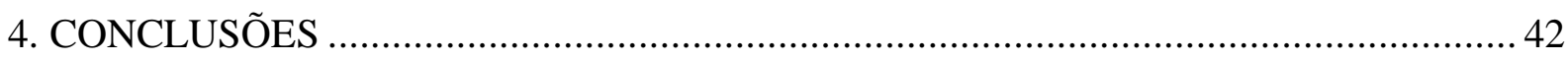

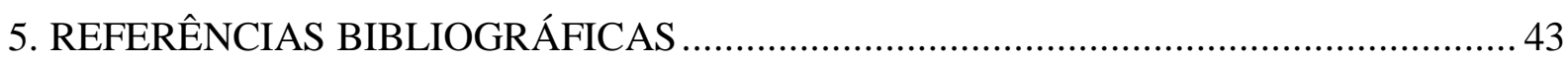

CAPÍTULO III: MÉTODOS PARA A AVALIAÇÃO DA QUALIDADE DE BRIQUETES CONFECCIONADOS A PARTIR DE SEIS BIOMASSAS AGROFLORESTAIS

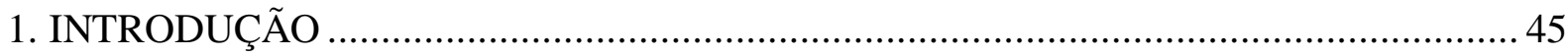

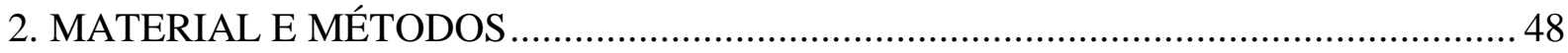

2.1. Obtenção das Biomassas Agroflorestais ................................................................ 49

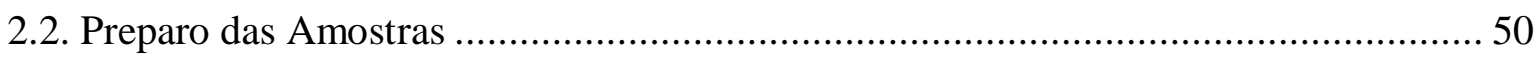

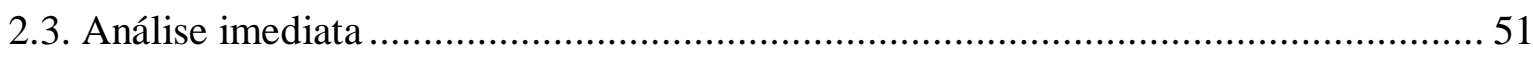

2.4. Determinação do Poder Calorífico ..................................................................... 52

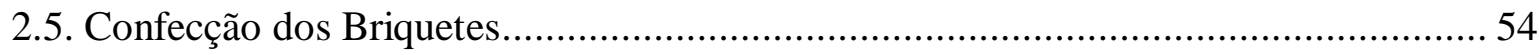

2.6. Determinação da Densidade Aparente do briquete ................................................. 55

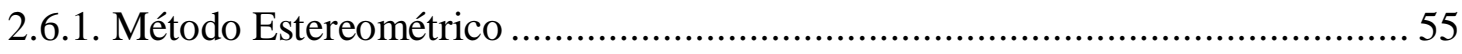

2.6.2. Método do Deslocamento de Mercúrio......................................................... 56

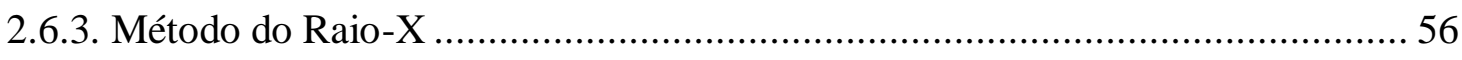

2.7. Determinação da Densidade Energética ............................................................. 58

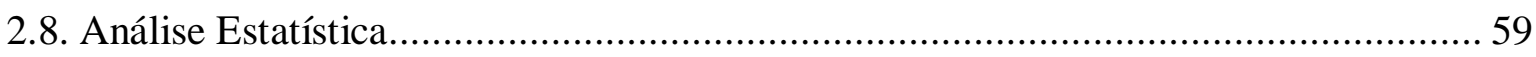




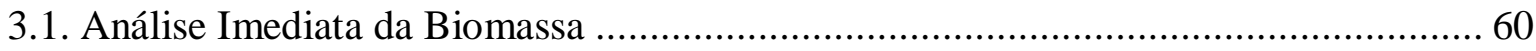

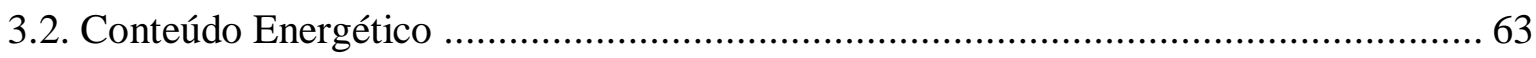

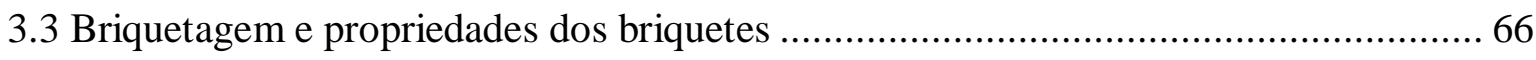

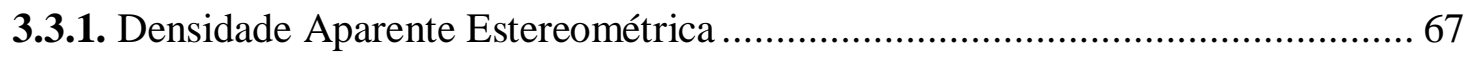

3.3.2. Densidade Aparente por Imersão em Mercúrio............................................. 71

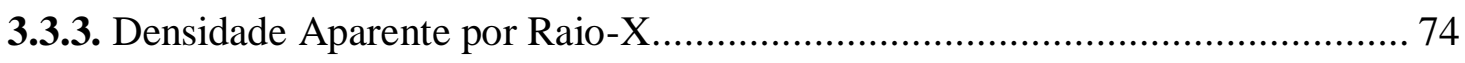

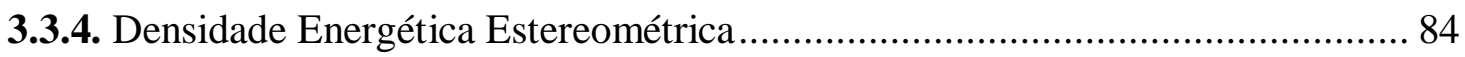

3.3.5. Densidade Energética por Imersão em Mercúrio ...................................... 88

3.3.6. Densidade Energética por Raio-X ................................................................ 91

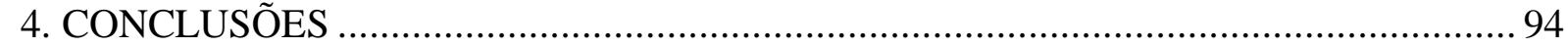

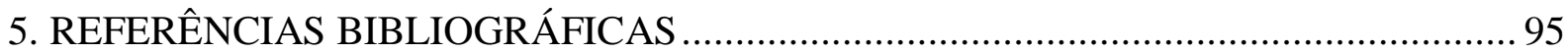

CAPÍTULO IV: INFLUÊNCIA DOS PARÂMETROS DA BRIQUETAGEM NA AVALIAÇÃO NÃO DESTRUTIVA E NA RESISTÊNCIA MECÂNICA DE BRIQUETES

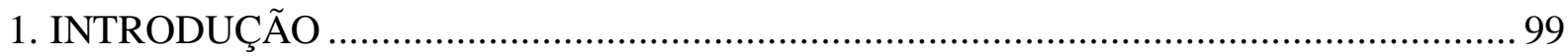

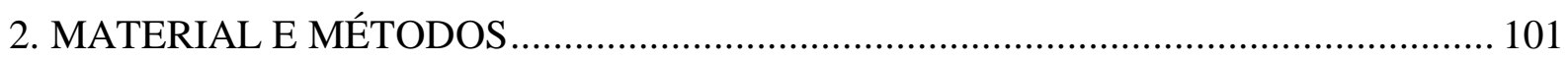

2.1. Obtenção das Biomassas Agroflorestais ................................................................. 102

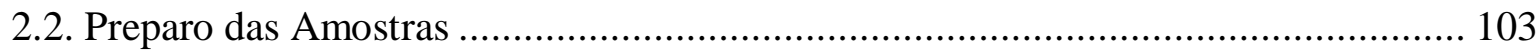

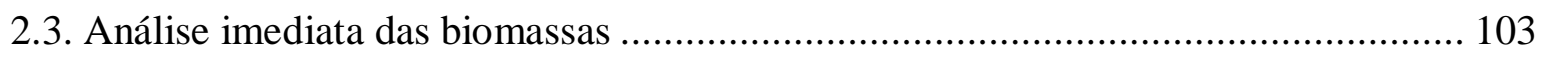

2.4. Determinação do Poder Calorífico das Biomassas ................................................. 104

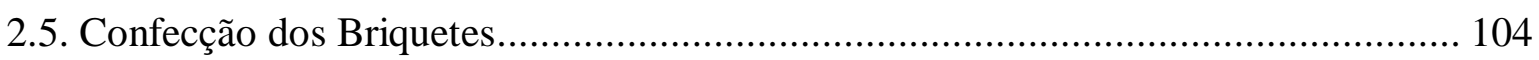

2.6. Determinação da Densidade Aparente do briquete ............................................. 105

2.7. Determinação da Densidade Energética .......................................................... 106

2.8. Avaliação Não-Destrutiva dos Briquetes ............................................................... 106

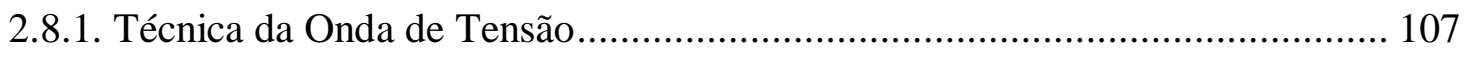

2.8.2. Técnica da Onda Ultrassônica ............................................................... 108

2.9. Determinação das Propriedades Mecânicas dos Briquetes ................................... 109

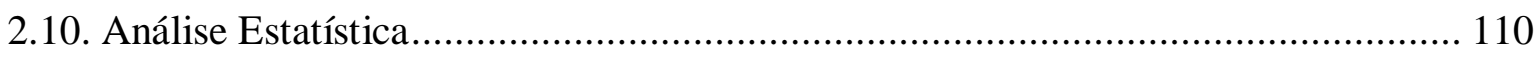

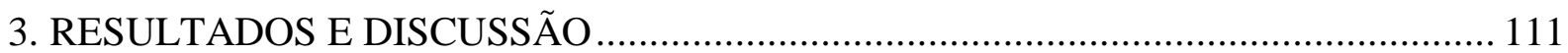




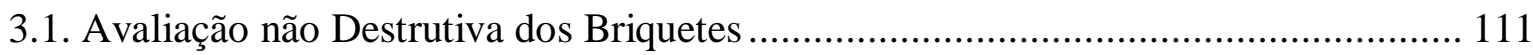

3.1.1. Velocidade de Propagação da Onda de Tensão............................................... 111

3.1.2. Velocidade de Propagação da Onda Ultrassônica .......................................... 121

3.2. Avaliação destrutiva dos briquetes ....................................................................... 129

3.2.1. Força Máxima de Compressão ……………………………………………... 129

3.2.1. Resistência à Tração por Compressão Diametral............................................ 133

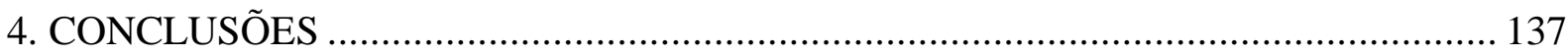

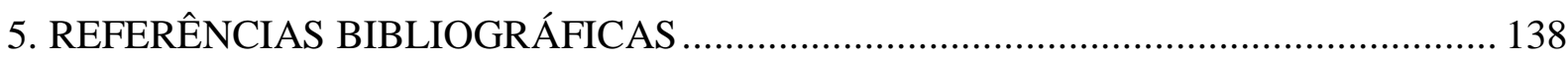

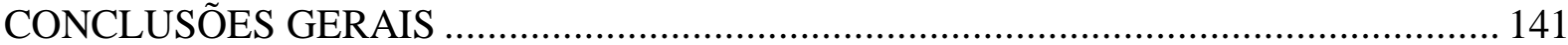

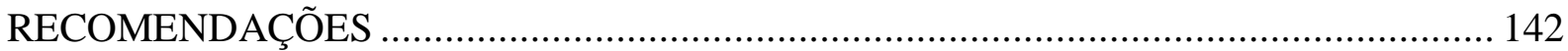




\section{LISTA DE FIGURAS}

\section{REVISÃO BIBLIOGRÁFICA}

Figura 1. Curva termogravimétrica da madeira e seus componentes fundamentais.

Fonte: Cetec (1980). 13

\section{CAPÍTULO I}

Figura 1. Prensa briquetadeira da marca Irmãos Lippel, modelo LB-32, onde se confeccionaram os briquetes .20

Figura 2. Ensaio de resistência à compressão longitudinal (A) e diametral (B) dos briquetes confeccionados com serragem de Cupiúba (Goupia glabra Aubl)............22 Figura 3. Médias da massa de partículas na serragem de cupiúba (Goupia glabra Aubl.) obtida na distribuição granulométrica em peneiras de 10 a 100 Mesh. .24

\section{CAPÍTULO II}

Figura 1. Processo de dimensionamento do briquete (corpo-de-prova) para a utilização no ensaio de resistência mecânica. .35

Figura 2. Ensaio de resistência à tração por compressão diametral dos briquetes de Tauari. .36

Figura 3. Valores da densidade aparente (DA) dos briquetes de Tauari distribuídos por tratamentos. .39

Figura 4. Valores médios da carga máxima de ruptura (CMR) para os briquetes de Tauari 40

Figura 5. Valores médios da resistência à tração por compressão diametral (RTCD) para os briquetes de Tauari.

\section{CAPÍTULO III}

Figura 1. Equipamento Calorímetro modelo IKA C2000 acoplado a um refrigerador IKA KV 600. .52

Figura 2. Equipamento de emissão de raio-x utilizado para a determinação do perfil de densidade dos briquetes .57 
Figura 3. À esquerda, a posição do seccionamento dos briquetes, adaptando-os para o equipamento de raio-x e à direita, o processo de lixamento dos briquetes e ajuste da espessura para $3 \mathrm{~mm}$. .58

Figura 4. Análise imediata das seis biomassas agroflorestais estudadas .61

Figura 5. Valores do poder calorífico das seis biomassas agroflorestais estudadas, .64

Figura 6. Danos à superfície dos briquetes (rachaduras e esmagamentos) que inviabilizaram a utilização dos briquetes com a torta de pinhão manso nos tratamentos 7 e 8 . .66

Figura 7. Valores da densidade aparente dos briquetes $\left(\mathrm{DA}-\mathrm{g} / \mathrm{cm}^{3}\right)$ obtidos pelo método estereométrico, a partir das biomassas de pinus, tauari, cumaru, casca de arroz, bagaço de cana e torta de pinhão manso; em função dos oito tratamentos propostos. .68

Figura 8. Valores da densidade aparente dos briquetes (DAHG - $\mathrm{g} / \mathrm{cm}^{3}$ ) obtidos pelo método de imersão em mercúrio, a partir das biomassas de pinus, tauari, cumaru, casca de arroz, bagaço de cana e torta de pinhão manso; em função dos oito tratamentos propostos .73

Figura 9. Valores da densidade aparente dos briquetes (DARX $-\mathrm{g} / \mathrm{cm}^{3}$ ) obtidos pelo método de raio-x, a partir das biomassas de pinus, tauari, cumaru, casca de arroz, bagaço de cana e torta de pinhão manso; em função dos oito tratamentos .75

Figura 10. Perfil densitométrico obtido pelo método de raio-x para os briquetes confeccionados com biomassa de pinus em função dos oito tratamentos. .77

Figura 11. Perfil densitométrico obtido pelo método de raio-x para os briquetes confeccionados com biomassa de tauari em função dos oito tratamentos. .78

Figura 12. Perfil densitométrico obtido pelo método de raio-x para os briquetes confeccionados com biomassa de cumaru em função dos oito tratamentos.. .79

Figura 13. Perfil densitométrico obtido pelo método de raio-x para os briquetes confeccionados com biomassa da casca de arroz em função dos oito tratamentos....80 Figura 14. Perfil densitométrico obtido pelo método de raio-x para os briquetes confeccionados com biomassa de bagaço de cana em função dos oito tratamentos.. 81 Figura 15. Perfil densitométrico obtido pelo método de raio-x para os briquetes confeccionados com biomassa da casca do pinhão manso em função dos oito tratamentos. 
Figura 16. Valores da densidade energética dos briquetes (DE - Mcal $/ \mathrm{m}^{3}$ ) obtidos pelo método estereométrico, a partir das biomassas florestais de pinus, tauari e cumaru; em função dos oito tratamentos propostos

Figura 17. Valores da densidade energética dos briquetes (DEHG - Mcal $/ \mathrm{m}^{3}$ ) obtidos pelo método de imersão em mercúrio, a partir das biomassas florestais; em função dos oito tratamentos propostos.

Figura 18. Valores da densidade energética dos briquetes (DERX - Mcal $/ \mathrm{m}^{3}$ ) obtidos pelo método de raio-x, a partir das biomassas florestais; em função dos oito tratamentos propostos. .92

\section{CAPÍTULO IV}

Figura 1. Equipamento Stress Wave Timer da marca Metriguard modelo 239-A para a avaliação não destrutiva de briquetes pela técnica da onda de tensão. 107

Figura 2. Equipamento de Ultrassom da marca USLAB-Agricel para a avaliação não destrutiva de briquetes pela técnica da onda ultrassônica.

Figura 3. Ensaio de resistência à compressão diametral realizado em máquina universal de ensaios, para a determinação da força máxima de compressão dos briquetes confeccionados com as seis diferentes biomassas. 110

Figura 4. Valores da Velocidade de Propagação da Onda $\left(\mathrm{V}_{0} \mathrm{~S}-\mathrm{m} / \mathrm{s}\right)$ obtida pelo equipamento Stress Wave Timer para os briquetes confeccionados a partir das biomassas de pinus, tauari, cumaru, casca de arroz, bagaço de cana e torta de pinhão manso; em função dos oito tratamentos propostos.

Figura 5. Predição da densidade aparente obtida pelo raio $X\left(D A R X-\mathrm{g} / \mathrm{cm}^{3}\right)$ em função da velocidade de propagação da onda de tensão $\left(\mathrm{V}_{0} \mathrm{~S}-\mathrm{m} / \mathrm{s}\right)$ para os briquetes confeccionados com a casca de arroz. 116

Figura 6. Predição da densidade aparente obtida pelo raio $X\left(D A R X-\mathrm{g} / \mathrm{cm}^{3}\right) \mathrm{em}$ função da velocidade de propagação da onda de tensão $\left(\mathrm{V}_{0} \mathrm{~S}-\mathrm{m} / \mathrm{s}\right)$ para os briquetes confeccionados com a torta de pinhão manso. 117

Figura 7. Predição da densidade aparente estereométrica $\left(\mathrm{DA}-\mathrm{g} / \mathrm{cm}^{3}\right)$ em função da velocidade de propagação da onda de tensão $\left(\mathrm{V}_{0} \mathrm{~S}-\mathrm{m} / \mathrm{s}\right)$ para os briquetes confeccionados com tauari.

Figura 8. Valores da Velocidade de Propagação da Onda $\left(\mathrm{V}_{0} \mathrm{U}-\mathrm{m} / \mathrm{s}\right)$ obtida pelo equipamento de Ultrassom USLAB-Agricel para os briquetes confeccionados a partir 
das biomassas de pinus, tauari, cumaru, casca de arroz, bagaço de cana e torta de pinhão manso; em função dos oito tratamentos propostos....................................122 Figura 9. Valores da Força Máxima de Compressão (FMC - kgf) para os briquetes confeccionados a partir das biomassas de pinus, tauari, cumaru, casca de arroz, bagaço de cana e torta de pinhão manso; em função dos oito tratamentos propostos.

Figura 10. Valores da Resistência à Tração por Compressão Diametral (RTCD $\mathrm{kgf} / \mathrm{cm}^{3}$ ) para os briquetes confeccionados a partir das biomassas de pinus, tauari, cumaru, casca de arroz, bagaço de cana e torta de pinhão manso; em função dos oito tratamentos propostos. 134 


\section{LISTA DE TABELAS}

\section{CAPÍTULO I}

Tabela 1. Delineamento experimental para os briquetes confeccionados com serragem de cupiúba (Goupia glabra Aubl.)

Tabela 2. Tempo de resfriamento em minutos para os briquetes confeccionados com serragem classificada de cupiúba (Goupia glabra Aubl.).

Tabela 3. Médias da densidade aparente, carga máxima de ruptura nos sentidos longitudinal (CMR long.) e diametral (CMR diam.) de briquetes confeccionados com serragem classificada de cupiúba (Goupia glabra Aubl.).....................................26

Tabela 4. Análise de Variância para a densidade dos briquetes confeccionados com serragem classificada de cupiúba (Goupia glabra Aubl.).

Tabela 5. Análise de Variância para a carga máxima de ruptura nos sentidos longitudinal e diametral de briquetes confeccionados com serragem classificada de cupiúba (Goupia glabra Aubl.). .26

\section{CAPÍTULO II}

Tabela 1. Delineamento experimental para a avaliação dos parâmetros de briquetagem: granulometria, temperatura e pressão.

Tabela 2. Valores médios da densidade aparente (DA), carga máxima de ruptura (CMR) e resistência à tração por compressão diametral (RTCD) dos briquetes confeccionados a partir dos oito tratamentos estudados.

Tabela 3. Análise de Variância ANOVA para os parâmetros: densidade, carga máxima de ruptura e resistência à tração por compressão diametral dos briquetes de Tauari.

\section{CAPÍTULO III}

Tabela 1. Valores citados na literatura para o teor de hidrogênio (\%) referentes às seis biomassas estudadas.

Tabela 2. Delineamento experimental para a avaliação dos parâmetros de briquetagem: granulometria, temperatura e pressão para cada biomassa agroflorestal estudada. 
Tabela 3. Valores citados na literatura da análise imediata para as seis biomassas estudadas.

Tabela 4. Valores citados na literatura para o conteúdo energético das seis biomassas estudadas.

\section{CAPÍTULO IV}

Tabela 1. Delineamento experimental para a avaliação dos parâmetros de briquetagem: granulometria, temperatura e pressão para cada uma das seis biomassas estudadas.

Tabela 2. Valores do coeficiente de determinação $-\mathrm{R}^{2}(\%)$ obtido pela análise de variância da regressão entre a avaliação não destrutiva e a densidade aparente obtida pelo raio $\mathrm{X}(\mathrm{DARX})$ para os briquetes com as seis biomassas estudadas.

Tabela 3. Valores do coeficiente de determinação $-\mathrm{R}^{2}(\%)$ obtido pela análise de variância da regressão entre a avaliação não destrutiva e a densidade aparente para os briquetes com as seis biomassas estudadas. 118

Tabela 4. Valores do coeficiente de determinação $-\mathrm{R}^{2}(\%)$ obtido pela análise de variância da regressão entre a avaliação não destrutiva e a densidade energética para os briquetes com as seis biomassas estudadas.

Tabela 5. Valores do coeficiente de determinação $-\mathrm{R}^{2}(\%)$ obtido pela análise de variância da regressão entre a avaliação não destrutiva e a densidade energética para os briquetes com as seis biomassas estudadas. 121

Tabela 6. Valores do coeficiente de determinação $-\mathrm{R}^{2}(\%)$ obtido pela análise de variância da regressão entre a avaliação não destrutiva e a densidade aparente para os briquetes com as seis biomassas estudadas.

125

Tabela 7. Valores do coeficiente de determinação $-\mathrm{R}^{2}(\%)$ obtido pela análise de variância da regressão entre a avaliação não destrutiva e a densidade aparente para os briquetes com as seis biomassas estudadas. 126

Tabela 8. Valores do coeficiente de determinação $-\mathrm{R}^{2}(\%)$ obtido pela análise de variância da regressão entre a avaliação não destrutiva e a densidade energética para os briquetes com as seis biomassas estudadas.

Tabela 9. Valores do coeficiente de determinação $-\mathrm{R}^{2}(\%)$ obtido pela análise de variância da regressão entre a avaliação não destrutiva e a densidade energética para os briquetes com as seis biomassas estudadas. 
Tabela 10. Valores do coeficiente de determinação - $\mathrm{R}^{2}(\%)$ obtido pela análise de variância da regressão entre a avaliação não destrutiva e a força máxima de compressão para os briquetes com as seis biomassas estudadas.

Tabela 11. Valores do coeficiente de determinação $-\mathrm{R}^{2}(\%)$ obtido pela análise de variância da regressão entre a avaliação não destrutiva e a resistência à tração por compressão diametral para os briquetes com as seis biomassas estudadas. .136 


\section{INTRODUÇÃO GERAL}

Dentre os usos da madeira para diversos os fins como a construção civil, painéis de madeira, produção de celulose, papel e a produção de energia, a aplicação energética é uma das mais importantes destinações dadas a esta matéria-prima (BRITO, 1994). Neste caso, a madeira como matéria-prima, incrementa diretamente ou indiretamente o PIB nacional pelo mercado de madeira ou pela sua transformação em processos e na exportação.

A biomassa é constituída por toda a massa de organismos (origem orgânica) por unidade de volume que possui potencial energético (WOOD e HALL, 1995 citado por MICHELAZZO e BRAUNBECK, 2008). Desta forma, da biomassa vegetal, segundo COUTO et al. (2004) pode se ter aproveitamento energético a partir de árvores (tronco/madeira, galhos, folhas e raízes) e de resíduos da agricultura convencional (palha e sabugo de milho, bagaço-de-cana, casca de arroz e de algodão, entre outros). Para OLIVEIRA e LOBO (2009), a biomassa como fonte de energia, atende a $14 \%$ do consumo no mundo. Nos países em desenvolvimento, este índice pode chegar a até 35\%.

Estas matérias-primas (resíduos vegetais) são comumente conhecidas como materiais ligno-celulósicos por serem constituídos basicamente de celulose e lignina (QUIRINO et al 2004; QUIRINO, 1991). De uma forma geral, vêm se observando que esses resíduos lignocelulósicos constituem-se em um problema social e ambiental devido à quantidade, dispersão e dificuldade de manuseio que os mesmos apresentam.

Ainda, os resíduos que são gerados em processos industriais exigem grandes áreas para armazenamento ou simplesmente são queimados ou incinerados sem que haja aproveitamento da energia neles contida, liberando desta forma para a atmosfera, grandes quantidades de gases poluentes, como o monóxido e dióxido de carbono e o metano (DINIZ et al, 2004; MIGLIORINI, 1980). Ainda, comparada aos combustíveis fósseis, tais resíduos apresentam um baixo teor de enxofre $(0,1$ a $0,2 \%)$ e, por isto, sua combustão é menos nociva à atmosfera do que aquela proveniente de combustíveis fósseis, além de serem considerados como renováveis (GENTIL, 2008, MIGUEL NÚÑEZ, 2008). 
A diminuição das fontes de energia globais e as severas leis ambientais estão fazendo com que as fontes de energias renováveis ou limpas se tornem uma opção cada vez mais tangível e necessária para os tempos modernos. Dentre as várias opções de fontes de energia que podem substituir os combustíveis fósseis, a biomassa se apresenta como uma opção de potencial mundial.

O setor de energia renovável vem se desenvolvendo ano a ano em diversas regiões do Brasil, com o surgimento de novas usinas de beneficiamento de resíduos vegetais e com o aumento da capacidade operacional das indústrias já instaladas (ALVES JÚNIOR, 2003; COUTO et al, 2004, GENTIL, 2008). Internacionalmente, os briquetes e pellets já são reconhecidos no mercado de energia da biomassa (VINTERBACK, 2006 citado por GENTIL, 2008).

Segundo ALVES JÚNIOR (2003) a região Nordeste do Brasil possui alta demanda por lenha (cerca de 4200 ton/mês) para residências, pizzarias e padarias. Tais produtos podem ser perfeitamente substituídos pelos briquetes e por pelets de resíduos da biomassa.

Dentre as formas de melhor se utilizar estes resíduos, observam-se os métodos de densificação (compactação, aglomeração ou adensamento) que proporcionam uma série de vantagens, quando comparado a sua utilização no estado natural, principalmente no tocante ao armazenamento, manuseio, aumento da densidade e poder calorífico (FRAZA, 2008; MIGLIORINI, 1980). Segundo BEZZON (1994), a compactação de descartes de madeira produz combustíveis sólidos de excelente qualidade e em alguns casos apresentam densidade, poder calorífico e resistência mecânica superiores à lenha, além de possuírem baixa umidade.

Dos métodos de compactação da biomassa existentes, destacam-se a briquetagem e a peletização. A briquetagem consiste em triturar resíduos vegetais e adensá-los a partir da aplicação de altas pressões e com elevação da temperatura. Desta forma, tem-se uma plastificação ou amolecimento da lignina, o que promove uma maior interação química entre as partículas, conferindo ao produto final, consistência e uma estrutura bem definida 
(QUIRINO, 1991). O produto formado tem dimensões aproximadas de 150-250 mm de comprimento e diâmetro de 50-100 mm.

A matriz energética brasileira, que ainda é baseada em combustíveis fósseis, vem sendo gradativamente substituída por energias renováveis como os biocombustíveis e os combustíveis sólidos (briquetes e pellets). Apesar de os processos de densificação da biomassa já estarem sendo aplicados de forma industrial, a carência de informação no que diz respeito à granulometria e teor de umidade da matéria-prima ainda devem ser estudados por influenciarem diretamente nas propriedades mecânicas e energéticas do produto final e consequentemente, na viabilidade econômica das instalações industriais (GOLDEMBERG, 2009).

Este trabalho foi dividido em quatro capítulos, além da contextualização geral, onde os Capítulos I e II foram tratados como ensaios preliminares.

O Capítulo I como ensaio preliminar da tese, apresenta a influência do tamanho da partícula no processo de briquetagem e na resistência mecânica dos briquetes. Após a classificação do pó de serra proveniente de serrarias foi possível interpretar a porcentagem de cada faixa de granulometria presente na biomassa e direcionar o trabalho final da tese com outras seis biomassas agroflorestais. Ainda para este capítulo, foi determinada de forma exploratória a resistência mecânica dos briquetes em dois sentidos de aplicação de uma carga externa: Longitudinal e Diametral, possibilitando a escolha do sentido com menor resistência.

O Capítulo II ainda como ensaio preliminar do trabalho, mostra a influência dos parâmetros da briquetagem, temperatura e pressão de compactação assim como a influência do tamanho da partícula em duas propriedades mecânicas dos briquetes: A força máxima de compressão e a resistência à tração por compressão diametral. Desta forma, foi possível testar a sensibilidade destas duas propriedades à detectar diferenças entre os tratamentos/briquetes e verificar a possibilidade de se escolher um tratamento com melhor resistência mecânica. 
O Capítulo III apresenta três métodos de determinação da densidade aparente dos briquetes, sendo dois deles, proposições para a obtenção de valores mais próximos do valor real de densidade, incluindo a técnica de emissão de raios X. Ainda será verificada a sensibilidade de cada um destes parâmetros em detectar diferenças pela variação da temperatura e pressão de compactação assim como pelo tamanho das partículas entre os tratamentos/briquetes confeccionados com seis biomassas agroflorestais. A partir destes três parâmetros de densidade aparente, foram calculadas as densidades energéticas como fator decisivo para a escolha do melhor tratamento e biomassa para a briquetagem.

O Capítulo IV mostra a viabilidade de se empregar dois métodos de avaliação não destrutiva baseados na velocidade de propagação de ondas, em detectar a influência da temperatura e pressão de compactação assim como a influência do tamanho da partícula em briquetes confeccionados com seis biomassas agroflorestais. Ainda, foi possível estimar algumas propriedades físicas, mecânicas e até energéticas a partir destas avaliações não destrutivas, tornando as avaliações para as biomassas e briquetes mais rápidas e práticas.

\section{OBJETIVOS}

Este trabalho teve como objetivo geral, a verificação da viabilidade técnica da densificação de resíduos agroflorestais pelo método da briquetagem de seis resíduos vegetais, sendo estes: o pó-de-serra de cumaru, tauari e pinus, além da torta de pinhão-manso, bagaço-decana e a casca de arroz; provenientes de diferentes processos industriais.

Como objetivos específicos, determinar-se-ão:

1. as propriedades energéticas das biomassas;

2. a análise elementar e imediata das matérias primas vegetais;

3. a resistência mecânica em ensaio de compressão dos briquetes;

4. a sensibilidade do método da densitometria de raio-X para avaliar a influência dos parâmetros da briquetagem na qualidade do briquete; 
5. a viabilidade da utilização de duas técnicas não-destrutivas para determinar a resistência mecânica e a densidade energética dos briquetes de seis diferentes resíduos agroflorestais.

\section{HIPÓTESES}

1. Existe um processo de densificação mais eficiente tecnicamente, em função da temperatura, pressão, granulometria da partícula e do material vegetal (resíduo agroflorestal/biomassa), que proporcione ao briquete, maior densidade energética;

2. É possível avaliar a qualidade dos briquetes a partir das técnicas de densitometria de raios-X e pela propagação da onda de tensão e ultrassônica;

3. É possível estimar as propriedades mecânicas e energéticas dos briquetes por meio da avaliação não destrutiva com a técnica da onda de tensão e da onda ultrassônica. 


\section{REVISÃO BIBLIOGRÁFICA}

\section{BIOMASSA VEGETAL}

O termo biomassa engloba a matéria vegetal gerada através da fotossíntese e os seus derivados, tais como: resíduos florestais e agrícolas e a matéria orgânica contida nos resíduos industriais, domésticos, municipais e outros (SILVA et al, 2008). Basicamente, a biomassa vegetal é formada, portanto, pela energia química provinda da transformação energética da radiação solar. Segundo Nogueira e Lora (2003) com o aproveitamento de $1 \%$ do total da radiação solar incidente na Terra, estima-se que pelo processo fotossintético, sejam produzidos de $2 \times 10^{9}$ ton de biomassa seca, o que equivale a uma energia de $2 \times 10^{15} \mathrm{MJ}$, ou seja, cerca de dez vezes a energia global consumida por ano no planeta.

$\mathrm{Na}$ produção da biomassa, estes materiais contêm energia química provinda da transformação energética da radiação solar. Essa energia química pode ser liberada diretamente por combustão, ou convertida por meio de algum processo em outras formas energéticas mais adequadas, para o fim desejado, tal como o álcool e o carvão vegetal (COUTO et al., 2004; NOGUEIRA e CRUZ, 2004).

Dentre os principais benefícios da utilização da biomassa citam-se o baixo custo de aquisição, liberação de resíduos menos agressivos ao meio ambiente, menor corrosão dos equipamentos, maior utilização de mão-de-obra e a redução das emissões de poluentes, uma vez que estes compostos apresentam balanço nulo de emissão de $\mathrm{CO}_{2}$ (GRAUER e KAWANO, 2001).

Quanto à utilização da biomassa, a grande importância diz respeito à liberação desta energia acumulada nos tecidos vegetais, pela combustão direta dos resíduos ou após a conversão do resíduo em produtos, como o briquete ou pellet, tornando a biomassa mais adequada para certos processos industriais (QUIRINO et al., 2004; QUIRINO, 1991). 
A biomassa, essencialmente como lenha, foi a primeira fonte energética empregada pelo homem, onde a partir do domínio do fogo a cerca de 1,4 milhão de anos atrás, foram encontrados vestígios de fogueiras com madeira. A fermentação alcoólica surgiu em torno de 28.000 anos atrás no Egito. Com o aperfeiçoamento dos sistemas de combustão da lenha e com o progressivo uso do carvão vegetal, a lenha se constitui na base energética da civilização antiga, permitindo o desenvolvimento de atividades importantes, como a cerâmica, a fabricação do vidro e fundição de metais (NOGUEIRA e LORA, 2003).

O potencial de obtenção da biomassa existente no país é enorme, considerando-se as diversas fontes de matéria-prima (bagaço da cana de açúcar, a palha do milho, cascas de arroz, baru, coco verde e resíduos do processamento mecânico da madeira, como é o caso do pó-de-serra, maravalha e aparas (COMITRE, 1995; QUIRINO, 1991).

De acordo com Nogueira e Lora (2003), se estas fontes de energia provinda da biomassa fossem usadas para a geração de energia, proporcionaria principalmente a diversificação das fontes tradicionalmente utilizadas, como é o caso do petróleo, gás natural e carvão mineral, que são fontes de energia não-renováveis. Além deste fato, a desconcentração dos meios produtores, a descentralização do local de geração e a preservação do meio ambiente, podem ser consideradas a base para a criação de um modelo energético cada vez mais limpo para o Brasil.

Ainda de acordo com estes autores, a biomassa não pode ser adotada como a única solução para ampla diversidade de situações dos sistemas energéticos. É estimado que a biomassa produzida pudesse fornecer aproximadamente $17 \%$ da eletricidade e $38 \%$ do consumo direto de combustíveis no mundo em 2050.

Segundo Leite (1997), a energia contida na biomassa contribui e poderá contribuir de uma forma mais positiva no balanço energético nacional chegando a maior fonte renovável de energia a nível mundial. Alguns países desenvolvidos já possuem plantas de produção de energia a partir de biomassa vegetal, principalmente a biomassa proveniente de resíduos da agricultura e poucos países em desenvolvimento, como é o caso do Brasil, já possuem a produção de energia elétrica desta forma renovável. 
No Brasil mais de dois terços da biomassa é utilizada de forma tradicional para aquecimento e preparação de alimentos. Em países em vias de desenvolvimento a sua utilização, em grande parte pode ser considerada como insustentável (GOLDEMBERG, 2009; LEITE, 1997).

Sendo assim, as pesquisas no setor energético buscam novas metodologias de se manipular a biomassa para a finalidade de produção de energia. Dentre estas formas, a briquetagem e a peletização viabilizam o aproveitamento da energia contida na biomassa de forma mais eficiente (COUTO et al., 2004).

A briquetagem é uma das alternativas tecnológicas para o melhor aproveitamento dos resíduos de biomassa, consistindo num processo de trituração e compactação que utiliza elevadas pressões para transformar os referidos resíduos em blocos denominados de briquetes, os quais possuem melhor potencial de geração de calor (energia) em relação aos resíduos in natura (GENTIL, 2008).

\section{A BIOMASSA PARA FINS ENERGÉTICOS}

Segundo Nogueira e Lora (1993) os recursos da biomassa, quando associados aos combustíveis, podem ser classificados como: da madeira (dendrocombustíveis), os combustíveis de plantações não-florestais (agrocombustíveis) e os resíduos urbanos. Segundo esta classificação, a madeira para fins energéticos pode então se classificar como: dendrocombustível no primeiro nível e como combustível direto (para madeiras em combustão para fornecer calor a alguns processos) no segundo nível, ou como combustível de madeira recuperada, quando usada diretamente ou indiretamente como combustível, derivada de atividades sócio-econômicas que empregam produtos de origem florestal.

Ainda de acordo com estes autores, o termo dendroenergia se associa com a biomassa energética lignocelulósica em geral e seus subprodutos, sobretudo de bases renováveis, sendo considerados como termos dendroenergéticos os aspectos técnicos, sócioeconômicos e ambientais relacionados com a produção florestal, o pré-processamento dos 
recursos florestais e semelhantes, sua eventual conversão em outras formas de energia final e por último, sua efetiva utilização.

Portanto, de uma forma geral, tais energéticos podem ser definidos como primários quando liberam a energia a partir da biomassa in natura e secundários quando existe algum processo de transformação envolvido, como é o caso da carbonização (GOLDEMBERG, 2009) e o valor energético desta biomassa tem a ver com os conteúdos de celulose e lignina presentes na biomassa em questão, apresentando em geral e baixa umidade.

Posteriormente foi a revolução industrial, onde houve uma grande substituição da matriz energética da biomassa pelos combustíveis fósseis, dada uma enorme expansão da demanda por combustíveis. Tal substituição só não foi completa, pois grande parte da população mundial ainda depende da biomassa para cozimento de alimentos, aquecimento e iluminação (NOGUEIRA e LORA, 2003).

Segundo Leite (1997) estima-se que a produção mundial de hidrocarbonetos fósseis em geral, estará reduzida à metade em 2050, época, em que essa produção não chegará a suprir $20 \%$ da demanda por combustíveis líquidos. Ainda segundo este autor, o petróleo convencional já atingiu praticamente sua máxima produção (27 bilhões de barris/ano) e provavelmente nos próximos anos deverá sofrer rápida queda, chegando em 2050, com uma produção de 8 bilhões de barris/ano.

No Brasil a situação não é muito diferente, pois apesar de estarmos muito próximos de atingir a autossuficiência em petróleo, a tendência é que tão logo esta meta seja alcançada, será rapidamente perdida, uma vez que o atual quadro de desenvolvimento colabora para que em menos de 10 anos, o déficit esteja na casa dos 50\%. Levando-se em consideração o aumento na utilização da biomassa energética, principalmente do álcool combustível, o Brasil dispõe de uma boa situação a médio prazo do que os demais países, que terão de recorrer ao carvão mineral para produzir combustíveis líquidos, a custos provavelmente muito elevados (LEITE, 1997).

Tecnicamente, a massa específica é uma das mais importantes propriedades da madeira, tendo alta relação com a qualidade desta para fins construtivos, entre outras utilidades. Esta 
propriedade é definida como a relação existente entre o peso e o volume de madeira, sem considerar os poros desta. Entretanto, quando se consideram os poros da madeira, têm-se outra definição, a massa específica aparente, sendo determinada para as diversas condições de umidade, em destaque para a condição de 12\% e 25-30\% (TUSET e DURAN, 1986).

Outra determinação para a massa específica é a massa específica básica, onde se dá a relação da madeira com massa seca ( $0 \%$ de umidade) para o seu volume saturado. Com relação à obtenção de energia da madeira, a massa específica (ou tratando-se como densidade) é característica para cada espécie e assim, possui relação direta com as propriedades energéticas (TUSET e DURAN, 1986).

De acordo com Quirino (1991) a densidade da madeira não exerce influência direta sobre o poder calorífico da madeira expresso por unidade de massa $(\mathrm{kcal} / \mathrm{kg})$. Sua influência passa a existir somente no momento em que a unidade de referência para a madeira passa a ser o seu volume $\left(\mathrm{Gcal} / \mathrm{m}^{3}\right)$.

Segundo Cunha et al. (1989) citado por Quirino et al. (2004), não há correlação entre a densidade básica e o poder calorífico. Entretanto, em relação ao volume de madeira a ser queimada, a densidade está positivamente ligada ao conteúdo calórico da madeira, estimulando o interesse de madeiras mais densas para a queima.

Ainda de acordo com estes autores o poder calorífico é mais alto quanto maior o teor de lignina e extrativos, porque eles contêm menos oxigênio que os polissacarídeos presentes na holocelulose (celulose e hemicelulose).

A umidade da madeira corresponde basicamente àquela circundante aos vasos (poros) que se deslocam das raízes às folhas para os processos fotossintéticos. Assim, para a madeira, determina-se em três tipos: a água de capilaridade (ou água livre) presente nos vasos e poros, a água de adesão (ou água higroscópica) presente nas paredes celulares e a água de constituição. A água de capilaridade e a água de adesão, juntas determinam o teor de umidade da madeira, dado em porcentagem e em base seca (T.U.B.S) ou úmida (T.U.B.U), e na prática, podem prejudicar ou comprometer a utilização da madeira para a fins energéticos (GALVÃO e JANKOWSKY, 1995). 
Para o processo de combustão, a influência da umidade se dá basicamente pela necessidade de secar a peça de madeira para que se iniciem tais processos. Assim, de acordo com Gomide (1984) para que seja liberada a água da madeira (transformação em vapor de água), uma parte da energia contida na madeira é perdida nesta transformação, conhecido como o calor latente de vaporização da água, conforme pode ser visualizado na Equação 1 e 2:

$$
\begin{aligned}
\mathrm{H}_{2}(\mathrm{~g})+1 / 2 \mathrm{O}_{2}(\mathrm{~g}) \rightarrow \mathrm{H}_{2} \mathrm{O}(\mathrm{l})-\Delta \mathrm{H} \quad(\Delta \mathrm{H}=-68.317 \mathrm{cal} / \mathrm{mol}) & \text { Equação } 1 . \\
\mathrm{H}_{2}(\mathrm{~g})+1 / 2 \mathrm{O}_{2}(\mathrm{~g}) \rightarrow \mathrm{H}_{2} \mathrm{O}(\mathrm{g})-\Delta \mathrm{H} \quad(\Delta \mathrm{H}=-57.798 \mathrm{cal} / \mathrm{mol}) & \text { Equação } 2 .
\end{aligned}
$$

Sabendo-se que diferença entre as Equações 1 e 2 correspondem ao valor de 10.519 $\mathrm{cal} / \mathrm{mol}$ e que o peso molecular da água $\left(\mathrm{H}_{2} \mathrm{O}\right)$ é igual a $18 \mathrm{~g} / \mathrm{mol}$, determina-se que a quantidade de energia por peso, que é igual a $584 \mathrm{cal} / \mathrm{g}$ de água. Assim, para a liberação de um grama de água na madeira, são necessárias 584 calorias.

De acordo com Cetec (1980), a condição mais favorável para a utilização da madeira é abaixo do ponto de saturação das fibras (PSF), que está em torno de 25-30\% (TUBS), pois se minimiza a perda de energia pelo calor latente de vaporização da água. Para Quirino et al. (2004), o conteúdo de umidade máximo que uma madeira pode ter para ser queimada no forno está em torno de $65-70 \%$ em base úmida.

Este efeito da umidade foi observado por Farinhaque (1981), onde para a madeira de bracatinga durante o processo de carbonização, o poder calorífico superior (PCS) passou de $4890 \mathrm{kcal} / \mathrm{kg}$ à $0 \%$ de umidade (base seca) para $2774 \mathrm{kcal} / \mathrm{kg}$. No caso do poder calorífico inferior (PCI), de 0\% de umidade para 80\%, o valor observado passou de 4566 para $1094 \mathrm{kcal} / \mathrm{kg}$. Desta forma, o poder calorífico de qualquer combustível é altamente dependente do conteúdo de umidade (FARINHAQUE, 1981).

O PCS é simplesmente a medida máxima da quantidade de energia contida num combustível e é determinado em calorímetros. A diferença deste parâmetro para o PCI é que neste último, é descontada a energia perdida pela transformação da água do estado líquido para o gasoso (calor latente de vaporização da água) tendo, portanto, o PCI um 
valor menor que o PCS. Desta forma, espera-se que para maiores valores do poder calorífico, melhor a matéria-prima para a utilização energética (QUIRINO et al., 2004).

Segundo Couto et al. (2004) esta é uma das propriedades mais importantes com relação à geração de energia a partir de materiais renováveis, como é o caso da madeira. O poder calorífico diz respeito à energia liberada quando o material combustível (madeira) queima totalmente.

A determinação do Poder Calorífico Superior (PCS) baseia-se no método de ensaio previsto na Norma NBR 8633/84 (ABNT, 1984) "Carvão Vegetal: determinação do poder calorífico". Esta norma estipula a utilização de um equipamento calorímetro ou bomba calorimétrica adiabática ou isotérmica (estática) em que ambos, são constituídos de três partes: bomba de oxigênio, vaso calorimétrico e camisa isolante. A bomba de oxigênio é constituída de um vaso metálico selado e resistente enquanto que o vaso calorimétrico é um recipiente metálico com certo volume de água, onde se encontra a bomba de oxigênio, um termômetro e um agitador.

Por fim, a terceira parte, a camisa isolante (adiabática) nada mais é que um recipiente que envolve todo o vaso calorimétrico, com a função de não permitir a troca de calor com o ambiente. No caso da camisa isotérmica, deve ser observada a temperatura do calorímetro antes, durante e depois para que se calcule a correção pela troca de calor com o ambiente (ABNT, 1984).

\section{COMPOSIÇÃO QUÍMICA E A DEGRADAÇÃO PELO EFEITO DO CALOR}

O conhecimento da composição química (teor de celulose, hemicelulose e lignina) da madeira e de outras biomassas é um fator importante para a avaliação do rendimento energético de um processo de combustão ou para a viabilidade na utilização de biomassas em processos de briquetagem ou peletização (COUTO et al., 2004). 
Sabe-se que cada biomassa tem proporções distintas dos seus constituintes químicos básicos: a celulose, hemicelulose e lignina. Para a utilização energética da biomassa são preferíveis espécies com maiores teores de lignina, pois este componente químico é o menos degradado termicamente durante a formação do briquete (CETEC, 1980), mantendo-se grande parte da sua massa, especialmente em processos que envolvam a utilização de altas temperaturas na manufatura do briquete (Figura 1).

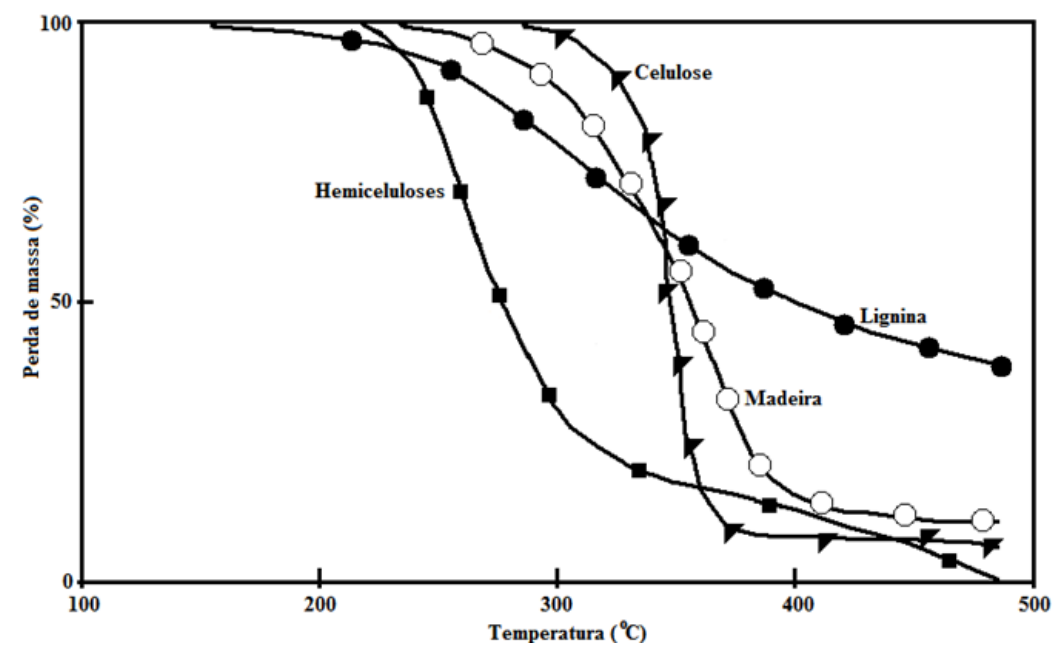

Figura 1. Curva termogravimétrica da madeira e seus componentes fundamentais. Fonte: Cetec (1980).

De acordo com Brito e Barrichelo (1977), para a espécie Eucalyptus spp. foram observadas drásticas alterações no percentual de celulose durante o processo de transformação química pelo efeito da temperatura nos primeiros minutos, enquanto que a lignina mantém altos percentuais de massa.

Além da composição química dos materiais lignocelulósicos, a eficiência na utilização energética depende também da sua composição em materiais voláteis, cinzas e carbono fixo, pois variam com a espécie e apresentam comportamento específico durante a combustão do material. (QUIRINO et al., 2004).

Segundo Gomes e Matos (1979) citado por Cetec (1980), o efeito da quantidade de carbono presente na madeira/briquete é refletido principalmente na utilização em fornos por unidade de volume. Assim, maior é a utilização do mesmo à medida que o carbono 
fixo aumenta. Isto significa um aumento no tempo de residência e assim, maior produção por unidade de volume.

O percentual de carbono fixo refere-se à fração da biomassa que se queima no estado sólido. Combustíveis com teores mais elevados de carbono fixo são preferíveis porque queimam mais lentamente. A determinação do carbono fixo é feita por diferença entre a soma dos teores (\%) de umidade, matéria volátil e cinzas e $100 \%$.

O teor de cinzas na biomassa indica o conteúdo de minerais presentes em sua composição, nas mais diferentes formas, sendo que os principais íons minerais normalmente encontrados em cinzas de madeira são o potássio, cálcio, magnésio, sódio, manganês, ferro, alumínio, além de radicais como carbonatos, silicatos, cloretos, sulfatos (CARDOSO, 2001 citado por PAULA et al. 2009).

De acordo com Cetec (1980), para a biomassa onde o teor de cinzas é sempre baixo o volume da escória (cinzas) dentro do autoforno não é de grande importância, entretanto, a composição destas cinzas é que tem influência no processo. Alguns metais alcalinos tem efeito catalisador sobre a reação C- $\mathrm{CO}_{2}$, ou seja, em algumas regiões do autoforno, pode-se formar CO com consumo de carbono sem sua utilização no processo de redução. Porém, este efeito só ocorre para minérios com conhecida redutibilidade baixa.

\section{REFERÊNCIAS BIBLIOGRÁFICAS}

ALMEIDA, J. M.; SILVA, D. J. Efeito da qualidade de extrativos e da acessibilidade do licor na polpação Kraft de clones de Eucalyptus. In: Congresso anual ABTCP, 34., 2001, São Paulo. Anais... São Paulo, ABTCP, 2001. P. 1-14.

ALVES JÚNIOR, F. T.; GUIMARÃES, J. L. S.; SANTOS, G. A.; LEITE, A. M. F.; BARROS, G. D. T. Utilização de biomassa para briquetagem como fonte de energia alternativa e a disponibilidade deste recurso na região do Cariri-CE. Ln: XXIII Encontro Nac. de Eng. de Produção - Ouro Preto, MG, Brasil, 21 a 24 de out de 2003.

BEZZON, G. Síntese de novos combustíveis sólidos a partir de resíduos agrolorestais e possívesi contribuições no cenário energético brasileiro. Dissertação (Mestrado em Engenharia Mecânica. Faculdade de engenharia Mecânica, Universidade de Campinas Unicamp. Campinas-SP, 1994. 
BRITO, J. O. Usos energéticos do Eucalyptus grandis. In: IX Jornadas Forestales de Entre Rios, Concórdia, 1994.

BRITO, J. O.; BARRICHELO, L. E. G. Comportamento isolado da lignina e da celulose da madeira frente à carbonização. Circular Técnica, n. 28, Piracicaba/SP: Instituto de Pesquisas e Estudos Florestais, n. 28, p. 9-20, 1977.

BRITO, J. O.; BARRICHELO, L. E. G. Correlações entre características físicas e químicas da madeira e a produção de carvão vegetal. I. Densidade e teor de lignina da madeira de eucalipto. Circular Técnica, n. 14, Piracicaba/SP: Instituto de Pesquisas e Estudos Florestais, n. 14, p. 9-20, 1977.

BRITO, J. O.; BARRICHELO, L. E. G. Usos diretos e propriedades da madeira para geração de energia. Circular Técnica, n. 52, Piracicaba/SP: Instituto de Pesquisas e Estudos Florestais, 1979.

CENTRO TECNOLÓGICO DE MINAS GERAIS. Uso da madeira para fins energéticos. In: PENEDO, W. R. (org.). Belo Horizonte: Série de Publicações Técnicas, 1980.

COMITRE, V. A questão energética e o padrão tecnológico da agricultura brasileira. Informações Econômicas, São Paulo/SP, v.25, n.12, dez. 1995.

COUTO, L. C.; COUTO, L.; WATZLAWICK, L. F. CÂMARA, D. Vias de valorização energética da biomassa. Biomassa \& Energia, v. 1, n. 1, p.71-92, 2004.

DINIZ, J.; CARDOSO, A. L.; STAHL, J. A; VILlETTI, M. A.; MARTINS, A. F. Poder calorífico da casca de arroz, caroço de pêssego, serragem de eucalipto e de seus produtos de pirólise. Ciência e Natura, n. 26, v. 2, p. 25 - 32, 2004.

FARINHAQUE, R. Influência da umidade no poder calorífico da madeira de Bracatinga (Mimosa scabrella Benth) e aspectos gerais de combustão. Circular Técnica, n. 06, Piracicaba/SP: Instituto de Pesquisas e Estudos Florestais, n. 6, 1981.

FRAZA, C. Densificação da madeira. In: $1^{\circ}$ Seminário Madeira Energética MADEM 2008, Rio de Janeiro/RJ, 2008.

GALVÃO, A. P. M.; JANKOWSKY, I. P. Secagem racional da madeira. São Paulo: Nobel, 1985.

GENTIL, L. V. B. Tecnologia e Economia do Briquete de Madeira. Tese (Doutorado em Ciências Florestais), Departamento de Engenharia Florestal. Universidade de Brasília. Brasília. DF, 2008; 195 p.

GOLDEMBERG, J. Biomassa e energia. Química Nova, v. 32, n. 3, p. 582-587, 2009.

GOMIDE, R. Estequiometria industrial. 2a Ed. São Paulo: R. Gomide, 1984.

GRAUER, A.; KAWANO, M. Boletim Informativo da Bolsa de Reciclagem, ano I, $\mathrm{n}^{\mathrm{o}} 5$ NOV/DEZ, 2001.

LEITE, A. D. A energia do Brasil. Rio de Janeiro: Nova Fronteira, 1997.

MICHELAZZO, M. B.; BRAUNBECK, O. A. Análise de seis sistemas de recolhimento do palhiço na colheita mecânica da cana-de-açúcar. Revista Brasileira de Engenharia Agrícola e Ambiental, v.12, n.5, p.546-552, 2008.

MIGLIORINI, A. J. Densificação de biomassa florestal. Série Técnica Instituto de Pesquisas e Estudos Florestais - IPEF, Piracicaba, v.1, n.2, p.1-9, 1980. 
MIGUEL NÚÑEZ, G. S. Fabricación de pellets de carbonilla, usando a serrin de Pinus radiata (D. Don), como material aglomerante. Maderas: Ciencia y tecnología v. 10, n. 2, p. 129-137, 2008.

NOGUEIRA, L. A. H.; LORA, E. S. 2003. Dendroenergia: fundamentos e aplicações. Ed. Interciência, $2^{\text {a }}$ edição, 144p.

NOGUEIRA, M. F. M.; CRUZ, P. T. A. Oportunidades para o desenvolvimento da biomassa energética no Brasil. Biomassa e Energia, v. 1, n. 2, p. 29-36. 2004.

OLIVEIRA, J. M. C; LOBO, P. C. Avaliação do Potencial Energético de Resíduos de Biomassa Amazônica. http://146.164.33.61/termo/Orientacao/Gaseificacao/0119.pdf>. Acesso em 07 fev. 2009. Departamento de Engenharia Mecânica, Universidade Federal de Itajubá. Itajubá-MG. / 2009.

PAUlA, M. O.; TINOCO, I. F. F.; RODRIGUES, C. S.; SILVA, E. N.; SOUZA, C. F. Potencial da cinza do bagaço da cana-de-açúcar como material de substituição parcial de cimento Portland. Revista Brasileira de Engenharia Agrícola e Ambiental, v. 13, p. 353357, 2009.

QUIRINO, W. F. Briquetagem de resíduos ligno-celulósicos. Brasília: LPF, 1991. (Circular Técnica 20).

QUIRINO, W. F.; VALE, A. T.; ANDRADE, A. P. A.; ABREU, V. L. S. A.; AZEVEDO, A. C. S. Poder calorífico da madeira e de resíduos lignocelulósicos. Biomassa \& Energia, v. 1, n. 2, p. 173-182, 2004.

SILVA, A. M. N.; ALBUQUERQUE, J. L.; SILVA, E. S.; SANTOS-FILHO, D.; BARBOSA, W. B. A biomassa florestal (lenha) como insumo energético para os artesãos da cidade de Tracunhaém/PE. Custos e agronegócio on line, v. 4, n. 3, 2008.

TUSET, R.; DURAN, F. Manual de maderas comerciales, equipos y procesos de utilización. Montevideo: Hemisferio Sur, 1986, 688p. 


\section{CAPÍTULO I}

\section{INFLUÊNCIA DO TAMANHO DAS PARTÍCULAS NA RESISTÊNCIA MECÂNICA DE BRIQUETES CONFECCIONADOS COM SERRAGEM DE CUPIÚBA (Goupia glabra Aubl).}

\section{INTRODUÇÃO}

O conceito de biomassa é referente à massa orgânica de origem vegetal. Citam-se: resíduos florestais e agrícolas e a matéria orgânica contida nos resíduos industriais, domésticos, municipais e outros (SILVA et al., 2008).

Segundo Goldemberg (2009), a energia química presente nas ligações entre as moléculas pode ser liberada diretamente por combustão, ou convertida através de algum processo em outras formas energéticas mais adequadas, para o fim desejado, tal como o álcool e o carvão vegetal.

Os resíduos de serrarias e madeireiras podem ser considerados como uma fonte de biomassa para a produção de briquetes, entretanto, possuem grande variação das partículas que constituem este resíduo. De acordo com IBQP (2002), os resíduos do setor madeireiro podem ser classificados a partir da dimensão das partículas que o compõem: os cavacos apresentam partículas com dimensões aproximadas a 50 x $20 \mathrm{~mm}$; a maravalha possui partículas com cerca de 2,5 $\mathrm{mm}$; a serragem apresenta partículas entre 0,5 e $2,5 \mathrm{~mm}$; e o pó-de-serra é caracterizado pelas partículas menores que $0,5 \mathrm{~mm}$

Dada a forma mais homogênea dos briquetes, a etapa industrial de armazenamento e transporte é facilitada, pois uma maior massa está adensada em um menor volume. De acordo com Flores et al (2009) citado por Vendrasco et al. (2010), levando-se em consideração a biomassa envolvida, a redução no volume pode ser observada entre 4 e 11 vezes. 
De acordo com Quirino (1991), além do tamanho da partícula na composição do briquete, a umidade da matéria prima também pode influenciar diretamente na qualidade do briquete produzido, no que diz respeito à sua resistência mecânica. Assim, para os materiais lignocelulósicos com teores de umidade em base seca muito acima de $15 \%$ ou muito secos (menor que 9\%), podem se observar estouros ou trincas e rachaduras no briquete recémformado, consequentemente causando a sua desintegração durante o transporte e manipulação ou inviabilizando tecnicamente a briquetagem.

De acordo com Sotannde et al. (2010), recomenda-se a determinação da CMR (carga máxima de ruptura) nos sentidos longitudinal e diametral para a determinação da resistência mecânica dos briquetes, pois em condições de transporte e manuseio, os briquetes estariam submetidos a ambos os esforços.

Por outro lado, vários são os estudos da resistência mecânica dos briquetes que indicam que estes materiais compactados devem apresentar maior resistência no sentido diametral, pois são observados valores de carga máxima de ruptura extremamente inferiores nesta posição, indicando uma possível quebra do briquete também para esta posição no caso de manuseio, quedas e durante o transporte (FURTADO et al, 2010; FERRAGUTTI et al, 2011; LEITE et al, 2011; RAMOS e PAULA et al, 2011).

Sendo assim, este Capítulo I foi realizado como ensaio preliminar à tese e teve como objetivo, determinar as frações de tamanhos das partículas presentes no resíduo do processamento mecânico da madeira e verificar a influência do tamanho das partículas presentes na serragem e pó-de-serra de cupiúba (Goupia glabra Aubl.) na resistência mecânica de briquetes confeccionados com estas matérias-primas.

\section{MATERIAL E MÉTODOS}

\subsection{OBTENÇÃO DA BIOMASSA}

O resíduo denominado serragem ou pó-de-serra foi obtido em uma madeireira particular no município de Mineiros-GO, que realiza apenas o desdobro de pranchões e tábuas. Coletaram- 
se aproximadamente $20 \mathrm{~kg}$ da serragem da espécie Goupia glabra Aubl. diretamente da caixa de armazenamento da máquina serra circular esquadrejadeira. Desta forma, garantiu-se que o resíduo não estava misturado com qualquer serragem de outra espécie de madeira.

A biomassa, portanto, foi embalada em sacos plásticos e encaminhada para o Laboratório de Produtos Florestais (LPF) do Serviço Florestal Brasileiro (SFB), que está vinculado ao Ministério do Meio Ambiente (MMA).

\subsection{DISTRIBUIÇÃO GRANULOMÉTRICA DA SERRAGEM}

Como ensaio preliminar desta tese, a avaliação do tamanho das partículas presentes na serragem foi realizada de forma a identificar os tamanhos mais representativos que constituem o resíduo do processamento da madeira. Desta forma, fez-se uma classificação em uma mesa vibratória por um período de 10 minutos e com as peneiras com abertura de 10 a 100 Mesh, onde: as partículas grossas foram obtidas nas peneiras 10, 20, 28 e $42 \mathrm{Mesh}$; as partículas intermediárias foram obtidas nas peneiras 48 e 60 Mesh; e as partículas finas foram obtidas nas peneiras 80, 100 e recipiente de fundo de 100 Mesh.

Utilizou-se para este procedimento, 3 repetições com $100 \mathrm{~g}$ de serragem por vez e as partículas obtidas em cada peneira foram coletadas em placas de petri e pesadas em uma balança analítica com precisão de $10^{-4} \mathrm{~g}$. Por fim, calculou-se a média da massa obtida em cada peneira das três repetições. Este procedimento foi adaptado de Adapa et al (2009) e também semelhante à Vendrasco et al (2010).

\subsection{CLASSIFICAÇÃO DAS PARTÍCULAS}

A serragem foi classificada em peneiras de 42 e 60 Mesh (abertura da malha de 0,355 e 0,250 $\mathrm{mm}$, respectivamente) e com o auxílio de uma mesa vibratória, por um período de 10 minutos (Figura 1). Desta forma, obtiveram-se as partículas classificadas em três diferentes níveis: partículas que ficaram retidas na peneira de 42 Mesh (partículas grossas); partículas que passaram pela peneira de 42 e ficaram retidas na peneira de 60 Mesh (partículas intermediárias); e as partículas que passaram pela peneira de 60 Mesh (partículas finas). 


\subsection{CONFECÇÃO DOS BRIQUETES}

Os briquetes foram confeccionados no Setor de Energia da Biomassa do LPF/SFB, utilizandose de uma prensa briquetadeira da marca Irmãos Lippel e modelo LB-32 (Figura 1). Adotouse a temperatura de compactação de $130{ }^{\circ} \mathrm{C}$, pressão do manômetro de $80 \mathrm{kgf} / \mathrm{cm}^{2}$, e um período de 5 minutos de compactação, variando-se apenas o tamanho das partículas na composição de cada briquete. Todas as partículas utilizadas apresentaram umidade próxima a $10 \%$.

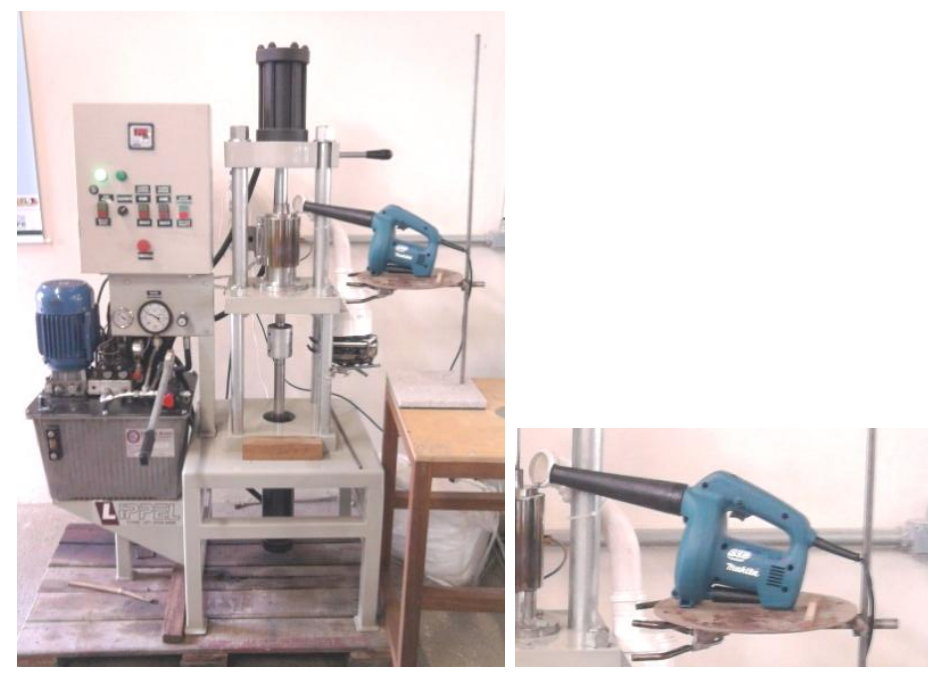

Figura 1. Prensa briquetadeira da marca Irmãos Lippel, modelo LB-32, onde se confeccionaram os briquetes. À direita, destaque para a sopradora utilizada no resfriamento do briquete.

Com o intuito de acelerar o resfriamento dos briquetes após a compactação, utilizou-se uma máquina sopradora da marca Makita, modelo MUB 101, posicionada a uma distância de cerca de $10 \mathrm{~cm}$ do briquete. $\mathrm{O}$ tempo de resfriamento variou entre os briquetes confeccionados para que se obtivessem todos os briquetes sem qualquer rachadura na sua superfície.

Desta forma, para cada tratamento foram confeccionados 10 briquetes, totalizando ao final, 60 briquetes produzidos conforme delineamento experimental da Tabela 1. 
Tabela 1. Delineamento experimental para os briquetes confeccionados com serragem de cupiúba (Goupia glabra Aubl.).

\begin{tabular}{ccc}
\hline Tratamento & Partículas & Tamanho das Partículas \\
\hline 1 & Grossa & Até 45 Mesh \\
2 & Intermediária & Entre 45 e 60 Mesh \\
3 & Fina & Acima de 60 Mesh \\
4 & Mistura 2:1:1 & Até 45:entre 45 e 60: acima de 60 Mesh \\
5 & Mistura 1:1:1 & Até 45:entre 45 e 60: acima de 60 Mesh \\
6 & In natura & Aleatório \\
\hline
\end{tabular}

Assim, o delineamento experimental foi: uma espécie de madeira, uma pressão de compactação, uma temperatura, três granulometrias, duas misturas de partículas e resíduo in natura, totalizando 6 tratamentos e 10 briquetes confeccionados por tratamento.

Após a confecção dos briquetes, estes foram dispostos em uma estufa a $50^{\circ} \mathrm{C}$ até a massa constante e a um teor de umidade próximo a $12 \%$.

\subsection{DETERMINAÇÃO DA DENSIDADE APARENTE}

A densidade aparente $\left(\mathrm{DA}, \mathrm{g} / \mathrm{cm}^{3}\right)$ dos briquetes foi determinada pelo método estereométrico, ou seja, pela relação da massa/volume em um dado teor de umidade. Para a determinação do volume de cada briquete produzido, foi adotado o volume de um cilindro circular qualquer e então foram feitas medições do diâmetro em três pontos, base, meio e topo do briquete utilizando-se um paquímetro digital com precisão de $10^{-3} \mathrm{~mm}$. A massa foi determinada por meio de uma balança analítica com precisão de $10^{-4} \mathrm{~g}$. Este procedimento foi semelhante ao realizado por Ramos e Paula et al (2011) e Vendrasco et al (2010).

Calculou-se a densidade aparente por tratamento, a partir da média dos 10 briquetes confeccionados. 


\subsection{DETERMINAÇÃO DA RESISTÊNCIA MECÂNICA}

Para o ensaio da determinação da resistência mecânica dos briquetes, utilizou-se uma máquina universal de ensaios da marca EMIC do Laboratório de Tecnologia da Madeira, da Universidade de Brasília, com o aparato para compressão paralela ou perpendicular de corpos-de-prova de madeira.

Realizou-se o ensaio de compressão nos sentidos: longitudinal do briquete (ou no sentido de compactação da biomassa) e no sentido diametral (perpendicular ao sentido da compactação da biomassa), que podem ser visualizados na Figura 2.

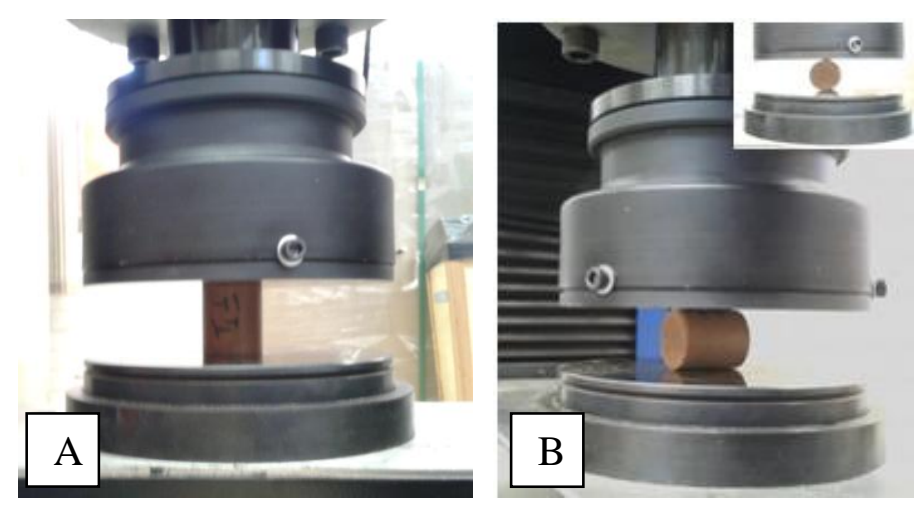

Figura 2. Ensaio de resistência à compressão longitudinal (A) e diametral (B) dos briquetes confeccionados com serragem de Cupiúba (Goupia glabra Aubl).

Dada a não existência de norma específica para o ensaio mecânico com briquetes, adotou-se a norma da Comissão Panamericana de Normas Técnicas COPANT 30:1-008 (COPANT, 1971a) para a compressão no sentido paralelo da madeira, representando o sentido longitudinal do briquete e a norma COPANT 30:1-011 (COPANT, 1971b) para a compressão no sentido perpendicular da madeira, representando o sentido diametral do briquete. As velocidades de carregamento foram: $0,6 \mathrm{~mm} \cdot \mathrm{min}^{-1}$ e $0,3 \mathrm{~mm} \cdot \mathrm{min}^{-1}$, respectivamente.

Para estes ensaios de compressão, foram utilizados 5 briquetes em cada sentido de aplicação da carga (longitudinal ou diametral). 
De forma semelhante, Kakitis et al (2010) realizaram o ensaio de compressão em briquetes a partir da posição diametral com a biomassa de palha de trigo, assim como Leite et al (2011) em briquetes confeccionados com casca de café.

\subsection{ANÁLISE ESTATÍSTICA}

Para a análise estatística, utilizou-se do pacote estatístico SPSS (Statistical Package for the Social Sciences), v. 17 para Windows.

Inicialmente, realizou-se uma análise de Outliers com o intuito de identificar resultados muito discrepantes do desvio padrão das amostras. Após esta análise, realizou-se um teste de médias ANOVA a um nível de 5\% de significância e por fim, fez-se um Teste Tukey para classificação da densidade aparente e da resistência mecânica em grupos.

As propriedades analisadas foram os valores máximos, mínimos e a média da densidade aparente (DA, g/ $\mathrm{cm}^{3}$ ), carga máxima de ruptura em compressão longitudinal (CMR, kgf) e carga máxima de ruptura em compressão diametral (CMR, kgf).

\section{RESULTADOS E DISCUSSÃO}

A Figura 3 ilustra a distribuição de tamanho das partículas observada para a serragem da espécie cupiúba (Goupia glabra Aubl.) coletada em uma madeireira no município de Mineiros-GO. 


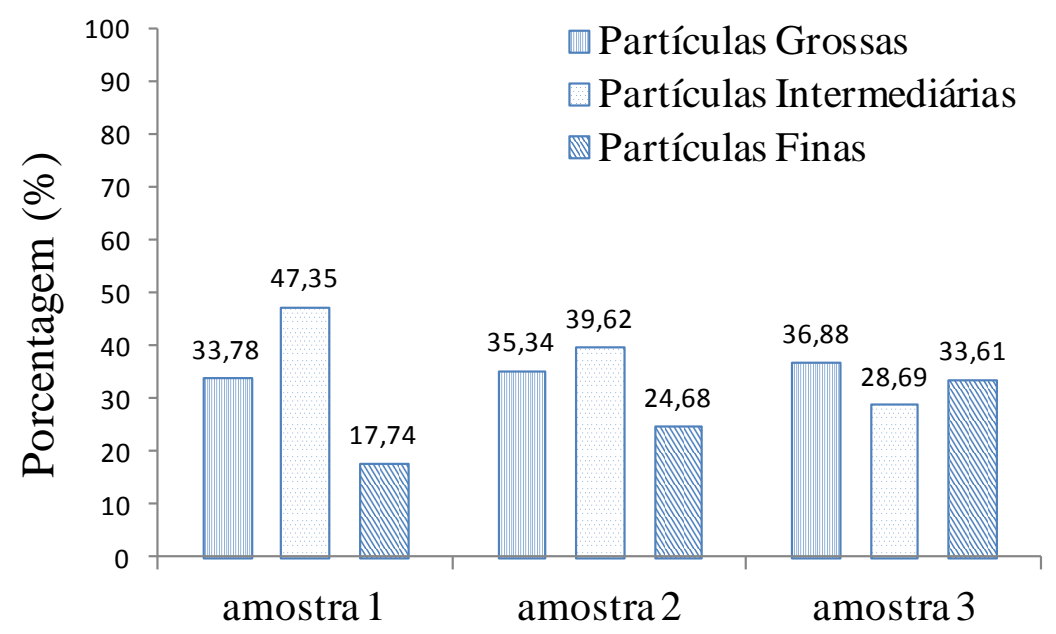

Figura 3. Médias da massa de partículas na serragem de cupiúba (Goupia glabra Aubl.) obtida na distribuição granulométrica em peneiras de 10 a 100 Mesh.

Assim, após a classificação, as partículas que estavam presentes em maiores quantidades na serragem desta espécie de madeira foram aquelas com granulometria superior a $60 \mathrm{Mesh}$, ou seja, as partículas classificadas como finas nas peneiras de 80, 100 e fundo de 100 Mesh.

Entretanto, não se observa grande diferença entre as quantidades de partículas grossas, intermediárias e finas, podendo classificar a serragem da madeira de cupiúba como sendo igualmente distribuída na proporção 1:1:1 (partículas grossas, intermediárias e finas).

Esta informação sugere que realmente é grande a importância das partículas mais finas na composição da serragem que foi utilizada para a confecção de briquetes.

De forma semelhante, Vendrasco et al. (2010) observaram que após a moagem, para as partículas de acículas de pinus e araucária e para o bagaço de cana, existe uma distribuição de cerca de $60 \%$ para a granulometria de 40-60 Mesh, relativamente semelhante ao do presente estudo. Por outro lado, Ferragutti et al. (2011) estudando a distribuição granulométrica de pó de lixa e de blendas de pinus, os autores observaram uma predominância das partículas com granulometria bastante reduzida, próximo à 200 Mesh.

Com relação aos briquetes confeccionados, o tempo de resfriamento para os 6 tratamentos variou em função do tamanho das partículas (Tabela 2), de 3 a 20 minutos. Assim, para os 
briquetes confeccionados com partículas mais grossas, o tempo de resfriamento foi inferior àqueles com partículas mais finas. Este fato sugere que para uma maior acomodação das partículas no interior do briquete, o processo de condução de calor foi facilitado e assim promoveu um maior aquecimento da porção do miolo.

Tabela 2. Tempo de resfriamento em minutos para os briquetes confeccionados com serragem classificada de cupiúba (Goupia glabra Aubl.).

\begin{tabular}{ccc}
\hline Tratamento & Partículas & Tempo de Resfriamento (minutos) \\
\hline 1 & Grossa & 3 \\
2 & Intermediária & 5 \\
3 & Fina & 20 \\
4 & Mistura 2:1:1 & 12 \\
5 & Mistura 1:1:1 & 14 \\
6 & In natura & 6 \\
\hline
\end{tabular}

Quando se promoveu o resfriamento de forma muito rápida, o choque térmico provocou rachaduras na superfície dos briquetes, para a liberação do calor retido no miolo. Assim, pode-se supor que os briquetes com partículas grossas apresentaram uma maior eficiência na liberação do calor, não ocasionando rachaduras em resfriamentos rápidos.

A Tabela 3 mostra as médias da densidade $\left(\mathrm{g} / \mathrm{cm}^{3}\right)$ e da carga máxima de ruptura (CMR, $\left.\mathrm{kgf}\right)$ nos sentidos longitudinal e diametral dos briquetes confeccionados para os 6 tratamentos. Com o auxílio da Tabela 4 é possível verificar que existe diferença significativa ao nível de $1 \%$ entre as médias da densidade dos briquetes com partículas grossas, intermediárias e finas e de acordo com a Tabela 5, verifica-se este efeito para a carga máxima de ruptura nos sentidos longitudinal e diametral dos briquetes. 
Tabela 3. Médias da densidade aparente, carga máxima de ruptura nos sentidos longitudinal (CMR long.) e diametral (CMR diam.) de briquetes confeccionados com serragem classificada de cupiúba (Goupia glabra Aubl.).

\begin{tabular}{cccccccc}
\hline Partícula & Tratamento & $\begin{array}{c}\text { Dens. Aparente }\left(\mathrm{kg} / \mathrm{m}^{3}\right) \\
\end{array}$ & & $\begin{array}{c}\text { CMR long. (kgf) } \\
\text { Média** }\end{array}$ & Desv. Pad & Média** & CMR diam. (kgf) \\
\hline Grossa & 1 & $1141,89 \mathrm{C}$ & 7,65 & $6168,42 \mathrm{C}$ & 459,74 & $595,18 \mathrm{~A}$ & 23,68 \\
\hline Intermediária & 2 & $1129,43 \mathrm{D}$ & 11,92 & $7393,52 \mathrm{~A}$ & 200,24 & $558,72 \mathrm{~A}$ & 18,89 \\
Fina & 3 & $1176,73 \mathrm{AB}$ & 13,63 & $5262,12 \mathrm{E}$ & 325,22 & $753,48 \mathrm{~A}$ & 19,93 \\
Mistura 2:1:1 & 4 & $1165,95 \mathrm{~B}$ & 8,10 & $5999,44 \mathrm{CD}$ & 330,55 & $651,37 \mathrm{~A}$ & 29,26 \\
Mistura 1:1:1 & 5 & $1172,77 \mathrm{AB}$ & 4,93 & $5669,56 \mathrm{DE}$ & 404,18 & $669,44 \mathrm{~A}$ & 27,16 \\
In natura & 6 & $1179,77 \mathrm{~A}$ & 5,89 & $6887,02 \mathrm{~B}$ & 159,91 & $694,06 \mathrm{~A}$ & 30,23
\end{tabular}

$(* *)=$ Significativo ao nível de $1 \%$ pelo teste $\mathrm{F} ;($ n.s. $)$ = valor não significativo ao nível de $5 \%$ pelo teste F; Letras iguais indicam médias semelhantes ao nível de 5\% no Teste Tukey;

Tabela 4. Análise de Variância para a densidade dos briquetes confeccionados com serragem classificada de cupiúba (Goupia glabra Aubl.).

\begin{tabular}{lccccc}
\hline & Soma de Quadrados & Graus de Liberdade & Quadrado Médio & F Calculado & Sig. \\
\hline Entre grupos & 20724,889 & 5 & 4144,978 & 47,436 &, $000^{\star *}$ \\
\hline Dentro de Grupos & 4543,820 & 52 & 87,381 & & \\
Total & 25268,709 & 57 & & \\
\hline
\end{tabular}

** significativo ao nível de $1 \%$ pelo Teste $\mathrm{F}$.

Tabela 5. Análise de Variância para a carga máxima de ruptura nos sentidos longitudinal e diametral de briquetes confeccionados com serragem classificada de cupiúba (Goupia glabra Aubl.).

\begin{tabular}{lccccc}
\hline & Soma de Quadrados & Graus de Liberdade & Quadrado Médio & F Calculado & Sig. \\
\hline Entre grupos & $4,306 \mathrm{E} 8$ & 11 & $3,915 \mathrm{E} 7$ & 713,682 &, $000^{\star *}$ \\
Dentro de Grupos & 2358756,410 & 43 & 54854,800 & & \\
Total & $4,330 \mathrm{E} 8$ & 54 & & \\
\hline
\end{tabular}

** significativo ao nível de $1 \%$ pelo Teste $\mathrm{F}$. 
Desta forma, pode-se observar que as maiores médias para a densidade foram para os briquetes confeccionados pelo tratamento 6,5 e 3 (todos próximos a $1170 \mathrm{~kg} / \mathrm{m}^{3}$ ) e o menor valor desta propriedade foi para o tratamento 1. Kakitis et al. (2010) observaram que para os briquetes confeccionados com palha de trigo, a densidade está próxima a $930 \mathrm{~kg} / \mathrm{m}^{3}$. Por outro lado, Leite et al (2011) observaram densidade aparente superior a $1000 \mathrm{~kg} / \mathrm{m}^{3} \mathrm{em}$ briquetes confeccionados com casca de café.

Conforme o exposto na Tabela 3 observou-se que os briquetes confeccionados com as partículas intermediárias (entre 42 e 60 Mesh) apresentaram melhores resistências mecânicas, pois maior foi o valor da carga máxima de ruptura no sentido longitudinal (7393,52 kgf ou $739,352 \mathrm{~kg}$ ) para que ocorresse a quebra destes briquetes.

Após o tratamento 2, os maiores valores da CMR longitudinal foram para o tratamento 6, ou seja, para os briquetes confeccionados com os resíduos in natura $(688,702 \mathrm{kgf})$, seguido do tratamento 1, com partículas grossas $(616,842 \mathrm{kgf})$. Acredita-se que o tratamento 2 apresentou maior valor para esta propriedade pela uniformização das partículas no interior do briquete, o que poderia ter promovido uma distribuição mais homogênea de calor para todas as partes do briquete. Este fato não ocorre nos tratamentos 1 e 3 pois existe uma grande variação de granulometria dentro de cada tratamento. No caso do tratamento 1, existem partículas superiores a $1 \mathrm{~mm}$ até partículas de 0,355 $\mathrm{mm}$. Este efeito também pode ser observado no tratamento 3, onde se tem partículas de 0,210 $\mathrm{mm}$ até partículas inferiores a 0,149 $\mathrm{mm}$.

Por outro lado, os menores valores observados de CMR no sentido longitudinal foram para o tratamento $3(526,212 \mathrm{kgf})$, tratamento $5(566,956 \mathrm{kgf})$ e tratamento $4(599,944 \mathrm{kgf})$.

Desta forma, os resultados da CMR no sentido longitudinal dos tratamentos 5 e 4 (misturas de partículas) corroboram a teoria de que dada a maior heterogeneidade das partículas do briquete, menores foram os valores desta propriedade. Porém, este fato não explica porque o tratamento 6 apresentou o segundo maior valor para esta propriedade. Contudo, é possível que durante a confecção dos briquetes do tratamento 6, na serragem estavam presentes grandes quantidades de partículas mais finas, proporcionando maiores valores para a CMR longitudinal. 
Ainda, ficou constatado que não há uma relação direta entre o aumento da densidade aparente com o aumento na CMR longitudinal para os briquetes confeccionados neste estudo.

Com relação aos resultados da CMR no sentido diametral, de acordo com a Tabela 3, não foram observadas diferenças estatisticamente significativas entre as médias dos tratamentos. Assim, todos os tratamentos receberam a mesma letra para o Teste Tukey ao nível de 5\% de significância, muito embora o tratamento $3(753,48 \mathrm{kgf}$ ou 75,48 kg) tenha demonstrado uma leve superioridade com relação aos demais tratamentos. De acordo com Leite et al (2011), também não foram observadas diferenças significativas ao nível de 5\% para os briquetes confeccionados com casca de café e ensaiados em compressão diametral. Os valores observados por estes autores na CMR diametral foram em média de $250 \mathrm{kgf}$.

Para Ferragutti et al. (2011), os briquetes confeccionados com blendas de pinus e pó de lixa após a determinação da CMR diametral, observaram-se que a força suportada por estes briquetes está entre 84,59 e 77,78 kgf. Entretanto, estes autores não utilizaram alta temperatura para que ocorresse a plastificação da lignina e assim conferindo adesão entre as partículas nos briquetes, o que pode ter ocasionado a baixa resistência destes briquetes.

\section{CONCLUSÕES}

Com base nas condições em que este trabalho foi realizado, podem-se inferir as seguintes conclusões:

- As partículas finas foram encontradas em grandes quantidades no resíduo estudado;

- Todos os briquetes confeccionados para as três diferentes partículas apresentaram valores satisfatórios de resistência mecânica à compressão, com destaque para os briquetes com partículas intermediárias e para o resíduo in natura;

- Com vistas à resistência mecânica, não é necessário a classificação das partículas da serragem de cupiúba para a confecção de briquetes de qualidade; 


\section{REFERÊNCIAS BIBLIOGRÁFICAS}

ADAPA, P.; TABIL, L.; SCHOENAU G. Compression characteristics of selected ground agricultural biomass. Agricultural engineering international: The CIGR Ejournal. Mauscript 1347. V. XI. Jun. 2009.

COPANT - COMISIÓN PANAMERICANA DE NORMAS TÉCNICAS. Maderas: método de determinación de la compresión axial, o paralela al grano. 30: 1- 008. COPANT, 1971a.

COPANT - COMISIÓN PANAMERICANA DE NORMAS TÉCNICAS. Maderas: método de determinación de la compresión perpendicular al grano. 466. COPANT, 1971 b.

FERRAGUTTI, A. C.; YAMAJI, F. M.; GRAÇA, J. S.; ALÓ, L. L. Determinação da resistência dos briquetes formados a partir de blendas de Pinus sp e pó de lixa. In: $6^{\circ}$ Congresso Internacional de Bioenergia, 2011, Curitiba. Anais... Curitiba: Centro de Eventos da FIEP, 16 a 19 de agosto de 2011.

FURTADO, T. S.; VALIN, M.; BRAND, M. A.; BELLOTE, A. F. J. Variáveis do processo de briquetagem e qualidade de briquetes de biomassa florestal. Pesquisa Florestal Brasileira, Colombo, v. 30, n. 62, p. 101-106, 2010.

GOLDEMBERG, J. Biomassa e energia. Química Nova, v. 32, n. 3, p. 582-587, 2009.

INSTITUTO BRASILEIRO DE QUALIDADE E PRODUTIVIDADE DO PARANÁ IBQP. Análise da competitividade da cadeia produtiva da madeira no estado do Paraná. Curitiba. 2002. 345f. (Relatório Final. IBQP).

KAKITIS, A.; NULLE I.; ANACANS, D. Durability of the arranged structure biomass briquettes. Engineering for rural development, Jelgava, mai. 2010.

LEITE, E. R. S.; PROTÁSIO, T. P.; COUTO, A. M.; VEloso, W.; SILVA, C. H.; ROSADO, S. C. S. Influência da granulometria e umidade das partículas nas propriedades mecânicas e físicas dos briquetes de casca de café. In: $6^{\circ}$ Congresso Internacional de Bioenergia, 2011, Curitiba. Anais... Curitiba: Centro de Eventos da FIEP, 16 a 19 de agosto de 2011.

QUIRINO, W. F. Briquetagem de resíduos ligno-celulósicos. Brasília: LPF, 1991. (Circular Técnica 20).

RAMOS E PAULA, L. E.; TRUGILHO, P. F.; REZENDE, R. N.; ASSIS, C. O.; BALIZA, A. E. R. Produção e avaliação de briquetes de resíduos lignocelulóscos. Pesquisa Florestal Brasileira, Colombo, v. 31, n. 66, p. 103-112, 2011.

SILVA, A. M. N.; AlBUQUERQUE, J. L.; SILVA, E. S.; SANTOS-FILHO, D.; BARBOSA, W. B. A biomassa florestal (lenha) como insumo energético para os artesãos da cidade de Tracunhaém/PE. Custos e agronegócio on line, v. 4, n. 3, 2008.

SOTANNDE, O. A.; OLUYEGE, A. O.; ABAH, G. B. Physical and combustion properties of briquetes from sawdust of Azadirachta indica. Journal of Forestry Research, v. 21, n. 1, p. 6367, 2010.

VENDRASCO, L.; YAMAJI, F. M.; COSTA, D. R.; FLORES, W. P.; CHRISOSTOMO, W. Determinação da densidade de briquetes pelo método estereométrico. In: $5^{\circ}$ Congresso Internacional de Bioenergia, 2010, Curitiba. Anais... Curitiba: Centro de Eventos da FIEP, 10 a 13 de agosto de 2010 . 


\section{CAPÍTULO II}

\section{ANÁLISE dA CARGA MÁXIMA E DA RESISTÊNCIA À TRAÇÃo PARA A CARACTERIZAÇÃO MECÂNICA DE BRIQUETES}

\section{INTRODUÇÃO}

A briquetagem pode ser entendida de forma geral como um processo no qual, por meio da aplicação de pressão e temperatura, certa massa de partículas é comprimida formando um produto final mais denso e uniforme (QUIRINO et al, 2004; QUIRINO, 2002; KALIYAN e MOREY, 2009). Como vantagem deste processo cita-se o aumento da densidade energética $\left(\mathrm{Gcal} / \mathrm{m}^{3}\right)$, diminuição da velocidade de liberação da energia comparando-se à biomassa não compactada, resultando em uma combustão mais uniforme e a facilidade em se transportar e armazenar grande quantidade de biomassa, geralmente proveniente de resíduos de grandes processos industriais (KARUNANITHY et al., 2012; WERTHER et al., 2000).

Segundo Kaliyan e Morey (2009), caracterizar mecanicamente os briquetes confeccionados com as diversas biomassas tem como objetivo determinar a carga máxima para o empilhamento no caso de armazenamento e transporte ou também, em casos de quedas, possa-se evitar fraturas ou esmagamentos dos briquetes, que o fazem retornar para o estágio de resíduo/biomassa, perdendo a finalidade para o qual eles foram formados.

A durabilidade dos briquetes, portanto, é avaliada a partir de forças destrutivas de compressão, impacto e cisalhamento durante o manuseio e transporte (KALIYAN e MOREY, 2009). Segundo Karunanithy et al. (2012), a produção de finos em até 5\% da massa do briquete após uma desfragmentação, seria considerada como nível aceitável e para valores acima de $5 \%$, prejudicial ao processo produtivo.

Desta maneira, para Sotannde et al. (2010), seria necessária a determinação da carga máxima de ruptura (CMR, kgf) em briquetes para a sua caracterização mecânica, em dois sentidos: 
longitudinalmente (no sentido de compactação da biomassa) e transversalmente (no sentido diametral ou perpendicular ao sentido de compactação da biomassa). Segundo este autor, determinar a resistência de briquetes em ambos os sentidos se explica pelas condições de transporte e manuseio a que os briquetes estariam submetidos.

Sendo assim, Souza et al. (2012a) que estudaram a resistência mecânica de briquetes confeccionados com pó de serra de Cupiúba (Goupia glabra) com a aplicação da carga em ambos os sentidos, observaram que a menor resistência à compressão que o briquete ofereceu foi no sentido perpendicular à compactação da biomassa, ou seja, no sentido diametral ao formato do briquete. De acordo com os autores, que avaliaram a resistência mecânica com vistas à carga máxima de ruptura (kgf), o rompimento dos briquetes no sentido diametral se deu a uma carga cerca de 10 vezes menor que no sentido de compactação da biomassa. Este fato também foi comprovado por Furtado et al. (2010), Ferragutti et al. (2011), Leite et al. (2011) e Ramos e Paula et al. (2011).

De forma semelhante, Kakitis et al. (2010) realizaram o ensaio de compressão em briquetes a partir da posição diametral com a biomassa de palha de trigo, assim como Leite et al. (2011) em briquetes confeccionados com casca de café, apontando que este seria o sentido de aplicação de cargas em que os briquetes estariam mais vulneráveis.

Entretanto, devido a uma inexistência de norma específica para a condução de um ensaio de determinação da resistência mecânica em briquetes, alguns estudos sugeriram possibilidades de se analisar esta característica apenas pelo sentido diametral, baseando-se em informações de várias outras normas. É grande também a variação da velocidade de carregamento empregada nos ensaios estudados, onde há na maior parte dos casos, uma indefinição entre as velocidades de $0,3 \mathrm{~mm} \cdot \mathrm{min}^{-1}$ e $0,6 \mathrm{~mm} \cdot \mathrm{min}^{-1}$.

De acordo com Souza et al. (2012b), foi utilizada a norma brasileira de avaliação de estruturas de madeira NBR 7190/97 para determinar a carga máxima de ruptura em ensaio de compressão diametral assim como por Souza et al. (2012a), entretanto este último se baseou na norma pan-americana COPANT 30:1-011 que trata da compressão perpendicular em amostras de madeira maciça. Ainda, outros autores determinaram a resistência mecânica de briquetes pelo ensaio de resistência à tração por compressão diametral, baseando-se na norma 
NBR 7222/94 que avalia a resistência de corpos-de-prova de concreto na forma cilíndrica, onde a aplicação de carga se dá no sentido do diâmetro, como foi utilizado por Protásio et al, (2011).

Também já foi utilizada a norma brasileira NBR 14351/05 que determina a resistência à compressão plana em tubetes, equipamentos utilizados no setor de viveiros florestais (BARROS et al., 2012).

De forma prática, utilizando-se as Normas COPANT 30:1-011 ou NBR 7190/97, apenas é possível a caracterização daquele briquete quanto à carga máxima de ruptura (kgf), ou seja, não é possível a determinação da resistência à compressão diametral $\left(\mathrm{kgf} / \mathrm{cm}^{2}\right)$, pois não há uma área de contato entre os pratos de compressão e a superfície cilíndrica do briquete e sim, um único ponto de contato, representado por uma tangente à seção transversal do briquete.

Sendo assim, é comum encontrar estudos sobre a resistência mecânica de briquetes a partir da determinação da resistência à tração por compressão diametral (KALIYAN e MOREY, 2009; PROTÁSIO et al, 2011; RAMOS e PAULA et al., 2011).

Por este método a aplicação de duas forças concentradas e diametralmente opostas de compressão em um cilindro, gera ao longo do diâmetro solicitado, tensões de tração uniformes e perpendiculares a este diâmetro (FALCÃO e SOARES, 2002). A deformação observada é caracterizada pela separação, na seção transversal do corpo-de-prova, em duas semicircunferências.

Também é grande a preocupação das recentes pesquisas na avaliação dos parâmetros da briquetagem na qualidade do produto final. As propriedades que são comumente avaliadas são: Granulometria, temperatura e pressão de compactação, tempo de compactação, tempo de armazenamento, teor de umidade da biomassa, entre outras (BRAND et al., 2009; KALIYAN e MOREY, 2009; PROTÁSIO et al., 2011; KARUNANITHY et al., 2012; OLAKEJI e ENWEREMADU, 2012; SOUZA et al., 2012a; SOUZA et al., 2012b).

Souza et al. (2012a) avaliaram o efeito da granulometria na resistência mecânica de briquetes em ensaio de compressão. Assim, os autores concluíram que para os briquetes confeccionados 
com partículas de granulometria superior a 60 mesh, foi necessária uma carga mais elevada para que houvesse o seu rompimento.

O teor de umidade das partículas antes da compactação também é um importante fator para a durabilidade final dos briquetes. Para partículas com teor de umidade acima de $10 \%$, durante a prensagem, pode-se produzir uma quantidade excessiva de vapor de água e consequentemente, provocar explosões que irão desfragmentar os briquetes. Por outro lado, partículas com teor de umidade inferior a $10 \%$ podem dificultar a formação do briquete, pelo aumento substancial da temperatura de transição viscoelástica da lignina, tornando o produto final quebradiço (OLAKEJI e ENWEREMADU, 2012).

De acordo com Karunanithy et al. (2012) as biomassas devem ter um teor de umidade entre 7 e $14 \%$ para que sejam produzidos briquetes de qualidade, ou seja, com alta densidade e alta durabilidade para transporte, manuseio e armazenamento.

Desta forma, este Capítulo II foi tratado como ensaio preliminar à tese e teve como objetivo, analisar a carga máxima de ruptura e a resistência à tração como forma de determinar a resistência mecânica de briquetes sob o efeito da variação de três parâmetros da briquetagem (granulometria, temperatura e pressão), em briquetes confeccionados com pó de serra de Tauari (Couratari oblongiflora).

\section{MATERIAIS E MÉTODOS}

\subsection{PREPARAÇÃO DA BIOMASSA}

A madeira de tauari (Couratari oblongiflora) foi adquirida em uma madeireira na cidade de Brasília/DF no formato de prancha com dimensões aproximadas de 1000 x 300 x $50 \mathrm{~mm}$ (comprimento x largura x espessura). Esta peça de madeira foi transformada em maravalha a partir de sucessivas passadas em plaina desempenadeira, na marcenaria do Laboratório de Produtos Florestais do Serviço Florestal Brasileiro (LPF/SFB). 
Este procedimento permitiu que a madeira de tauari fosse moída em um moinho de facas tipo Willey para uma posterior classificação do pó, em peneira com abertura da malha de 40 Mesh (0,420 mm), em mesa vibratória. Sendo assim, a classificação do pó de serra resultou em dois diferentes materiais moídos: 1- partículas com granulometria até 40 Mesh (partículas grossas); 2- partículas com granulometria superior a 40 Mesh (partículas finas). Determinouse após a moagem, o teor de umidade das partículas pela norma TAPPI T-257 cm - 85/96 (TAPPI, 1996a).

\subsection{CONFECÇÃO DOS BRIQUETES}

Os briquetes foram confeccionados em prensa briquetadeira da marca Irmãos Lippel e modelo LB-32, pertencente ao Setor de Energia da Biomassa do LPF/SFB.

Para cada briquete confeccionado, foram utilizados 40 gramas da biomassa reduzida a pó, classificada em partículas grossas e partículas finas e a um teor de umidade de aproximadamente $10 \%$ (em base seca). Os briquetes foram formados a partir de duas temperaturas 130 e $200^{\circ} \mathrm{C}\left( \pm 10^{\circ} \mathrm{C}\right)$, duas pressões do manômetro $\left(80\right.$ e $\left.120 \mathrm{kgf} / \mathrm{cm}^{2}\right)$ e com tempo de compactação de 5 minutos, contados a partir do momento em que se atingiu a pressão estabelecida.

Após a compactação, os briquetes foram expulsos da matriz, porém com o auxílio de uma leve contrapressão, fazendo com que houvesse uma mínima dilatação em diâmetro provocada pela liberação do vapor de água. Também se realizou o resfriamento forçado conforme descrito no Capítulo I, porém o tempo de resfriamento variou entre os tratamentos, pois foi ajustado para que se obtivessem todos os briquetes com suas superfícies íntegras, sem rachaduras ou trincas.

A partir de cada briquete confeccionado, estes foram seccionados na região próxima ao centro e lixados até que atingissem o comprimento final de $10 \mathrm{~mm}$ (Figura 1). 

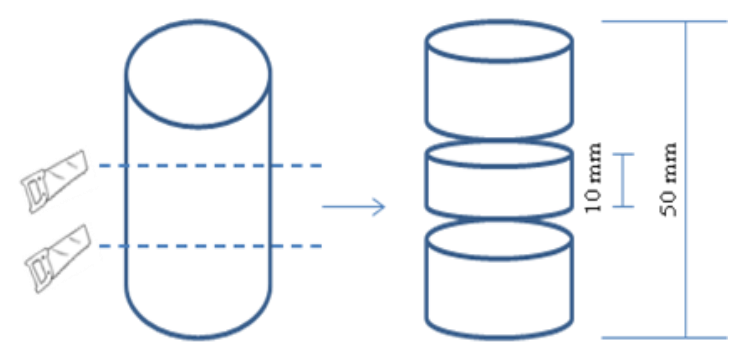

$32 \mathrm{~mm}$

Figura 1. Processo de dimensionamento do briquete (corpo-de-prova) para a utilização no ensaio de resistência mecânica.

Desta forma, para a análise dos parâmetros de densificação dos resíduos, o delineamento experimental (Tabela 1) estabelecido foi de 3 repetições/briquetes confeccionados para duas temperaturas $\left(130\right.$ e $\left.200{ }^{\circ} \mathrm{C}\right)$, duas pressões $\left(80\right.$ e $\left.120 \mathrm{kgf} / \mathrm{cm}^{2}\right)$, duas granulometrias (partícula grossa e fina), resultando em 8 tratamentos e 24 briquetes confeccionados.

Tabela 1. Delineamento experimental para a avaliação dos parâmetros de briquetagem: granulometria, temperatura e pressão.

\begin{tabular}{cccc}
\hline Tratamento & Granulometria & Temperatura $\left({ }^{\circ} \mathrm{C}\right)$ & Pressão $\left(\mathrm{kgf} / \mathrm{cm}^{2}\right)$ \\
\hline 1 & Grossa & 130 & 80 \\
2 & Grossa & 130 & 120 \\
3 & Grossa & 200 & 80 \\
4 & Grossa & 200 & 120 \\
\hline 5 & Fina & 130 & 80 \\
6 & Fina & 130 & 120 \\
7 & Fina & 200 & 80 \\
8 & Fina & 200 & 120 \\
\hline
\end{tabular}

\subsection{DETERMINAÇÃO DA DENSIDADE APARENTE}

A Densidade Aparente (DA, $\mathrm{g} / \mathrm{cm}^{3}$ ) foi determinada pelo método estereométrico no qual cada briquete teve a sua massa determinada em balança de precisão igual a $10^{-2} \mathrm{~g}$ e teve suas d2imensões determinadas por paquímetro com precisão de $10^{-2} \mathrm{~mm}$. A densidade aparente foi calculada pela relação entre a massa e volume de cada briquete, considerando-se a forma cilíndrica dos briquetes. 


\subsection{DETERMINAÇÃO DA RESISTÊNCIA MECÂNICA}

Os briquetes foram analisados mecanicamente do ponto de vista da Carga Máxima de Ruptura (CMR, kgf) e da Resistência à Tração por Compressão Diametral (RTCD, kgf/ $\mathrm{cm}^{2}$ ), utilizando-se uma máquina universal de ensaios EMIC DL30000 acoplada a uma célula de carga de até 2000 kgf e uma chapa metálica com as superfícies lisas e perfeitamente paralelas (Figura 2). A velocidade do carregamento foi de $0,3 \mathrm{~mm} \cdot \mathrm{min}^{-1}$ conforme o utilizado por Protásio (2011), baseando-se na norma NBR 7222/94 (ABNT, 1994).

Após o ensaio, determinou-se o teor de umidade (\%) para todos os briquetes.

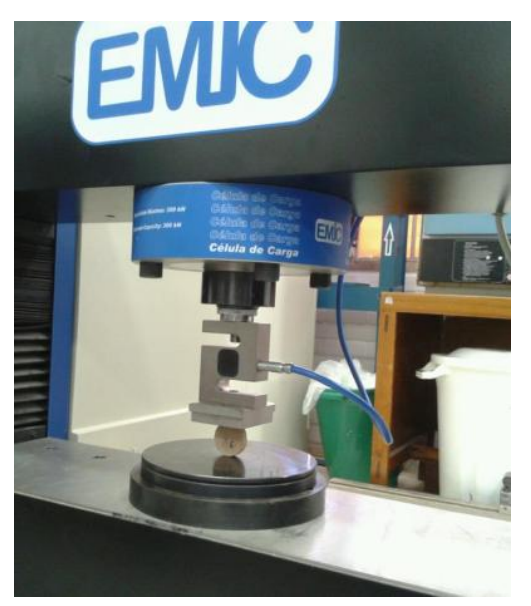

Figura 2. Ensaio de resistência à tração por compressão diametral dos briquetes de Tauari.

A resistência à tração por compressão diametral (RTCD) foi calculada por meio da Equação 1 .

$$
R T C D=\frac{2 \times P}{\pi \times \mathrm{D} \times \mathrm{L}}
$$

Equação 1.

Onde:

$R T C D=$ resistência à tração por compressão diametral, $\left(\mathrm{kgf} / \mathrm{cm}^{2}\right)$;

$P=$ carga máxima de ruptura do briquete, $(\mathrm{kgf})$;

$D=$ diâmetro do briquete, $(\mathrm{cm})$;

$L=$ comprimento do briquete $(\mathrm{cm})$. 


\subsection{ANÁLISE ESTATÍSTICA}

Para a análise estatística, utilizou-se do pacote estatístico SPSS (Statistical Package for the Social Sciences), v. 17 para Windows e baseou-se inicialmente em uma análise de variância (ANOVA) ao nível de 5\% de significância e posterior teste de comparação de médias de Tukey.

\section{RESULTADOS E DISCUSSÃO}

A Tabela 2 apresenta os valores médios observados da densidade aparente, carga máxima de ruptura e resistência à tração por compressão diametral para os briquetes confeccionados.

Tabela 2. Valores médios da densidade aparente (DA), carga máxima de ruptura (CMR) e resistência à tração por compressão diametral (RTCD) dos briquetes confeccionados a partir dos oito tratamentos estudados.

\begin{tabular}{cccc}
\hline Tratamento & $\begin{array}{c}\text { DA } \\
\left(\mathrm{g} / \mathrm{cm}^{3}\right)\end{array}$ & $\begin{array}{c}\text { CMR } \\
(\mathrm{kgf})\end{array}$ & $\begin{array}{c}\text { RTCD Médio } \\
\left(\mathrm{kgf} / \mathrm{cm}^{2}\right)\end{array}$ \\
\hline 1 & 1,19 & 81,34 & 156,93 \\
2 & 1,17 & 70,71 & 134,24 \\
3 & 1,23 & 119,3 & 237,97 \\
4 & 1,23 & 106,75 & 208,32 \\
5 & 1,19 & 115,53 & 222,86 \\
6 & 1,19 & 117,51 & 220,24 \\
7 & 1,25 & 234,59 & 443,16 \\
8 & 1,27 & 238,79 & 441,44 \\
\hline
\end{tabular}

Com relação à (DA), verificou-se que os valores obtidos no presente estudo estão de acordo com os observados na literatura a respeito da briquetagem (PROTÁSIO et al, 2011; BARROS et al., 2012; SOUZA et al, 2012a; SOUZA et al, 2012b).

Entende-se como efeito primário da briquetagem, o aumento da densidade aparente do material, comparando-se com a densidade a granel da mesma biomassa. Ainda, são comumente observados altos valores de DA em briquetes (geralmente acima de $1 \mathrm{~g} / \mathrm{cm}^{3}$ ) em função da utilização de altas temperaturas e pressões de compactação. Este fato associados às 
partículas com pequenas dimensões, promovem uma densificação e melhor acomodação das partículas no interior da prensa briquetadeira, formando um produto mais sólido e com densidades mais elevadas que a biomassa de origem.

Em se tratando de volume da biomassa, Olakeji e Enweremadu (2012) observaram uma redução de $626 \%$ do volume dos resíduos de milho, quando este foi transformado em briquetes.

Segundo Protásio et al (2011), após a transformação dos resíduos de café, milho e serragem de eucalipto em briquetes, aumentou-se a densidade de cada material em 179, 322 e 321\%, respectivamente. Segundo estes autores, o aumento da densidade nesta transformação da biomassa, refletem diretamente no interesse energético da briquetagem, pois há um aumento na densidade energética do briquete em função do aumento da densidade, visto que há uma relação direta entre estas duas características.

Também é possível se observar na literatura uma relação diretamente proporcional entre a DA e a pressão de compactação, onde a partir de um aumento da pressão de compactação, observam-se maiores valores da DA. Desta maneira, Olakeji e Enweremadu (2012) observaram que o aumento da pressão de compactação resultou em um aumento da DA em briquetes confeccionados com resíduos de milho.

Entretanto, conforme se confirma pela Figura 3, a variação da granulometria, da pressão de compactação e da temperatura não influenciaram de forma estatisticamente significativa a DA, mas pode-se observar um pequeno aumento numérico da DA nos tratamentos 3 e $4(1,23$ $\left.\mathrm{g} / \mathrm{cm}^{3}\right)$ e 7 e $8\left(1,25\right.$ e $\left.1,27 \mathrm{~g} / \mathrm{cm}^{3}\right)$, onde se empregou a temperatura mais elevada, de $200^{\circ} \mathrm{C}$. 


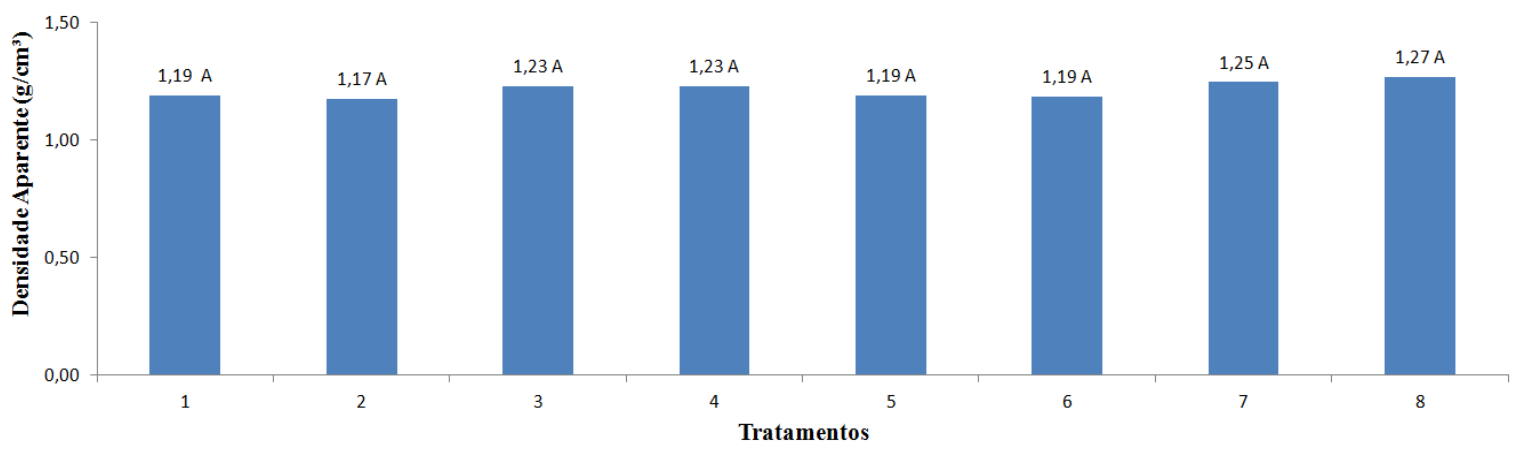

Figura 3. Valores da densidade aparente (DA) dos briquetes de Tauari distribuídos por tratamentos. Onde: Letras iguais indicam que não houve diferença estatisticamente significativa pelo Teste Tukey a 5\% de significância.

A Tabela 3 mostra os resultados da análise de variâncias (ANOVA) realizada na análise estatística.

Tabela 3. Análise de Variância ANOVA para os parâmetros: densidade, carga máxima de ruptura e resistência à tração por compressão diametral dos briquetes de Tauari.

\begin{tabular}{ccccccc}
\hline FV & & SQ & GL & QM & F & Sig. \\
\hline \multirow{2}{*}{ DENSIDADE } & Entre Grupos & 0,024 & 7 & 0,003 & 1,977 & 0,123 \\
& Dentro dos Grupos & 0,028 & 16 & 0,002 & & \\
\cline { 2 - 5 } & Total & 0,052 & 23 & & & \\
\hline \multirow{2}{*}{ CMR } & Entre Grupos & 88284,052 & 7 & 12612,007 & 16,487 & 0 \\
& Dentro dos Grupos & 12239,402 & 16 & 764,963 & & \\
& Total & 100523,454 & 23 & & & \\
\hline \multirow{2}{*}{ RCD } & Entre Grupos & 296983,185 & 7 & 42426,169 & 14,173 & \\
& Dentro dos Grupos & 47896,443 & 16 & 2993,528 & & \\
& Total & 344879,628 & 23 & & & \\
\hline
\end{tabular}

Onde: FV = Fonte de Variação; SQ = Soma de Quadrados; GL = Graus de Liberdade e QM = Quadrado Médio.

$\mathrm{Na}$ Figura 4, observou-se que os maiores valores da carga máxima de ruptura (CMR, kgf) foi para os tratamentos 7 e 8, 234,59 e 238,79 kgf, respectivamente. Os menores valores numéricos observados foram para os tratamentos 1 e 2, com 81,34 e 70,71 kgf, respectivamente. 


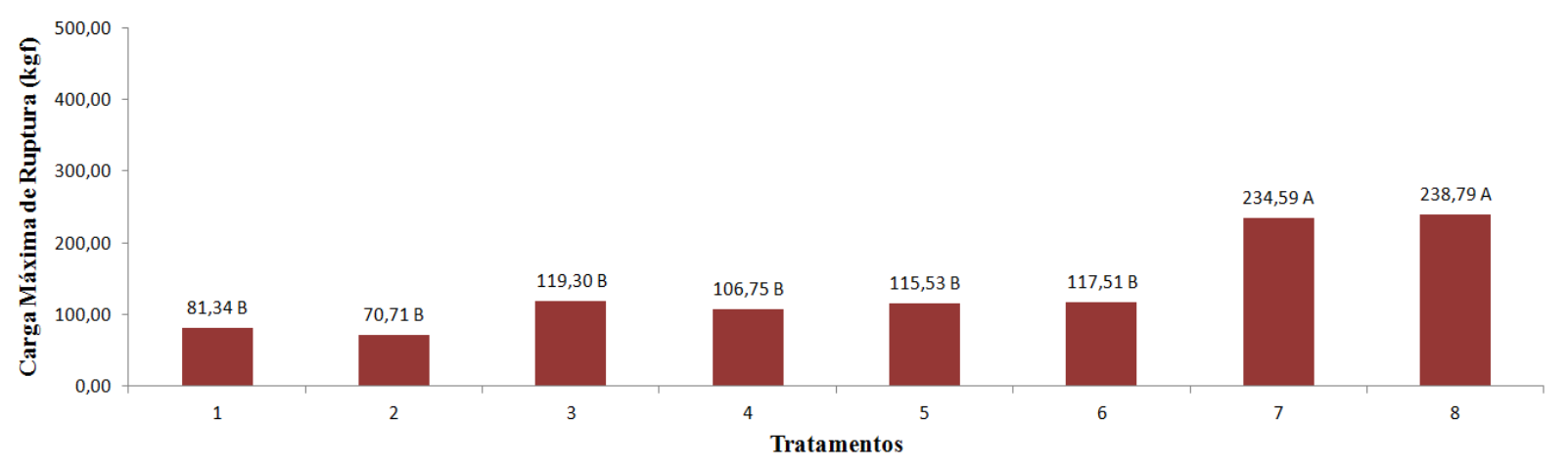

Figura 4. Valores médios da carga máxima de ruptura (CMR) para os briquetes de Tauari. Onde: Letras iguais indicam que não houve diferença estatisticamente significativa pelo Teste Tukey a 5\% de significância.

Estes maiores valores que foram destacados podem ser explicados pela aplicação de temperatura mais elevada para os tratamentos 7 e 8 , associados à menor dimensão da partícula utilizada (menores que 0,420 mm). Assim, os briquetes em que se utilizou das partículas com menores dimensões, estas se acomodaram melhor e com maior área de contato, auxiliando na transferência de calor entre as partículas, comparando-se com os briquetes em que se utilizaram as partículas mais grossas.

Ainda, a utilização de maior temperatura $\left(200{ }^{\circ} \mathrm{C}\right)$ promoveu de forma mais rápida o amolecimento da lignina contida na biomassa, fazendo com que as partículas aderissem mais umas às outras, explicando os maiores valores da CMR para os tratamentos 7 e 8 . De uma forma geral, a lignina para os resíduos de madeira tem uma temperatura de amolecimento em torno de $140^{\circ} \mathrm{C}$ (KARUNANITHY et al., 2012), contribuindo para explicar os resultados obtidos.

Segundo Karunanithy et al. (2012) e Granada et al. (2002) a lignina pode atuar como substância termoplástica ou aglutinante durante a compactação da biomassa na briquetagem, fazendo com que as partículas fiquem mais aderidas entre si, tendo por consequência, possíveis elevações nas propriedades mecânicas. Além disso, a pressão durante a compactação da biomassa promove um entrelaçamento entre as partículas e por estas estarem muito próximas, forças de atração intensas são promovidas fazendo com que permaneçam unidas. 
Por outro lado, apesar de ter sido observado uma superioridade dos valores da CMR para os tratamentos 3 e 4 com relação aos valores dos tratamentos 1 e 2, apenas o efeito da elevação da temperatura não possibilitou que houvesse diferença estatisticamente significativa entre eles. Possivelmente, não foi observada diferença significativa entre os tratamentos de 1 a 4 por ter sido utilizada as partículas de maiores dimensões, ocasionando menor área de contato e menor condução do calor entre as partículas.

Souza et al. (2012a) verificaram que, para os briquetes confeccionados com pó de serra de cupiúba, a pressão do manômetro de $80 \mathrm{kgf} / \mathrm{cm}^{2}$, a $130^{\circ} \mathrm{C}$ e com diversas granulometrias, o valor médio da CMR foi entre 558 e $750 \mathrm{kgf}$, onde o maior valor observado foi para os briquetes confeccionados com partículas superiores a 60 Mesh. Protásio et al. (2011) observaram valores entre 280 e $370 \mathrm{kgf}$ para os briquetes confeccionados com serragem de eucalipto, resíduo de milho e casca de café.

Ainda, Olakeji e Enweremadu (2012) determinaram que para briquetes com resíduos de milho, quando se utilizou de partículas com menores dimensões $(0,6 \mathrm{~mm})$, produziram-se os briquetes de melhores qualidades. Este fato também foi comprovado por (KARUNANITHY et al., 2012).

Com relação à resistência à tração por compressão diametral (RTCD), os maiores valores observados também foram para os tratamentos 7 e $8,443,16$ e $441,44 \mathrm{kgf} / \mathrm{cm}^{2}$, respectivamente (Figura 5). Estes valores corroboram o efeito combinado da temperatura elevada com partículas de menores dimensões observada para a CMR, onde devido a maior área de contato entre as partículas e o maior amolecimento da lignina, promoveram-se mais ligações entre as partículas, aumentando assim a resistência à tração. 


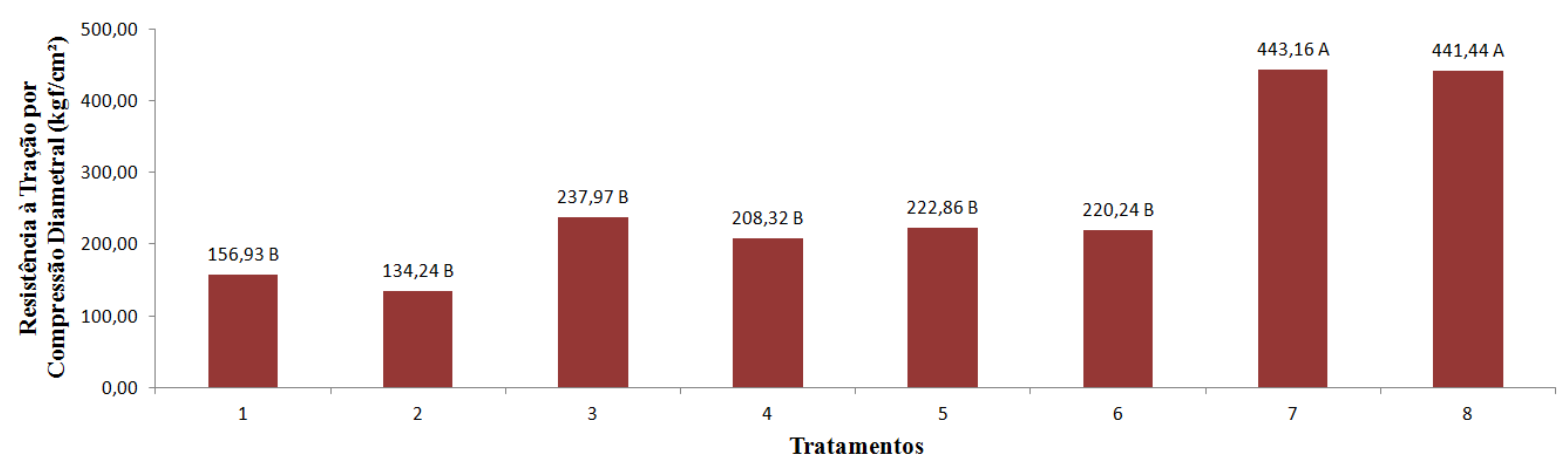

Figura 5. Valores médios da resistência à tração por compressão diametral (RTCD) para os briquetes de Tauari. Onde: Letras iguais indicam que não houve diferença estatisticamente significativa pelo Teste Tukey a 5\% de significância.

Comparando-se o comportamento dos dados para a carga máxima de ruptura e a resistência à tração por compressão diametral, verificou-se que ambos explicam a variação dos parâmetros da briquetagem, ou seja, são sensíveis à variação da granulometria, temperatura e pressão de compactação. Portanto, ambos podem ser utilizados, mas recomenda-se a utilização da RTCD pelo fato deste parâmetro já levar em consideração o formato do briquete (diâmetro e comprimento), sugerindo a utilização de briquetes com formatos diferentes na mesma análise.

\section{CONCLUSÕES}

Os briquetes confeccionados com pó de serra de tauari tiveram os valores de densidade aparente condizentes com o observado na literatura específica e este parâmetro não foi influenciado pela variação da temperatura, pressão ou granulometria;

A $(\mathrm{CMR})$ e a (RTCD) foram influenciados pelo efeito combinado do aumento da temperatura com a diminuição da dimensão das partículas, onde foram observadas as maiores médias para estes dois parâmetros;

Para os parâmetros de resistência mecânica, CMR e RTCD, estes apresentaram distribuição semelhante a partir dos oito tratamentos empregados, ou seja, tanto a CMR quanto a RTCD 
mostraram o efeito dos parâmetros de briquetagem na resistência mecânica dos briquetes de Tauari;

Recomenda-se a utilização da RTCD para a determinação da resistência mecânica de briquetes pelo fato deste parâmetro já levar em consideração no seu cálculo a dimensão do briquete.

\section{REFERÊNCIAS BIBLIOGRÁFICAS}

ASSOCIAÇÃO BRASILEIRA DE NORMAS TÉCNICAS. NBR 7222: argamassa e concreto: determinação da resistência à tração por compressão diametral de corpos-de-prova cilíndricos: método de ensaio. Rio de Janeiro, 1994. 3 p.

BARROS, V. C. C.; CARNEIRO, A. C. O.; JACOVINE, L. G.; TOLÊDO, D. P.; VITAL, B. R. Aproveitamento dos resíduos de eucalipto e oleaginosas pela técnica de briquetagem. In: XIII ENCONTRO BRASILEIRO EM MADEIRAS E EM ESTRUTURAS DE MADEIRAS, Vitória, 2012. Anais... Vitória: EBRAMEM, 2012.

BRAND, M. A.; MUNIZ, G. I. B.; VALIN, M.; QUIRINO, W. F. Influência da pressão e material nas propriedades de briquetes de biomassa florestal. In: $1^{\circ}$ CONGRESSO BRASILEIRO SOBRE FLORESTAS ENERGÉTICAS, Belo Horizonte, 2009. Anais... Belo Horizonte: CBFE, 2009.

FALCÃO, M.F.B.; SOARES, J.B. (2002) Considerações Sobre o Ensaio de Compressão Diametral no Estudo de Materiais de Pavimentação. Associação Nacional de Ensino e Pesquisa em Transportes (ANPET) - anais, v.1.

FERRAGUTTI, A. C.; YAMAJI, F. M.; GRAÇA, J. S.; ALÓ, L. L. Determinação da resistência dos briquetes formados a partir de blendas de Pinus sp e pó de lixa. In: $6^{\circ}$ Congresso Internacional de Bioenergia, 2011, Curitiba. Anais... Curitiba: Centro de Eventos da FIEP, 16 a 19 de agosto de 2011.

FURTADO, T. S.; VALIN, M.; BRAND, M. A.; BELLOTE, A. F. J. Variáveis do processo de briquetagem e qualidade de briquetes de biomassa florestal. Pesquisa Florestal Brasileira, Colombo, v. 30, n. 62, p. 101-106, 2010.

GRANADA, E.; LÓPEZ GONZÁLEZ, L. M.; MÍGUEZ, J. L.; MORAN, J. Fuel lignocellulosic briquettes, die design and products study. Renewable Energy, Oxford, GB, v. 27, n. 4, p. 561-573, 2002.

KALIYAN, N.; MOREY, R. V. Factors affecting strength and durability of densified biomass products. Biomass and Bioenergy, v. 33, n. 3, p. 337-359. 2009.

KAKITIS, A.; NULLE I.; ANACANS, D. Durability of the arranged structure biomass briquettes. Engineering for rural development, Jelgava, mai. 2010. 
KARUNANITHY, C.; WANG, Y.; MUTHUKUMARAPPAN, K.; PUGALENDHI, S. Physiochemical characterization of briquettes made from different feedstocks. Biotechnology Research International, v. 2012, n. 1, p. 1-12. 2012.

LEITE, E. R. S.; PROTÁSIO, T. P.; COUTO, A. M.; VElOSO, W.; SILVA, C. H.; ROSADO, S. C. S. Influência da granulometria e umidade das partículas nas propriedades mecânicas e físicas dos briquetes de casca de café. In: $6^{\circ}$ Congresso Internacional de Bioenergia, 2011, Curitiba. Anais... Curitiba: Centro de Eventos da FIEP, 16 a 19 de agosto de 2011.

OLAKEJI, J. T.; ENWEREMADU, C. C. The effects of some processing parameters on physical and densification characteristics of corncob briquettes. International Jounal of Energy Engineering, n. 2, v. 1, p. 22-27. 2012.

PROTÁSIO, T. P.; ALVES, I. C. N.; TRUGIlHO, P. F.; SILVA, V. O.; BALIZA, A. E. R. Compactação de biomassa vegetal visando à produção de biocombustíveis sólidos. Pesquisa Florestal Brasileira, Colombo, v. 31, n. 68, p. 273-283, 2011.

QUIRINO, W. F. Utilização energética de resíduos vegetais. Brasília: LPF/IBAMA, 2002. 35 p.

QUIRINO, W. F.; VALE, A. T.; ANDRADE, A. P. A.; ABREU, V. L. S.; AZEREDO, A. C. S. Poder calorífico da madeira e de resíduos lignocelulósicos. Biomassa \& Energia, Viçosa, v. 1, n. 2, 2004.

RAMOS E PAULA, L. E.; TRUGILHO, P. F.; REZENDE, R. N.; ASSIS, C. O.; BALIZA, A. E. R. Produção e avaliação de briquetes de resíduos lignocelulóscos. Pesquisa Florestal Brasileira, Colombo, v. 31, n. 66, p. 103-112, 2011.

SOTANNDE, O. A.; OLUYEGE, A. O.; ABAH, G. B. Physical and combustion properties of briquetes from sawdust of Azadirachta indica. Journal of Forestry Research, v. 21, n. 1, p. 63$67,2010$.

SOUZA, F.; VALE, A. T.; QUIRINO, W. F.; TELES, R. F.; RIBEIRO, P. G. Influência do tamanho das partículas na resistência mecânica de briquetes confeccionados com serragem de Goupia glabra Aubl. In: XIII ENCONTRO BRASILEIRO EM MADEIRAS E EM ESTRUTURAS DE MADEIRAS, Vitória, 2012. Anais... Vitória: EBRAMEM, 2012a.

SOUZA, M. M.; BARROS, V. C. C.; VITAL, B. R.; CARNEIRO, A. C. O.; BARBOSA, A. C. Análise de briquetes produzidos com resíduos de poda urbana e embalagens cartonadas. In: XIII ENCONTRO BRASILEIRO EM MADEIRAS E EM ESTRUTURAS DE MADEIRAS, Vitória, 2012. Anais... Vitória: EBRAMEM, 2012b.

TAPPI (TECHNICAL ASSOCIATION OF THE PULP AND PAPER INDUSTRY). 1996. Sampling and Preparing Wood for Analysis. T-257 cm-85. TAPPI Test Methods. TAPPI Pres, Atlanta.

WERTHER, J. et al. Combustion of agricultural residues. Progress in Energy and Combustion Science, v. 26, p. 1-27, 2000. 


\section{CAPÍTULO III}

\section{MÉTODOS PARA A AVALIAÇÃO DA QUALIDADE DE BRIQUETES CONFECCIONADOS A PARTIR DE SEIS BIOMASSAS AGROFLORESTAIS}

\section{INTRODUÇÃO}

Briquetes são materiais compactados para formar blocos de forma definida e de menor tamanho a partir do uso de alta pressão e temperatura e possuem a finalidade de liberação de energia para processos industriais. Desta forma, resíduos agroflorestais como palhas, cascas, serragem e maravalha são convertidos em um material com maior valor comercial e com maior conteúdo energético por unidade de volume (ANTUNES, 1982).

Segundo Pinheiro et al (2005) as indústrias agroflorestais, por exemplo a sucro-alcooleira, papel, celulose e madeireira, são importantes setores da economia que produzem resíduos com grande potencial de aproveitamento energético no Brasil. É comum esses resíduos possuírem grande variedade de formas, densidades, granulometrias e umidades, ou seja, com considerável heterogeneidade.

Para Kaliyan e Morey (2009), quanto menor o tamanho da partícula melhor será a compactação. Partículas com dimensões pequenas são interessantes pelo fato de abranger uma área maior de superfície e consequentemente, promovendo, uma melhor interação.

Segundo Arrieche et al. (2011), a produção de briquetes envolve um alto investimento em infraestrutura e um gasto muito grande de energia, principalmente nas etapas de secagem, trituração da biomassa e compactação. Por outro lado, os mesmos autores informam que a confecção de briquetes é totalmente viável do ponto de vista do balanço energético no processo de briquetagem, onde, por exemplo, trabalhando com briquetes confeccionados com 
resíduos de madeira, o consumo de energia para a sua produção foi menor que $8 \%$ do total de energia obtida na combustão destes.

Ainda segundo estes autores, de uma forma geral, a energia utilizada para a confecção de adensados de resíduos agroflorestais é de aproximadamente 0,5 a 1\% do total de energia contida na biomassa, mas quando se trata da produção de briquetes, que envolvem as etapas de trituração e classificação, secagem e compactação, o gasto de energia no processo pode atingir entre 5 e $15 \%$ do total de energia contida na biomassa de origem.

A biomassa que está presente no briquete é o fator principal que influencia na sua qualidade. A constituição química (teor de lignina, teor de extrativos principalmente para os resinosos, teor de cinzas, entre outras características) influencia drasticamente a densidade energética $\left(\mathrm{DE}, \mathrm{Mcal} / \mathrm{m}^{3}\right)$ dos briquetes formados, principalmente porque estas propriedades alteram o poder calorífico da biomassa. Em termos energéticos, Souza et al. (2010a) verificaram que para a madeira de jacarandá caviúna (Machaerium scleroxylon), os extrativos totais contribuem com aproximadamente $4 \%$ do poder calorífico inferior (PCI).

O teor de umidade das partículas antes da compactação também é um importante fator para a durabilidade final dos briquetes. Na prensagem de partículas com teor de umidade acima de $10 \%$ pode ocorrer a produção de quantidade excessiva de vapor de água e consequentemente, provocarem estouros que irão desfragmentar os briquetes. Por outro lado, pode haver dificuldade na formação do briquete quando se utiliza partículas com teor de umidade inferior a $10 \%$ devido ao aumento substancial da temperatura de transição viscoelástica da lignina, tornando o produto final quebradiço (OLAKEJI e ENWEREMADU, 2012). De acordo com Karunanithy et al. (2012) as biomassas devem ter um teor de umidade entre 7 e 14\% para que sejam produzidos briquetes de qualidade, ou seja, com alta densidade e alta durabilidade para transporte, manuseio e armazenamento.

Pesquisas recentes indicam grande preocupação dos pesquisadores na avaliação dos parâmetros da briquetagem e sua influência na qualidade do produto final. As propriedades que são comumente avaliadas são: granulometria, temperatura e pressão de compactação, tempo de compactação, tempo de armazenamento, entre outras (BRAND et al., 2009; 
KALIYAN e MOREY, 2009; PROTÁSIO et al., 2011; KARUNANITHY et al., 2012; OLAKEJI e ENWEREMADU, 2012; SOUZA et al., 2010b; SOUZA et al., 2012).

A determinação da densidade aparente de certo material pela emissão de raios X, ou seja, a densitometria por raios $\mathrm{X}$ é uma metodologia a muitos anos consagrada pela medicina (densitometria óssea) e a alguns anos esta metodologia foi adaptada para o estudo em madeira ou derivados (QUIRINO et al., 2012). Exatamente como na utilização clínica, esta técnica permite o detalhamento da estrutura interna de um corpo de prova da madeira.

A metodologia de utilização do raio $\mathrm{X}$ ao longo dos últimos anos consistiu na concentração e direcionamento da radiação sobre um corpo de prova, onde era capturada e revelada em filme radiográfico em câmaras reveladoras após atravessar o material analisado. Por outro lado, atualmente a técnica se desenvolveu para aparelhos específicos de emissão de radiação X e com funções específicas para a análise de madeira e derivados.

Mundialmente, a técnica de raios X tem sido intensamente aplicada para a determinação do perfil de densidade em painéis de madeira reconstituída, como o Oriented Strand Board OSB, Medium Density Fiberboard - MDF e Medium Density Particleboard - MDP (COWN e CLEMENT, 1983; CHEN et al., 2010; BELINI et al., 2011; KNAPIC et al., 2013 ). A grande vantagem de se utilizar a densitometria por raios $\mathrm{X}$ em contraposição ao método estereométrico (relação entre a pesagem e volume da amostra) ou ao método de imersão em mercúrio é que a medição é realizada ponto a ponto, geralmente a pequenas distâncias entre as medições, $40 \mu \mathrm{m}$ (QUIRINO et al., 2012) e com alta sensibilidade às variações de densidade existentes no corpo de prova. Também se observa como vantagem, a velocidade no processamento dos dados pela utilização de microcomputadores (CHAGAS, 2013).

No Brasil, os estudos têm se concentrado na Escola Superior de Agricultura Luiz de Queiroz - ESALQ, que pertence à Universidade de São Paulo e se baseiam na aplicação do raio X para a determinação da estrutura morfológica de sementes florestais, na determinação da densidade e posição dos anéis de crescimento e principalmente para verificar a influência dos tratos silviculturais na qualidade da madeira. 
Segundo Quirino e Brito (1991), a principal característica que determina a qualidade de um briquete é a sua densidade aparente, pois é a partir desta propriedade, que se determina a quantidade de energia acumulada neste material com volume definido, ou a densidade energética $\left(\mathrm{Mcal} / \mathrm{m}^{3}\right)$. Outras propriedades também são relevantes para um briquete de maior qualidade, como as características da biomassa (poder calorífico alto, baixo teor de cinzas e alto teor de carbono fixo; baixo teor de umidade, entre outras).

Recentemente, o primeiro estudo sobre a viabilidade técnica foi realizado com a densitometria por raios X para a determinação do perfil de densidade em briquetes confeccionados com resíduos da produção de serrados da espécie Eucalyptus sp (QUIRINO et al., 2012). Segundo os autores foi possível determinar a densidade média dos briquetes pela nova metodologia assim como foi possível determinar as zonas de quebras de briquetes durante a liberação da prensa, pelo efeito da pressão dos vapores.

Ainda segundo estes autores, a técnica pode ser empregada para a determinação de propriedades físicas dos briquetes, mas deve-se investigar mais profundamente o efeito da espessura do material (comprimento do briquete) na precisão dos resultados, pois quando se reduziu a espessura, os resultados foram mais precisos.

Este capítulo teve como objetivo, determinar a influência dos parâmetros de briquetagem (biomassa, granulometria, pressão e temperatura) na qualidade de briquetes, avaliando-se a densidade aparente e a densidade energética calculada a partir de três métodos; assim como verificar a viabilidade técnica da densitometria de raio $\mathrm{X}$ em briquetes confeccionados por seis biomassas agroflorestais.

\section{MATERIAL E MÉTODOS}

As análises e ensaios com as matérias-primas (biomassas) foram realizados no Laboratório de Tecnologia da Madeira do Departamento de Engenharia Florestal da Universidade de Brasília (EFL/UnB) e nos Setores de Energia da Biomassa, Setor de Química, Adesivos e Borracha Natural e no Setor de Engenharia e Física da Madeira do Laboratório de Produtos Florestais 
(LPF) no Serviço Florestal Brasileiro (SFB), que está vinculado ao Ministério do Meio Ambiente (MMA).

A determinação da densidade aparente pelo método de imersão em mercúrio foi realizada no Laboratório de Anatomia da Madeira na Escola Superior de Agricultura Luiz de Queiroz (ESALQ), vinculado à Universidade de São Paulo (USP).

\subsection{OBTENÇÃO DAS BIOMASSAS AGROFLORESTAIS}

Para este estudo foram selecionadas seis diferentes biomassas, incluindo três materiais oriundos da obtenção de madeira serrada ( $2^{\mathrm{a}}$ transformação) e três oriundos de processos industriais de produção de alimentos, etanol e biodiesel.

Com relação às biomassas de origem florestal, foram selecionadas as espécies Pinus (Pinus spp.), Tauari (Couratari guianensis Aubl.) e Cumarú (Dipteryx odorata Aubl. Willd.), identificadas macroscopicamente por meio da comparação com as amostras da Xiloteca (Index Xylarium FPBw) do Laboratório de Produtos Florestais (LPF/SFB).

Tais espécies de madeiras foram selecionadas devido à presença constante no mercado madeireiro na região de Brasília-DF e por abrangerem uma ordem crescente de densidade básica, respectivamente. As amostras foram adquiridas de uma empresa, na forma de pranchas com dimensões aproximadas de 200 x 20 x 4,5 cm (comprimento x largura x espessura) de forma que o peso das mesmas totalizou aproximadamente $15 \mathrm{~kg}$ para cada uma das espécies.

Para as biomassas de origem agrícola selecionou-se a casca de arroz (Oriza sativa L.), bagaço-de-cana (Saccharum officinarum) e torta de pinhão-manso (Jatropha curcas L.), por representarem atividades agrícolas importantes para a região do Centro-Oeste e Sudeste brasileiro. Todas as amostras coletadas foram ensacadas em sacos de polietileno e encaminhadas ao Setor de Energia da Biomassa do LPF/SFB, em quantidade de aproximadamente $15 \mathrm{~kg}$ cada. 
A casca de arroz, resíduo da produção de alimentos, foi obtida em uma empresa de materiais agrícolas na região de Brasília-DF, enquanto que a torta de pinhão manso, resíduo gerado pelo processamento (esmagamento) da semente do pinhão-manso para a produção de biocombustível, foi adquirido por meio da empresa BIOJAN Agroindustrial, instalada no município de Janaúba-MG.

O bagaço-de-cana foi proveniente da usina de produção de etanol combustível, instalada no município de Lençóis Paulista-SP, operada pela Usina Barra Grande de Lençóis S.A. Este material foi obtido a partir do convênio entre a Universidade de Brasília e o Laboratório de Produtos Florestais.

\subsection{PREPARO DAS AMOSTRAS}

Inicialmente, os materiais de origem florestal foram desdobrados em plaina desengrossadeira na Carpintaria do LPF/SFB, reduzindo toda a prancha de madeira em maravalha (ou cepilho). A transformação da madeira em maravalha teve como finalidade, a redução das partículas para que se fizesse a moagem. No caso dos resíduos agrícolas, não foram necessárias etapas prévias de preparação.

Assim, as maravalhas e os resíduos agrícolas de cada espécie foram moídos separadamente em moinho de facas tipo Willey e para que se controlasse a influência da granulometria nas propriedades mecânicas dos briquetes produzidos, foi feita a classificação do pó obtido do moinho, em peneira com a abertura da malha de 35 Mesh (aproximadamente 0,355 mm) e em mesa vibratória pertencente ao LPF/SFB resultando em dois diferentes materiais moídos: 1partículas até 35 Mesh (partícula grossa); 2- partículas superiores a 35 Mesh (partícula fina).

Após a moagem, determinou-se para todas as biomassas o Teor de Umidade em Base Seca (TUbs\%) seguindo as recomendações da TAPPI T 257 om - 85/96 (TAPPI, 1996a).

Para o cálculo do poder calorífico útil, utilizou-se o teor de umidade em base úmida, conforme Brito (1993) e Vale et al. (2007), calculado por meio da Equação 1. 


$$
T U b u(\%)=\frac{100 x T U b s}{100+T U b s}
$$

Onde:

TUbu = teor de umidade em base úmida $(\%)$;

TUbs = teor de umidade em base seca (\%);

\subsection{ANÁLISE IMEDIATA}

A análise imediata foi realizada com o intuito de caracterizar as amostras energeticamente. Foi avaliado o teor de material volátil, teor de cinzas e teor de carbono fixo de acordo com a norma NBR 8112/86 (ABNT, 1986).

O teor de material volátil (TMV\%), teor de cinzas (TCZ\%) e teor de carbono fixo (TCF\%) foram determinados conforme as Equações 2, 3 e 4, respectivamente.

$$
\operatorname{TMV}(\%)=\frac{m 2-m 3}{m} \times 100
$$

Onde:

$T M V=$ teor de material volátil (\%);

$m=$ massa da biomassa seca $(g)$;

$m 2$ = massa da amostra seca + cadinho $(g)$;

$m 3=$ massa do cadinho após mufla a $900^{\circ} \mathrm{C}(\mathrm{g})$.

Onde:

$$
\operatorname{TCZ}(\%)=\frac{m 1-m 0}{m} x 100
$$

$T C Z=$ teor de cinzas $(\%)$;

$m 0=$ massa do cadinho $(\mathrm{g})$;

$m=$ massa da amostra seca $(g)$;

$m 1$ = massa do cadinho após mufla a $700^{\circ} \mathrm{C}(\mathrm{g})$. 


$$
T C F(\%)=100-(T C Z+T M V)
$$

Equação 4

Onde:

$T C F=$ Teor de carbono fixo $(\%)$;

$T C Z=$ teor de cinzas $(\%)$;

$T M V=$ teor de material volátil (\%).

\subsection{DETERMINAÇÃO DO PODER CALORÍFICO}

Para a determinação Poder Calorífico Superior (PCS, cal $/ \mathrm{g}$ ou $\mathrm{kcal} / \mathrm{kg}$ ), foi utilizado um equipamento Calorímetro modelo IKA C2000 acoplado a um refrigerador IKA KV 600 (Figura 1) em unidade de cal/g, pertencente ao Laboratório de Tecnologia da Madeira da Universidade de Brasília-UnB, baseando-se na norma NBR 8633 da ABNT/1984 (ABNT, 1984).

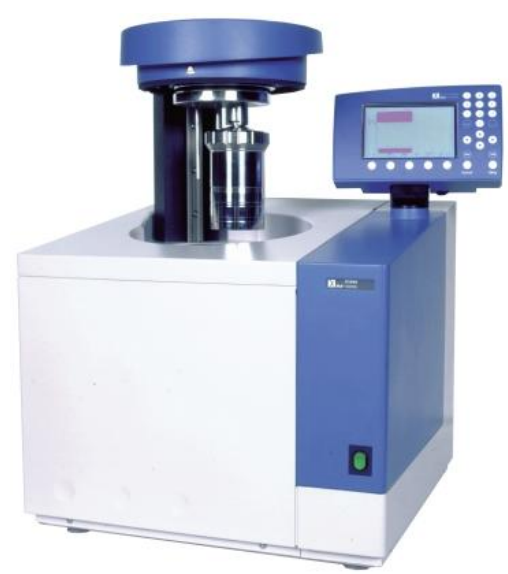

Figura 1. Equipamento Calorímetro modelo IKA C2000 acoplado a um refrigerador IKA KV 600.

Os resíduos agroflorestais após serem transformados em pó, e classificados em peneiras de 60 Mesh, foram utilizados com a granulometria que passou por esta peneira (fundo de 60 Mesh). Assim, foi utilizado cerca de $0,7 \mathrm{~g}$ da amostra em pó por medição.

A determinação do PCS foi dada pela média da duplicata quando dois valores consecutivos foram inferiores à $40 \mathrm{cal} / \mathrm{g}$. Também foi determinado o Poder Calorífico Inferior (PCI, cal/g 
ou kcal/kg), desconsiderando-se o calor de vaporização da água. O PCI foi calculado pela Equação 5, a fórmula de Launt citada por Gomide (1984).

$$
P C I=P C S-600\left[\left(\frac{9 H}{100}\right)\right]
$$

Onde:

$P C I=$ Poder Calorífico Inferior $(\mathrm{kcal} / \mathrm{kg})$;

PCS = Poder Calorífico Superior (kcal/kg);

$H=$ Teor de Hidrogênio (\%).

Utilizaram-se como teor de hidrogênio para as seis biomassas estudadas, os valores estipulados na Tabela 1. Para a biomassa de pinhão manso, adotou-se a média para os valores presentes na literatura $(6,54 \%)$ e para as demais biomassas, adotou-se o valor médio de $6 \%$ para o teor de hidrogênio. De acordo com Brito e Barrichelo (1981), o teor de hidrogênio (\%) das biomassas provenientes de madeiras é cerca de $6 \%$ independentemente da espécie.

Tabela 1. Valores citados na literatura para o teor de hidrogênio (\%) referentes às seis biomassas estudadas.

\begin{tabular}{lcc}
\hline \multicolumn{1}{c}{ Biomassa } & $\begin{array}{c}\text { Teor de Hidrogênio } \\
(\mathbf{\%})\end{array}$ & Autor(es) \\
\hline Pinus & 6 & CALEGARI et al. (2005) \\
Pinus & 6 & BRITO e BARRICHELO (1981) \\
\hline Tauari & 6 & BRITO e BARRICHELO (1981) \\
\hline Cumaru & 6 & BRITO e BARRICHELO (1981) \\
\hline Casca de Arroz & 6,08 & MACÊDO (2012) \\
\hline Bagaço de Cana & 5,9 & HORST (2013) \\
Bagaço de Cana & 5,77 & SILVA (2013) \\
Bagaço de Cana & 6,3 & MBOYADE et al. (2002) \\
Bagaço de Cana & 5,87 & LABEGALINI (2013) \\
\hline Torta de Pinhão Manso & 6,92 & RIBEIRO (2012) \\
Torta de Pinhão Manso & 6,7 & \\
Torta de Pinhão Manso & 6 & \\
Onde: TCF\% - Teor de carbono fixo; TMV\% - teor de materiais voláteis; TCZ\% - teor de \\
cinzas; *valor definido para a espécie Pinus taeda.
\end{tabular}


Por fim, foi determinado o Poder Calorífico Útil (PCU, cal/g ou kcal/kg), levando-se em consideração o teor de umidade da biomassa, calculado de acordo com a Equação 6 e seguindo as recomendações de Brito (1993) e Vale et al. (2007).

$$
P C U=P C I(1-U)-600 U
$$

Equação 6.

Onde:

PCU = Poder Calorífico Útil (kcal/kg);

PCI = Poder Calorífico Inferior ( $\mathrm{kcal} / \mathrm{kg})$;

$U=$ Teor de umidade da amostra em base úmida (\%).

\subsection{CONFECÇÃO DOS BRIQUETES}

Os briquetes foram confeccionados em prensa briquetadeira da marca Irmãos Lippel e modelo LB-32, pertencente ao Setor de Energia da Biomassa do LPF/SFB, onde se acoplou uma máquina sopradora para o resfriamento dos briquetes.

Os briquetes/corpo-de-prova foram confeccionados conforme o descrito no Capítulo II, utilizando-se para cada briquete, $40 \mathrm{~g}$ da classificada (partículas grossas e partículas finas), temperatura de compactação de 130 ou $200^{\circ} \mathrm{C}\left( \pm 10^{\circ} \mathrm{C}\right)$, pressões de compactação do manômetro de 80 ou $120 \mathrm{kgf} / \mathrm{cm}^{2}$ e com tempo de compactação de 5 minutos, contados a partir do momento em que se atingiu a pressão estabelecida. O resfriamento também foi o mesmo descrito no Capítulo II.

Desta forma, para a análise dos parâmetros de densificação dos resíduos, o delineamento experimental (Tabela 2) estabelecido foi de 6 corpos-de-prova confeccionados para duas temperaturas $\left(130\right.$ e $\left.200{ }^{\circ} \mathrm{C}\right)$, duas pressões $\left(80\right.$ e $\left.120 \mathrm{kgf} / \mathrm{cm}^{2}\right)$, duas granulometrias (partícula grossa e fina), resultando em 8 tratamentos e 48 corpos-de-prova confeccionados para cada uma das biomassas já citadas. Ao final, confeccionou-se um total de 288 briquetes, com as seis biomassas. 
Tabela 2. Delineamento experimental para a avaliação dos parâmetros de briquetagem: granulometria, temperatura e pressão para cada biomassa agroflorestal estudada.

\begin{tabular}{cccc}
\hline Tratamento & Granulometria & Temperatura $\left({ }^{\circ} \mathrm{C}\right)$ & Pressão $\left(\mathrm{kgf} / \mathrm{cm}^{2}\right)$ \\
\hline 1 & Grossa & 130 & 80 \\
2 & Grossa & 130 & 120 \\
3 & Grossa & 200 & 80 \\
4 & Grossa & 200 & 120 \\
\hline 5 & Fina & 130 & 80 \\
6 & Fina & 130 & 120 \\
7 & Fina & 200 & 80 \\
8 & Fina & 200 & 120 \\
\hline
\end{tabular}

Por fim, outras 3 repetições/briquetes foram confeccionados em iguais condições para cada uma das seis biomassas, com o intuito de realizar o ensaio de determinação da densidade aparente e densidade energética por meio de imersão em mercúrio e pela densitometria de raio $\mathrm{X}$, totalizando 144 briquetes.

Todos os corpos-de-prova confeccionados foram dispostos em câmara climática com temperatura e umidade relativa controlada $\left(20^{\circ} \mathrm{C}\right.$ e $65 \%$ de umidade relativa), por um período de aproximadamente 90 dias.

\subsection{DETERMINAÇÃO DA DENSIDADE APARENTE DO BRIQUETE}

\subsubsection{MÉTODO ESTEREOMÉTRICO}

A Densidade Aparente (DA, $\mathrm{g} / \mathrm{cm}^{3}$ ) foi determinada pelo método estereométrico no qual cada corpo-de-prova teve a sua massa determinada em balança de sensibilidade igual a $10^{-2} \mathrm{~g}$ e teve suas dimensões determinadas por paquímetro com sensibilidade de $10^{-2} \mathrm{~mm}$. A densidade aparente foi calculada pela relação entre a massa e volume, considerando-se a forma cilíndrica dos corpos-de-prova, após permanecerem em câmara climática por cerca de 90 dias. 


\subsubsection{MÉTODO DO DESLOCAMENTO DE MERCÚRIO}

A Densidade Aparente (DAHG, $\mathrm{g} / \mathrm{cm}^{3}$ ) foi determinada pelo método de deslocamento de mercúrio (ou imersão em mercúrio), após a imersão do corpo-de-prova sustentado por uma haste, em um recipiente sobre uma balança de precisão igual a $10^{-2} \mathrm{~g}$, contendo mercúrio puro (Hg). A densidade aparente foi calculada pela relação demonstrada pela equação 7.

$$
\rho_{A P}=\frac{m_{1}}{\frac{m_{1}+m_{2}}{\rho_{H g}}}
$$

Equação 7.

Onde:

$\rho_{A P}=$ Densidade aparente pelo método de deslocamento/imersão em mercúrio $\left(\mathrm{g} / \mathrm{cm}^{3}\right)$;

$m_{1}=$ massa do briquete $(g)$;

$m_{2}=$ massa do mercúrio deslocado pelo briquete $(g)$;

$\rho_{\mathrm{Hg}}=$ Densidade do mercúrio na temperatura do ensaio $\left(25^{\circ} \mathrm{C}\right)$

A metodologia de preparação dos corpos de prova foi semelhante ao descrito no Capítulo II e foi adaptada de Souza et al. (2010b) e Quirino et al (2012), onde se reduziu o comprimento do briquete de aproximadamente $50 \mathrm{~mm}$ para cerca de $3 \mathrm{~mm}$.

\subsubsection{MÉTODO DO RAIO-X}

Determinou-se a Densidade Aparente pela emissão de raios-x (DARX, g/ $\mathrm{cm}^{3}$ ) utilizando-se o equipamento Quintek Measurement Systems (QMS), modelo QTRS-01X acoplado a um microcomputador (Figura 2) e por meio do software Tree Ring System. 

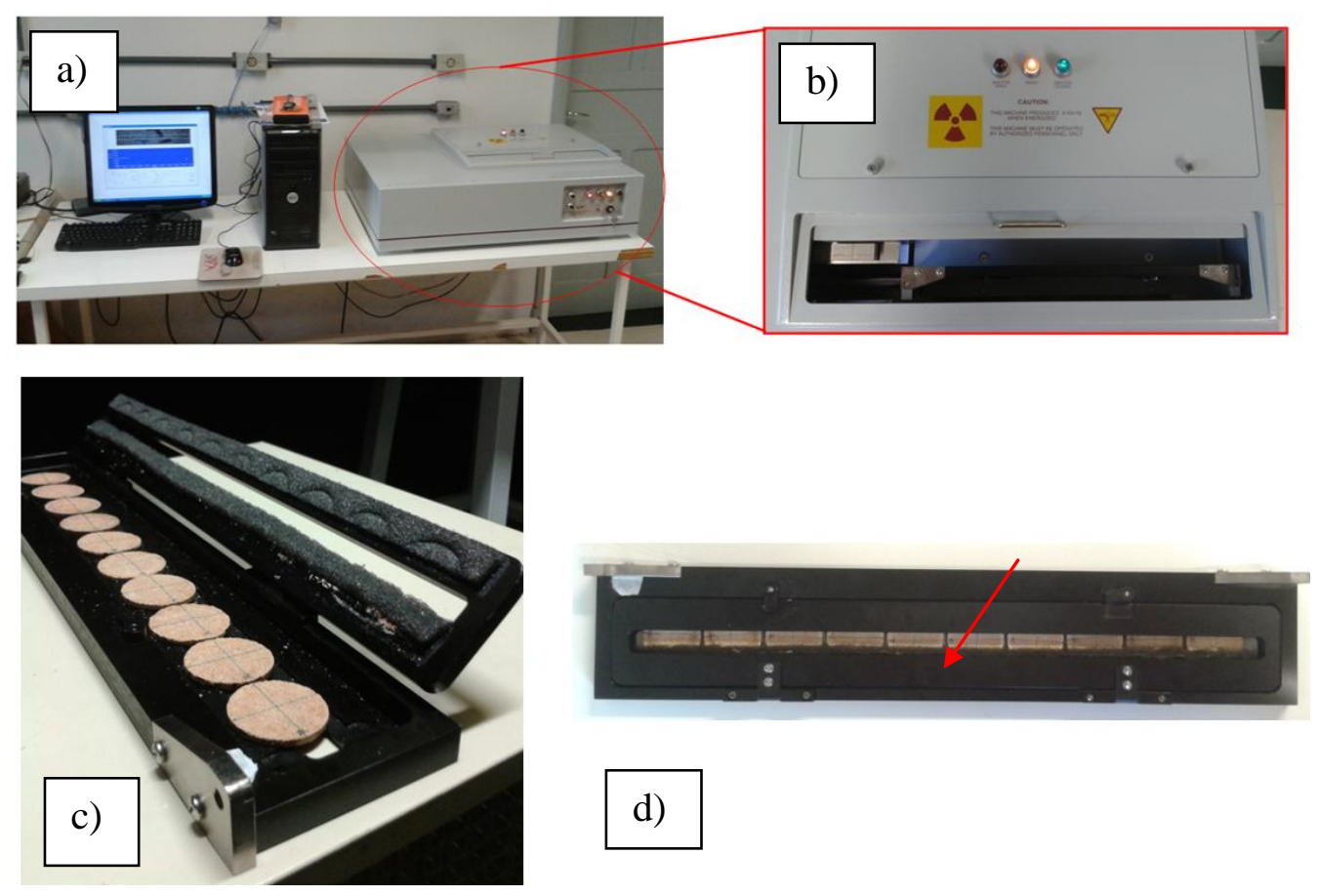

Figura 2. Equipamento de emissão de raio-x utilizado para a determinação do perfil de densidade dos briquetes, onde: a) visão geral do equipamento acoplado à um microcomputador; b) destaque para a abertura do equipamento onde são inseridas as amostras; c) suporte de amostras; d) destaque para a abertura no suporte de amostras, onde incidem as emissões de raio-X.

De acordo com Quirino et al. (2012), detectou-se a necessidade de reduzir o comprimento dos briquetes (ou espessura do corpo de prova), adaptando-os à câmara de emissão de raio-x e permitindo que a potência do equipamento fosse suficiente para realizar as leituras de densidade.

Desta forma, os briquetes foram inicialmente seccionados na sua porção mediana por uma serra esquadria manual (Figura 3) para atingirem cerca de $10 \mathrm{~mm}$ de espessura. Posteriormente, cada briquete foi lixado em uma lixadeira de disco estacionária com granulometria comercial da lixa P100, até atingirem a espessura de $3 \mathrm{~mm}$. 

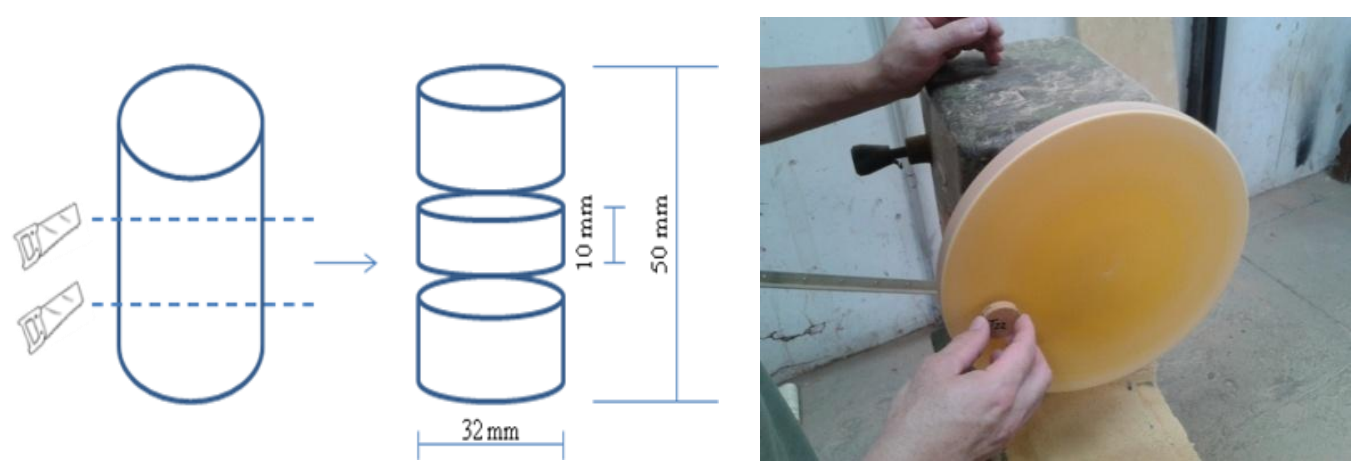

Figura 3. À esquerda, a posição do seccionamento dos briquetes, adaptando-os para o equipamento de raio-x e à direita, o processo de lixamento dos briquetes e ajuste da espessura para $3 \mathrm{~mm}$.

Determinou-se a densidade pelo equipamento de raio-x em três repetições/briquetes por tratamento e a varredura se deu por toda a porção diametral (seção transversal), realizando uma leitura de densidade a cada $40 \mu \mathrm{m}(0,004 \mathrm{~mm})$, totalizando cerca de 8.000 leituras por briquete. Este procedimento foi o adotado por Quirino et al. (2012) e adaptado de Castro (2011).

A partir dos dados gerados pelo software do equipamento, calculou-se a média por ponto de leitura da densidade, repetindo este procedimento por toda a extensão diametral do briquete. Por fim, as informações foram tabuladas em gráficos, que ilustram o perfil densitométrico médio ao longo do diâmetro dos briquetes (perfil densitométrico).

\subsection{DETERMINAÇÃO DA DENSIDADE ENERGÉTICA}

A Densidade Energética (DE ou DEHG, Gcal $/ \mathrm{m}^{3}$ ), segundo Pinheiro et al. (2005) é a propriedade que avalia o desempenho da biomassa como combustível e é definida como o produto entre poder calorífico útil e a densidade aparente (DA; DAHG; DARX), conforme Equação 8 para a densidade obtida pelo método estereométrico, Equação 9, para a densidade obtida pelo método de imersão em mercúrio; e Equação 10 para a densidade obtida pelo método de raio-X. 


$$
\begin{array}{cr}
D E=P C U \times D A & \text { Equação } 8 . \\
D E H G=P C U \times D A H G & \text { Equação 9. } \\
D E R X=P C U \times D A R X & \text { Equação } 10 .
\end{array}
$$

Onde:

$D E=$ Densidade energética em função da densidade aparente estereométrica $\left(\mathrm{Gcal} / \mathrm{m}^{3}\right)$;

DEHG = Densidade energética em função da densidade aparente por deslocamento de mercúrio $\left(\mathrm{Gcal}^{\mathrm{m}} \mathrm{m}^{3}\right)$;

DERX = Densidade energética em função da densidade aparente por raio-X $\left(\mathrm{Gcal} / \mathrm{m}^{3}\right)$;

$P C U=$ Poder calorífico útil ( $\mathrm{kcal} / \mathrm{kg})$;

$D A=$ Densidade aparente pelo método estereométrico $\left(\mathrm{kg} / \mathrm{m}^{3}\right)$;

$D A H G=$ Densidade aparente pelo método de deslocamento de mercúrio $\left(\mathrm{kg} / \mathrm{m}^{3}\right)$.

$D A R X=$ Densidade aparente pelo método de raio- $x\left(\mathrm{~kg} / \mathrm{m}^{3}\right)$.

Optou-se por empregar o PCU no cálculo da densidade energética, pois esta unidade representa a condição real da biomassa a ser utilizada na fabricação do briquete, retratando a densidade aparente do briquete após a climatização e o real conteúdo de energia presente na biomassa.

\subsection{ANÁLISE ESTATÍSTICA}

A análise estatística foi realizada pelo software SPSS (Statistical Package for Social Sciences) v. 19 para sistema operacional Windows.

Inicialmente, baseou-se em uma avaliação descritiva, considerando os valores máximos, mínimos, a média, o desvio padrão e o coeficiente de variação para o teor de carbono fixo (TCF, \%), teor de materiais voláteis (TMV, \%), teor de cinzas (TCZ, \%), densidade aparente estereométrica (DA, g/cm³), a densidade aparente por imersão em mercúrio (DAHG, g/cm³), a 
densidade aparente pelo método do raio-x $\left(\mathrm{DARX}, \mathrm{g} / \mathrm{cm}^{3}\right)$ e a densidade energética obtida por estes três últimos parâmetros (DE, DEHG e DERX, respectivamente, Gcal $/ \mathrm{m}^{3}$ ). Também foram analisadas as propriedades energéticas das biomassas, entre elas, o poder calorífico superior (PCS, $\mathrm{kcal} / \mathrm{kg}$ ), poder calorífico inferior (PCI, $\mathrm{kcal} / \mathrm{kg}$ ) e poder calorífico útil (PCU, $\mathrm{kcal} / \mathrm{kg})$.

Posteriormente, investigou-se o efeito dos parâmetros da briquetagem para cada biomassa, realizando-se análise de variância - ANOVA, considerando como fonte de variação, os parâmetros da briquetagem (granulometria, temperatura e pressão). As diferenças entre os grupos foram analisadas por meio do teste Tukey a um nível de significância de 5\%.

\section{RESULTADOS E DISCUSSÃO}

\subsection{ANÁLISE IMEDIATA DA BIOMASSA}

A Figura 4 apresenta os resultados para a análise imediata das seis biomassas estudadas, considerando o teor de carbono fixo (TCF\%), o teor de materiais voláteis (TMV\%) e teor de cinzas $(\mathrm{TCZ} \%)$. 


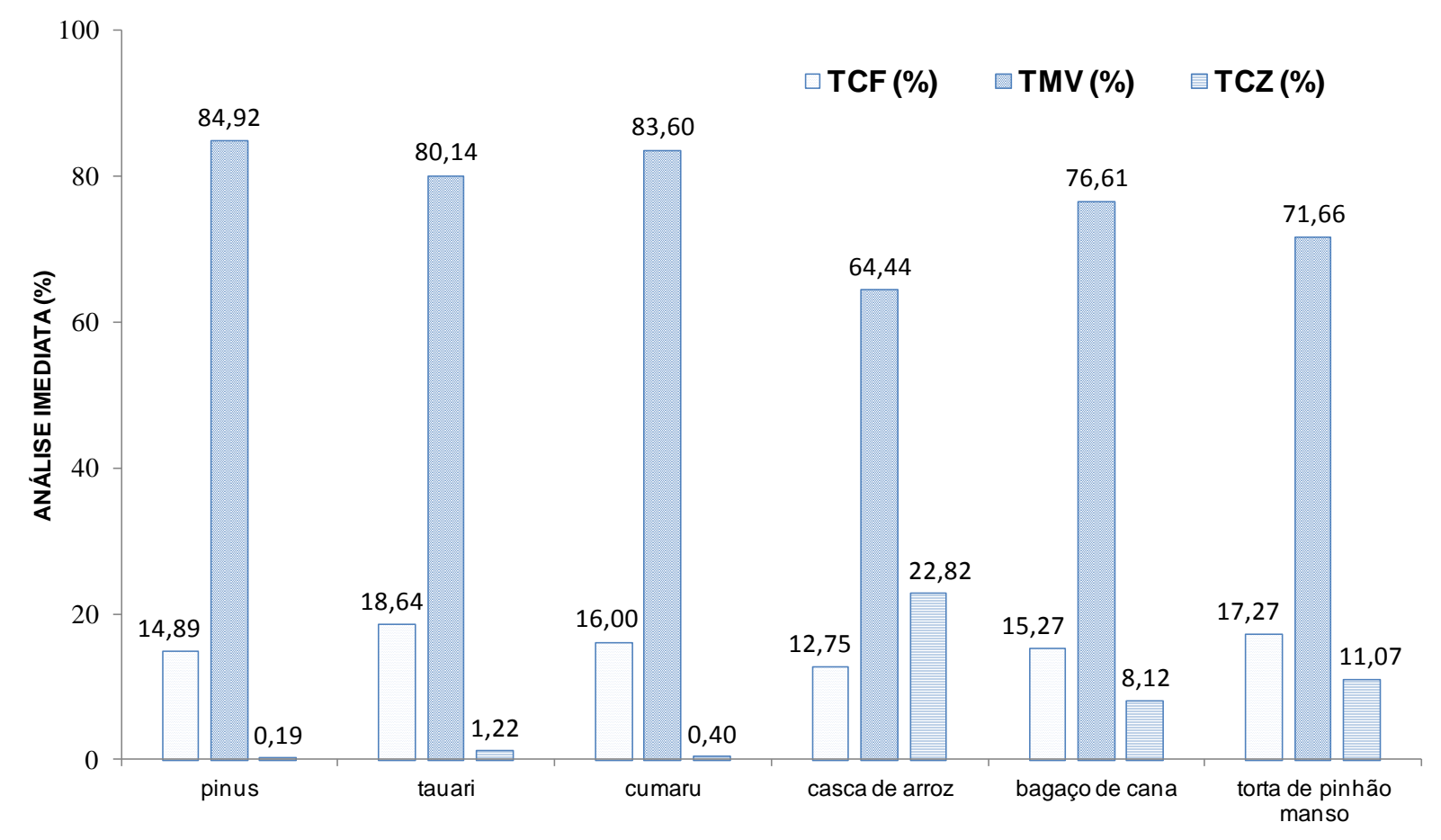

Figura 4. Análise imediata das seis biomassas agroflorestais estudadas, onde: TCF - Teor de carbono fixo; TMV - Teor de materiais voláteis; e TCZ - Teor de cinzas.

Observa-se pela Figura 4 que os maiores valores observados para o TMV\% foram para os resíduos florestais (média de 82,89\%), sendo aproximadamente $17 \%$ superior à média dos resíduos agrícolas (70,90\%). Os valores de TMV\% dos resíduos florestais permaneceram entre 80 e $85 \%$, onde o maior valor encontrado foi para a madeira de pinus $(84,92 \%)$ e o menor, para tauari $(80,14 \%)$. Para os resíduos agrícolas, os valores da TMV\% permaneceram entre 64 e $76 \%$, destacando-se a superioridade para o bagaço de cana $(76,61 \%)$ e do pinhão manso $(71,66 \%)$.

Com relação à TCZ\%, os maiores valores observados foram para os resíduos agrícolas, onde de uma forma geral (média de 14\%), foram aproximadamente $2233 \%$ superiores à média dos resíduos florestais $(0,6 \%)$. Esta diferença entre os resultados obtidos entre os resíduos florestais e agrícolas já era esperada, em função dos baixos valores de TCZ\% observados para as madeiras de uma forma geral, assunto amplamente discutido na literatura específica. Ainda, destaca-se a utilização de fertilizantes geralmente em maior quantidade nas culturas agrícolas, que promovem o acúmulo de minerais na constituição dos tecidos vegetais, aumentando assim, os valores de TCZ\%. 
Pode-se observar ainda que, o maior valor de TCZ\% foi para a casca de arroz, ultrapassando os 22\%. De acordo com Ramos e Paula et al. (2011), este alto valor para o TCZ\% está ligado ao elevado conteúdo de sílica $\left(\mathrm{SiO}_{2}\right)$ presente nesta biomassa. Ainda de acordo com estes autores, foram observados mais de 8\% de sílica nas cinzas. De acordo com Vale et al. (2011) que estudaram a análise imediata da torta de pinhão manso, a presença significativa dos minerais cálcio, potássio, fósforo, ferro, manganês, sódio, magnésio, nitrogênio, enxofre, boro, zinco e cobre, fez com que se observasse altos valores para o TCZ\%, cerca de $8 \%$.

Ainda, a grande quantidade de minerais presentes na biomassa e consequentemente nas cinzas, podem reduzir o poder calorífico desta biomassa assim como interferir na condução de calor por se tratar de um material com características de isolamento térmico. De acordo com Furtado et al. (2010), as cinzas presentes na biomassa são consideradas como incombustíveis ou a fração inerte da amostra e podem efetivamente reduzir o poder calorífico.

O menor valor observado dentre os resíduos agrícolas foi para o bagaço de cana $(8,12 \%)$. Dentre as madeiras o tauari apresentou o maior valor de TCZ\% $(1,22 \%)$ e o menor valor observado foi para a madeira de pinus $(0,19 \%)$.

Por fim, a média dos valores do TCF\% dos resíduos florestais foram cerca de 9,34\% superiores aos valores dos resíduos agrícolas, destacando-se a superioridade dos valores do TCF\% para as madeiras de tauari e cumaru, respectivamente 18,64 e 16\%. Para os resíduos agrícolas, a superioridade do TCF\% foi para o pinhão manso e bagaço de cana, 17,27 e $15,27 \%$ respectivamente. Segundo Brito e Barrichello (1982) a vantagem para um maior valor do TCF\% se dá por uma liberação da energia presente na biomassa de uma forma mais lenta, implicando em um maior tempo de residência nos fornos.

Os valores obtidos da análise imediata das biomassas estudadas estão coerentes com a literatura. A Tabela 3 traz um comparativo do presente estudo com valores citados por outros autores. 
Tabela 3. Valores citados na literatura da análise imediata para as seis biomassas estudadas.

\begin{tabular}{lcccc}
\hline \multirow{1}{*}{ Biomassa } & \multicolumn{3}{c}{ Análise Imediata } & Autor(es) \\
& TCF\% & TMV\% & TCZ\% & \\
\hline Pinus & 14,80 & 84,90 & 0,30 & Souza et al. (2012a)* \\
\hline Tauari & 17,00 & 82,00 & 1,00 & Pinheiro et al. (2005) \\
\hline Cumaru & 15,00 & 84,00 & 1,00 & Pinheiro et al. (2005) \\
\hline Casca de Arroz & 17,67 & 55,90 & 26,43 & Macedo (2012) \\
Casca de Arroz & 16,67 & 65,47 & 17,86 & Jenkins (1990) \\
Casca de Arroz & 17,30 & 66,36 & 16,34 & Ramos e Paula et al. (2011) \\
Casca de Arroz & 11,90 & 64,26 & 23,84 & Morais et al. (2006) \\
\hline Bagaço de Cana & 17,16 & 82,31 & 0,53 & Ramos e Paula et al. (2011) \\
Bagaço de Cana & 16,87 & 82,33 & 0,80 & Horst (2013) \\
Bagaço de Cana & 13,92 & 75,05 & 11,03 & Macêdo (2012) \\
\hline Torta de Pinhão Manso & 14,21 & 77,40 & 7,95 & Vale et al. (2011) \\
\hline
\end{tabular}

Onde: TCF\% - Teor de carbono fixo; TMV\% - teor de materiais voláteis; TCZ\% - teor de cinzas; *valor definido para a espécie Pinus taeda.

\subsection{CONTEÚDO ENERGÉTICO}

A Figura 5 apresenta os resultados para o conteúdo energético das seis biomassas estudadas, considerando o poder calorífico superior (PCS), o poder calorífico inferior (PCI) e poder calorífico útil (PCU). 


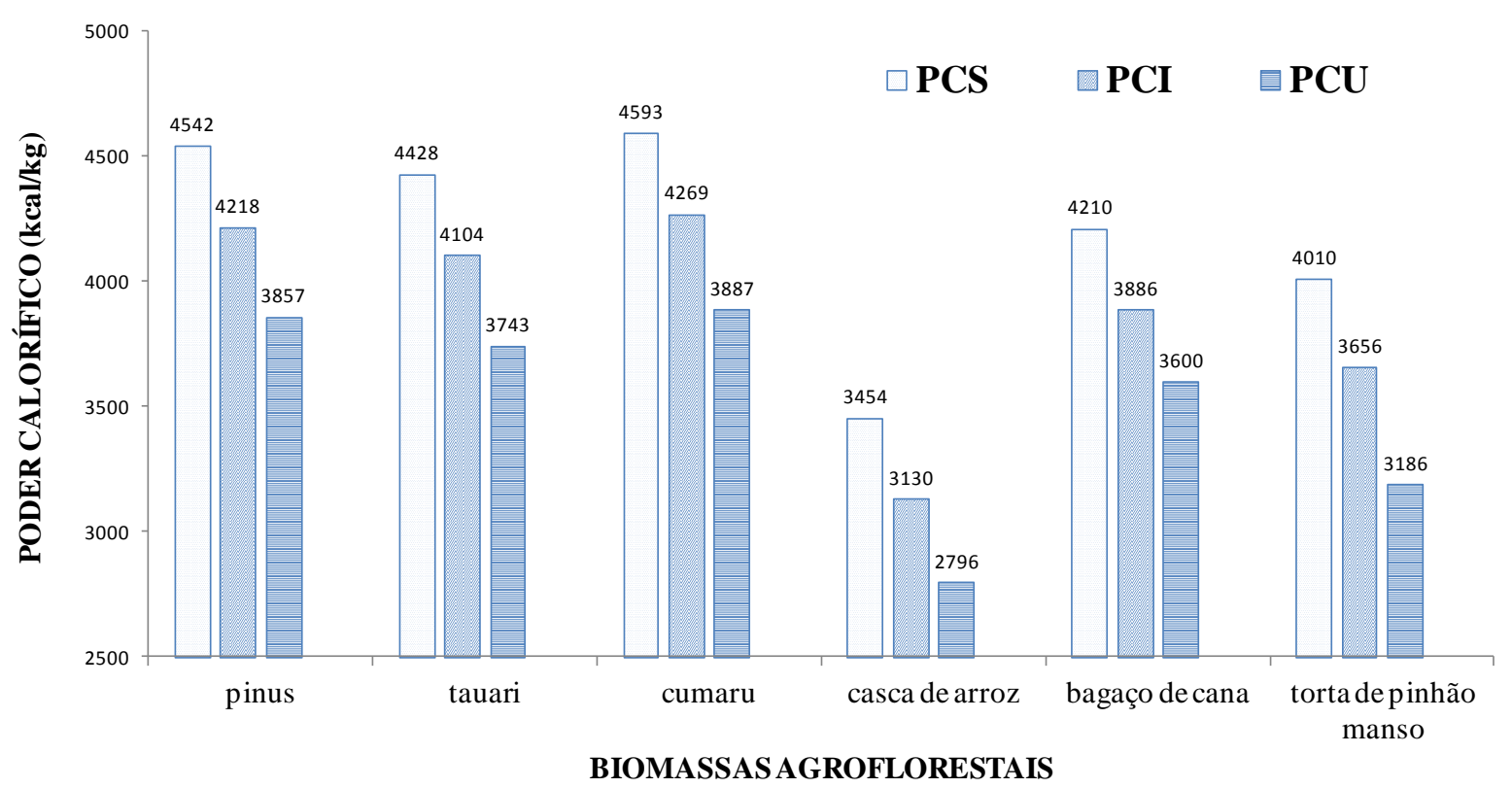

Figura 5. Valores do poder calorífico das seis biomassas agroflorestais estudadas, onde: PCS - Poder calorífico superior; PCI - Poder calorífico inferior; e PCU - Poder calorífico útil.

Conforme os dados apresentados na Figura 5 é possível observar que o PCI médio para os resíduos florestais (4197 kcal/kg) foi cerca de 17,65\% superior ao valor médio para os resíduos agrícolas $(3567 \mathrm{kcal} / \mathrm{kg}$ ). Dentre os resíduos florestais, destaca-se o cumaru com maior PCS igual a $4593 \mathrm{kcal} / \mathrm{kg}$, seguido do pinus com PCS de $4542 \mathrm{kcal} / \mathrm{kg}$. Por outro lado, dentre os resíduos agrícolas, o bagaço de cana se mostrou com maior conteúdo energético (4210 kcal/kg), à frente da torta de pinhão manso (4010 kcal/kg).

De acordo com Brand (2010), para o setor energético, apenas diferenças de mais de 300 $\mathrm{kcal} / \mathrm{kg}$ podem ser consideradas como significativas, para o poder calorífico entre duas biomassas. Desta forma, comparando-se as biomassas estudadas, apenas a biomassa da casca de arroz e da torta de pinhão manso, com os valores mais baixos, apresentaria uma redução significativa no PCS, sendo mais expressiva para a casca de arroz.

Os resultados obtidos para o PCS e PCI estão de acordo com a literatura. Pinheiro et al. (2005) obtiveram para os valores de PCS e PCI na biomassa de cumaru, cerca de 4750 e 4400 $\mathrm{kcal} / \mathrm{kg}$ respectivamente. Ainda de acordo com estes autores, para a biomassa de tauari, os valores observados foram cerca de 4700 e $4100 \mathrm{kcal} / \mathrm{kg}$, respectivamente. 
Ramos e Paula et al. (2011) obtiveram os valores de 4274,48 e $3855,78 \mathrm{kcal} / \mathrm{kg}$ para o PCS e PCI respectivamente, para a biomassa de bagaço de cana. Ainda de acordo com estes autores, outras biomassas estudadas para a geração de energia, como palha de milho, apresentaram os valores de 4443,38 e 4024,68 kcal/kg, enquanto que para a palha da cana de açúcar, os valores foram de 4315,66 e 3907,25kcal/kg, respectivamente para o PCS e PCI.

Com relação ao PCU mostrado na Figura 5, que leva em consideração a umidade presente no briquete biomassa/amostra, a média dos valores para os resíduos florestais $(3829 \mathrm{kcal} / \mathrm{kg}$ ) foi superior em 19,88\% em relação à média dos resíduos agrícolas (3194kcal/kg).

Os valores absolutos de umidade em base úmida observados para as biomassas foram: pinus $(7,49 \%)$, tauari $(7,66 \%)$, cumaru $(7,83 \%)$, casca de arroz $(8,93 \%)$, bagaço de cana $(6,37 \%)$ e torta de pinhão manso $(11,03 \%)$. De uma forma geral, os resíduos florestais apresentaram menor teor de umidade da biomassa durante a fabricação do briquete, que as biomassas agrícolas. Este fato aliado ao maior PCI resultou em maiores valores do PCU para os briquetes confeccionados com resíduos florestais e consequentemente são mais indicados para a utilização final.

A Tabela 4 mostra alguns valores do PCS e PCI observados na literatura, como forma comparativa aos resultados observados para as seis biomassas no presente estudo.

Tabela 4. Valores citados na literatura para o conteúdo energético das seis biomassas estudadas.

\begin{tabular}{lccc}
\hline \multicolumn{1}{c}{ Biomassa } & \multicolumn{2}{c}{ Conteúdo Energético } & Autor(es) \\
& PCS & PCI & \\
\hline Pinus** & 4786 & $4462^{*}$ & Quirino et al. (2004) \\
\hline Tauari & 4735 & $4411^{*}$ & Quirino et al. (2004) \\
\hline Cumaru & 4866 & $4542^{*}$ & Quirino et al. (2004) \\
\hline Casca de Arroz & 3812 & 3445 & Ramos e Paula et al. (2011) \\
Casca de Arroz & 3852 & $3528^{*}$ & Jenkins (1990) \\
\hline Bagaço de Cana & 4274 & 3855 & Ramos e Paula et al. (2011) \\
Bagaço de Cana & 4139 & 3815 & Jenkins (1990) \\
\hline Torta de Pinhão Manso & 5122 & $4798^{*}$ & Vale et al. (2011) \\
\hline
\end{tabular}

Onde: PCS - Poder calorífico superior; PCI - Poder calorífico inferior; *valor calculado com base no teor de hidrogênio a $6 \%$; **espécie Pinus elliottii. 


\subsection{BRIQUETAGEM E PROPRIEDADES DOS BRIQUETES}

Os briquetes confeccionados apresentaram a superfície totalmente íntegra, não apresentando visualmente fissuras e/ou rachaduras, considerando desta forma, as biomassas e os tratamentos empregados como tecnicamente viáveis para a briquetagem, com poucas exceções, onde estouros ou fissuras inviabilizaram a briquetagem nas condições estabelecidas em tratamentos com cumaru ou torta de pinhão manso.

Para a biomassa da torta de pinhão manso, nos tratamentos 7 e 8 , a produção dos briquetes foi inviabilizada, pois todos os briquetes formados apresentaram rachaduras profundas causadas por estouros após a liberação da pressão na máquina briquetadeira e esmagamentos causados pela contrapressão do pistão superior (Figura 6). Nestes tratamentos, variou-se apenas a pressão de 80 e $120 \mathrm{kfg} / \mathrm{cm}^{2}$, associada a $200^{\circ} \mathrm{C}$ de temperatura e a partícula com granulometria superior a 35 Mesh.

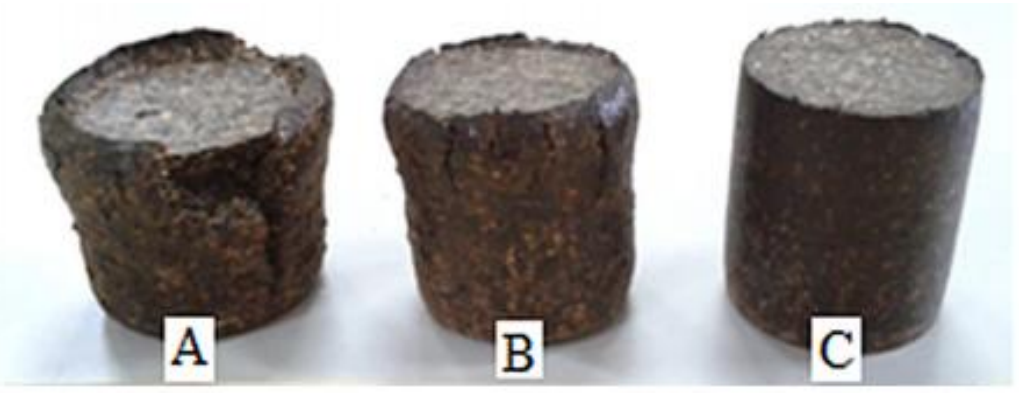

Figura 6. Danos à superfície dos briquetes (rachaduras e esmagamentos) que inviabilizaram a utilização dos briquetes com a torta de pinhão manso nos tratamentos 7 e 8 ; onde A: 3 minutos de compactação a $200^{\circ} \mathrm{C}$; B: 2 minutos de compactação; e C: apenas 1 minuto de compactação.

Desta forma, acredita-se que a produção de briquetes foi inviabilizada pela grande formação de vapores de água e do óleo presente na torta de pinhão manso, não permitindo a agregação das partículas a fim de formar o briquete.

Segundo Barros (2012) que estudou a viabilidade técnica da briquetagem com as biomassas de casca maracujá, de coco, de laranja, mandioca e de sabugo de milho, foi observado o 
mesmo fenômeno de estouros e esmagamentos para os briquetes com a casca de laranja e de mandioca que inviabilizaram a sua produção, na condição estipulada.

O mesmo fenômeno observado por Barros (2012) ocorreu para o tratamento 8 para a biomassa de cumaru, onde todos os briquetes apresentavam profundas rachaduras e esmagamentos. Apesar de não conter grande teor de umidade na biomassa durante a briquetagem, acredita-se que a liberação de extrativos juntamente associado ao pequeno tamanho da partícula, contribuíram para que não ocorresse adesão.

Conforme ilustrado na Figura 6, os briquetes com a torta de pinhão manso para os tratamentos 7 e 8 , puderam ser confeccionados com a redução do tempo de compactação de 5 minutos para apenas 1 minuto.

Para os briquetes de cumaru e da torta de pinhão manso, foi possível ajustar o tempo de compactação juntamente à umidade da biomassa e o tempo de resfriamento para que se produzissem os briquetes, entretanto, neste capítulo pretendeu-se avaliar os briquetes confeccionados a partir de um mesmo tratamento, nas seis biomassas citadas.

Pelo fato de ter sido alterado o procedimento de confecção dos briquetes, diferenciando-os das demais biomassas, os tratamentos 7 e 8 da torta de pinhão manso e o tratamento 8 do cumaru não foram levados em consideração para os ensaios laboratoriais.

\subsubsection{DENSIDADE APARENTE ESTEREOMÉTRICA}

A Figura 7 apresenta os resultados obtidos para a Densidade Aparente (DA $-\mathrm{g} / \mathrm{cm}^{3}$ ) determinada pelo método estereométrico, para as seis biomassas estudadas. 

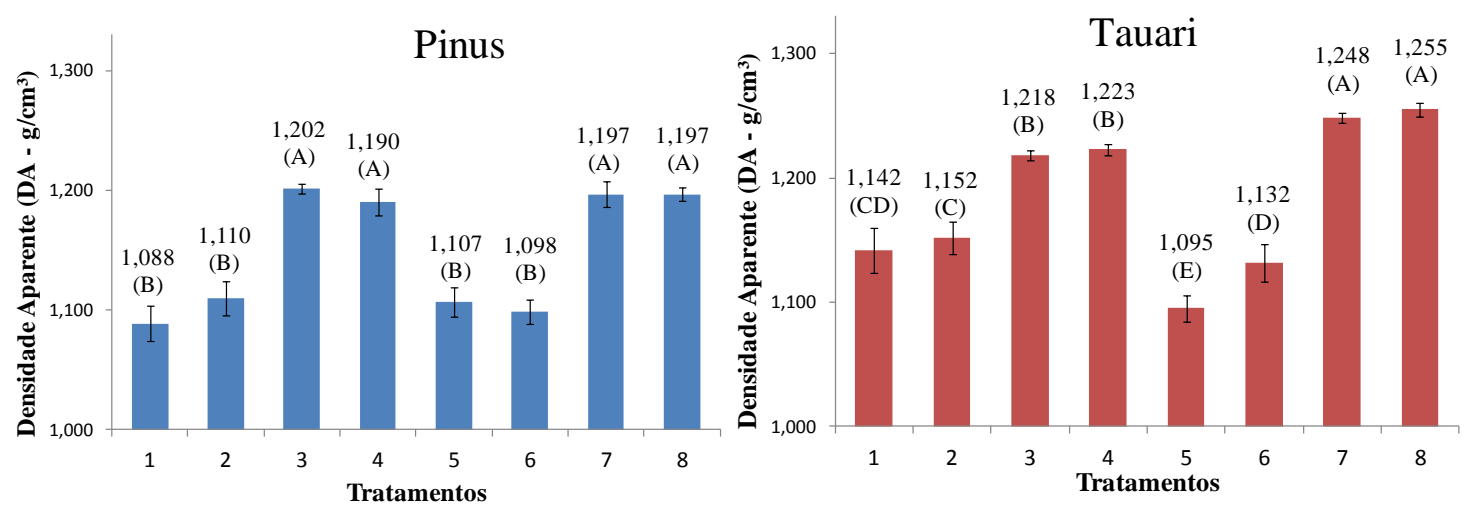

Cumaru

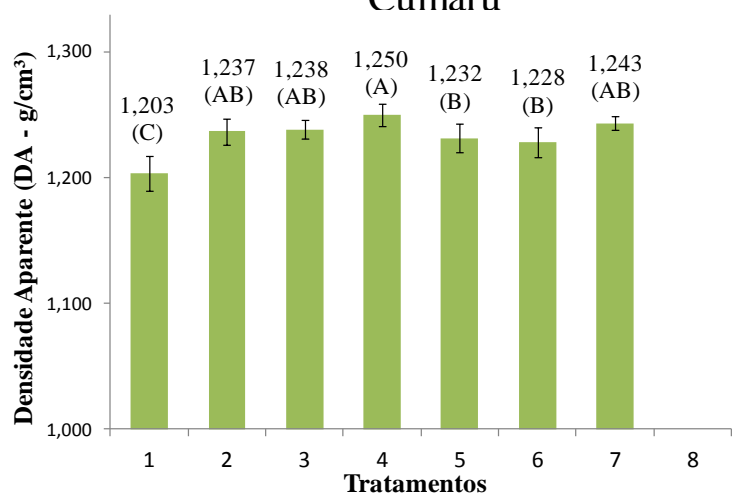

Casca de Arroz

Bagaço de Cana
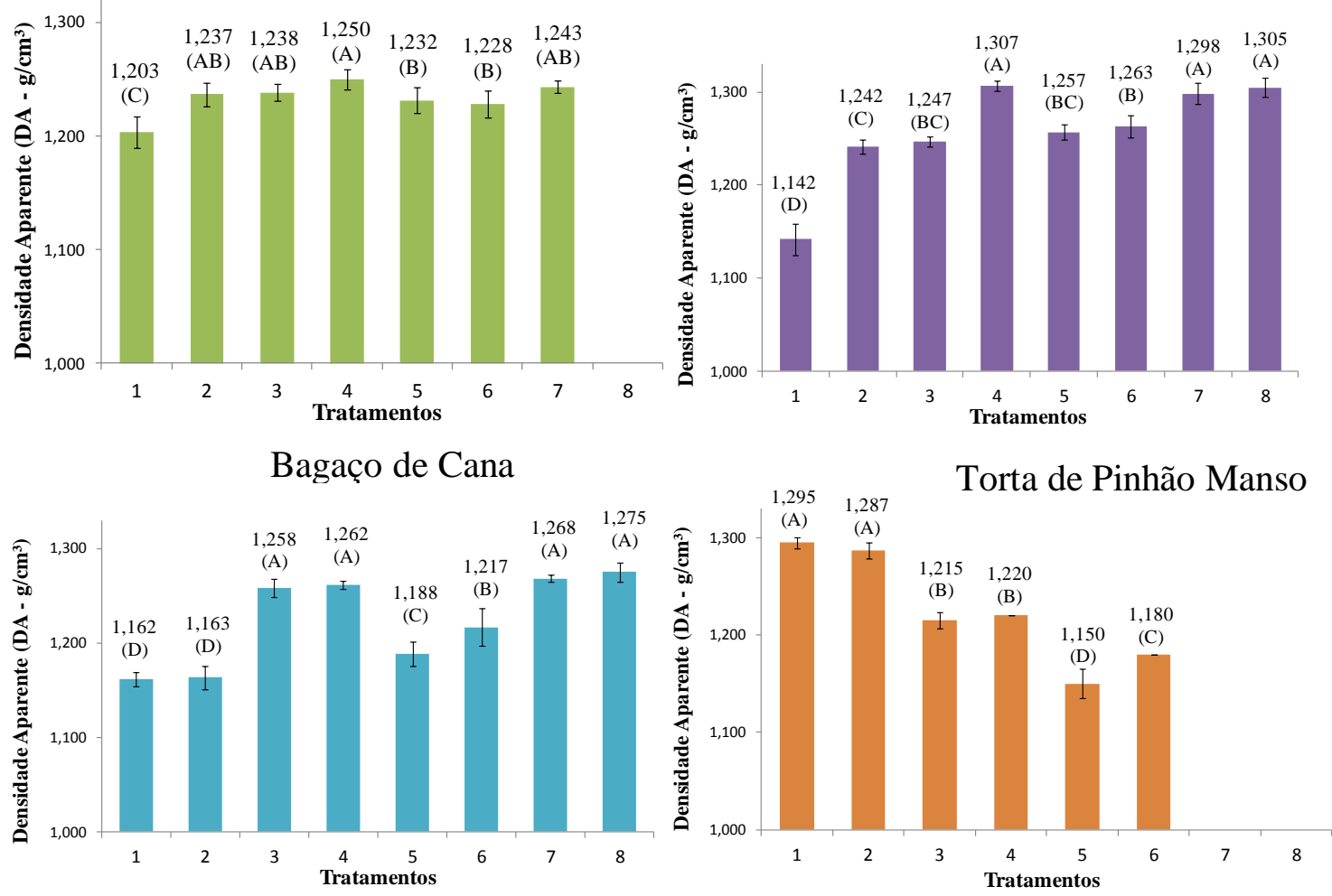

Figura 7. Valores da densidade aparente dos briquetes (DA $-\mathrm{g} / \mathrm{cm}^{3}$ ) obtidos pelo método estereométrico, a partir das biomassas de pinus, tauari, cumaru, casca de arroz, bagaço de cana e torta de pinhão manso; em função dos oito tratamentos propostos. Onde: Letras diferentes para a mesma biomassa representam diferenças estatisticamente significativas entre os tratamentos pelo Teste Tukey a 5\% de significância.

Conforme apresentado na Figura 7, uma análise geral dos resultados mostrou que existe uma tendência de elevação da densidade aparente para os tratamentos 3 e 4 (partículas grossas), assim como para os tratamentos 7 e 8 (partículas finas) utilizando-se a temperatura de $200^{\circ} \mathrm{C}$, 
independentemente da biomassa utilizada para a confecção do briquete. Apenas para a biomassa da torta de pinhão manso este comportamento não foi observado.

Tecnicamente, o maior valor da densidade aparente é desejável, uma vez que existe uma relação diretamente proporcional entre o aumento da densidade aparente e a densidade energética do briquete, assim como proporciona uma maior resistência mecânica, tornando os briquetes mais íntegros após o transporte e possíveis quedas. Desta forma, do ponto de vista técnico, para a confecção dos briquetes podem ser sugeridas a temperatura de $200^{\circ} \mathrm{C}$ e a pressão de $80 \mathrm{kgf} / \mathrm{cm}^{2}$. Da mesma forma, Ramos e Paula et al. (2011b) observaram que o aumento da temperatura de compactação, fez com que aumentasse a densidade aparente dos briquetes de pergaminho do grão do cafeeiro e consequentemente a sua resistência mecânica.

Os briquetes de uma forma geral têm o valor da densidade aparente próximo a $1 \mathrm{~g} / \mathrm{cm}^{3} \mathrm{ou}$, em muitos casos, superior a este. Os briquetes apresentam densidade aparente superiores à biomassa de origem em função da sua preparação, ou seja, com o uso de diferentes biomassas, partículas moídas/trituradas, emprego de altas temperaturas e pressões de compactação. Segundo Quirino et al. (2012), considera-se como favorável a briquetagem quando a densidade aparente do briquete se torna maior que a densidade aparente da biomassa de origem. Também se sabe que a variação nestes parâmetros de briquetagem afeta diretamente a densidade aparente do briquete, permitindo apenas, comparações entre os valores da densidade em iguais condições de manufatura.

Barros (2012) fabricou briquetes em condições semelhantes ao do presente estudo, ou seja, a $130^{\circ} \mathrm{C}$ de temperatura, pressão de $80 \mathrm{MPa}$, partículas menores que 40 mesh e obteve os valores de densidade aparente para as biomassas de sabugo de milho $\left(1,404 \mathrm{~g} / \mathrm{cm}^{3}\right)$, casca de maracujá $\left(1,344 \mathrm{~g} / \mathrm{cm}^{3}\right)$ e coco $\left(1,177 \mathrm{~g} / \mathrm{cm}^{3}\right)$. De forma comparativa, PAULA et al. (2011b) determinaram a densidade aparente para os briquetes do pergaminho do grão do cafeeiro e de casca de arroz, respectivamente de 0,946 e 1,077 $\mathrm{g} / \mathrm{cm}^{3}$. As condições empregadas para a fabricação destes briquetes foram semelhantes ao do presente estudo, a partir de uma temperatura de $125^{\circ} \mathrm{C}$ e pressão de $153 \mathrm{~kg} / \mathrm{cm}^{2}$ a 8 minutos de compactação.

Foi possível observar também que para as biomassas de pinus e bagaço de cana, não houve diferença estatisticamente significativa entre os tratamentos com densidade aparente mais 
elevada, ou seja, os tratamentos 3, 4, 7 e 8 . Analisando os resultados para a biomassa da casca de arroz, o comportamento foi semelhante ao pinus e bagaço de cana, entretanto, entre os tratamentos 3 e 4 houve diferença estatisticamente significativa, com maior valor médio para o tratamento 4.

Já para a biomassa de tauari, o tamanho da partícula influenciou o resultado da densidade aparente, onde o uso de partículas finas fez com que se observassem maiores valores da densidade. Tais diferenças foram estatisticamente significativas a 5\% de significância.

Por outro lado, de uma forma geral, não se observou esta tendência de aumento da densidade aparente somente pelo aumento da pressão de compactação. Furtado et al. (2010) observaram este mesmo comportamento, onde o aumento da pressão de compactação não resultou em ganho efetivo na densidade aparente do briquete com a casca ou serragem de Pinus sp.

Apenas houve ganho efetivo na densidade aparente com o aumento da pressão entre os tratamentos 1 e 2 para os briquetes com biomassa de pinus, cumaru e casca de arroz, ou seja, apenas quando se utilizou temperatura mais baixa $\left(130^{\circ} \mathrm{C}\right)$ juntamente a partículas mais grossas. Este ganho de deu, possivelmente, pela melhor acomodação das partículas com a pressão mais elevada e consequentemente uma redução discreta do volume do briquete.

Possivelmente, a maior pressão de compactação não tenha sido eficiente da mesma forma que o aumento da temperatura para a elevação da densidade aparente, pois a diferença entre as pressões selecionadas para este estudo tenha sido relativamente pequena.

Ainda com relação à Figura 7, os briquetes que apresentaram um comportamento mais uniforme nos valores da densidade aparente foram os confeccionados com biomassa de cumaru, onde todos os valores foram superiores a $1,2 \mathrm{~g} / \mathrm{cm}^{3}$ e com uma discreta elevação da densidade para o tratamento 4 , chegando a $1,25 \mathrm{~g} / \mathrm{cm}^{3}$. Possivelmente, o comportamento uniforme desta biomassa, frente à variação dos parâmetros da briquetagem foi devido à alta densidade do material de origem, não permitindo uma maior razão de compactação, mesmo empregando maior temperatura e maior pressão. De acordo com os princípios aplicáveis à painéis de partículas, Iwakiri et al. (2008) determinaram que quanto menor a densidade do 
material de origem, maior a razão de compactação e consequentemente, maior densidade final do produto.

Sendo assim, apenas como forma ilustrativa observou-se que, utilizando a partícula grossa (tratamentos de 1 a 4) ou fina (tratamentos 5 a 8), os maiores valores médios de densidade aparente foram para os briquetes de casca de arroz, sendo superiores a 1,2 $\mathrm{g} / \mathrm{cm}^{3}$, chegando a $1,307 \mathrm{~g} / \mathrm{cm}^{3}$ em média para o tratamento 4 . Para esta propriedade, os menores valores médios observados foram para os briquetes de pinus, onde permaneceram com médias entre 1,088 e $1,202 \mathrm{~g} / \mathrm{cm}^{3}$.

\subsubsection{DENSIDADE APARENTE POR IMERSÃO EM MERCÚRIO}

A obtenção da densidade aparente pelo método do deslocamento/imersão em mercúrio apresentou-se como alternativa para a determinação desta propriedade em briquetes, pois mostrou um controle experimental satisfatório, representado pelo desvio padrão dos tratamentos, que permaneceu entre 1 e $5 \%$ independentemente da biomassa utilizada.

Apenas para os briquetes com torta de pinhão manso, o desvio padrão foi bastante elevado nos tratamentos de 3 a 6 , chegando a cerca de $20 \%$ e $13 \%$ respectivamente. Possivelmente, os briquetes com a torta de pinhão manso se tornaram mais quebradiços pelo aumento da temperatura e redução do tamanho da partícula, sugerindo uma degradação térmica dos seus componentes químicos e consequentemente redução na resistência mecânica, que deve ser investigada mais profundamente.

O método de imersão em mercúrio apresentou como vantagem, a não preocupação com a forma geral do briquete para a obtenção da sua densidade aparente, diferentemente do método estereométrico, que se baseia na teoria de um cilindro perfeito, superestimando o valor final da densidade aparente. Desta forma, pequenas imperfeições na superfície e arestas, assim como pequenas variações no diâmetro ao longo do comprimento do briquete não são levadas em consideração pelo método estereométrico, tornando o método por deslocamento em mercúrio mais preciso. 
Por outro lado se percebeu que a forma de se manusear as amostras e posicioná-las na agulha foi determinante para a quebra de alguns briquetes, sugerindo a fabricação de mais repetições por tratamento para uma possível substituição de amostras. Também se indica como desvantagem da utilização deste método, a necessidade de recipientes e câmaras apropriadas para o manuseio do mercúrio, devido à sua elevada toxicidade.

A Figura 8 apresenta os valores médios da densidade aparente dos briquetes com as seis diferentes biomassas, obtidos pelo método de imersão em mercúrio. 

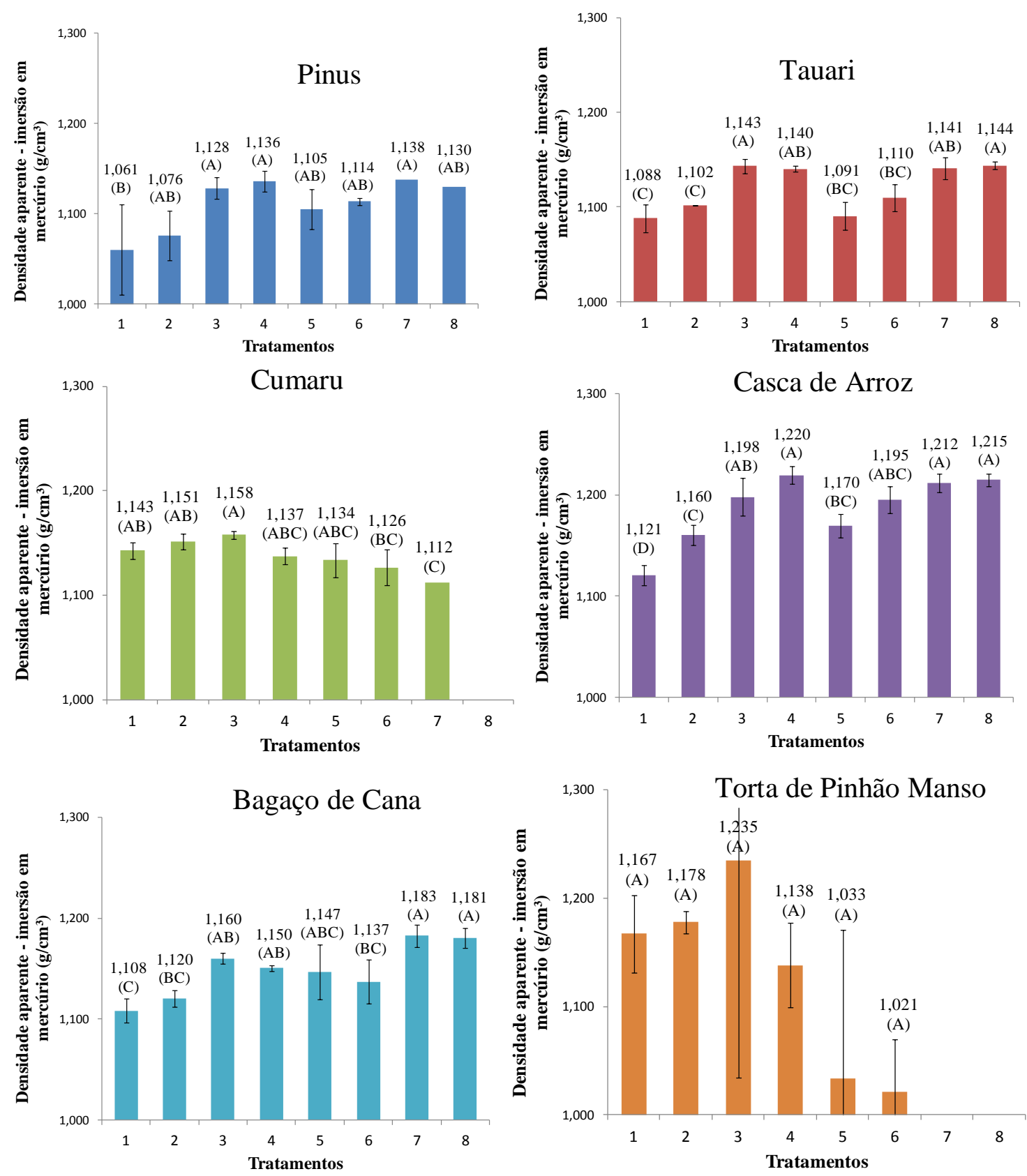

Figura 8. Valores da densidade aparente dos briquetes (DAHG - $\mathrm{g} / \mathrm{cm}^{3}$ ) obtidos pelo método de imersão em mercúrio, a partir das biomassas de pinus, tauari, cumaru, casca de arroz, bagaço de cana e torta de pinhão manso; em função dos oito tratamentos propostos. Onde: Letras diferentes para a mesma biomassa representam diferenças estatisticamente significativas entre os tratamentos pelo Teste Tukey a 5\% de significância.

Conforme apresentado na Figura 8, uma análise geral dos resultados mostrou que existe uma tendência de elevação da densidade aparente para os tratamentos 3 e 4 (partículas grossas), assim como para os tratamentos 7 e 8 (partículas finas) utilizando-se a temperatura de $200^{\circ} \mathrm{C}$, 
independentemente da biomassa utilizada para a confecção do briquete. Este comportamento observado para esta propriedade foi bastante semelhante à densidade aparente obtida pelo método estereométrico. Apenas para a biomassa da torta de pinhão manso este comportamento não foi observado.

Para esta variável, não houve uma tendência de aumento da densidade aparente a partir de um aumento da pressão de compactação. Esta variável apenas foi influenciada de forma diretamente proporcional pela temperatura. Assim, aumentando-se a temperatura de 130 para $200^{\circ} \mathrm{C}$ se obtém maior densidade aparente, excetuando-se os briquetes com a biomassa de cumaru que apresentaram comportamento mais uniforme em função do tamanho da partícula, variação de pressão e variação de temperatura de compactação.

Quirino et al. (2012) estudaram os efeitos da variação de temperatura (130 e $\left.200^{\circ} \mathrm{C}\right)$, pressão de compactação (80 e $120 \mathrm{kgf} / \mathrm{cm}^{2}$ ) e tamanho da partícula (grossa - entre 2 e $10 \mathrm{~mm}$; fina inferior a $1 \mathrm{~mm}$ ) na densidade aparente determinada por imersão mercúrio nos briquetes com biomassa de Eucalyptus sp. Assim, foi observado o valor máximo de $1,343 \mathrm{~g} / \mathrm{cm}^{3}\left(200^{\circ} \mathrm{C} ; 80\right.$ $\mathrm{kgf} / \mathrm{cm}^{2}$ e partícula fina) e mínimo de $1,132 \mathrm{~g} / \mathrm{cm}^{3}\left(130^{\circ} \mathrm{C} ; 120 \mathrm{kgf} / \mathrm{cm}^{2}\right.$ e partícula grossa). Tais valores foram equivalentes em condições de fabricação dos briquetes e de ensaio, sendo compatíveis com os valores observados no presente estudo.

Ainda de acordo com estes autores, ao se utilizar a maior temperatura $\left(200^{\circ} \mathrm{C}\right)$, maiores foram os valores da densidade aparente, corroborando as informações deste presente estudo.

\subsubsection{DENSIDADE APARENTE POR RAIO-X}

Na Figura 9 são apresentados os valores da densidade aparente obtida pelo método de raio-X $\left(\mathrm{DARX}, \mathrm{g} / \mathrm{cm}^{3}\right)$, para os briquetes confeccionados com as seis biomassas agroflorestais. 

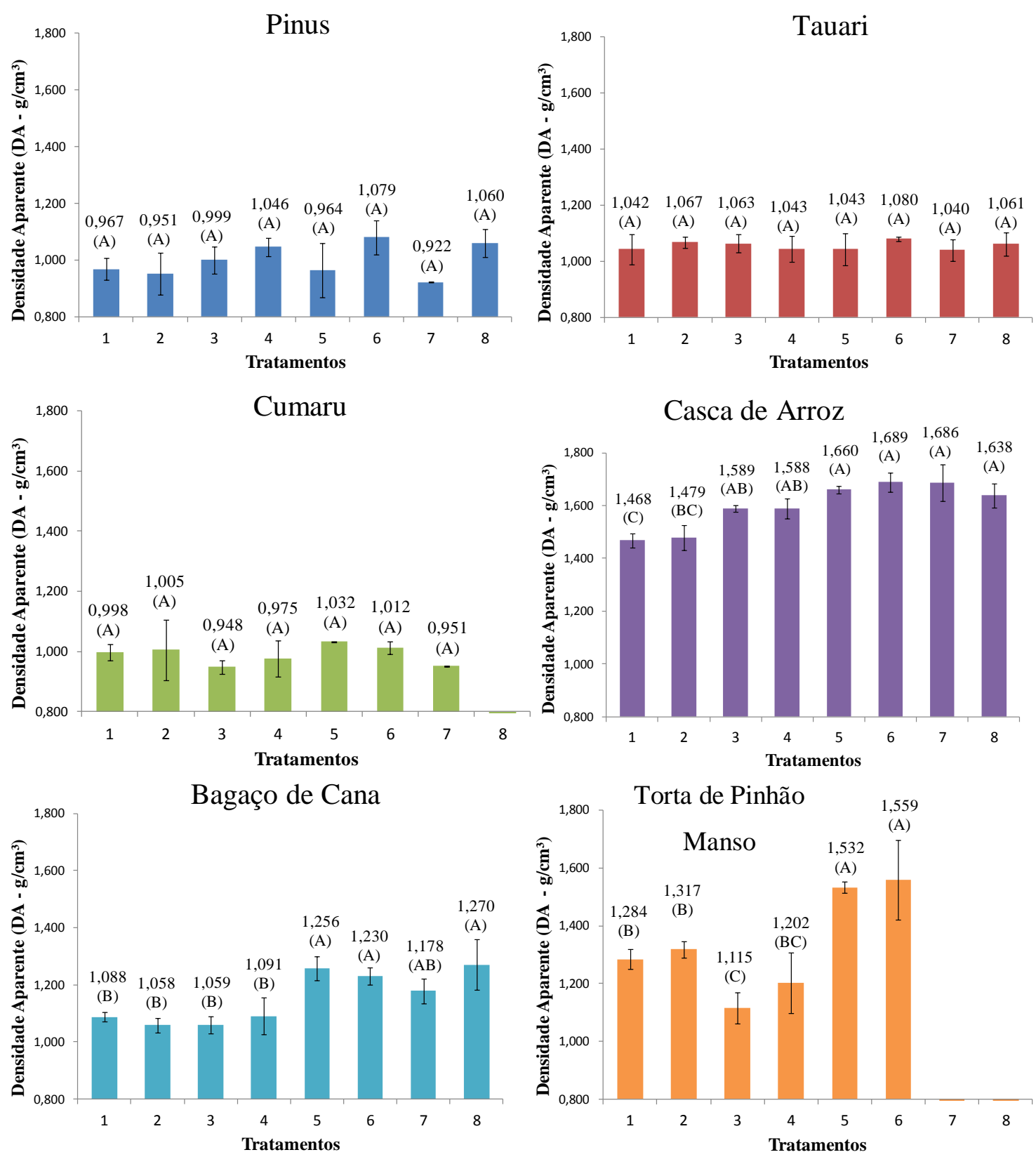

Figura 9. Valores da densidade aparente dos briquetes (DARX - $\mathrm{g} / \mathrm{cm}^{3}$ ) obtidos pelo método de raio-x, a partir das biomassas de pinus, tauari, cumaru, casca de arroz, bagaço de cana e torta de pinhão manso; em função dos oito tratamentos propostos. Onde: Letras diferentes para a mesma biomassa representam diferenças estatisticamente significativas entre os tratamentos pelo Teste Tukey a 5\% de significância.

Analisando a Figura 9, percebe-se que nos briquetes confeccionados com as biomassas florestais, a técnica de obtenção da densidade aparente pela emissão de radiação-x não 
detectou diferenças significativas entre os oito tratamentos, diferentemente dos resíduos agrícolas. Desta forma, os briquetes de pinus, tauari e cumaru se apresentaram em apenas uma classe de densidade aparente, sendo considerados como satisfatórios, pois apresentaram valores próximos ou superiores à $1 \mathrm{~g} / \mathrm{cm}^{3}$.

Com relação aos briquetes com resíduos agrícolas, os valores da densidade aparente também foram considerados como satisfatórios com a média superior a $1,2 \mathrm{~g} / \mathrm{cm}^{3}$, porém, destacam-se os altos valores obtidos para os briquetes com a biomassa da casca de arroz. Neste caso, a DARX variou entre 1,468 e $1,689 \mathrm{~g} / \mathrm{cm}^{3}$, para os tratamentos 1 e 6 , respectivamente. Possivelmente, o alto teor de sílica presente nesta biomassa fez com que se observasse este aumento expressivo na DARX. De acordo com Ramos e Paula et al. (2011), o teor de sílica pode chegar a $8 \%$ para esta biomassa, referente a um teor de cinzas de $22 \%$.

Para os parâmetros da briquetagem, a influência positiva do menor tamanho da partícula foi perceptível para os briquetes com bagaço de cana e torta de pinhão manso, apesar de neste último, não ter se conseguido briquetar nas condições dos tratamentos 7 e 8 . A DARX passou de aproximadamente 1,07 para cerca de $1,24 \mathrm{~g} / \mathrm{cm}^{3} \mathrm{com}$ a casca de arroz e variou entre 1,25 e $1,5 \mathrm{~g} / \mathrm{cm}^{3}$ para a torta de pinhão manso.

A temperatura influenciou positivamente apenas entre os tratamentos 1 e 3 dos briquetes da casca de arroz (de 1,468 para 1,589 $\mathrm{g} / \mathrm{cm}^{3}$ ) e negativamente entre os tratamentos 1 e 3 dos briquetes da torta de pinhão manso (de 1,284 para 1,115 $\mathrm{g} / \mathrm{cm}^{3}$ ). Ambos os casos foram observados utilizando as partículas grossas e baixa pressão de compactação. Este efeito se deu de forma menos evidente que para os valores da DA e DAHG, onde se utilizando de maior temperatura, de uma forma geral, maiores valores de densidade foram observados.

Observou-se que o efeito mais efetivo da temperatura tenha ocorrido nas bordas do briquete o que representa uma área menor que a área transversal do briquete. Por outro lado, o efeito negativo da temperatura ocorreu devido à uma possível degradação térmica causada à biomassa, reduzindo a massa do briquete e consequentemente a densidade aparente.

A pressão de compactação não influenciou de forma estatisticamente significativa os valores da DARX em nenhum dos tratamentos e em nenhuma das biomassas empregadas. 
As Figuras 10 a 15 mostram o perfil densitométrico médio para os briquetes confeccionados com as seis biomassas agroflorestais, onde os valores da densidade aparente foram obtidos ao longo do diâmetro dos briquetes por meio do raio-X
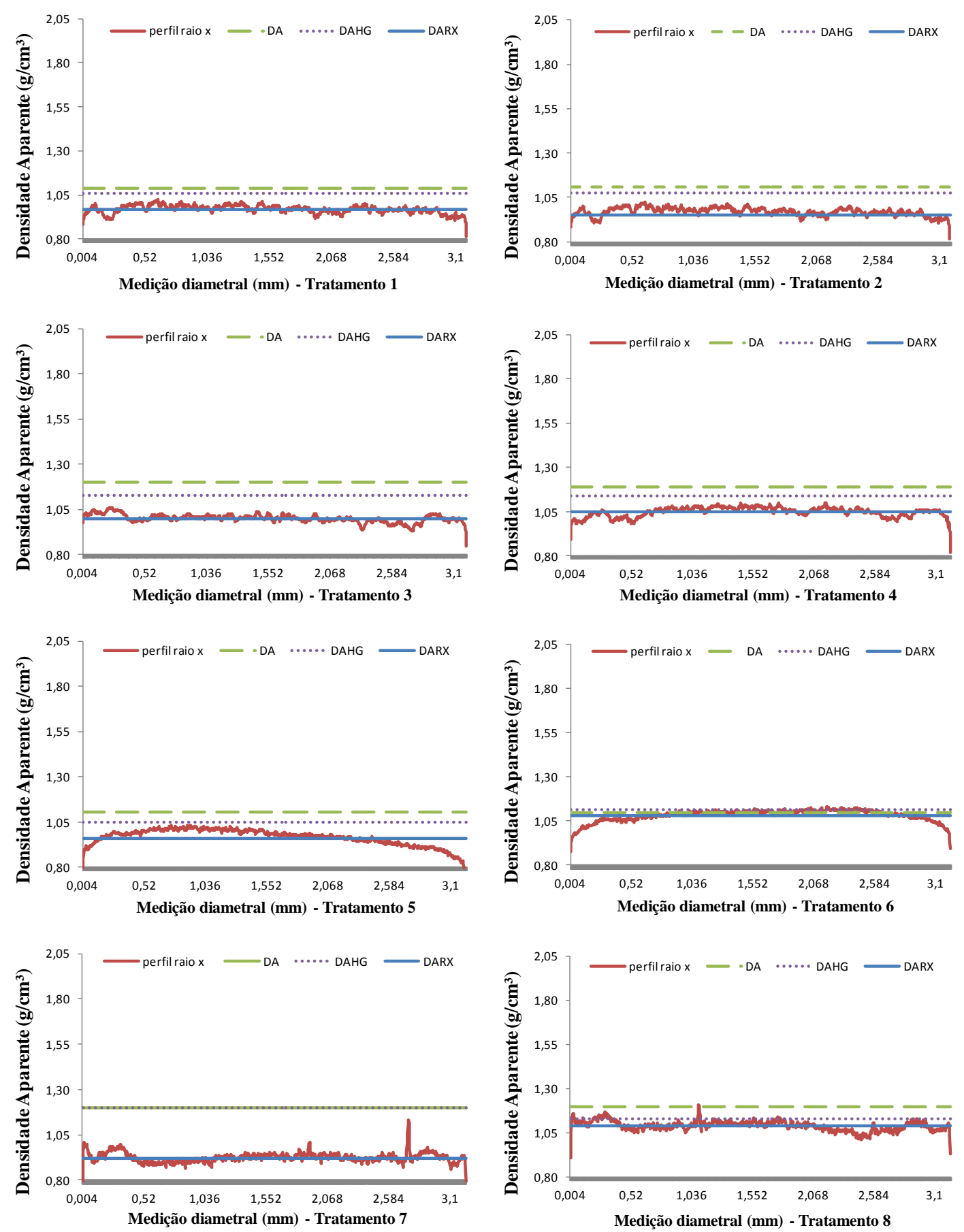

Figura 10. Perfil densitométrico obtido pelo método de raio- $x$ para os briquetes confeccionados com biomassa de pinus em função dos oito tratamentos propostos. Onde: DA - Densidade aparente média esteriométrica $\left(\mathrm{g} / \mathrm{cm}^{3}\right)$; DAHG - Densidade aparente média por imersão em mercúrio $\left(\mathrm{g} / \mathrm{cm}^{3}\right)$; e DARX - Densidade aparente média pelo raio-X $\left(\mathrm{g} / \mathrm{cm}^{3}\right)$. 

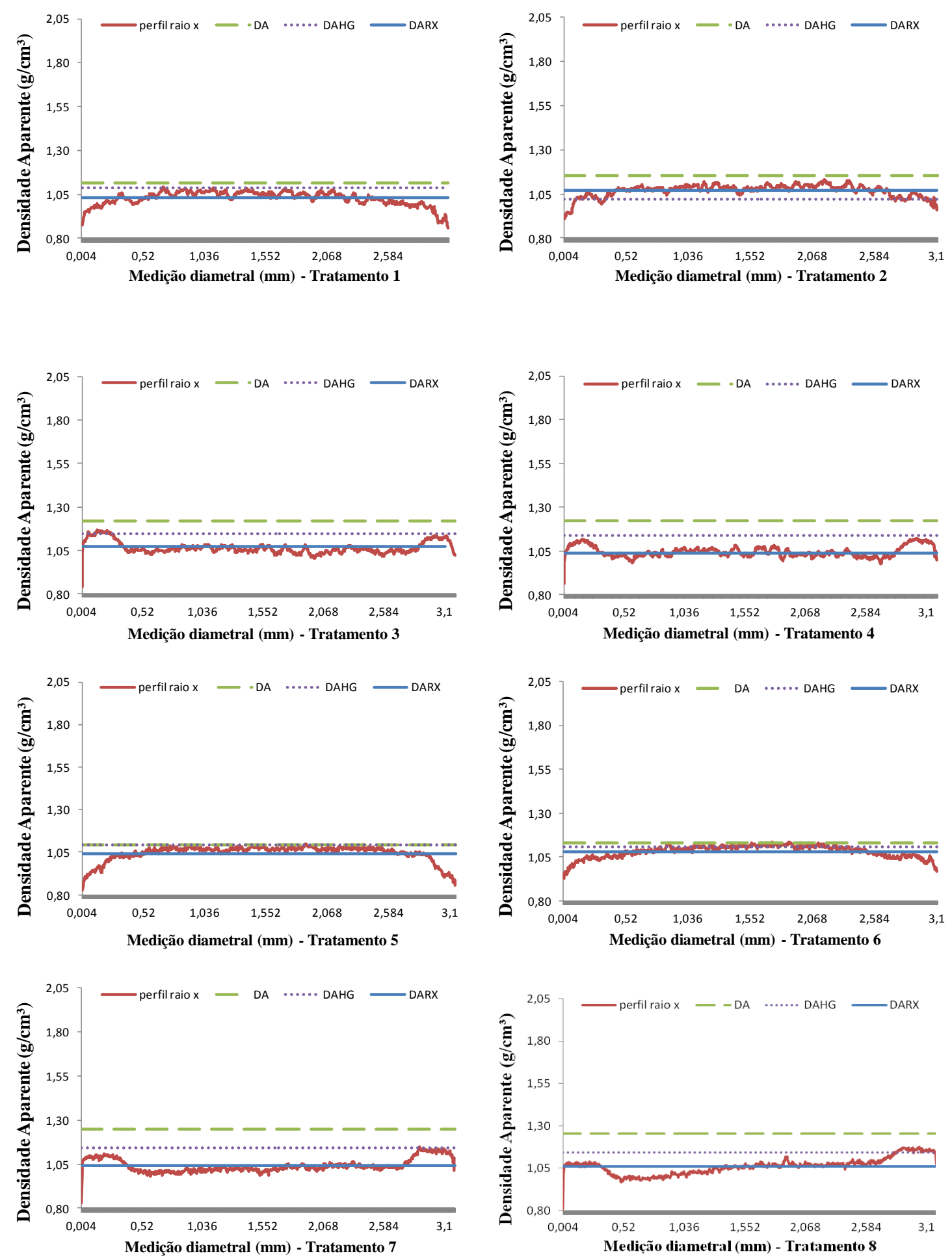

Figura 11. Perfil densitométrico obtido pelo método de raio- $x$ para os briquetes confeccionados com biomassa de tauari em função dos oito tratamentos propostos. Onde: DA - Densidade aparente média esteriométrica $\left(\mathrm{g} / \mathrm{cm}^{3}\right)$; DAHG - Densidade aparente média por imersão em mercúrio $\left(\mathrm{g} / \mathrm{cm}^{3}\right)$; e DARX - Densidade aparente média pelo raio-x $\left(\mathrm{g} / \mathrm{cm}^{3}\right)$. 

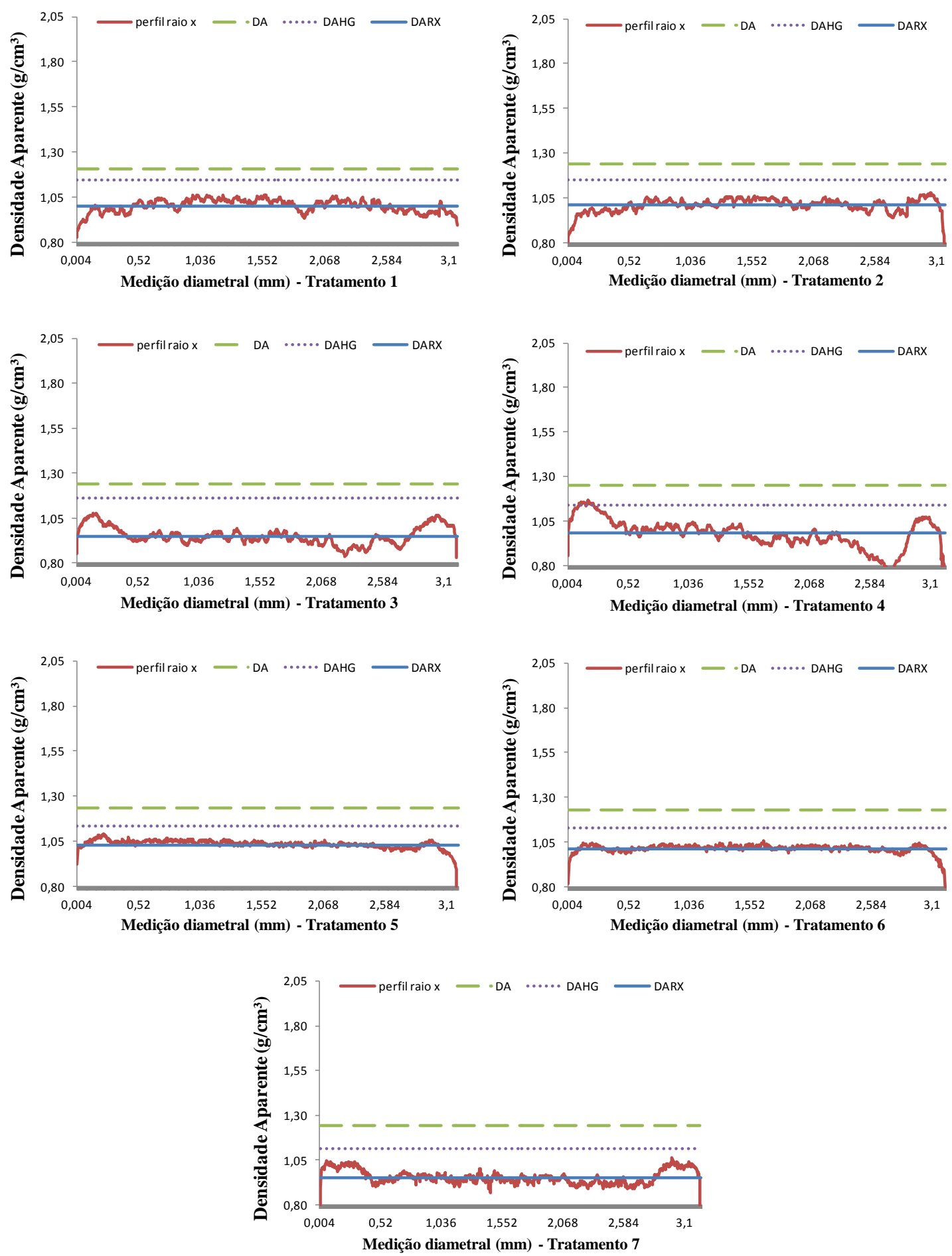

Figura 12. Perfil densitométrico obtido pelo método de raio-x para os briquetes confeccionados com biomassa de cumaru em função dos oito tratamentos propostos. Onde: DA - Densidade aparente média esteriométrica $\left(\mathrm{g} / \mathrm{cm}^{3}\right) ;$ DAHG - Densidade aparente média por imersão em mercúrio $\left(\mathrm{g} / \mathrm{cm}^{3}\right)$; e DARX - Densidade aparente média pelo raio-X $\left(\mathrm{g} / \mathrm{cm}^{3}\right)$. Não foi possível confeccionar os briquetes nas condições do tratamento 8 . 

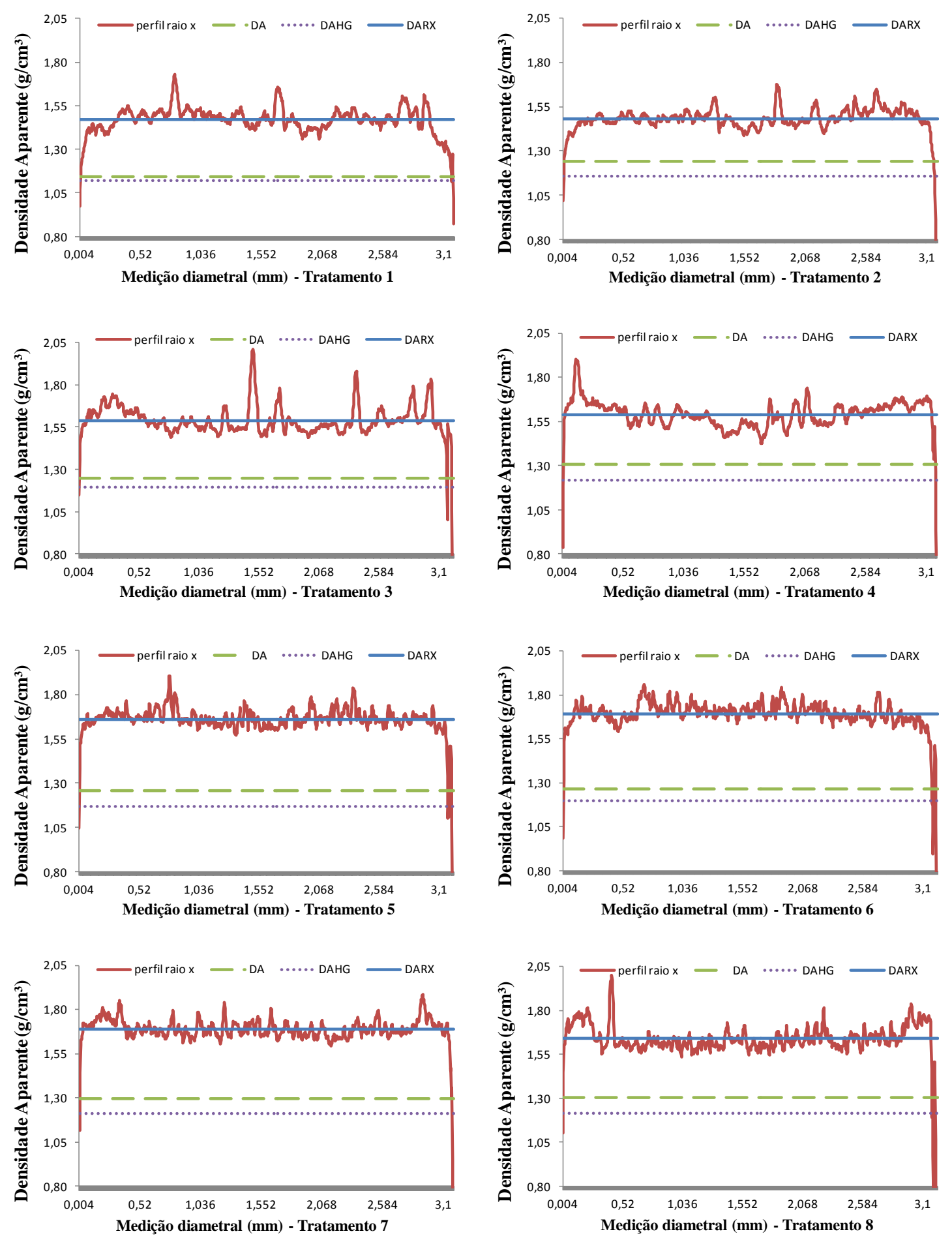

Figura 13. Perfil densitométrico obtido pelo método de raio-x para os briquetes confeccionados com biomassa da casca de arroz em função dos oito tratamentos propostos. Onde: DA - Densidade aparente média esteriométrica $\left(\mathrm{g} / \mathrm{cm}^{3}\right)$; DAHG - Densidade aparente média por imersão em mercúrio $\left(\mathrm{g} / \mathrm{cm}^{3}\right)$; e DARX - Densidade aparente média pelo raio-X $\left(\mathrm{g} / \mathrm{cm}^{3}\right)$. Não foi possível confeccionar os briquetes nas condições do tratamento 8 . 

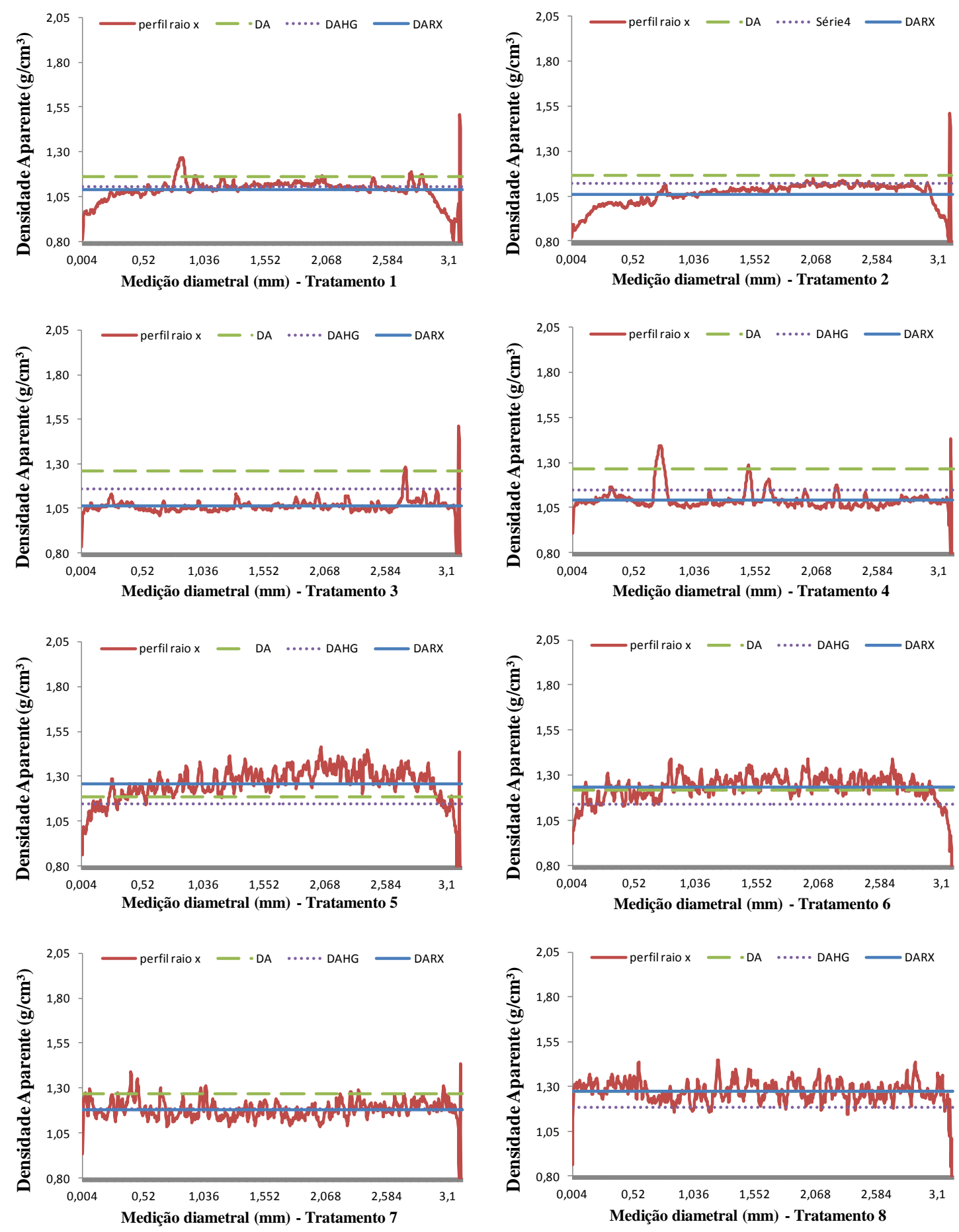

Figura 14. Perfil densitométrico obtido pelo método de raio-x para os briquetes confeccionados com biomassa de bagaço de cana em função dos oito tratamentos propostos. Onde: DA - Densidade aparente média esteriométrica $\left(\mathrm{g} / \mathrm{cm}^{3}\right)$; DAHG - Densidade aparente média por imersão em mercúrio $\left(\mathrm{g} / \mathrm{cm}^{3}\right)$; e DARX - Densidade aparente média pelo raio-X $\left(\mathrm{g} / \mathrm{cm}^{3}\right)$. 

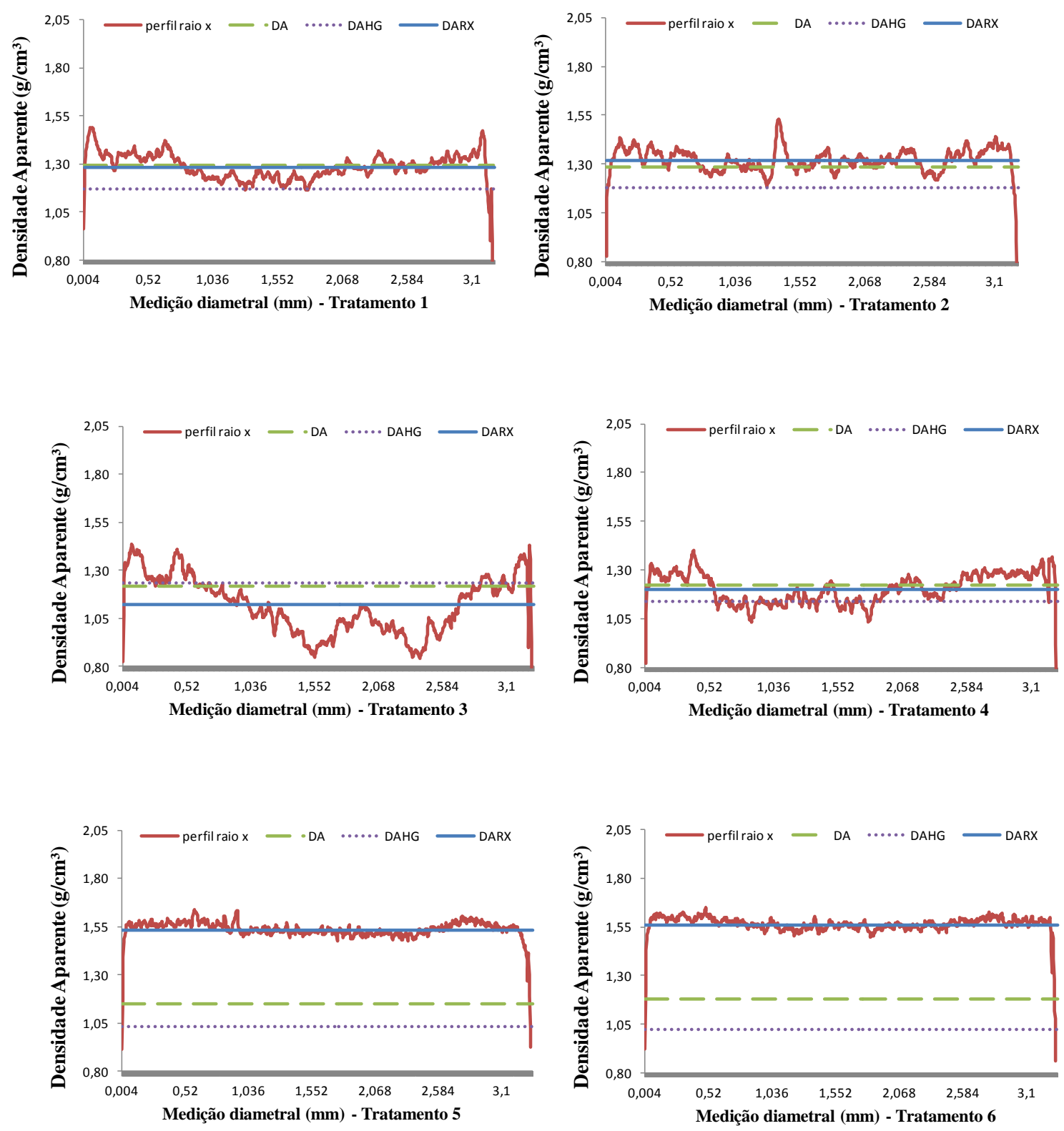

Figura 15. Perfil densitométrico obtido pelo método de raio-x para os briquetes confeccionados com biomassa da casca do pinhão manso em função dos oito tratamentos propostos. Onde: DA - Densidade aparente média esteriométrica $\left(\mathrm{g} / \mathrm{cm}^{3}\right)$; DAHG Densidade aparente média por imersão em mercúrio $\left(\mathrm{g} / \mathrm{cm}^{3}\right)$; e DARX - Densidade aparente média pelo raio-x $\left(\mathrm{g} / \mathrm{cm}^{3}\right)$. Não foi possível confeccionar os briquetes nas condições do tratamento 7 e 8 . 
Analisando os perfis densitométricos ilustrados nas Figuras 10 a 15 percebe-se que houve picos de densidade nas bordas até à profundidade de aproximadamente $5 \mathrm{~mm}$, nos briquetes de tauari e cumaru, apenas quando se empregou a temperatura de $200^{\circ} \mathrm{C}$ (tratamentos $3,4,7 \mathrm{e}$ 8) e independentemente do tamanho da partícula. Nos demais briquetes incluindo as demais biomassas, estes picos de densidade nas bordas não foram observados.

Quirino et al. (2012) observaram que o aumento da densidade aparente na borda do briquete se deu a uma profundidade de aproximadamente $5 \mathrm{~mm}$ a partir das bordas, sendo mais efetivo à $200^{\circ} \mathrm{C}$ e com partículas finas, nos briquetes com Eucalyptus sp. Este efeito de borda em consequência da alta temperatura de compactação foi bastante semelhante ao deste presente estudo.

Comparando-se a técnica do raio-x (DARX) com os outros métodos de determinação da densidade aparente (DA e DAHG), observa-se que, de uma forma geral, os valores obtidos da DARX se mostraram com valores médios inferiores aos obtidos para a densidade aparente pelo método estereométrico (DA) e pelo método de imersão em mercúrio (DAHG). Este comportamento foi observado para os briquetes de pinus, tauari, cumaru e bagaço de cana.

As exceções para este comportamento, DARX inferior à DA e DAHG, foram os valores da DARX para os briquetes confeccionados com a biomassa da casca de arroz, onde os valores médios para os oito tratamentos foram superiores aos valores médios da DA. De forma semelhante, nos tratamentos 5 e 6 dos briquetes com a torta de pinhão manso, a média da DARX foi superior às médias da DA e DAHG.

Portanto, comparando-se os métodos de avaliação da densidade aparente para briquetes (DA, DAHG e DARX) e considerando a maior precisão do método do raio-x com a determinação da densidade ponto a ponto por toda a extensão diametral do briquete, acredita-se que o valor da DARX seja considerado como mais próximo da realidade, recomendando a sua utilização para cálculos de densidade energética em empresas que utilizam fontes de energia renováveis em algum processo.

Contudo, deve-se avaliar a disponibilidade destes equipamentos, o valor de aquisição e instalação, assim como fatores intrínsecos à biomassa, como por exemplo, o teor de cinzas 
contido nas diversas biomassas existentes, pois, por serem materiais incombustíveis, elevaram a densidade aparente do briquete sem necessariamente aumentar a densidade energética final do produto.

Quirino et al. (2012) estudaram de forma preliminar a diferença existente entre a DAHG e a DARX em briquetes de Eucalyptus sp, variando-se a temperatura, a pressão e o tamanho da partícula na compactação. Assim, foi observado que os valores médios da DARX foram mais baixos que da DAHG, onde a diferença foi estatisticamente significativa ao nível de 5\%. De uma forma geral, os valores da DARX foram $14 \%$ menores que os valores da DAHG, corroborando os dados do presente estudo.

\subsubsection{DENSIDADE ENERGÉTICA ESTEREOMÉTRICA}

A Figura 16 apresenta os valores médios da densidade energética (DE, Gcal $/ \mathrm{m}^{3}$ ) dos briquetes com as seis diferentes de biomassas, obtidos pelo método estereométrico. 


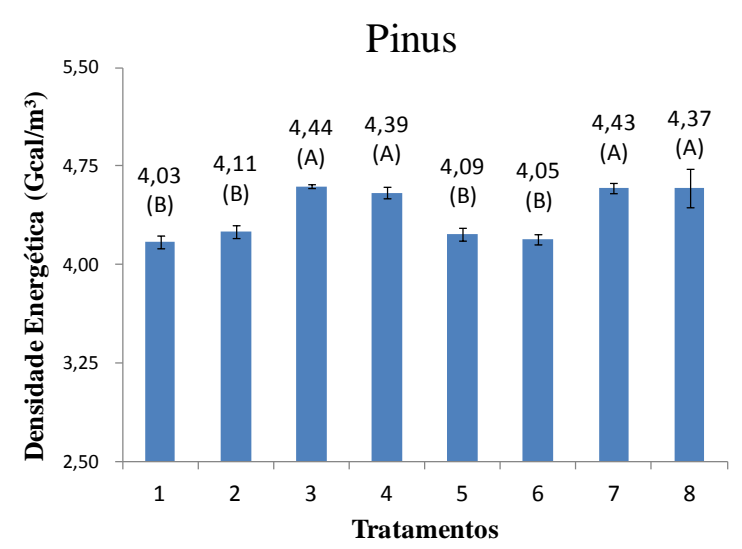

Cumaru
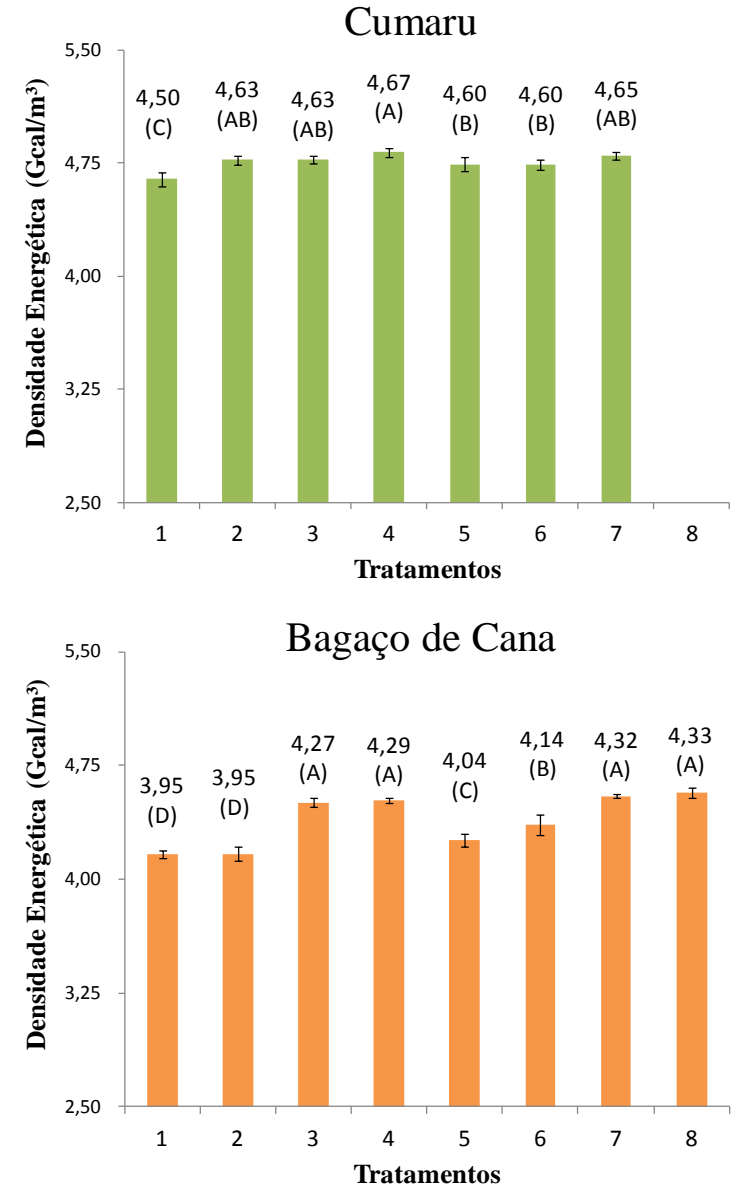

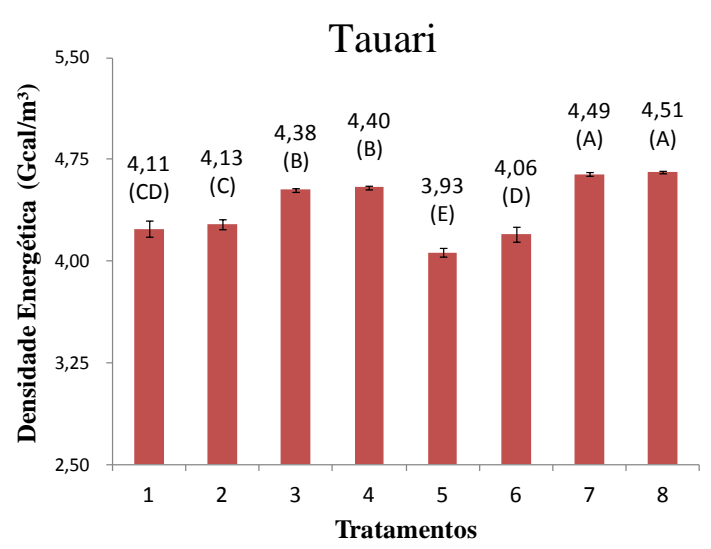

Casca de Arroz
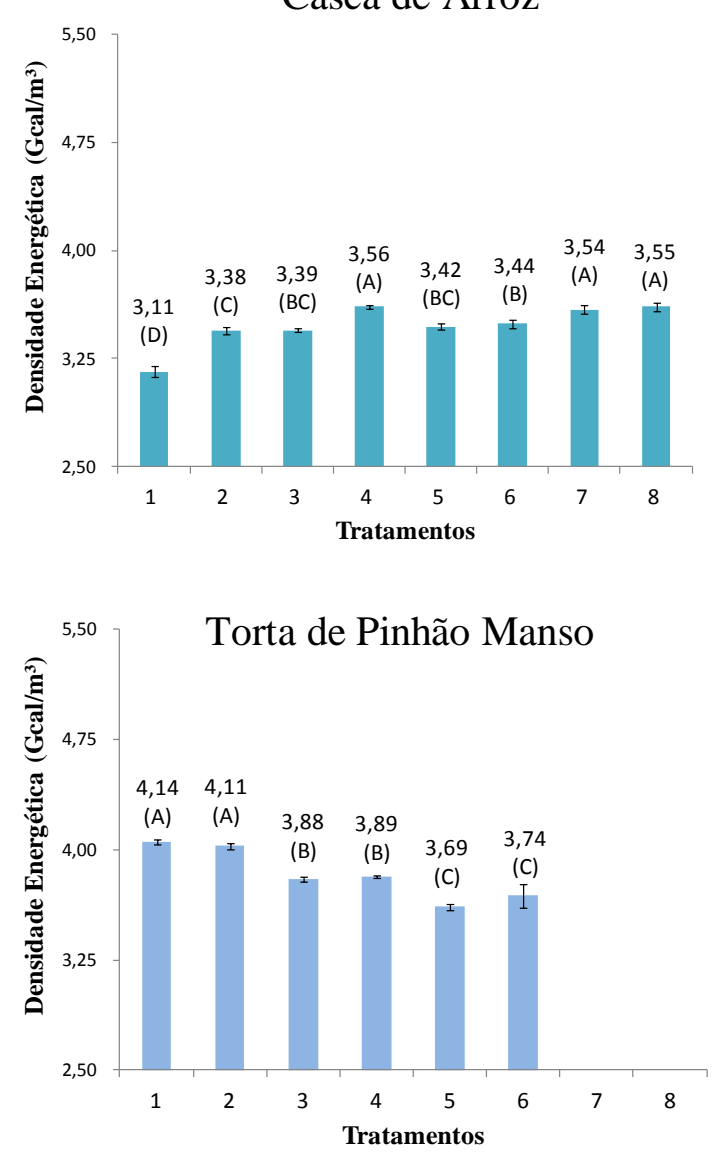

Figura 16. Valores da densidade energética dos briquetes (DE - Mcal $/ \mathrm{m}^{3}$ ) obtidos pelo método estereométrico, a partir das biomassas florestais de pinus, tauari e cumaru; em função dos oito tratamentos propostos. Onde: Letras diferentes para a mesma biomassa representam diferenças estatisticamente significativas entre os tratamentos pelo Teste Tukey a 5\% de significância. 
Desta forma, dentre os resíduos florestais, o valor mais elevado para a DE foi para os briquetes de cumaru, chegando a $4,67 \mathrm{Gcal} / \mathrm{m}^{3}$ e para os briquetes de tauari, cerca de 4,51 $\mathrm{Gcal} / \mathrm{m}^{3}$. Por outro lado, para os resíduos agrícolas, nos briquetes com bagaço de cana o valor atingiu $4,33 \mathrm{Gcal} / \mathrm{m}^{3}$ e os briquetes com a torta de pinhão manso, o valor da DE chegou a 4,14 $\mathrm{Gcal} / \mathrm{m}^{3}$.

Analisando os resultados da Figura 16, percebeu-se que o comportamento da densidade energética se mostrou semelhante ao comportamento da densidade aparente, onde de uma forma geral, maiores valores de densidade aparente determinaram maiores valores da densidade energética. Este fato foi observado tendo em vista uma relação diretamente proporcional entre estas variáveis e a condição semelhante de umidade após a climatização, proporcionando pouca variação no PCU.

Observou-se também que, de uma forma geral, nos tratamentos 3 e 4, assim como nos tratamentos 7 e 8 com o emprego de $200^{\circ} \mathrm{C}$, os valores da densidade energética foram os mais elevados não importando o tamanho da partícula envolvida. Entretanto, para a biomassa de tauari o valor médio da DE para os briquetes com partículas mais finas, passou de 4,39 para $4,50 \mathrm{Gcal} / \mathrm{m}^{3}$ considerando a temperatura de $200^{\circ} \mathrm{C}$.

Apenas nos briquetes com a biomassa de cumaru e da torta de pinhão manso este comportamento não foi observado. Para os briquetes com cumaru, os valores da DE foram mais homogêneos independentemente do tratamento empregado, variando entre 4,50 e 4,67 $\mathrm{Gcal} / \mathrm{m}^{3}$. Já para os briquetes de pinhão manso, houve um decréscimo no valor da $\mathrm{DE}$ tanto com o aumento da temperatura como pela redução no tamanho da partícula, provavelmente causado por uma degradação térmica na biomassa, que consequentemente reduziu a massa final do briquete e por fim, a sua densidade aparente. Conforme afirmativa anterior, os briquetes com a torta de pinhão manso apresentaram aspecto quebradiço para as condições de temperatura mais elevada.

De uma forma geral, o efeito da temperatura mais elevada foi mais significativo para o ganho final em quantidade de energia por unidade de volume $\left(\mathrm{Gcal} / \mathrm{m}^{3}\right)$ que os outros parâmetros da briquetagem, como o tamanho da partícula e a pressão de compactação. 
Com relação à pressão de compactação, em poucos casos houve ganho na DE aumentando-se de 80 para $120 \mathrm{kgf} / \mathrm{cm}^{2}$ durante a formação dos briquetes. O ganho em DE mais efetivo foi para os briquetes com a biomassa da casca de arroz utilizando as partículas grossas, onde o valor da DE passou de 3,11 para 3,38 Gcal/m² entre os tratamentos 1 e 2; assim como de 3,39 para $3,56 \mathrm{Gcal} / \mathrm{m}^{3}$ entre os tratamentos 3 e 4 . Por outro lado, considerando as partículas finas, a pressão de compactação não influenciou de forma estatisticamente significativa a DE para esta biomassa.

A densidade energética resume em um só valor as características da biomassa como a constituição química (análise elementar, imediata e macromolecular), as propriedades físicas (densidade) e a condição de umidade no momento da sua determinação. Neste sentido é possível observar diversas formas de cálculo desta característica, onde mais frequentemente é utilizado o poder calorífico superior ou inferior; a densidade a granel ou a densidade aparente (BARROS, 2012; PROTÁSSIO et al., 2011; FURTADO et al., 2010), além da possibilidade de uso do poder calorífico útil e da densidade do estéreo. Portanto deve-se atentar para a interpretação dos resultados da densidade energética, principalmente na comparação de biomassas.

Assim, a utilização do poder calorífico superior ou inferior para o cálculo da densidade energética deve ser compatibilizada pelo uso da densidade em condição seca, pois aquelas propriedades são determinadas para uma amostra seca de biomassa. Portanto, acredita-se que a forma que expressa a condição mais próxima da realidade referente ao conteúdo energético para os briquetes é o uso do poder calorífico útil e a densidade aparente

Segundo Protássio et al. (2011), a densidade energética foi determinada utilizando-se a densidade aparente a aproximadamente $6 \%$ de umidade do briquete e o poder calorífico superior, para as biomassas da casca do café, resíduos de milho e serragem de eucalipto. Para esta condição de cálculo da densidade energética o valor final possivelmente estaria superestimado, pois não se desconsiderou o teor de umidade do briquete, realizando o cálculo da DE em função do PCU. Desta forma, os valores de $5,69 \mathrm{Gcal} / \mathrm{m}^{3}$ para os briquetes da casca de café, $4,22 \mathrm{Gcal} / \mathrm{m}^{3}$ para os briquetes de resíduos de milho e $4,17 \mathrm{Gcal} / \mathrm{m}^{3}$ para os briquetes da serragem de eucalipto só poderiam ser comparados com os resultados do presente estudo após a correção destes valores, adotando o poder calorífico útil como variável de cálculo da 
densidade energética e convertendo os valores do teor de umidade em base seca para a base úmida, conforme descrito por Vale et al. (2007).

Furtado et al. (2010) também utilizou o poder calorífico superior e a densidade aparente a aproximadamente $9 \%$ de teor de umidade dos briquetes para a determinação da densidade energética dos briquetes com casca, cavacos e serragem de pinus. Para os briquetes confeccionados com a casca de pinus e utilizando-se $120^{\circ} \mathrm{C}$ e pressão de $132,5 \mathrm{kgf} / \mathrm{cm}^{2}$, o valor observado foi de 5,4 Gcal $/ \mathrm{m}^{3}$. Assim como no estudo de Protássio et al. (2011), o valor da densidade energética estaria superestimado, pois não foi levado em consideração o teor de umidade da biomassa.

Como forma comparativa, Barros (2012) determinou a densidade energética para os briquetes confeccionados com coco $\left(4,04 \mathrm{Gcal} / \mathrm{m}^{3}\right)$, sabugo de milho $\left(4,17 \mathrm{Gcal} / \mathrm{m}^{3}\right)$ e casca de maracujá $\left(4,46 \mathrm{Gcal} / \mathrm{m}^{3}\right)$. Neste estudo foi utilizado para o cálculo da DE o poder calorífico útil e a densidade aparente, com partículas mais grossas e temperatura de $130^{\circ} \mathrm{C}$, representando a metodologia mais aproximada à utilizada no presente estudo. Assim uma comparação é viabilizada por se tratar dos mesmos parâmetros, tanto na briquetagem como na forma de cálculo da densidade energética.

\subsubsection{DENSIDADE ENERGÉTICA POR IMERSÃO EM MERCÚRIO}

A Figura 17 apresenta os valores médios da densidade energética (DEHG, Gcal $/ \mathrm{m}^{3}$ ) dos briquetes com as seis diferentes biomassas, obtidos pelo método de imersão em mercúrio. 

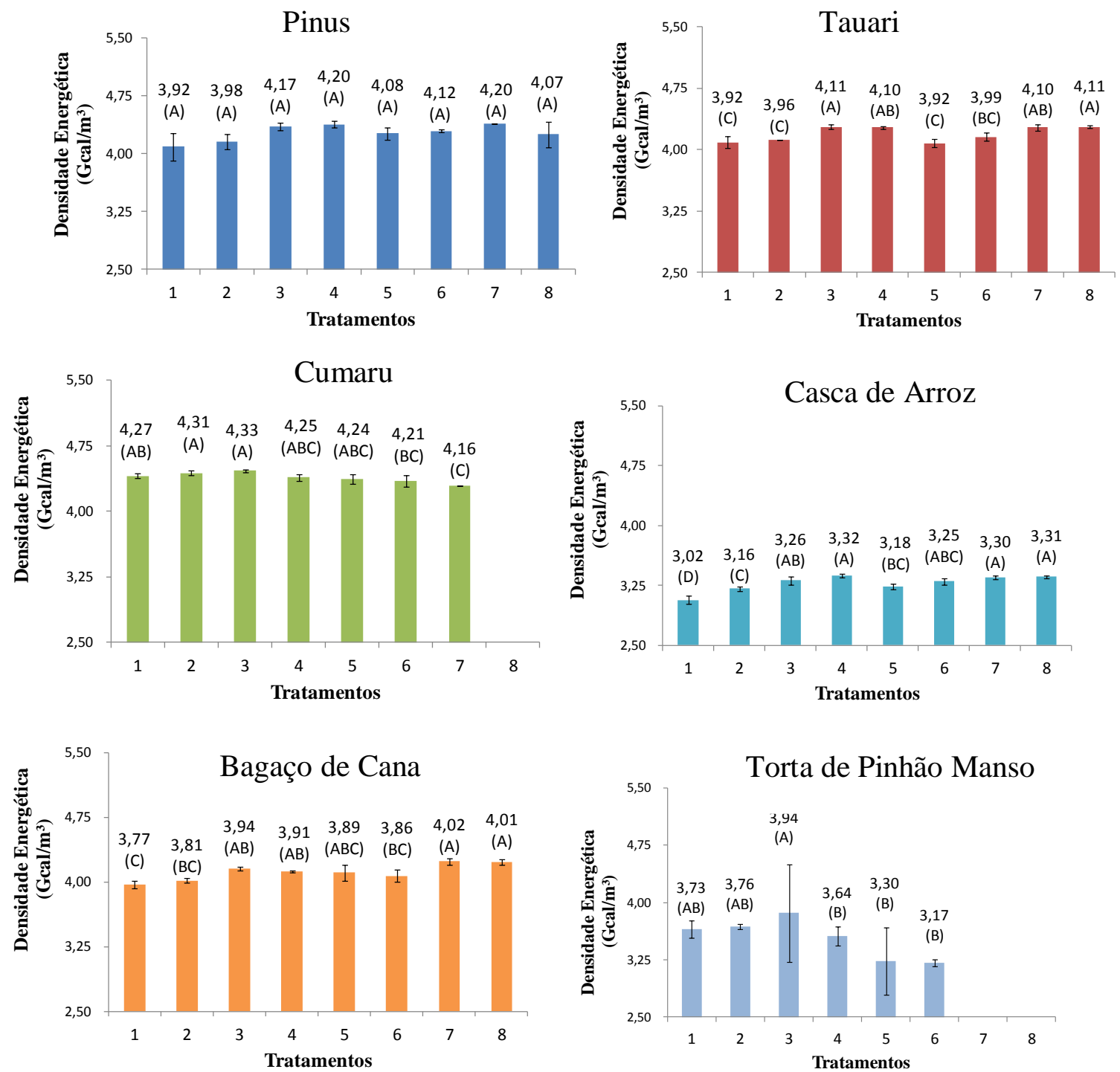

Figura 17. Valores da densidade energética dos briquetes (DEHG - Mcal $/ \mathrm{m}^{3}$ ) obtidos pelo método de imersão em mercúrio, a partir das biomassas florestais; em função dos oito tratamentos propostos. Onde: Letras diferentes para a mesma biomassa representam diferenças estatisticamente significativas entre os tratamentos pelo Teste Tukey a 5\% de significância.

A obtenção da densidade energética pelo método do deslocamento/imersão em mercúrio também se mostrou como alternativa para a determinação desta propriedade em briquetes, pois mostrou um controle experimental satisfatório, representado pelo desvio padrão dos tratamentos, que permaneceu entre 1 e $5 \%$ independentemente da biomassa utilizada. 
Comparando os resultados obtidos pela imersão em mercúrio com os resultados do método estereométrico, percebeu-se que aquele procedimento apresentou valores médios absolutos mais baixos, porém mais precisos, pois o formato do briquete foi levado em consideração assim como foi utilizado um material com propriedades conhecidas, o mercúrio.

Observou-se também que no método de imersão em mercúrio, houve uma tendência de uniformização dos resultados, diminuindo a diferença nos valores médios entre os oito tratamentos. Notou-se que os tratamentos 1, 2 ou 5 foram igualados estatisticamente em valor médio com os tratamentos 3, 4, 7 e 8 . Este fato ficou mais evidente para os briquetes de pinus, onde nenhum dos parâmetros da briquetagem influenciou de forma significativa estatisticamente o valor da DEHG.

O valor da densidade energética por este método permaneceu próximo de $4,0 \mathrm{Gcal} / \mathrm{m}^{3}$ para qualquer uma das seis biomassas empregadas na fabricação do briquete. Apenas os briquetes da casca de arroz e da torta de pinhão manso apresentaram a densidade energética por imersão em mercúrio próximo a 3,3-3,5 Gcal/ $/ \mathrm{m}^{3}$.

Ainda, nos briquetes com a biomassa da torta de pinhão manso, o desvio padrão foi bastante elevado nos seis tratamentos possíveis, em função dos resultados obtidos pela densidade aparente por imersão em mercúrio. Justifica-se este resultado conforme descrito anteriormente.

Contudo, conforme apresentado na Figura 17, percebeu-se que de uma forma geral, ainda existiu uma tendência de elevação da densidade energética para os tratamentos 3 e 4 (partículas grossas), assim como para os tratamentos 7 e 8 (partículas finas) utilizando-se a temperatura de $200^{\circ} \mathrm{C}$; fato evidenciado nos briquetes com a biomassa de tauari. Entretanto, houve uma diminuição acentuada no valor médio da densidade energética nos tratamentos com temperatura mais elevada, sugerindo assim, que os valores determinados pelo método estereométrico estejam superestimados

Para esta variável (DEHG), não houve uma tendência de aumento da densidade energética a partir de um aumento da pressão de compactação. Contudo, apenas para os briquetes de casca 
de arroz e a uma temperatura mais baixa (tratamentos 1 e 2) é que houve um ganho em valor médio, diferentes estatisticamente a 5\% de significância pelo Teste Tukey.

O tamanho da partícula apenas influenciou nos casos: negativamente para os briquetes de cumaru, onde entre os tratamentos 2 e 6, assim como entre os tratamentos 3 e 7, houve redução no valor médio da DE, passando de 4,31 para 4,21 e de 4,33 para $4,16 \mathrm{Gcal} / \mathrm{m}^{3}$, respectivamente. Nos demais briquetes, densidade energética não foi influenciada pelo tamanho da partícula, independentemente da biomassa utilizada para a confecção dos briquetes.

\subsubsection{DENSIDADE ENERGÉTICA POR RAIO-X}

A Figura 18 apresenta os valores médios da densidade energética (DERX, Gcal $/ \mathrm{m}^{3}$ ) dos briquetes com as seis diferentes de biomassas, obtidos pelo método do raio-x. 

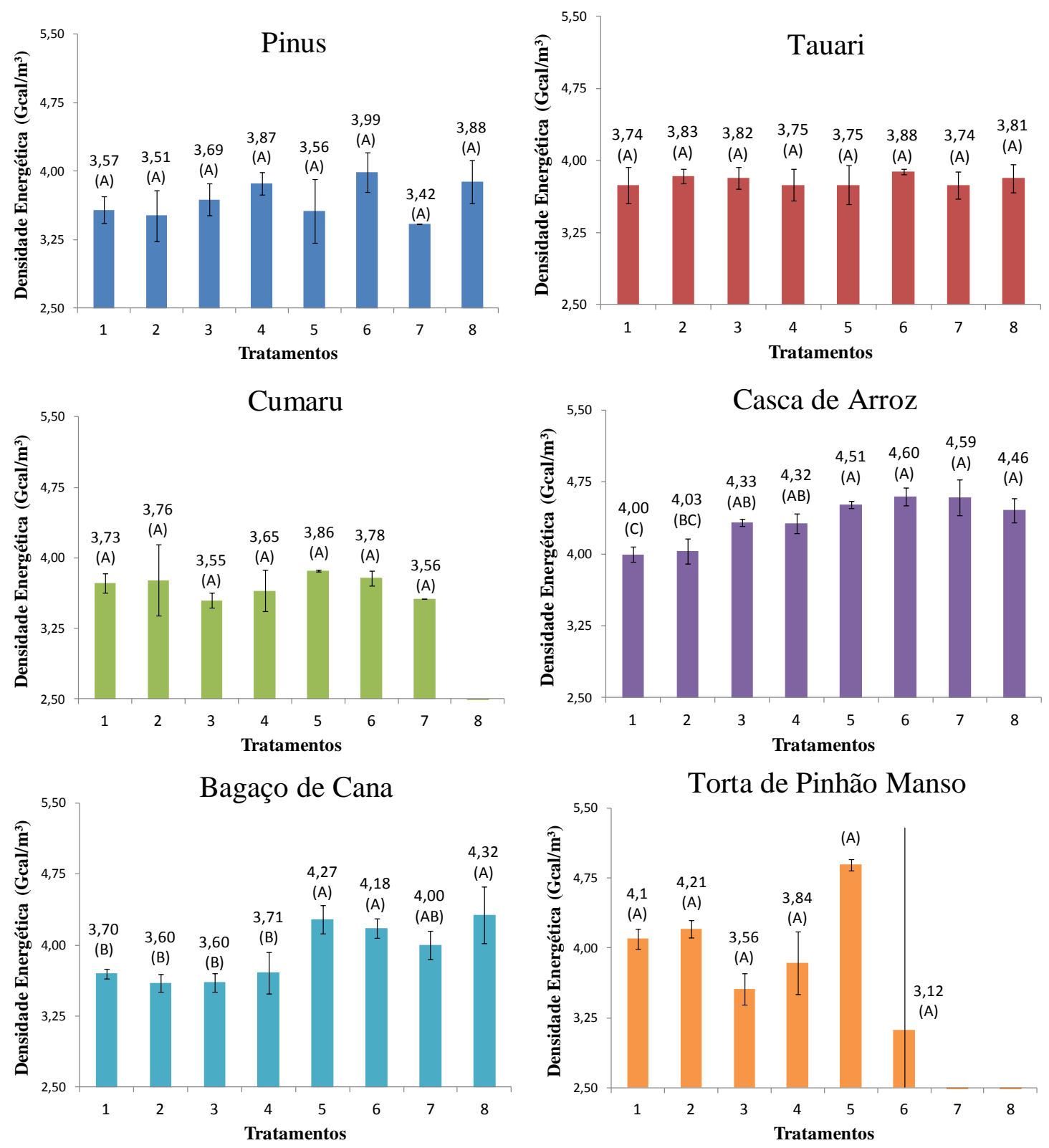

Figura 18. Valores da densidade energética dos briquetes (DERX - Mcal $/ \mathrm{m}^{3}$ ) obtidos pelo método de raio-x, a partir das biomassas florestais; em função dos oito tratamentos propostos. Onde: Letras diferentes para a mesma biomassa representam diferenças estatisticamente significativas entre os tratamentos pelo Teste Tukey a 5\% de significância.

O método do raio-x para a determinação da densidade energética também se mostrou como alternativa para a determinação desta propriedade em briquetes, pois se observou um controle experimental satisfatório, representado pelo desvio padrão dos tratamentos, que permaneceu entre 1 e $5 \%$ independentemente da biomassa utilizada. Apenas os briquetes do tratamento 6 
com a biomassa de pinhão manso foi que o desvio padrão foi bastante elevado, informação já discutida anteriormente.

Ao se comparar o método estereométrico (DE) com os dados de raio-x (DERX), percebeu-se que neste último, quando se utilizou das biomassas florestais, apresentou valores médios absolutos mais baixos, porém mais precisos, pois a densidade foi determinada ponto a ponto e por toda a extensão diametral do briquete. Assim os valores utilizados pelo método estereométrico para o cálculo da densidade energética mostraram-se superestimados. Comportamento semelhante foi observado para os briquetes com bagaço de cana quando se utilizou de partículas grossas.

Para os briquetes com a torta de pinhão manso, os valores da DE e DERX pouco variaram entre si. Por outro lado, nos briquetes com a casca de arroz, observou-se um aumento expressivo da densidade energética em função de um aumento da densidade aparente. Ainda, um alto conteúdo de cinzas, incluindo a sílica na biomassa da casca de arroz fez com que se aumentasse a DERX, atingindo o patamar de 4,60 $\mathrm{Gcal} / \mathrm{m}^{3}$, superando ainda os valores da DERX para os briquetes de biomassas florestais.

Sendo assim, recomenda-se cautela na utilização do raio-x para a determinação da densidade energética, pois biomassas que contenham altos valores de cinzas e baixo poder calorífico apesar de mostrarem altos valores de densidade energética, a quantidade de energia presente no briquete estaria superestimada visto que os materiais minerais são considerados como incombustíveis e isolantes térmicos.

$\mathrm{O}$ valor da densidade energética por este método permaneceu próximo de 3,5-4,0 Gcal/ $/ \mathrm{m}^{3}$ para qualquer uma das seis biomassas empregadas na fabricação do briquete. Apenas os briquetes da casca de arroz e do bagaço de cana (com partículas finas) apresentaram a densidade energética por imersão em mercúrio superiores $4,0 \mathrm{Gcal} / \mathrm{m}^{3}$.

Diferentemente da DE e DEHG, a DERX não foi influenciada pela temperatura, ou seja, um aumento da temperatura de compactação não proporcionou um aumento da densidade energética. 
Da mesma forma, para esta variável (DERX), não houve uma tendência de aumento da densidade energética a partir de um aumento da pressão de compactação.

O tamanho da partícula apenas influenciou nos casos: positivamente para os briquetes de bagaço de cana, variando entre 3,65 e $4,2 \mathrm{Gcal} / \mathrm{m}^{3}$; e para os briquetes da casca de arroz, onde variou de 4,0 para 4,5 Gcal $/ \mathrm{m}^{3}$ apenas quando se utilizou de menor temperatura de compactação $\left(130^{\circ} \mathrm{C}\right)$.

\section{CONCLUSÕES}

Conforme os resultados apresentados para o presente estudo pode-se concluir que:

- As biomassas apresentaram as propriedades energéticas (PCS, PCI, PCU, TCZ\%, TCF\%, TMV\% e teor de umidade) satisfatórias e de acordo com a literatura. Destaca-se que a biomassas agrícolas apresentaram elevados TCZ\% em função dos tratamentos culturais, como a adubação;

. Os valores da densidade energética ultrapassaram $4 \mathrm{Gcal} / \mathrm{m}^{3}$ na DE e DEHG, excetuando-se os briquetes com a torta de pinhão manso e casca de arroz, porém para DERX o efeito foi contrário e esta última biomassa mostrou maior desempenho para a densidade energética;

- A influência mais significativa para o aumento da densidade energética do briquete foi devido à variação da temperatura durante a formação do briquete, no método estereométrico e por imersão em mercúrio. De uma forma geral, quanto maior a temperatura de compactação $\left(200^{\circ} \mathrm{C}\right)$, maior o valor da densidade aparente e densidade energética. Para a DERX os parâmetros da briquetagem pouco influenciaram;

- A variação na pressão de compactação pouco influenciou nas propriedades finais do briquete, nos três métodos (estereométrico, imersão em mercúrio e raio-x); 
- A variação no tamanho da partícula pouco diferenciou a densidade aparente e energética entre os tratamentos. Em alguns casos a redução do tamanho da partícula foi favorável a estas variáveis e em outros casos, foi considerada desfavorável.

- O comportamento da densidade aparente e da densidade energética entre os métodos estereométrico e de imersão em mercúrio foram bastante semelhantes, independentemente da biomassa utilizada, entretanto, destacou-se uma tendência na uniformização dos valores médios utilizando-se a imersão em mercúrio;

. Os valores da densidade aparente e da densidade energética, determinados pelo método de imersão em mercúrio são mais baixos, porém, mais precisos comparativamente ao método estereométrico. Os valores obtidos pelo raio-x para estas variáveis são ainda mais baixos, excetuando-se os briquetes com a casca de arroz. Por outro lado, aquele método necessita de maiores investigações referentes à melhoria na metodologia e amostragem;

\section{REFERÊNCIAS BIBLIOGRÁFICAS}

ABOYADE, A. O.; HUGO, T. J.; CARRIER, M.; MEYER, E. L.; STAHL, R.; KNOETZE, J. H.; GORGEN, J. F. Non-isothermal kinetic analysis of the devolatilization of corn cobs and sugar cane bagasse in an inert atmosphere. Thermochimica Acta, v. 517, n. 2, p. 81-89. 2011.

ANTUNES, R. C. Briquetagem de carvão vegetal. Produção e Utilização de CarvãoVegetal Belo Horizonte. CETEC Outubro, 1982.

ARRIECHE, R.; VAN DYK, H.; SALONI, D., LEMASTER, R. Evaluation of the energy balance for the production of briquettes from biomass. Forest Product Journal, n. 61, v. 4, p. 302-309, 2011.

ASSOCIAÇÃO BRASILEIRA DE NORMAS TÉCNICAS. NBR 8112: Carvão vegetal: análise imediata, 1986.

ASSOCIAÇÃO BRASILEIRA DE NORMAS TÉCNICAS. NBR 8633: Carvão vegetal: determinação do poder calorífico, 1984.

BARROS, L. O. Densidade energética de briquetes produzidos a partir de resíduos agrícolas. 2012. 37f. Trabalho de Graduação (Graduação em Engenharia Florestal) - Faculdade de Tecnologia, Departamento de Engenharia Florestal, Unb, Brasília, 2012.

BELINI, U. L.; TOMAZELLO FILHO, M.; CASTRO, V. R.; MUNIZ, G. I. B.; LASSO, P. R. O. ; VAZ, C. M. P. Microtomografia de raios X (micro CT) aplicada na caracterização anatômica da madeira de folhosas e coníferas. Floresta e Ambiente, Rio de Janeiro. v. 18, n.1, p.30-36, 2011. 
BRAND, M. A. Energia da biomassa florestal. Rio de Janeiro: Interciência, 2010. 114p.

BRAND, M. A.; MUNIZ, G. I. B.; VALIN, M.; QUIRINO, W. F. Influência da pressão e material nas propriedades de briquetes de biomassa florestal. In: $1^{\circ}$ CONGRESSO BRASILEIRO SOBRE FLORESTAS ENERGÉTICAS, Belo Horizonte, 2009. Anais... Belo Horizonte: CBFE, 2009.

BRITO, J. O. Expressão da produção florestal em unidades energéticas. In Congresso Florestal Panamericano, 1, Congresso Florestal Brasileiro, 7, 1993, Curitiba, Anais...Curitiba: Sociedade Brasileira de Silvicultura, 1993, p.280-282.

BRITO, J. O.; BARRICHELO, L. E. G. Carvão vegetal de madeira de desbaste de Pinus. Circular Técnica IPEF, Piracicaba, v. 146, p. 1-12, jun. 1981.

BRITO, J. O.; BARRICHELO, L. E. G. Considerações sobre a produção de carvão vegetal com madeiras da Amazônia. n. 2. 1981. 25p. (Série Técnica. IPEF).

CALEGARI, L.; FOELKEL, C. E. B.; HASELEIN, C. R.; ANDRADE, J. L. S.; SILVEIRA, P.; SANTINI, E. J. Características de algumas biomassas usadas na geração de energia no sul do Brasil. Biomassa \& Energia, v. 2, n. 1, p. 37-46. 2005.

CASTRO, V.R. Aplicação de métodos modernos não destrutivos de caracterização da estrutura anatômica e das propriedades físicas do lenho de árvores em pé: espécies nativas e introduzidas em plantações florestais. 2011. 106p. Dissertação (Mestrado em Recursos Florestais) - Escola Superior de Agricultura "Luiz de Queiroz", Universidade de São Paulo, Piracicaba, 2011.

CHAGAS, S. F. (2013). Propriedades da madeira de Tectona grandis (L.f.), visando a sua utilização para peças preservadas. Dissertação (Mestrado em Ciência Florestal), Departamento de Engenharia Florestal, Universidade Federal de Viçosa, Viçosa-MG, 78p.

CHEN, S.; LIU, X.; FANG, L.; WELLWOOD, R. Digital X-ray analysis of density distribuition characteristics of wood-based panels. Wood Science and Technology, n. 44, p. 85-93, 2010.

COWN, D. J.; CLEMENT, B. C. A wood densitometer using direct scanning with X-rays. Wood Science and Technology, n. 17, p. 91-99, 1983,

FURTADO, T. S.; VALIN, M.; BRAND, M. A.; BELLOTE, A. F. J. Variáveis do processo de briquetagem e qualidade de briquettes de biomassa florestal. Pesquisa Florestal Brasileira, Colombo, v. 30, n. 62, p. 101-106, 2010.

GOMIDE, R. Estequiometria industrial. 3ª ed. São Paulo: 1984. 423 p.

HORST, D. (2013). Avaliação da produção energética a partir de ligninas contidas em biomassas. Dissertação (Mestrado em Engenharia de Produção) - Programa de pós-graduação em engenharia de produção, Universidade Tecnológica Federal do Paraná, Ponta Grossa-PR. 106f.

IWAKIRI, S.; ALBUQUERQUE, C. E. C.; PRATA, J. G.; COSTA, A. C. B. Utilização da madeira de Eucalyptus grandis e Eucalyptus dunnii para produção de painéis de partículas orientadas - OSB. Ciência Florestal, Santa Maria, v. 18, n. 2, p. 265-270, 2008.

JENKINS, B. M. Fuel properties for biomass materials. In: INTERNATIONAL SYMPOSIUM ON APPLICATION AN MANAGEMENT OF ENERGY IN AGRICULTURE: THE ROLE BIOMASS FUELS, 1., 1990, New Delhi. Proceedings... Ludhiana: Punjab Agricultural University, 1990. p. 21-23. 
KALIYAN, N.; MOREY, R. V. Factors affecting strength and durability of densified biomass products. Biomass and Bioenergy, v. 33, n. 3, p. 337-359. 2009.

KARUNANITHY, C.; WANG, Y.; MUTHUKUMARAPPAN, K.; PUGALENDHI, S. Physiochemical characterization of briquettes made from different feedstocks. Biotechnology Research International, v. 2012, n. 1, p. 1-12. 2012.

KNAPIC, S.; PIRRALHO, M.; LOUZADA, J. L.; PEREIRA, H. Early assessment of density features for 19 Eucalyptus species using X-ray microdensitometry in a perspective of potential biomass production. Wood Science and Technology, v. 1, n. 48, p. 37-50, 2014.

KURNIAWAN, A.; ISMADJI, S. Potential utilization of Jatropha curcas L. press cake residue as new precursor for activated carbon preparation: Application in methylene blue removal from aqueous solution. Journal of the Taiwan Institute of Chemical Engineers, v. 42, p. 826-836. 2011.

LABEGALINI, A. (2013). Obtenção de biochar a partir da pirólise rápida da torta de pinhão manso: uso como adsorvente e suporte. Dissertação (Mestrado em Agroquímica), Instituto de Química Ambiental, Universidade Federal de Lavras, Lavras-MG, 116p.

MACEDO, L. A. (2012). Influência da composição da biomassa no rendimento em condensáveis do processo de torrefação. Dissertação (Mestrado em Ciências Florestais), Departamento de Engenharia Florestal, Universidade de Brasília, Brasília-DF, 49p.

MORAIS, M. R., SEYE, O.; FREITAS, K. T. Obtenção de briquetes de carvão vegetal de cascas de arroz utilizando baixa pressão de compactação.. In: ENCONTRO DE ENERGIA NO MEIO RURAL, 6., 2006, Campinas. Anais... Disponível em:<http://www.proceedings.scielo.br/scielo.php?script=sci_arttext\&pid=MSC00000000220 06000200019\&lng=en\&nrm=abn>. Acesso em: 19 Sep. 2014.

OLAKEJI, J. T.; ENWEREMADU, C. C. The effects of some processing parameters on physical and densification characteristics of corncob briquettes. International Jounal of Energy Engineering, n. 2, v. 1, p. 22-27. 2012.

PAULA, L. E. R.; TRUGILHO, P. F.; NAPOLI, A.; BIANCHI, M. L. Characterization of residues from plant biomass for use in energy generation. Cerne, v. 17, n. 2, p. 237-246. 2011.

PINHEIRO, G. F.; RENDEIRO, G.; PINHO, J. T. Densidade energética de resíduos vegetais. Biomassa \& Energia, v. 2, n. 2, p. 113-123. 2005.

PROTÁSSIO, T. P.; ALVES, I. C. N.; TRUGILHO, P. F.; SILVA, V. O.; BALIZA, A. E. R. Compactação de biomassa vegetal visando à produção de biocombustíveis sólidos. Pesquisa Florestal Brasileira, Colombo, v. 31, n. 68, p. 273-283, 2011.

QUIRINO, W. F.; PINHA, I. V. O.; MOREIRA, A. C. O. M.; SOUZA, F.; TOMAZELLO FILHO, M. Densitometria de raios x na análise da qualidade de briquetes de resíduos de madeira. Scientia Forestalis, v. 40, n. 96, p. 525-536. 2012.

QUIRINO, W. F.; VALE, A. T.; ANDRADE, A. P. A.; ABREU, V. L. S.; AZEVEDO, A. C. S. Poder calorífico da madeira e de resíduos lignocelulósicos. Biomassa \& Energia, v. 1, n. 2, p. 173-182. 2004.

QUIRINO, W.F.; BRITO, J.O. Características e índice de combustão de briquetes de carvão vegetal. Brasília: IBAMA / LPF- Laboratório de Produtos Florestais, 1991. (Série Técnica, n.13). 
RAMOS E PAULA, L. E.; TRUGILHO, P. F.; REZENDE, R. N.; ASSIS, C. O.; BALIZA, A. E. R. Produção e avaliação de briquetes de resíduos lignocelulóscos. Pesquisa Florestal Brasileira, Colombo, v. 31, n. 66, p. 103-112, 2011.

RIBEIRO, R. F. L. (2012). Avaliação de tortas de oleaginosas com potencial para produção de biodiesel na obtenção de materiais adsorventes para remoção de metais em meio aquoso. Tese (Doutorado em Química), Departamento de Química, Universidade Federal de Minas Gerais, Belo Horizonte-MG, 159p.

SILVA, C. V. (2013). Caracterização do bio-óleo produzido por pirólise rápida do bagaço de cana de açúcar. Dissertação (Mestrado em Química), Instituto de Química, Universidade Federal de Uberlândia, Uberlândia-MG, 90p.

SOUZA, F.; TELES, R. F.; RIBEIRO, P. G.; CAMARGOS, A. M.; DEL MENEZZI, C. H. S. Resistência natural e alteração da cor da madeira de Machaerium scleroxylon Tul. submetida ao ataque de fungos apodrecedores. Scientia Forestalis, v. 38, n. 87, p. 449-457, 2010a.

SOUZA, M. M.; SILVA, D. A.; ROCHADELLI, R.; SANTOS, R. C. Estimativa de poder calorífico e caracterização para uso energético de resíduos da colheita e do processamento de Pinus taeda. Floresta, v. 42, n. 2, p. 325-334. 2012a.

SOUZA, S. N. M.; VIEIRA, A. C.; SANTOS, R. F.; SECCO, D.; BARICCATTI, R. A.; NOGUEIRA, C. E. C. Potencial de geração de bioeletricidade com casca de arroz no Brasil. Cultivando o Saber, v. 5, n. 1, p. 1-8. 2012 b.

TECHNICAL ASSOCIATION OF PULP AND PAPER - TAPPI. Sampling and preparation wood for analysis. T $257 \mathrm{om}-88$. TAPPI, test chemical, Atlanta, TAPPI press, 1996a.

VALE, A. T.; GENTIL, L. V.; GONÇALEZ, J. C.; COSTA, A. F. Caracterização energética e rendimento da carbonização de resíduos de grãos de café (Coffea arabica) e de madeira (Credrelinga catenaeformis). Cerne, Lavras. V.13, n.4, p.416-420, out./dez 2007

VALE, A. T.; MENDES, R. M.; AMORIM, M. R. S.; DANTAS, V. F. S. Potencial energético da biomassa e carvão vegetal do epicarpo e da torta de pinhão manso (Jatropha curcas). Cerne, v. 17, n. 2, p. 267-279. 2011. 


\section{INFLUÊNCIA DOS PARÂMETROS DA BRIQUETAGEM NA AVALIAÇÃO NÃO DESTRUTIVA E NA RESISTÊNCIA MECÂNICA DE BRIQUETES}

\section{INTRODUÇÃO}

A briquetagem consiste em triturar resíduos vegetais e adensá-los a partir da aplicação de altas pressões e com elevação da temperatura. Desta forma, tem-se uma plastificação ou amolecimento da lignina, o que promove uma maior interação química entre as partículas, conferindo ao produto final, consistência e uma estrutura bem definida (QUIRINO, 1991).

$\mathrm{Na}$ indústria, os briquetes são formados a partir de diversas biomassas agroflorestais empregando-se diferentes pressões e temperaturas de compactação (QUIRINO et al, 2005) conforme a disponibilidade da biomassa e condições de umidade da matéria prima (QUIRINO et al, 2004), entretanto, as características finais do produto, como as propriedades mecânicas são pouco conhecidas e os métodos para a determinação das propriedades energéticas são demorados e a partir de equipamentos onerosos de laboratório.

Para Ross et al. (1998) a ciência de identificar as propriedades físicas e mecânicas de uma amostra é mundialmente conhecida como avaliação não destrutiva (AND) ou ensaio não destrutivo (END), termo oriundo do non destructive evaluation (NDE) ou non destructive testing (NDT) (PELLERIN e ROSS, 2002).

Diversas são as vantagens na utilização dos métodos não destrutivos para a caracterização da madeira ou derivados, em relação aos métodos tradicionais de laboratório. Cita-se a manutenção da integridade estrutural das amostras, sem a necessidade de se retirar corpos de prova assim como também são possíveis análises rápidas e confiáveis de propriedades mecânicas, físicas e químicas (ROSS et al, 1999; OLIVEIRA e SALES, 2002). Ainda, tais 
informações obtidas podem ajudar na tomada de decisões, resguardando uma aplicação apropriada.

Nas avaliações utilizando o ultra-som, por exemplo, o corpo-de-prova pode ser a própria árvore, peças pequenas e isentas de defeitos obtidos de madeira maciça, peças de tamanho estrutural ou ainda compósito à base de madeira (PUCCINI, 2002).

Os estudos empregando as técnicas não destrutivas têm se baseado na utilização tanto do equipamento Stress Wave quando do Ultrassom na classificação de lâminas para a confecção de compensados (CARVALHO, 2004) e LVL - laminated veneer lumber (MELO, 2012; SOUZA et al, 2011; GABRIEL, 2007), onde essa classificação das lâminas pode conferir propriedades de resistência mais seguras e precisas aos painéis (BULIGON, 2011). Ainda, são utilizadas para a avaliação e predição da resistência mecânica em árvores em pé e posteriormente transformadas em tábuas (STANGERLIN et al, 2010), em postes de madeira (MINÁ et al, 2004) ou em vigas (OLIVEIRA et al, 2006).

De acordo com Morales (2006) a utilização do equipamento de ultrassom apresenta características semelhantes à utilização do stress wave por se basearem em propriedades acústicas da madeira e derivados, entretanto, no ultrassom as ondas são induzidas com mais altas frequências e por transdutores, enquanto para o stress wave as ondas são geradas por impacto. Ambos os métodos baseiam-se nos princípios da propagação de ondas acústicas e nas correlações existentes entre as velocidades de transmissão e as propriedades elásticas da madeira. (BODIG, 2001).

Ainda de acordo Morales (2006), o equipamento stress wave baseia-se em baixos movimentos moleculares de tensão para medir duas propriedades fundamentais dos materiais que são: a energia armazenada (representada pela velocidade com a qual a onda percorre a amostra) e a dissipação (fração dissipada de energia pelo fenômeno da atenuação).

O grande entrave para a aplicação dos métodos não destrutivos em briquetes está baseado na atenuação das ondas ou decréscimo acústico, determinado pela redução da amplitude da onda e redução da intensidade à medida que esta se afasta da origem (ROSS e PELLERIN, 1998). 
Por se tratarem de materiais constituídos totalmente de partículas com granulometrias variadas e com pouca ou nenhuma continuidade de tecidos da biomassa que lhe deu origem (QUIRINO, 1991), os briquetes podem ser classificados como materiais atenuantes para a propagação das ondas de tensão e ultrassônicas.

De acordo com Morales (2006) a influência do material na propagação da onda pode ser dividida de duas formas: primeiramente pela dispersão, onde pela não homogeneidade do material, cada vez que a onda encontrar um obstáculo não alinhado à sua propagação, a onda se dividirá em onda incidente e onda transmitida. A segunda forma trata-se da absorção, que consiste na conversão da energia sonora em calor e pode ser entendida como a redução da oscilação das partículas.

Para Azevedo Júnior (2002) a atenuação das ondas está relacionada aos desvios de energia do feixe paralelo pelos fenômenos de reflexão, refração, difração e dispersão (espalhamento), assim como pela absorção energética, em que parte da energia mecânica das partículas oscilantes é covertida em calor, devido ao atrito interno entre as mesmas.

Considerando o exposto, este capítulo teve como objetivo principal avaliar a influência dos parâmetros da briquetagem (biomassa, granulometria, pressão e temperatura) na resistência mecânica e na avaliação não destrutiva por ondas de tensão e ultrassônica em briquetes confeccionados com seis diferentes biomassas agroflorestais. Como objetivo complementar verificou-se a viabilidade de se empregar os ensaios não destrutivos por meio da velocidade de propagação da onda, na predição da resistência mecânica e do conteúdo energético em briquetes.

\section{MATERIAL E MÉTODOS}

As análises e ensaios com as matérias-primas (biomassas) foram realizados no Laboratório de Tecnologia da Madeira do Departamento de Engenharia Florestal da Universidade de Brasília (EFL/UnB) e nos Setores de Energia da Biomassa, Setor de Química, Adesivos e Borracha Natural e no Setor de Engenharia e Física da Madeira do Serviço Florestal Brasileiro (SFB), que está vinculado ao Ministério do Meio Ambiente (MMA). 
A determinação da densidade aparente pelo método de imersão em mercúrio foi realizada no Laboratório de Anatomia da Madeira na Escola Superior de Agricultura Luiz de Queiroz (ESALQ), vinculado à Universidade de São Paulo (USP).

\subsection{OBTENÇÃO DAS BIOMASSAS AGROFLORESTAIS}

Para este estudo foram selecionadas seis diferentes biomassas, incluindo três materiais oriundos da obtenção de madeira serrada ( $2^{\mathrm{a}}$ transformação) e três oriundos de processos industriais de produção de alimentos, etanol e biodiesel.

Com relação às biomassas de origem florestal, foram selecionadas as espécies Pinus (Pinus spp.), Tauari (Couratari guianensis Aubl.) e Cumarú (Dipteryx odorata Aubl. Willd.), identificadas macroscopicamente por meio da comparação com as amostras da Xiloteca (Index Xylarium FPBw) do Laboratório de Produtos Florestais (LPF/SFB).

Tais espécies de madeiras foram selecionadas devido à presença constante no mercado madeireiro na região de Brasília-DF e por abrangerem uma ordem crescente de densidade básica, respectivamente. As amostras foram adquiridas de uma madeireira particular, na forma de pranchas com dimensões aproximadas de 200 x 20 x 4,5 cm (comprimento x largura $\mathrm{x}$ espessura), com massa aproximada de $15 \mathrm{~kg}$ para cada uma das espécies.

Para as biomassas de origem agrícola selecionou-se a casca de arroz (Oriza sativa L.), bagaço-de-cana (Saccharum officinarum) e torta de pinhão-manso (Jatropha curcas L.), por representarem atividades agrícolas importantes para a região do Centro-Oeste e Sudeste brasileiro. Todas as amostras coletadas foram ensacadas em sacos de polietileno e encaminhadas ao Setor de Energia da Biomassa do LPF/SFB, em quantidade de aproximadamente $15 \mathrm{~kg}$ cada.

A casca de arroz, resíduo da produção de alimentos, foi obtida em uma empresa de materiais agrícolas na região de Brasília-DF, enquanto que a torta de pinhão manso, resíduo gerado pelo processamento (esmagamento) da semente do pinhão-manso para a produção de 
biocombustível, foi adquirida por meio de uma empresa Agroindustrial do interior de Minas Gerais.

O bagaço-de-cana foi proveniente da usina de produção de etanol combustível, instalada no município de Lençóis Paulista-SP, operada pela Usina Barra Grande de Lençóis S.A. Este material foi obtido a partir do convênio entre a Universidade de Brasília e o Laboratório de Produtos Florestais.

\subsection{PREPARO DAS AMOSTRAS}

O preparo das amostras foi realizado de forma semelhante ao descrito no Capítulo III. Inicialmente, os materiais de origem florestal foram transformados em maravalha e depois moídos em moinho de facas tipo Willey e posteriormente classificadas. A classificação das partículas após a moagem também foi semelhante ao descrito no Capítulo III

Após a moagem, determinou-se para todas as biomassas o Teor de Umidade em Base Seca (TUbs\%) seguindo as recomendações da TAPPI T 257 om - 85/96 (TAPPI, 1996a). Para o cálculo do poder calorífico útil, utilizou-se o teor de umidade em base úmida, conforme Brito (1993) e Vale et al. (2007).

\subsection{ANÁLISE IMEDIATA DAS BIOMASSAS}

A análise imediata das biomassas foi realizada com o intuito de caracterizá-las energeticamente. Foi avaliado o teor de material volátil, teor de cinzas e teor de carbono fixo de acordo com o cálculo descrito pela norma NBR 8112/86 (ABNT, 1986). 


\subsection{DETERMINAÇÃO DO PODER CALORÍFICO DAS BIOMASSAS}

Para a determinação do Poder Calorífico Superior (PCS, cal/g ou kcal/kg) utilizou-se da metodologia descrita no Capítulo III e foi utilizado um equipamento Calorímetro modelo IKA C2000 acoplado a um refrigerador IKA KV $600 \mathrm{em}$ unidade de cal/g, pertencente ao Laboratório de Tecnologia da Madeira da Universidade de Brasília-UnB, baseando-se na norma NBR 8633 da ABNT/1984 (ABNT, 1984).

Os ensaios foram feitos em duplicata e o PCS médio foi dado pela média da duplicata para valores consecutivos inferiores à $40 \mathrm{cal} / \mathrm{g}$. Também foi determinado o Poder Calorífico Inferior (PCI, cal/g ou kcal/kg), desconsiderando-se o calor de vaporização da água. O PCI foi calculado utilizando-se a fórmula de Launt (citada por Gomide, 1984), conforme Capítulo III.

Para a biomassa de pinhão manso, adotou-se a média para os valores do percentual de hidrogênio da biomassa, encontrados na literatura (6,54\%, conforme descrito no Capítulo anterior) e para as demais biomassas, adotou-se o valor médio de $6 \%$ para o teor de hidrogênio. De acordo com Brito e Barrichelo (1981), o teor de hidrogênio (\%) das biomassas provenientes de madeiras é cerca de $6 \%$ independentemente da espécie.

Por fim, foi determinado o Poder Calorífico Útil (PCU, cal/g ou kcal/kg), levando-se em consideração o teor de umidade da biomassa, calculado seguindo as recomendações de Brito (1993) e Vale et al. (2007) e descrito no Capítulo III.

\subsection{CONFECÇÃO DOS BRIQUETES}

Os briquetes foram confeccionados conforme metodologia descrita no capítulo III, no qual se utilizou de uma prensa briquetadeira da marca Irmãos Lippel e modelo LB-32 pertencente ao Setor de Energia da Biomassa do LPF/SFB, onde se acoplou uma máquina sopradora para o resfriamento dos briquetes.

Desta forma, para a análise dos parâmetros de densificação dos resíduos, o delineamento experimental (Tabela 1) estabelecido foi de 6 repetições/briquetes confeccionados para duas 
temperaturas $\left(130\right.$ e $\left.200{ }^{\circ} \mathrm{C}\right)$, duas pressões $\left(80\right.$ e $\left.120 \mathrm{kgf} / \mathrm{cm}^{2}\right)$, duas granulometrias (partícula grossa e fina), resultando em 8 tratamentos e 48 briquetes confeccionados para cada uma das biomassas já citadas. Ao final, confeccionou-se um total de 288 briquetes, com as seis biomassas.

Tabela 1. Delineamento experimental para a avaliação dos parâmetros de briquetagem: granulometria, temperatura e pressão para cada uma das seis biomassas estudadas.

\begin{tabular}{cccc}
\hline Tratamento & Granulometria & Temperatura $\left({ }^{\circ} \mathrm{C}\right)$ & Pressão $\left(\mathrm{kgf} / \mathrm{cm}^{2}\right)$ \\
\hline 1 & Grossa & 130 & 80 \\
2 & Grossa & 130 & 120 \\
3 & Grossa & 200 & 80 \\
4 & Grossa & 200 & 120 \\
\hline 5 & Fina & 130 & 80 \\
6 & Fina & 130 & 120 \\
7 & Fina & 200 & 80 \\
8 & Fina & 200 & 120 \\
\hline
\end{tabular}

Por fim, outras 3 repetições/briquetes foram confeccionados em iguais condições para cada uma das seis biomassas, com o intuito de realizar o ensaio de determinação da densidade aparente e densidade energética por meio de imersão em mercúrio, totalizando 144 briquetes.

Todos os briquetes confeccionados foram dispostos em câmara climática com temperatura e umidade relativa controlada $\left(20^{\circ} \mathrm{C}\right.$ e $65 \%$ de umidade relativa), por um período de aproximadamente 90 dias.

\subsection{DETERMINAÇÃO DA DENSIDADE APARENTE DO BRIQUETE}

\subsubsection{MÉTODO ESTEREOMÉTRICO}

A Densidade Aparente (DA, $\mathrm{g} / \mathrm{cm}^{3}$ ) foi determinada pelo método estereométrico onde cada briquete teve a sua massa determinada em balança de sensibilidade igual a $10^{-2} \mathrm{~g}$ e teve suas dimensões determinadas por paquímetro com sensibilidade de $10^{-2} \mathrm{~mm}$. A densidade aparente foi calculada pela relação entre a massa e volume de cada briquete, considerando-se a forma cilíndrica dos briquetes, após permanecerem em câmara climática por cerca de 90 dias. 


\subsubsection{MÉTODO DO DESLOCAMENTO DE MERCÚRIO}

A Densidade Aparente (DAHG, $\mathrm{g} / \mathrm{cm}^{3}$ ) foi determinada pelo método de deslocamento de mercúrio (ou imersão em mercúrio), após a imersão do briquete sustentado por uma haste, em um recipiente sobre uma balança de precisão igual a $10^{-2} \mathrm{~g}$, contendo mercúrio puro $(\mathrm{Hg})$.

A metodologia de preparação das amostras foi adaptada de Souza et al. (2010) e Quirino et al (2012). Após o resfriamento, os briquetes foram seccionados transversalmente na sua região mediana e posteriormente lixados, de forma que a amostra a ser utilizada, permanecesse com a espessura final de cerca de $3 \mathrm{~mm}$.

\subsubsection{MÉTODO DO RAIO-X}

A Densidade Aparente pela emissão de raios-x (DARX, $\mathrm{g} / \mathrm{cm}^{3}$ ) foi determinada conforme metodologia descrita no Capítulo III, utilizando-se do equipamento Quintek Measurement Systems (QMS), modelo QTRS-01X acoplado a um microcomputador (Figura 5) e por meio do software Tree Ring System.

\subsection{DETERMINAÇÃO DA DENSIDADE ENERGÉTICA}

A Densidade Energética (DE ou DEHG, Gcal $/ \mathrm{m}^{3}$ ), segundo Pinheiro et al. (2005) foi calculada conforme descrito no capítulo III. Foram utilizadas as densidades aparente obtidas pelo método estereométrico, imersão em mercúrio e pelo raio x para o cálculo da densidade energética (DA, DAHG e DARX, respectivamente).

\subsection{AVALIAÇÃO NÃO-DESTRUTIVA DOS BRIQUETES}

Todos os 288 briquetes produzidos foram analisados de forma não destrutiva pelos equipamentos de onda de tensão e de ultrassom, antes que se fizesse a determinação da resistência à compressão perpendicular ou diametral na máquina universal de ensaios. 


\subsubsection{TÉCNICA DA ONDA DE TENSÃO}

Neste estudo, utilizou-se o equipamento Stress Wave Timer da marca Metriguard modelo 239A (Figura 1) para a determinação do tempo de propagação das ondas de tensão $\left(\mathrm{V}_{0} \mathrm{~S}, \mu \mathrm{s}\right)$ longitudinalmente através dos briquetes. Cada briquete possuía dimensões aproximadas de 30 mm x 40 mm (diâmetro x comprimento) e vão entre os acelerômetros de aproximadamente 40 mm. Para a avaliação com esse equipamento, utilizou-se o ganho máximo do aparelho, conforme utilizado por BRASHAW et al. (2004) de forma a maximizar a sensitividade no recebimento do sinal da onda de tensão.

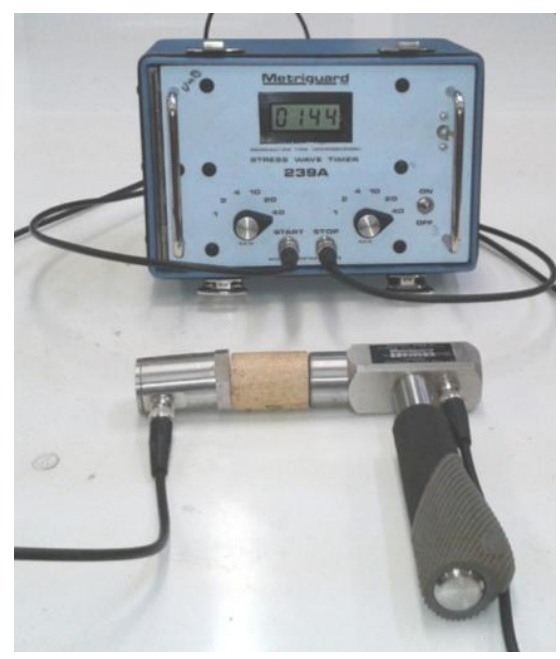

Figura 1. Equipamento Stress Wave Timer da marca Metriguard modelo 239-A para a avaliação não destrutiva de briquetes pela técnica da onda de tensão.

Ainda, por não ter sido possível a utilização dos grampos e o pêndulo do equipamento Stress Wave Timer, utilizou-se o martelo para a geração da onda de tensão. Todas as medições foram realizadas pelo mesmo operador e com aplicação de impacto bastante semelhante entre cada medição.

Por fim, calculou-se a Velocidade de Propagação das ondas de tensão $\left(\mathrm{V}_{0} \mathrm{~S}\right)$ para cada um dos 288 briquetes, utilizando a Equação 2. 


$$
V_{0}=\frac{L}{t \times 10^{-6}}
$$

Onde:

Vo = velocidade de propagação da onda, $\mathrm{m} / \mathrm{s}$;

$L=$ distância percorrida pela onda, $m$;

$t=$ tempo de trânsito da onda, $\mu$;

\subsubsection{TÉCNICA DA ONDA ULTRASSÔNICA}

Também foi utilizado o equipamento de ultrassom, marca USLAB-Agricel, para os mesmos 288 briquetes confeccionados, mantendo-se também os mesmos parâmetros, como o vão entre os transdutores, cerca de $40 \mathrm{~mm}$ devido ao comprimento total dos briquetes; para a avaliação não destrutiva dos briquetes.

De acordo com Trinca (2011) a escolha do material acoplante pode reduzir o fenômeno de atenuação das ondas longitudinais que afetam ou inviabilizam a leitura do tempo de propagação. Ainda de acordo com estes autores, a escolha do acoplante depende das condições superficiais da amostra, do tipo de material que está sendo ensaiado e do tipo de onda a ser induzida. Além do gel medicinal, que é comumente utilizado, pode-se utilizar como acoplante: glucose de amido, glucose de milho e Carboxymethylcelulose a 6 e $10 \%$ (TRINCA et al, 2009).

Utilizou-se o gel medicinal como material acoplante devido à sua disponibilidade no Laboratório de Tecnologia da Madeira da Universidade de Brasília, para os transdutores longitudinais cilíndricos de $29 \mathrm{~mm}$ de diâmetro e frequência de $45 \mathrm{KHz}$, onde foram determinados o tempo de propagação das ondas ultrassônicas (Figura 2). 


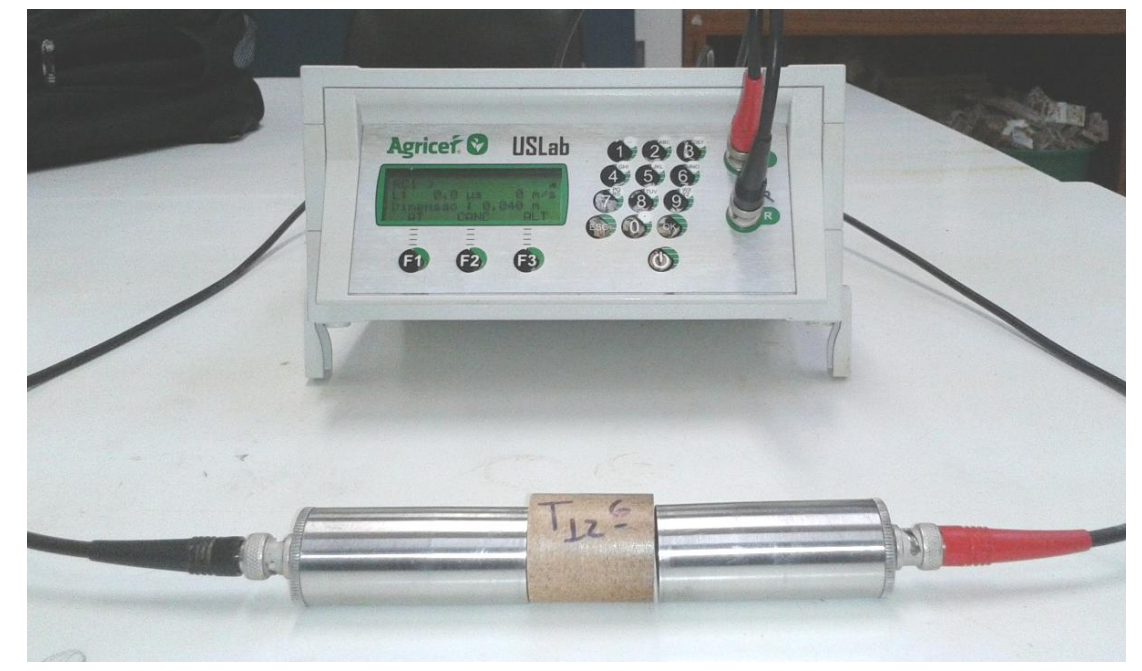

Figura 2. Equipamento de Ultrassom da marca USLAB-Agricel para a avaliação não destrutiva de briquetes pela técnica da onda ultrassônica.

Por fim, calculou-se a Velocidade de Propagação das ondas ultrassônicas $\left(\mathrm{V}_{0} \mathrm{U}, \mathrm{m} / \mathrm{s}\right)$ para cada um dos 288 briquetes, utilizando a mesma e fórmula empregada para a $\mathrm{V}_{0} \mathrm{~S}$.

\subsection{DETERMINAÇÃO DAS PROPRIEDADES MECÂNICAS DOS BRIQUETES}

Os briquetes foram analisados mecanicamente do ponto de vista da Carga Máxima de Ruptura (CMR, kgf) e da Resistência à Tração por Compressão Diametral (RTCD, kgf/cm²), utilizando-se uma máquina universal de ensaios EMIC DL30000 acoplada a uma célula de carga de até $2000 \mathrm{kgf}$ e uma base de aço perfeitamente plana e com as superfícies lisas e paralelas (Figura 3). A velocidade do carregamento foi de $0,3 \mathrm{~mm} \cdot \mathrm{min}^{-1}$ conforme o utilizado por Protásio et al. (2011), baseando-se na norma NBR 7222/94 (ABNT, 1994). 

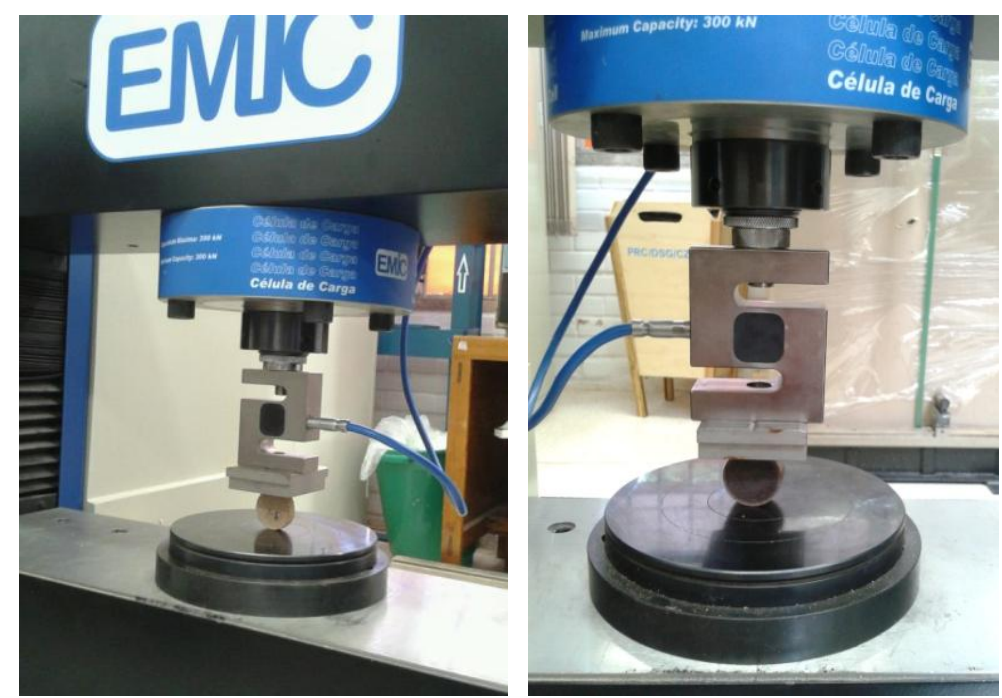

Figura 3. Ensaio de resistência à compressão diametral realizado em máquina universal de ensaios, para a determinação da força máxima de compressão dos briquetes confeccionados com as seis diferentes biomassas.

A resistência à tração por compressão diametral (RTCD) foi calculada por meio da Equação 1.

$$
R T C D=\frac{2 \times P}{\pi \times \mathrm{D} \times \mathrm{L}}
$$

Equação 1.

Onde:

$R T C D=$ resistência à tração por compressão diametral, $\left(\mathrm{kgf} / \mathrm{cm}^{2}\right)$;

$P=$ carga máxima de ruptura do briquete, $(k g f)$;

$D=$ diâmetro do briquete, $(\mathrm{cm})$;

$L=$ comprimento do briquete $(\mathrm{cm})$.

\subsection{ANÁLISE ESTATÍSTICA}

A análise estatística foi realizada pelo software SPSS (Statistical Package for Social Sciences) v. 19 para sistema operacional Windows.

Inicialmente, baseou-se em uma avaliação descritiva, considerando os valores máximos, mínimos, a média, o desvio padrão e o coeficiente de variação para a velocidade de 
propagação de ondas de tensão $\left(\mathrm{V}_{0} \mathrm{~S}, \mathrm{~m} / \mathrm{s}\right)$, velocidade de propagação de ondas ultrassônicas $\left(\mathrm{V}_{0} \mathrm{U}, \mathrm{m} / \mathrm{s}\right)$, a força máxima de ruptura em compressão diametral (CMR, kgf) e a resistência à tração por compressão diametral (RTCD, $\left.\mathrm{kgf} / \mathrm{cm}^{2}\right)$.

Posteriormente, investigou-se o efeito dos parâmetros da briquetagem para cada biomassa, realizando-se análise de variância - ANOVA, considerando como fonte de variação, os parâmetros da briquetagem (granulometria, temperatura e pressão). As diferenças entre os grupos foram analisadas por meio do teste Tukey a um nível de significância de 5\%.

As correlações foram determinadas entre a avaliação não-destrutiva (Stress Wave Timer e Ultrassom) e a destrutiva por compressão diametral, em nível dos tratamentos para cada biomassa individualmente, onde se analisaram um total de 48 tratamentos para os seis resíduos agroflorestais. Assim foram avaliados o coeficiente de determinação $\left(R^{2}\right)$ e a significância dos parâmetros (Teste "F").

Com isso, foram gerados modelos de regressão linear simples $y=a+b x$, tendo a velocidade de propagação das ondas de tensão $\left(\mathrm{V}_{0} \mathrm{~S}, \mathrm{~m} / \mathrm{s}\right)$ e ultrassônica $\left(\mathrm{V}_{0} \mathrm{U}, \mathrm{m} / \mathrm{s}\right)$, como variáveis independentes (x), a força máxima de ruptura diametral (FMR), a resistência à tração por compressão diametral (RTCD) e a densidade energética (DE) como variáveis dependentes (y), com a finalidade de avaliar a adequação da $\mathrm{V}_{0} \mathrm{~S}$ e $\mathrm{V}_{0} \mathrm{U}$ como estimadores da resistência mecânica e da densidade energética.

\section{RESULTADOS E DISCUSSÃO}

\subsection{AVALIAÇÃO NÃO DESTRUTIVA DOS BRIQUETES}

\subsubsection{Velocidade de Propagação da Onda de Tensão}

A Figura 4 traz os valores médios por tratamento da velocidade de propagação da onda de tensão $\left(\mathrm{V}_{0} \mathrm{~S}, \mathrm{~m} / \mathrm{s}\right)$ para os briquetes confeccionados com as seis biomassas agroflorestais. 

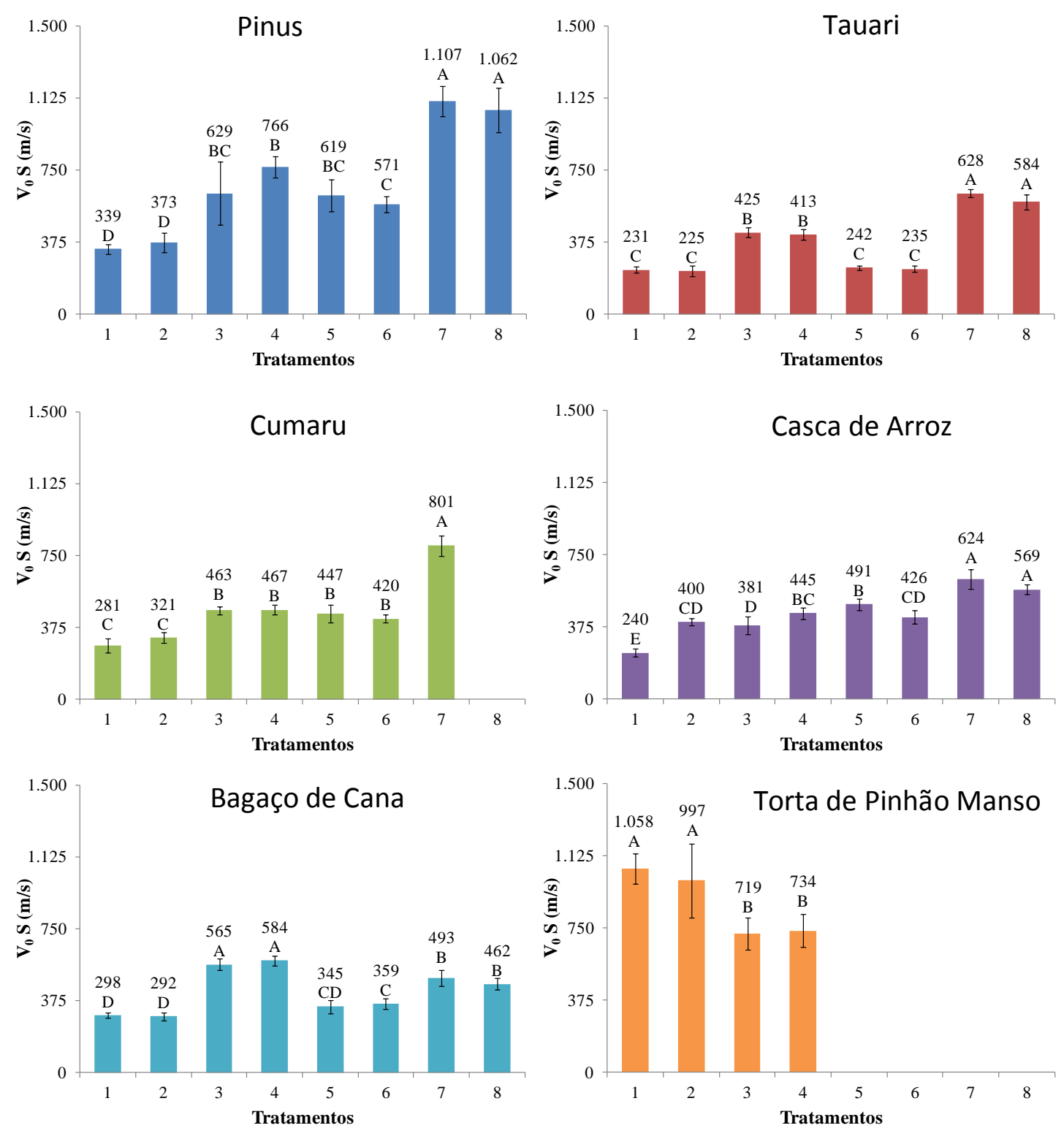

Figura 4. Valores da Velocidade de Propagação da Onda $\left(\mathrm{V}_{0} \mathrm{~S}-\mathrm{m} / \mathrm{s}\right)$ obtida pelo equipamento Stress Wave Timer para os briquetes confeccionados a partir das biomassas de pinus, tauari, cumaru, casca de arroz, bagaço de cana e torta de pinhão manso; em função dos oito tratamentos propostos. Onde: Letras diferentes para a mesma biomassa representam diferenças estatisticamente significativas entre os tratamentos pelo Teste Tukey a 5\% de significância.

Analisando as médias mostradas na Figura 4, percebeu-se de forma mais evidente o efeito da temperatura na velocidade de propagação da onda de tensão - $\mathrm{V}_{0} \mathrm{~S}$. Desta forma, nos 
tratamentos 3 e 4 com as partículas grossas, assim como nos tratamentos 7 e 8 com as partículas finas, com temperatura de $200^{\circ} \mathrm{C}$, os maiores valores médios foram observados, com destaque para partículas finas. Este comportamento foi observado para os briquetes confeccionados com as biomassas de pinus, tauari e casca de arroz. Para briquetes com cumaru, o tratamento $7(801 \mathrm{~m} / \mathrm{s})$ também foi superior aos demais.

Os valores médios da velocidade de propagação de ondas de tensão $-\mathrm{V}_{0} \mathrm{~S}$ nos tratamentos $3 \mathrm{e}$ 4 para os briquetes produzidos com a biomassa de cumaru, foram superiores aos tratamentos 1 e 2 em valores absolutos porém, sem significância estatística pelo Teste Tukey ao nível de $5 \%$ de significância. E para os briquetes produzidos com a casca de arroz, apenas os tratamentos 7 e 8 foram superiores aos demais, com cerca de 624 e 569 m/s, respectivamente.

A $\mathrm{V}_{0} \mathrm{~S}$ para os briquetes fabricados com a torta de pinhão manso com granulometria grossa, temperatura de $130^{\circ} \mathrm{C}$ e pressões de $80 \mathrm{kgf} / \mathrm{cm}^{2}$ (T1) e $120 \mathrm{kgf} / \mathrm{cm}^{2}(\mathrm{~T} 2)$ superou $1.000 \mathrm{~m} / \mathrm{s}$ enquanto, briquetes produzidos com a mesma granulometria porém com temperatura de $200^{\circ} \mathrm{C}$ e pressões de $80 \mathrm{kgf} / \mathrm{cm}^{2}$ (T3) e $120 \mathrm{kgf} / \mathrm{cm}^{2}$ (T4) apresentaram $\mathrm{V}_{0} \mathrm{~S}$ entre 719 e 734 $\mathrm{m} / \mathrm{s}$.

Portanto, o tamanho da partícula foi um fator que também influenciou significativamente a $\mathrm{V}_{0} \mathrm{~S}$ dos briquetes confeccionados com as biomassas agroflorestais estudadas, excetuando-se os briquetes constituídos com a torta de pinhão manso. Nestes últimos briquetes não se pôde avaliar esta característica, pois se apresentaram com algumas rachaduras no momento do ensaio e não foram considerados.

Com relação à pressão de compactação, a influência deste parâmetro da briquetagem ficou limitada aos briquetes confeccionados com a casca de arroz. Assim, nos briquetes com partículas grossas (tratamentos 1 a 4) o emprego da pressão de $120 \mathrm{kgf} / \mathrm{cm}^{2}$ promoveu um aumento da velocidade de propagação, também em ambas as temperaturas. $\mathrm{A} \mathrm{V}_{0} \mathrm{~S}$ passou de 240 para $400 \mathrm{~m} / \mathrm{s}$ entre os tratamentos 1 e 2; e variou de 381 para $445 \mathrm{~m} / \mathrm{s}$ entre os tratamentos 3 e 4 .

Por outro lado, ao se utilizar as partículas finas, o aumento da pressão foi inversamente proporcional à $\mathrm{V}_{0} \mathrm{~S}$, ou seja, quando se aumentou a pressão de 80 para $120 \mathrm{kgf} / \mathrm{cm}^{2}$, a 
velocidade de propagação da onda de tensão passou de 491 para $426 \mathrm{~m} / \mathrm{s}$ (tratamentos 5 e 6 , respectivamente). Apesar de ter havido uma pequena diferença entre estes últimos tratamentos, esta diferença foi estatisticamente significativa ao nível de 5\% de significância. Uma possível explicação para o fato de pressão não ter influenciado significativamente a velocidade de propagação de ondas de tensão dos briquetes para as outras biomassas foi a variação relativamente pequena entre 80 e $120 \mathrm{kgf} / \mathrm{cm}^{2}$.

De uma forma geral, quando se comparou as velocidades de propagação observadas para os briquetes com as médias observadas para diferentes espécies de madeira maciça ou à derivados como os painéis compensados ou aglomerados, foi observado que as médias deste parâmetro para os briquetes foram mais baixas. Acredita-se que fatores intrínsecos à biomassa ou às características do material briquete podem ter influenciado na redução das médias.

Para os briquetes, as maiores médias foram para os tratamentos $7(1.107 \mathrm{~m} / \mathrm{s})$ e $8(1.062 \mathrm{~m} / \mathrm{s})$ quando se empregou a partícula fina de pinus sob temperatura de $200^{\circ} \mathrm{C}$ e as pressões de 80 e $120 \mathrm{kgf} / \mathrm{cm}^{2}$.

De acordo com Bartholomeu (2001) o fenômeno de transferência de energia por meio de uma onda sonora está mais associado à estrutura celular da madeira que a sua densidade aparente. Assim, de acordo com este autor, tanto a composição anatômica como química das paredes celulares modificaram as velocidades de propagação diferindo-as entre si para as biomassas estudadas.

De acordo com Puccini (2002), para amostras com pequenas dimensões em relação ao comprimento de onda, as condições de propagação das ondas sonoras podem ser afetadas.

Para Oliveira et al. (2006) as dimensões e formato do corpo-de-prova pode influenciar drasticamente o valor final da velocidade de propagação assim como na forma de propagação desta onda. Assim, conforme a onda sonora interage com os contornos do corpo-de-prova, forças de tração, compressão ou cisalhamento distorcem e interfere na onda, dificultando a precisão do tempo de propagação e consequentemente a velocidade. 
Portanto, acredita-se que o fenômeno da atenuação foi decisivo para a redução da velocidade de propagação nos briquetes, em função da composição particularizada e com pouca continuidade de tecidos vegetais, assim como pelas pequenas dimensões do briquete.

Desta forma, após a determinação da velocidade de propagação da onda de tensão, realizou-se a análise de regressão entre estas variáveis, como forma de estimar a DARX em função da $\mathrm{V}_{0} \mathrm{~S}$. A Tabela 2 resume os coeficientes de determinação $\left(\mathrm{R}^{2}\right)$ gerados pela análise de variância da regressão pelo modelo linear simples, utilizando a velocidade de propagação da onda de tensão como variável independente e a DARX como variável dependente.

Conforme discutido no capítulo anterior, acredita-se que os valores médios da densidade aparente determinados pelo método do raio-x (DARX) sejam os que mais expressaram o valor real desta propriedade para os briquetes, devido à precisão do método.

Tabela 2. Valores do coeficiente de determinação $-\mathrm{R}^{2}(\%)$ obtido pela análise de variância da regressão entre a avaliação não destrutiva e a densidade aparente obtida pelo raio X (DARX) para os briquetes com as seis biomassas estudadas.

\begin{tabular}{lcccc}
\hline \multicolumn{1}{c}{ Biomassa } & Eixo $x$ & \multicolumn{3}{c}{ Eixo y } \\
& & DARX & F de signif. & Signif. \\
\hline Pinus & & 5,75 & 0,3085 & n.s. \\
\hline Tauari & & 0,03 & 0,9472 & n.s. \\
Cumaru & & 5,27 & 0,3443 & n.s. \\
\hline Casca de Arroz & \multirow{2}{*}{$\mathrm{V}_{0} \mathrm{~S}$} & 47,06 & 0,0002 & $* *$ \\
\hline Bagaço de Cana & & 2,09 & 0,5007 & n.s. \\
\hline Torta de Pinhão Manso & & 34,44 & 0,0350 & $*$ \\
\hline
\end{tabular}

Onde: $\mathrm{V}_{0} \mathrm{~S}$ - velocidade de propagação da onda de tensão; DARX - densidade aparente obtida pelo raio $\mathrm{X} ;\left(^{*}\right)$ - significativo ao nível de $5 \%$; (**) - significativo ao nível de $1 \%$; (n.s) - não significativo.

Observou-se que a $\mathrm{V}_{0} \mathrm{~S}$ na predição da DARX para os briquetes com a casca de arroz e com a torta de pinhão manso se mostrou promissor, pois a análise de regressão entre aquelas variáveis foi estatisticamente significativa. Entretanto, os valores do coeficiente de 
determinação foram considerados baixos (47,06 e 34,44\%, respectivamente). Com relação aos outros briquetes, a $\mathrm{V}_{0} \mathrm{~S}$ não se mostrou como um bom estimador para a DARX, pois as regressões não foram significativa ao nível de $5 \%$.

Possivelmente a alteração dos valores da DARX em função do conteúdo mineral (cinzas) discutido no capítulo anterior possa também ter elevado os valores da $\mathrm{V}_{0} \mathrm{~S}$, tornando significativa a relação entre estas propriedades nos briquetes com a casca de arroz e torta de pinhão manso. Contudo, a influência das cinzas ainda deve ser mais profundamente investigada na análise da DARX e seus efeitos na $\mathrm{V}_{0} \mathrm{~S}$.

As Figuras 5 e 6 trazem a análise de regressão e a equação de reta gerada para os briquetes com as duas biomassas.

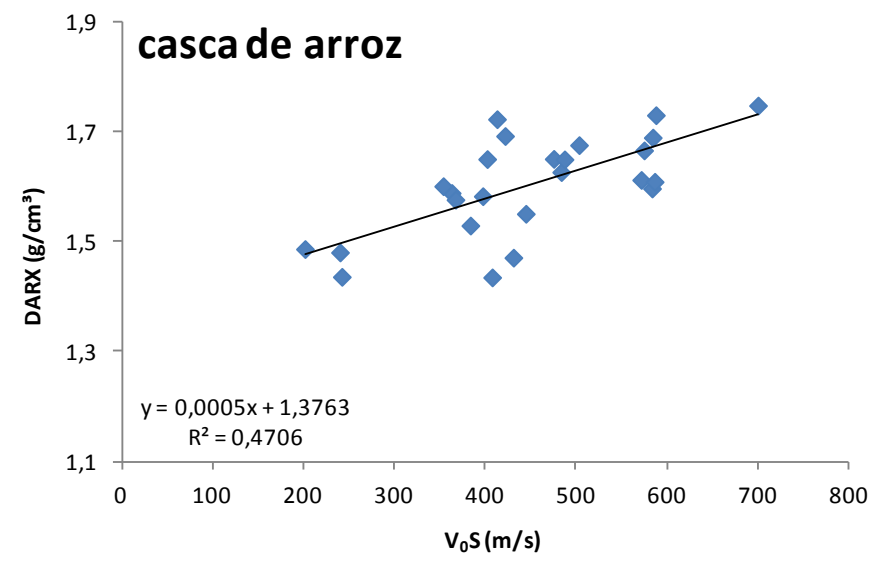

Figura 5. Predição da densidade aparente obtida pelo raio $X\left(D A R X-\mathrm{g} / \mathrm{cm}^{3}\right)$ em função da velocidade de propagação da onda de tensão $\left(\mathrm{V}_{0} \mathrm{~S}-\mathrm{m} / \mathrm{s}\right)$ para os briquetes confeccionados com a casca de arroz. 


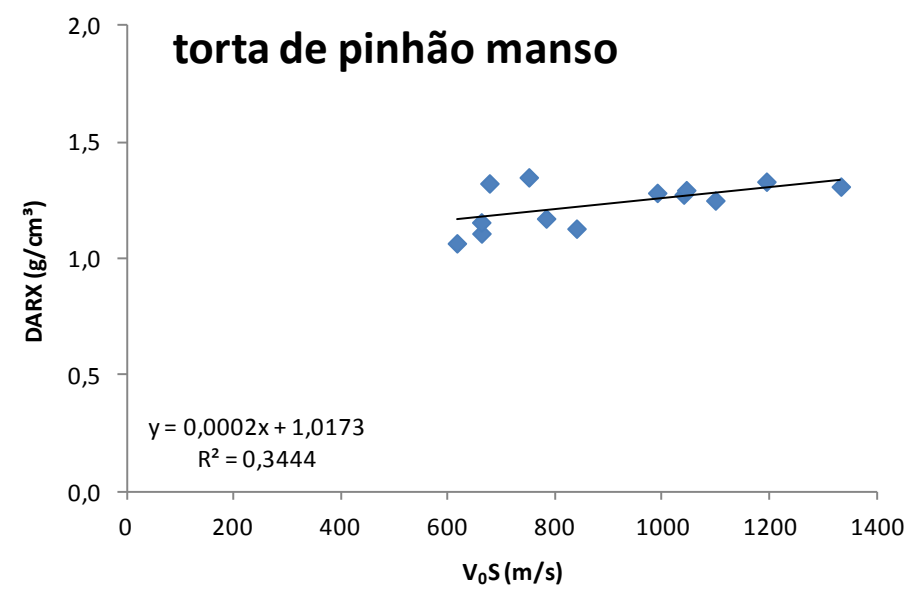

Figura 6. Predição da densidade aparente obtida pelo raio $X\left(D A R X-g / \mathrm{cm}^{3}\right)$ em função da velocidade de propagação da onda de tensão $\left(\mathrm{V}_{0} \mathrm{~S}-\mathrm{m} / \mathrm{s}\right)$ para os briquetes confeccionados com a torta de pinhão manso.

$\mathrm{O}$ comportamento da $\mathrm{V}_{0} \mathrm{~S}$ entre os tratamentos/biomassas pôde ser mais bem explicado pelo comportamento da densidade aparente obtida pelo método estereométrico (DA, $\mathrm{g} / \mathrm{cm}^{3}$ ), em comparação com a densidade obtida pelo método de imersão em mercúrio (DAHG) ou pelo raio $X(D A R X)$.

Assim, para os maiores valores da DA nos tratamentos 3, 4, 7 e 8, maiores foram os valores da velocidade de propagação da onda de tensão nos briquetes. Este fato foi comprovado para os briquetes com pinus, tauari, bagaço de cana e pinhão manso.

De acordo com Azevedo Júnior (2002) e Bucur (1995), a velocidade de propagação da onda tem valores médios superiores quanto maior for a densidade do material. Esta relação diretamente proporcional está relacionada a uma maior deposição e aproximação de feixes celulósicos, reduzindo o espalhamento da onda.

Portanto, a $\mathrm{V}_{0} \mathrm{~S}$ se mostrou um bom estimador para a DA e DAHG, pois além de as regressões terem sido significativas ao nível de $1 \%$, altos valores do $\mathrm{R}^{2}$ também foram observados. 
A Tabela 3 resume os coeficientes de determinação $\left(\mathrm{R}^{2}\right)$ gerados pela análise de variância da regressão pelo modelo linear simples, utilizando a velocidade de propagação da onda de tensão como variável independente e as densidades aparentes (DA, DAHG) como variáveis dependentes, em comparação à DARX.

Tabela 3. Valores do coeficiente de determinação $-\mathrm{R}^{2}(\%)$ obtido pela análise de variância da regressão entre a avaliação não destrutiva e a densidade aparente para os briquetes com as seis biomassas estudadas.

\begin{tabular}{|c|c|c|c|c|c|c|c|}
\hline \multirow[t]{2}{*}{ Biomassa } & \multirow[t]{2}{*}{ Eixo $x$} & \multicolumn{6}{|c|}{ Eixo y } \\
\hline & & DA & $\begin{array}{l}\text { F de } \\
\text { signif. }\end{array}$ & Signif. & DAHG & $\begin{array}{c}\text { F de } \\
\text { signif. }\end{array}$ & Signif. \\
\hline Pinus & & 53,65 & 0,0000 & $* *$ & 32,47 & 0,0087 & $* *$ \\
\hline Tauari & & 84,1 & 0,0000 & $* *$ & 70,91 & 0,0000 & $* *$ \\
\hline Cumaru & & 28,68 & 0,0003 & $* *$ & 17,21 & 0,0774 & n.s. \\
\hline Casca de Arroz & $V_{0} S$ & 68,71 & 0,0000 & $* *$ & 51,34 & 0,0001 & $* *$ \\
\hline Bagaço de Cana & & 75,05 & 0,0000 & $* *$ & 35,58 & 0,0021 & $* *$ \\
\hline Torta de Pinhão Manso & & 66,43 & 0,0000 & $* *$ & 3,56 & 0,5372 & n.s. \\
\hline
\end{tabular}

Onde: $\mathrm{V}_{0} \mathrm{~S}$ - velocidade de propagação da onda de tensão; DA - densidade aparente estereométrica; DAHG - densidade aparente por imersão em mercúrio; $\left(^{*}\right)$ - significativo ao nível de 5\%; (**) - significativo ao nível de 1\%; (n.s) - não significativo.

Desta forma, após ter sido realizada a regressão linear simples e a análise de variância da regressão, os maiores valores do coeficiente de determinação $\left(\mathrm{R}^{2}\right)$ foram os obtidos entre a velocidade de propagação e a densidade aparente estereométrica. Destaca-se o alto valor do $\mathrm{R}^{2}(0,841$ ou $84,1 \%)$ obtido para os briquetes de tauari em função destas propriedades (Figura 7). 


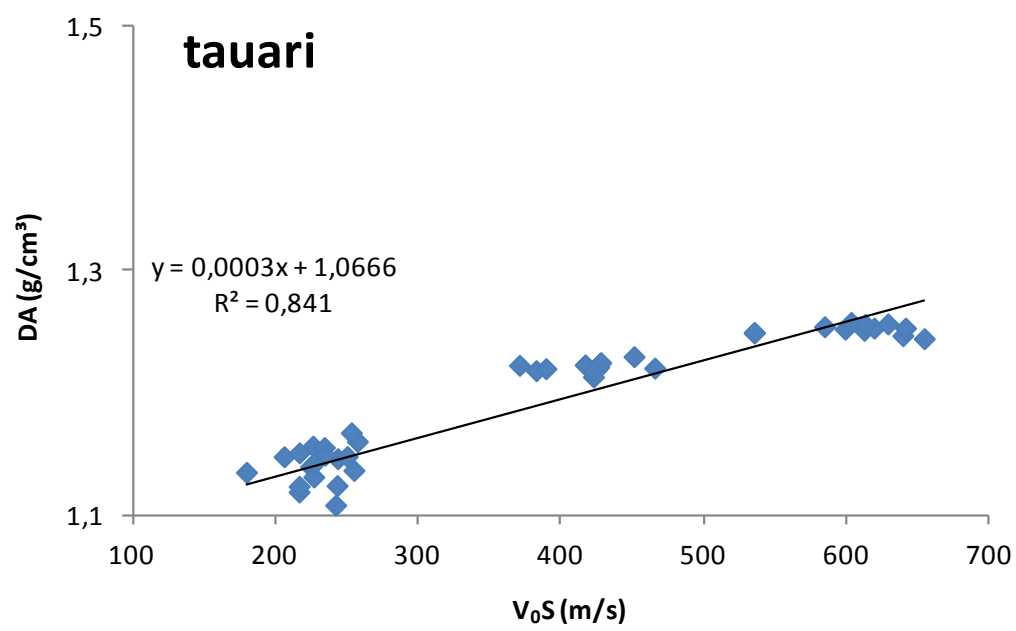

Figura 7. Predição da densidade aparente estereométrica (DA $-\mathrm{g} / \mathrm{cm}^{3}$ ) em função da velocidade de propagação da onda de tensão $\left(\mathrm{V}_{0} \mathrm{~S}-\mathrm{m} / \mathrm{s}\right)$ para os briquetes confeccionados com tauari.

Ainda, para os briquetes com a casca de arroz, os maiores valores da DA só corresponderam a maiores valores da $\mathrm{V}_{0} \mathrm{~S}$ nos tratamentos 7 e 8 . Entretanto ainda se observou uma tendência em se manter a relação descrita anteriormente, onde para maiores valores da DA, maiores valores da $\mathrm{V}_{0} \mathrm{~S}$ seriam observados.

Com relação à densidade aparente obtida pelo método de imersão em mercúrio (DAHG), esta propriedade física também se mostrou com potencial para explicar as médias observadas para a $\mathrm{V}_{0} \mathrm{~S}$. Assim, nos briquetes com pinus, tauari, casca de arroz e bagaço de cana, quanto maior a DAHG, maior foi a $\mathrm{V}_{0} \mathrm{~S}$. Entretanto, os menores valores do $\mathrm{R}^{2}$ utilizando a DAHG sugeriram que a DA foi o parâmetro melhor estimado pela $\mathrm{V}_{0} \mathrm{~S}$.

Tentou-se também, estimar a densidade energética obtida pelo raio $\mathrm{X}$ em função da $\mathrm{V}_{0} \mathrm{~S}$. $\mathrm{A}$ Tabela 4 resume os coeficientes de determinação obtidos pela análise de regressão entre estas variáveis. 
Tabela 4. Valores do coeficiente de determinação $-\mathrm{R}^{2}(\%)$ obtido pela análise de variância da regressão entre a avaliação não destrutiva e a densidade energética para os briquetes com as seis biomassas estudadas.

\begin{tabular}{|c|c|c|c|c|}
\hline \multirow[t]{2}{*}{ Biomassa } & \multirow[t]{2}{*}{ Eixo $x$} & \multicolumn{3}{|c|}{ Eixo y } \\
\hline & & DERX & $\mathrm{F}$ de signif. & Signif. \\
\hline Pinus & & 4,85 & 0,3247 & n.s \\
\hline Tauari & & 0,30 & 0,9472 & n.s \\
\hline Cumaru & & 8,08 & 0,2245 & n.s \\
\hline Casca de Arroz & $\mathrm{V}_{0} \mathrm{~S}$ & 47,06 & 0,0002 & $* *$ \\
\hline Bagaço de Cana & & 2,09 & 0,5007 & n.s \\
\hline Torta de Pinhão Manso & & 34,44 & 0,0350 & $*$ \\
\hline
\end{tabular}

Onde: $\mathrm{V}_{0} \mathrm{~S}$ - velocidade de propagação da onda de tensão; DE - densidade energética estereométrica; DEHG - densidade energética obtida por imersão em mercúrio; DERX densidade aparente por raio $\mathrm{X} ;\left(^{*}\right)$ - significativo ao nível de 5\%; $(* *)$ - significativo ao nível de $1 \%$; (n.s) - não significativo.

Percebeu-se, no entanto, que, conforme observado para a predição da DA em função da $\mathrm{V}_{0} \mathrm{~S}$, a predição da DERX só foi eficiente para os briquetes confeccionados com a casca de arroz e a torta de pinhão manso, ainda que os valores do $\mathrm{R}^{2}$ tenham sido considerados baixos $(47,06 \mathrm{e}$ $34,44 \%$, respectivamente).

Por fim, foi empregada a predição da DE e DEHG em função da $\mathrm{V}_{0} \mathrm{~S}$ na tentativa de se obter melhores parâmetros que na predição da DERX. A Tabela 5 resume os coeficientes de determinação obtidos pela análise de regressão entre estas variáveis. 
Tabela 5. Valores do coeficiente de determinação $-\mathrm{R}^{2}(\%)$ obtido pela análise de variância da regressão entre a avaliação não destrutiva e a densidade energética para os briquetes com as seis biomassas estudadas.

\begin{tabular}{|c|c|c|c|c|c|c|c|}
\hline \multirow[t]{2}{*}{ Biomassa } & \multirow[t]{2}{*}{ Eixo $x$} & \multicolumn{6}{|c|}{ Eixo y } \\
\hline & & $\mathrm{DE}$ & $\begin{array}{c}\mathrm{F} \text { de } \\
\text { signif. }\end{array}$ & Signif. & DEHG & $\begin{array}{c}\mathrm{F} \text { de } \\
\text { signif. }\end{array}$ & Signif. \\
\hline Pinus & & 53,65 & 0,0000 & $* *$ & 35,24 & 0,0036 & $* *$ \\
\hline Tauari & & 84,10 & 0,0000 & $* *$ & 70,91 & 0,0000 & $* *$ \\
\hline Cumaru & & 28,68 & 0,0003 & $* *$ & 26,84 & 0,0193 & $*$ \\
\hline Casca de Arroz & $\mathrm{V}_{0} \mathrm{~S}$ & 68,71 & 0,0000 & $* *$ & 51,34 & 0,0001 & $* *$ \\
\hline Bagaço de Cana & & 75,02 & 0,0000 & $* *$ & 35,58 & 0,0021 & $* *$ \\
\hline Torta de Pinhão Manso & & 66,43 & 0,0000 & $* *$ & 3,56 & 0,5372 & n.s \\
\hline
\end{tabular}

Onde: $\mathrm{V}_{0} \mathrm{~S}$ - velocidade de propagação da onda de tensão; DE - densidade energética estereométrica; DEHG - densidade energética obtida por imersão em mercúrio; (*) significativo ao nível de 5\%; (**) - significativo ao nível de 1\%; (n.s) - não significativo.

A partir da predição da DE e DEHG em função da $\mathrm{V}_{0} \mathrm{~S}$, a análise de variância da regressão foi significativa para todas as biomassas, ou seja, a $\mathrm{V}_{0} \mathrm{~S}$ pode ser utilizada para a predição destas variáveis energéticas. Excetuando-se os briquetes com a biomassa de cumaru ( $\mathrm{R}^{2}$ de 28,68\%) e pinus ( $\mathrm{R}^{2}$ de $53,65 \%$ ), altos valores do $\mathrm{R}^{2}$ foram observados, destacando os valores obtidos para os briquetes com tauari e bagaço de cana $(84,10$ e $75,05 \%$ respectivamente) na predição da DE.

Sendo assim, concluiu-se que a $\mathrm{V}_{0} \mathrm{~S}$ foi um bom estimador para a DE e DEHG, embora os coeficientes de determinação para a DEHG tenham sido menores que para a DE.

\subsubsection{Velocidade de Propagação da Onda Ultrassônica}

A Figura 8 mostra os valores médios por tratamento da velocidade de propagação da onda ultrassônica $\left(\mathrm{V}_{0} \mathrm{U}, \mathrm{m} / \mathrm{s}\right)$ para os briquetes confeccionados com as seis biomassas agroflorestais. 

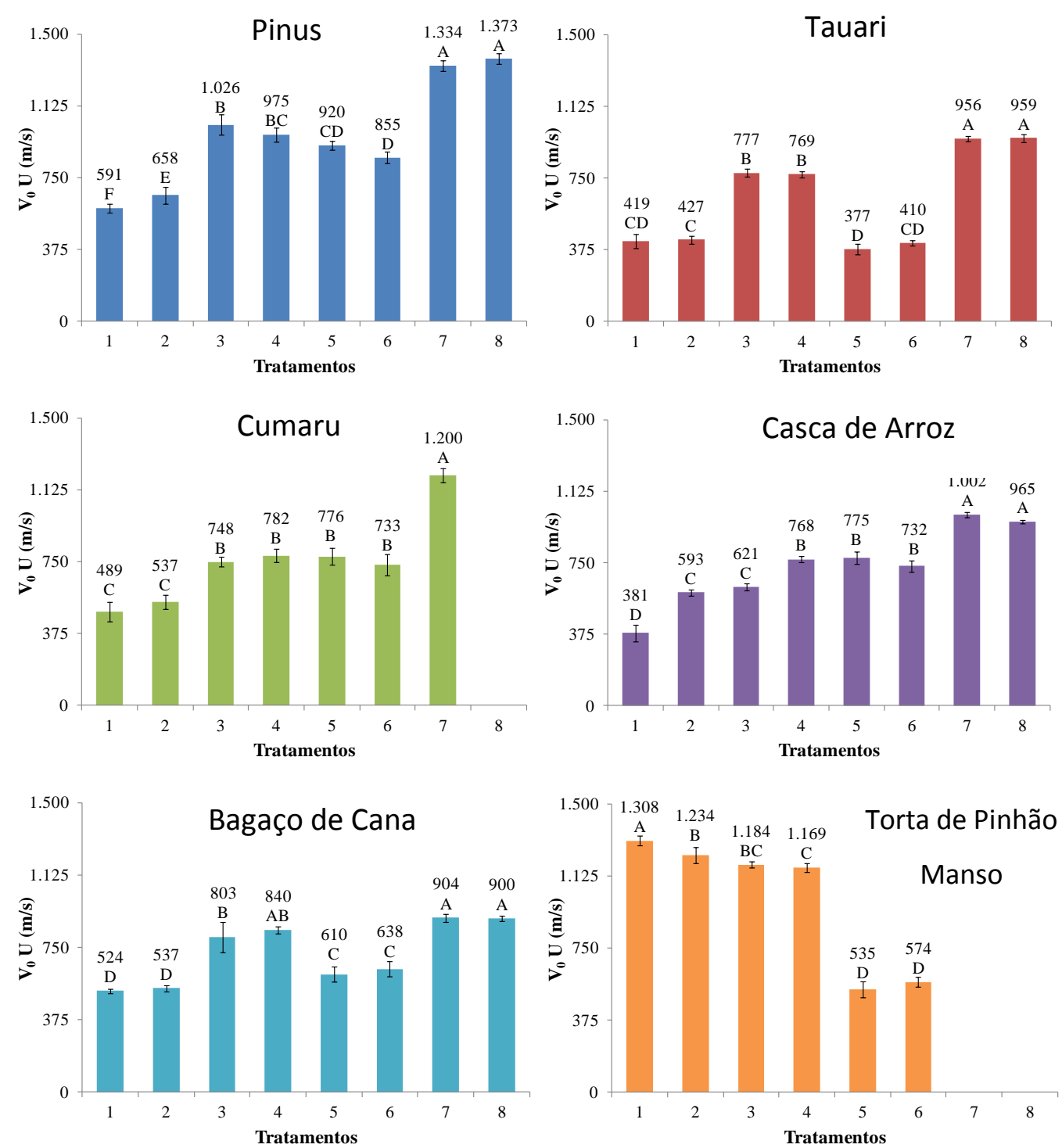

Figura 8. Valores da Velocidade de Propagação da Onda $\left(\mathrm{V}_{0} \mathrm{U}\right.$ - m/s) obtida pelo equipamento de Ultrassom USLAB-Agricel para os briquetes confeccionados a partir das biomassas de pinus, tauari, cumaru, casca de arroz, bagaço de cana e torta de pinhão manso; em função dos oito tratamentos propostos. Onde: Letras diferentes para a mesma biomassa representam diferenças estatisticamente significativas entre os tratamentos pelo Teste Tukey a $5 \%$ de significância.

Observa-se na Figura 8 que o comportamento da velocidade de propagação da onda ultrassônica $-\mathrm{V}_{0} \mathrm{U}$ foi semelhante àquela observado para a $\mathrm{V}_{0} \mathrm{~S}$. De uma forma geral, os maiores valores médios da $\mathrm{V}_{0} \mathrm{U}$ foram para os tratamentos com maior temperatura 
(tratamentos 3, 4, 7 e 8), porém, destacando-se a superioridade para estes últimos. Isto ocorreu claramente para os briquetes de pinus, tauari e bagaço de cana.

Por outro lado os briquetes produzidos com resíduos de cumaru, o tratamento 7 foi o que teve maior $\mathrm{V}_{0} \mathrm{U}(1200 \mathrm{~m} / \mathrm{s})$, seguido dos tratamentos 3, 4, 5, e 6, com médias variando entre 733 e $786 \mathrm{~m} / \mathrm{s}$. O comportamento da $\mathrm{V}_{0} \mathrm{U}$ para os briquetes de casca de arroz foi semelhante ao observado para os de cumaru, porém o tratamento 3 apresentou em média $621 \mathrm{~m} / \mathrm{s}$, com diferença estatisticamente significativa para os tratamentos 4, 5 e 6 (entre 732 e $768 \mathrm{~m} / \mathrm{s}$ ).

Comportamento diferente foi apresentado pelos briquetes confeccionados com a torta de pinhão manso apresentaram os maiores valores médios da $\mathrm{V}_{0} \mathrm{U}$ para os tratamentos 1 e 2 ( 1.308 e $1.234 \mathrm{~m} / \mathrm{s}$, respectivamente) seguidos dos tratamentos 3 e 4 , com 1.184 e $1.169 \mathrm{~m} / \mathrm{s}$. O pior desempenho apresentado foi para os tratamentos 5 e 6 com aproximadamente $550 \mathrm{~m} / \mathrm{s}$.

Desta forma, pode-se inferir que a temperatura foi o fator que mais influenciou a $V_{0} U$, onde o aumento de 130 para $200^{\circ} \mathrm{C}$ quase sempre acarretou em aumento da velocidade de propagação da onda ultrassônica.

A influência da pressão de compactação se restringiu aos briquetes confeccionados com partículas finas e com as biomassas de pinus, casca de arroz e torta de pinhão manso. Para os briquetes com pinus e torta de pinhão manso, a variação se deu apenas para a temperatura mais baixa (tratamentos 1 e 2) e, apesar de pequena, foi estatisticamente significativa ao nível de $5 \%$ pelo Teste de Tukey. Para os briquetes fabricados com resíduo de pinus a $\mathrm{V}_{0} \mathrm{U}$ passou de 591 para $658 \mathrm{~m} / \mathrm{s}$ e para aqueles produzidos com torta de pinhão manso, variou de 1.308 para $1.234 \mathrm{~m} / \mathrm{s}$.

Ainda, para os briquetes confeccionados com a casca de arroz, a influência da pressão de compactação se deu tanto na temperatura mais baixa (tratamentos 1 e 2), quanto na mais alta (tratamentos 3 e 4). No primeiro caso, a $V_{0} U$ passou de 381 para $593 \mathrm{~m} / \mathrm{s}$ e no segundo, de 621 para $768 \mathrm{~m} / \mathrm{s}$.

A granulometria teve influência significativa em todos os briquetes com as seis biomassas estudadas. O tamanho da partícula só não influenciou nos tratamentos com temperatura baixa 
(par de tratamentos 1-5 e 2-6) com biomassa de tauari; e temperatura e pressão altas (tratamentos 4-8) com a biomassa de bagaço de cana. Para temperatura e pressão altas (tratamento 4-8) com a biomassa de cumaru, não foi possível avaliar, pois não se confeccionaram briquetes referentes ao tratamento 8 .

Excetuando-se os briquetes com a torta de pinhão manso, sempre que se reduziu o tamanho da partícula, houve ganho na velocidade de propagação da onda ultrassônica. Tal fato foi vantajoso para a qualidade dos briquetes, pois a $\mathrm{V}_{0} \mathrm{U}$ possui forte correlação com a densidade aparente do briquete. Portanto, para maior $\mathrm{V}_{0} \mathrm{U}$, melhor a qualidade do briquete.

Comparando-se as médias da $\mathrm{V}_{0} \mathrm{U}$ obtidas para os briquetes, às médias observadas para madeiras maciças em geral, os valores para os briquetes foram inferiores. De forma ilustrativa, Oliveira et al. (2002) que estudaram a velocidade de propagação das ondas ultrassônicas nas madeiras de cupiúba e jatobá, destacam-se os valores médios de 4.514 e $4.279 \mathrm{~m} / \mathrm{s}$ respectivamente.

Conforme descrito para a $\mathrm{V}_{0} \mathrm{~S}$, a predição da DARX pela $\mathrm{V}_{0} \mathrm{U}$ não mostrou resultados favoráveis, ou seja, a análise de regressão entre estas propriedades só foi significativa para os briquetes com a casca de arroz e com a torta de pinhão manso. Nestes casos, apesar de o coeficiente de determinação ter ultrapassado os $50 \%$ em ambos os briquetes, tais valores foram considerados baixos, fazendo com que a $\mathrm{V}_{0} \mathrm{U}$ não seja indicada para a predição da DARX.

A Tabela 6 resume os valores do coeficiente de determinação obtido pela análise de regressão entre a DARX e $\mathrm{V}_{0} \mathrm{U}$. 
Tabela 6. Valores do coeficiente de determinação - $\mathrm{R}^{2}(\%)$ obtido pela análise de variância da regressão entre a avaliação não destrutiva e a densidade aparente para os briquetes com as seis biomassas estudadas.

\begin{tabular}{lcccc}
\hline \multicolumn{1}{c}{ Biomassa } & Eixo $x$ & \multicolumn{3}{c}{ Eixo y } \\
& & DARX & F de signif. & Signif. \\
\hline Pinus & & 3,50 & 0,4298 & n.s. \\
\hline Tauari & 0,002 & 0,9847 & n.s. \\
Cumaru & & 5,92 & 0,3155 & n.s. \\
\hline Casca de Arroz & VoU & 51,98 & 0,0000 & $* *$ \\
\hline Bagaço de Cana & & 2,23 & 0,4860 & n.s. \\
\hline Torta de Pinhão Manso & & 65,52 & 0,0000 & $* *$ \\
\hline
\end{tabular}

Onde: $\mathrm{V}_{0} \mathrm{U}$ - velocidade de propagação da onda ultrassônica; DARX - densidade aparente por raio $\mathrm{X} ;\left(^{*}\right)$ - significativo ao nível de 5\%; (**) - significativo ao nível de 1\%; (n.s) - não significativo.

A Tabela 7 resume os valores dos coeficientes de determinação obtidos pela regressão entre estas variáveis nos briquetes com as seis biomassas. $\mathrm{O}$ comportamento da $\mathrm{V}_{0} \mathrm{U}$ entre os tratamentos/biomassas pôde ser mais bem explicado pelo comportamento da densidade aparente obtida pelo método estereométrico (DA, g/ $\mathrm{cm}^{3}$ ), em comparação com a densidade obtida pelo método de imersão em mercúrio (DAHG) ou pelo raio X (DARX), assim como o descrito para a $\mathrm{V}_{0} \mathrm{~S}$. 
Tabela 7. Valores do coeficiente de determinação - $\mathrm{R}^{2}(\%)$ obtido pela análise de variância da regressão entre a avaliação não destrutiva e a densidade aparente para os briquetes com as seis biomassas estudadas.

\begin{tabular}{|c|c|c|c|c|c|c|c|}
\hline \multirow[t]{2}{*}{ Biomassa } & \multirow[t]{2}{*}{ Eixo $x$} & \multicolumn{6}{|c|}{ Eixo y } \\
\hline & & DA & $\begin{array}{l}\mathrm{F} \text { de } \\
\text { signif. }\end{array}$ & Signif. & DAHG & $\begin{array}{l}\mathrm{F} \mathrm{de} \\
\text { signif. }\end{array}$ & Signif. \\
\hline Pinus & & 63,15 & 0,0000 & ** & 45,61 & 0,0011 & $* *$ \\
\hline Tauari & & 93,73 & 0,0000 & $* *$ & 82,53 & 0,0000 & $* *$ \\
\hline Cumaru & & 31,2 & 0,0001 & $* *$ & 18,86 & 0,0632 & n.s. \\
\hline Casca de Arroz & $\mathrm{V}_{0} \mathrm{U}$ & 78,76 & 0,0000 & $* *$ & 67,39 & 0,0000 & $* *$ \\
\hline Bagaço de Cana & & 89,1 & 0,0000 & $* *$ & 69,2 & 0,0000 & $* *$ \\
\hline Torta de Pinhão Manso & & 73,95 & 0,0000 & $* *$ & 36,43 & 0,0062 & $* *$ \\
\hline
\end{tabular}

Onde: $\mathrm{V}_{0} \mathrm{U}$ - velocidade de propagação da onda ultrassônica; DA - densidade aparente estereométrica; DAHG - densidade aparente por imersão em mercúrio; (*) - significativo ao nível de 5\%; (**) - significativo ao nível de 1\%; (n.s) - não significativo.

Observou-se que para os maiores valores da DA nos tratamentos 3, 4, 7 e 8, maiores foram os valores da velocidade de propagação da onda ultrassônica nos briquetes. Este fato foi comprovado para os briquetes com pinus, tauari, bagaço de cana e pinhão manso.

Para os briquetes com a casca de arroz se observou uma tendência em se manter a relação descrita anteriormente, onde para maiores valores da $D A$, maiores valores da $V_{0} U$ seriam observados, porém os maiores valores da DA só corresponderam a maiores valores da $\mathrm{V}_{0} \mathrm{U}$ nos tratamentos 7 e 8 , onde se empregou maior temperatura associado à partícula fina.

Para a relação entre a DAHG e $\mathrm{V}_{0} \mathrm{U}$, não se observou a mesma relação descrita para a DA e $\mathrm{V}_{0} \mathrm{U}$. Portanto, os maiores valores da DAHG não corresponderam aos maiores valores da $\mathrm{V}_{0} \mathrm{U}$.

A Tabela 8 resume os coeficientes de determinação obtidos pela análise de regressão entre a densidade energética calculada a partir da densidade aparente por raio $\mathrm{X}$ e a $\mathrm{V}_{0} \mathrm{U}$. 
Tabela 8. Valores do coeficiente de determinação $-\mathrm{R}^{2}(\%)$ obtido pela análise de variância da regressão entre a avaliação não destrutiva e a densidade energética para os briquetes com as seis biomassas estudadas.

\begin{tabular}{lcccc}
\hline \multicolumn{1}{c}{ Biomassa } & Eixo $\mathrm{x}$ & \multicolumn{3}{c}{ Eixo y } \\
& & DERX & F de signif. & Signif. \\
\hline Pinus & 2,70 & 0,4650 & n.s \\
\hline Tauari & 0,00 & 0,9847 & n.s \\
Cumaru & & 8,83 & 0,2032 & n.s \\
\hline Casca de Arroz & $V_{0} U$ & 51,98 & 0,0000 & $* *$ \\
Bagaço de Cana & & 2,23 & 0,4860 & n.s \\
\hline Torta de Pinhão Manso & & 65,52 & 0,0000 & $* *$ \\
\hline
\end{tabular}

Onde: $\mathrm{V}_{0} \mathrm{U}$ - velocidade de propagação da onda ultrassônica; DERX - densidade aparente por raio $\mathrm{X} ;\left(^{*}\right)$ - significativo ao nível de $5 \% ;(* *)$ - significativo ao nível de $1 \%$; (n.s) - não significativo.

Análogo ao que foi observado para a predição da DA em função da $\mathrm{V}_{0} \mathrm{U}$, a predição da DERX foi eficiente para os briquetes confeccionados com a casca de arroz e a torta de pinhão manso, ainda que os valores do $\mathrm{R}^{2}$ tenham sido considerados baixos $(51,98$ e $65,52 \%$, respectivamente).

Comparando-se os métodos não destrutivos, a velocidade de propagação por meio das ondas ultrassônicas apresentou maiores valores dos coeficientes de determinação para os briquetes com as biomassas da casca de arroz e torta de pinhão manso. Neste caso o uso da $\mathrm{V}_{0} \mathrm{U}$ para a predição da DERX, pode ser recomendado.

A predição da DE e DEHG em função da $V_{0} U$ foi empregada e na Tabela 9 estão os coeficientes de determinação obtidos pela análise de regressão entre estas variáveis. 
Tabela 9. Valores do coeficiente de determinação $-\mathrm{R}^{2}(\%)$ obtido pela análise de variância da regressão entre a avaliação não destrutiva e a densidade energética para os briquetes com as seis biomassas estudadas.

\begin{tabular}{|c|c|c|c|c|c|c|c|}
\hline \multirow[t]{2}{*}{ Biomassa } & \multirow[t]{2}{*}{ Eixo $x$} & \multicolumn{6}{|c|}{ Eixo y } \\
\hline & & $\mathrm{DE}$ & $\begin{array}{c}\mathrm{F} \text { de } \\
\text { signif. }\end{array}$ & Signif. & DEHG & $\begin{array}{c}\mathrm{F} \text { de } \\
\text { signif. }\end{array}$ & Signif. \\
\hline Pinus & & 63,15 & 0,0000 & $* *$ & 45,18 & 0,0006 & $* *$ \\
\hline Tauari & & 93,73 & 0,0000 & $* *$ & 82,53 & 0,0000 & $* *$ \\
\hline Cumaru & & 31,20 & 0,0001 & $* *$ & 28,89 & 0,0145 & $*$ \\
\hline Casca de Arroz & $\mathrm{V}_{0} \mathrm{U}$ & 78,76 & 0,0000 & $* *$ & 67,39 & 0,0000 & $* *$ \\
\hline Bagaço de Cana & & 89,10 & 0,0000 & $* *$ & 69,20 & 0,0000 & $* *$ \\
\hline Torta de Pinhão Manso & & 73,95 & 0,0000 & ** & 36,43 & 0,0062 & ** \\
\hline
\end{tabular}

Onde: $\mathrm{V}_{0} \mathrm{U}$ - velocidade de propagação da onda de tensão; DE - densidade energética estereométrica; DEHG - densidade energética obtida por imersão em mercúrio; (*) significativo ao nível de 5\%; (**) - significativo ao nível de 1\%; (n.s) - não significativo.

A análise de variância da regressão para predição da DE e DEHG em função da $V_{0} U$, mostrou-se significativa para todas as biomassas, ou seja, a $V_{0} U$ foi capaz de estimar valores para estas variáveis energéticas. Excetuando-se os briquetes com a biomassa de cumaru $\left(\mathrm{R}^{2} \mathrm{de}\right.$ $31,20 \%$ ) e pinus ( $\mathrm{R}^{2}$ de $63,15 \%$ ), altos valores do $\mathrm{R}^{2}$ foram observados, destacando os valores obtidos para os briquetes com tauari e bagaço de cana (93,73 e 89,10\% respectivamente) na predição da DE.

Também foi observado que os valores do $\mathrm{R}^{2}$ referentes à relação da DE/DEHG em função da $\mathrm{V}_{0} \mathrm{U}$ foram superiores quando se utilizou como variável independente a $\mathrm{V}_{0} \mathrm{~S}$. Sendo assim, concluiu-se que a $\mathrm{V}_{0} \mathrm{U}$ foi um bom estimador para a DE e DEHG. Recomenda-se a utilização do parâmetro $\mathrm{DE}$ na predição do conteúdo energético de briquetes por meio da $\mathrm{V}_{0} \mathrm{U}$, pois maiores coeficientes de determinação foram observados. 


\subsection{AVALIAÇÃO DESTRUTIVA DOS BRIQUETES}

\subsubsection{Força Máxima de Compressão}

A Figura 9 mostra os valores médios obtidos para a força máxima de compressão (FMC, kgf) ou a carga máxima de ruptura, obtida para os briquetes confeccionados com as seis diferentes biomassas.

Pinus
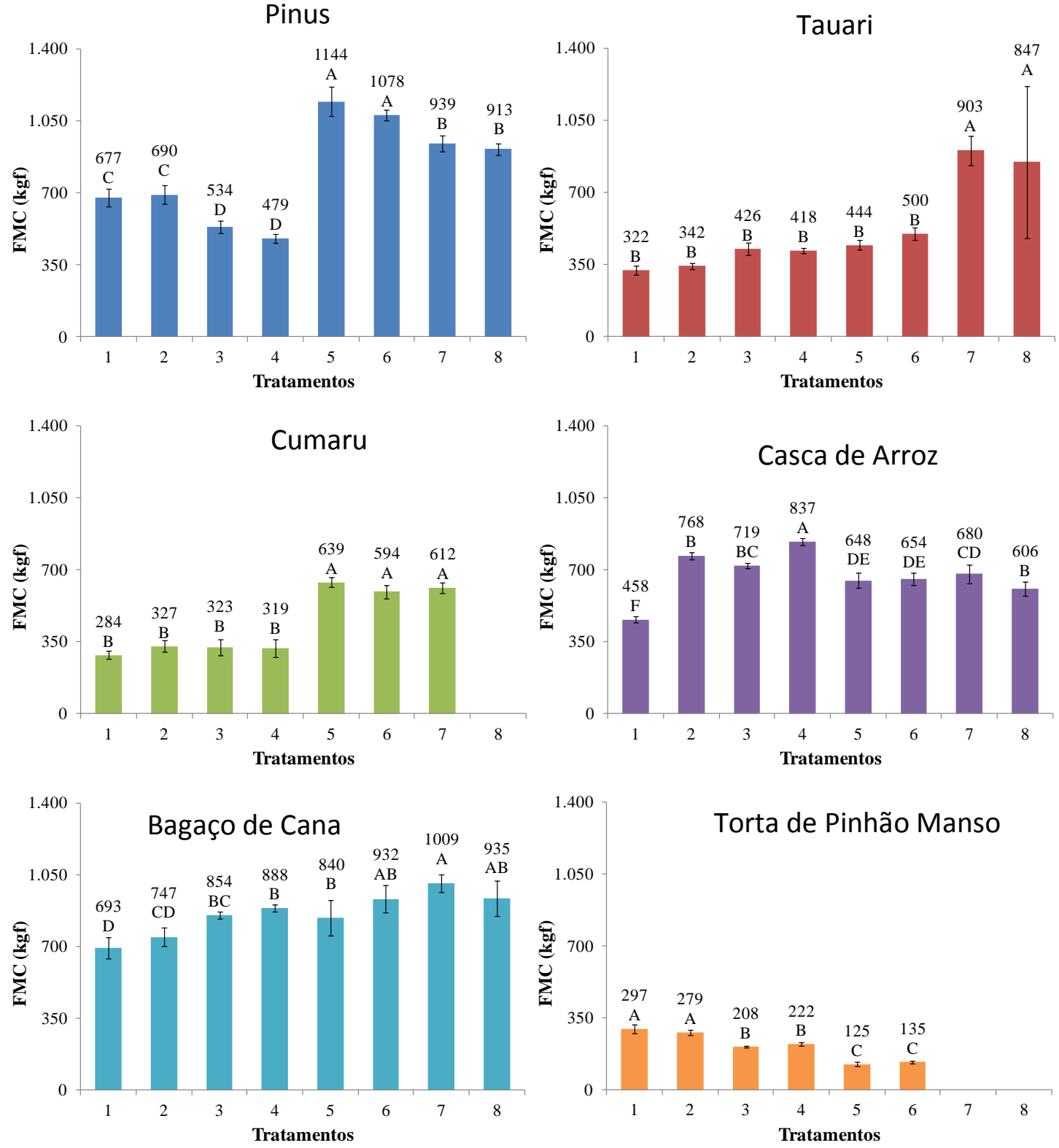

Figura 9. Valores da Força Máxima de Compressão (FMC - kgf) para os briquetes confeccionados a partir das biomassas de pinus, tauari, cumaru, casca de arroz, bagaço de cana e torta de pinhão manso; em função dos oito tratamentos propostos. Onde: Letras 
diferentes para a mesma biomassa representam diferenças estatisticamente significativas entre os tratamentos pelo Teste Tukey a 5\% de significância.

Observou-se que para os briquetes confeccionados com as biomassas florestais, existiu uma tendência de elevação dos valores médios utilizando-se a partícula fina. Para os briquetes confeccionados com cumaru, não houve diferença estatisticamente significativa entre os tratamentos com partículas finas, onde o valor médio observado foi entre 594 e 639 kgf. Por outro lado, os briquetes de pinus apresentaram um maior valor médio para os tratamentos $5 \mathrm{e}$ 6 (1144 e $1078 \mathrm{kgf}$, respectivamente), utilizando partícula fina e temperatura de $130^{\circ} \mathrm{C}$, diferindo estatisticamente dos tratamentos 7 e 8 (valores de 939 e 913 kgf, respectivamente).

No caso dos briquetes com tauari, a influência da partícula fina só foi observada com o emprego concomitante à temperatura de $200^{\circ} \mathrm{C}$. Possivelmente, o emprego de maior temperatura que favoreceu a resistência mecânica nos briquetes com tauari esteja ligada à temperatura de transição viscoelástica mais elevada nesta biomassa, onde após a elevação de 130 para $200^{\circ} \mathrm{C}$, ocorreu um maior amolecimento da lignina e consequentemente maior interação entre as partículas.

Para os briquetes confeccionados com biomassa agrícola, percebeu-se que não houve um só comportamento para as três biomassas. Para os briquetes com casca de arroz, o maior valor médio foi para o tratamento 4 (837 kgf) empregando partícula grossa, $200^{\circ} \mathrm{C}$ e pressão de 120 $\mathrm{kgf} / \mathrm{cm}^{2}$ na compactação. A menor média foi para o tratamento 1 (458 kgf), utilizando a partícula grossa, $130^{\circ} \mathrm{C}$ e $80 \mathrm{kgf} / \mathrm{cm}^{2}$ na compactação.

Para os briquetes com bagaço de cana, houve uma discreta superioridade dos valores da FMC utilizando-se partículas finas e destacou-se a maior média para o tratamento 7, apresentando 1009 kgf na resistência mecânica.

Por fim, o pior desempenho em termos de resistência diametral dos briquetes foi para os que se utilizaram a torta de pinhão manso para a compactação da biomassa. O valor mais alto da FMC com esta biomassa foi para o tratamento 1 e 2 (297 e 279 kgf, respectivamente) e o valor mais baixo foi de 125 e $135 \mathrm{kgf}$ nos tratamentos 5 e 6 , respectivamente. Estes resultados 
corroboraram o descrito no capítulo anterior, onde se observou o aspecto quebradiço dos briquetes confeccionados com esta biomassa.

De uma forma geral, a pressão de compactação influenciou apenas os briquetes constituídos com a casca de arroz. Assim, a influência da pressão na resistência mecânica (FMC) foi positiva, ou seja, os briquetes se tornaram mais resistentes mecanicamente entre os tratamentos 1 e 2 (de 458 para $768 \mathrm{kgf}$ ) assim como entre os tratamentos 3 e 4 (de 719 para 837 kgf). Por outro lado, a pressão de compactação reduziu a resistência mecânica dos briquetes entre os tratamentos 7 e 8 (de 680 para $606 \mathrm{kgf}$ ), possivelmente por estar associada à temperatura de $200^{\circ} \mathrm{C}$ e com partículas finas.

Ainda, o efeito da temperatura só foi evidenciado nos briquetes de pinus e tauari. Com os briquetes de pinus, quanto menor a temperatura de compactação, maiores foram os valores da FMC, tanto para partículas finas como partículas grossas. Já para os briquetes com tauari, o efeito foi o contrário, porém, só ocorreu para partículas finas.

Analisando os resultados da FMC, percebeu-se que a densidade aparente obtida pelo método estereométrico $\left(\mathrm{DA}, \mathrm{g} / \mathrm{cm}^{3}\right.$ ) não corroboram os valores observados para esta variável que expressa a resistência mecânica dos briquetes. Para os briquetes de pinus, os menores valores da DA foram os maiores valores da FMC. Citam-se os valores dos tratamentos 5 e 6 com DA de 1,107 e 1,098 g/cm³ respectivamente; apresentaram valores da FMC de 1144 e 1078 kgf. Por outro lado, os tratamentos 3 e 4 com DA de 1,202 e 1,190 g/ $\mathrm{cm}^{3}$ mostraram FMC de 534 e $479 \mathrm{kgf}$, respectivamente.

Esta relação entre a DA e a FMC só foi caracterizada como diretamente proporcional para os briquetes com a torta de pinhão manso e tauari, onde os maiores valores da DA para os tratamentos 1 e 2 representaram maiores valores da FMC com a primeira biomassa e para os tratamentos 7 e 8 com a segunda. Destaca-se que neste último caso, esta relação diretamente proporcional só foi observada para os briquetes confeccionados com alta temperatura e partículas finas.

Conforme já descrito no capítulo anterior, o comportamento da densidade aparente obtida pelo método de imersão em mercúrio (DAHG, $\mathrm{g} / \mathrm{cm}^{3}$ ) foi bastante semelhante ao 
comportamento da DA. Assim, o efeito da DAHG na FMC foi também semelhante ao observado pela DA. O mesmo foi observado utilizando-se a densidade aparente obtida pelo método do raio-X (DARX, $\left.\mathrm{g} / \mathrm{cm}^{3}\right)$.

Ainda, investigou-se a viabilidade de se empregar a $V_{0} S$ e $V_{0} U$ como forma de predição da FMC para os briquetes com as seis biomassas estudadas. Excetuando-se os casos onde se empregou a $\mathrm{V}_{0} \mathrm{~S}$ para a predição da $\mathrm{FMC}$ nos briquetes com a casca de arroz e com pinus, verificou-se que as demais regressões foram significativas ao nível de $5 \%$ na análise de variância. A Tabela 10 resume os valores do coeficiente de determinação $\mathrm{R}^{2}(\%)$ para a análise de regressão entre as variáveis não destrutivas (independentes) e a destrutiva (dependente) nos briquetes com as seis biomassas estudadas.

Tabela 10. Valores do coeficiente de determinação $-\mathrm{R}^{2}(\%)$ obtido pela análise de variância da regressão entre a avaliação não destrutiva e a força máxima de compressão para os briquetes com as seis biomassas estudadas.

\begin{tabular}{|c|c|c|c|c|}
\hline \multirow[t]{2}{*}{ Biomassa } & \multirow[t]{2}{*}{ Eixo $x$} & \multicolumn{3}{|c|}{ Eixo y } \\
\hline & & FMC & F de signif. & Signif. \\
\hline Pinus & & 3,2 & 0,2453 & n.s. \\
\hline Tauari & & 71,74 & 0,0000 & $* *$ \\
\hline Cumaru & & 28,59 & 0,0003 & $* *$ \\
\hline Casca de Arroz & $\mathrm{V}_{0} \mathrm{~S}$ & 4,29 & 0,1775 & n.s. \\
\hline Bagaço de Cana & & 26,48 & 0,0003 & $* *$ \\
\hline Torta de Pinhão Manso & & 65,05 & 0,0000 & $* *$ \\
\hline Pinus & & 3,43 & 0,0140 & $*$ \\
\hline Tauari & & 77,26 & 0,0000 & $* *$ \\
\hline Cumaru & & 35,34 & 0,0000 & $* *$ \\
\hline Casca de Arroz & $\mathrm{V}_{0} \mathrm{U}$ & 10,22 & 0,0344 & $*$ \\
\hline Bagaço de Cana & & 40,12 & 0,0000 & $* *$ \\
\hline Torta de Pinhão Manso & & 66,37 & 0,0000 & $* *$ \\
\hline
\end{tabular}

Onde: $\mathrm{V}_{0} \mathrm{~S}$ - velocidade de propagação da onda de tensão; $\mathrm{V}_{0} \mathrm{U}$ - velocidade de propagação da onda ultrassônica; FMC - força máxima de compressão; (*) - significativo ao nível de 5\%; (**) - significativo ao nível de 1\%; (n.s) - não significativo. 
Com os dados da Tabela 10, notou-se que a $\mathrm{V}_{0} \mathrm{~S}$ e $\mathrm{V}_{0} \mathrm{U}$ só podem ser empregadas para a estimativa dos valores da FMC para os briquetes com a biomassa de tauari, onde os valores do $\mathrm{R}^{2}$ superaram os $70 \%(71,74 \%$ e $77,26 \%$ respectivamente). Percebeu-se também a superioridade do $\mathrm{R}^{2}$ para a relação $\mathrm{V}_{0} \mathrm{U}$ e $\mathrm{FMC}$, sugerindo a maior precisão do método de ultrassom para a estimativa daquela propriedade.

Para os briquetes com as demais biomassas, a $V_{0} S$ e $V_{0} U$ não devem ser utilizadas como parâmetros para estimar a resistência mecânica devido aos baixos valores do coeficiente de determinação.

\subsubsection{Resistência à Tração por Compressão Diametral}

A Figura 10 mostra os valores médios para a resistência à tração por compressão diametral $\left(\mathrm{RTCD}, \mathrm{kgf} / \mathrm{cm}^{2}\right.$ ), obtido para os briquetes confeccionados com as seis diferentes biomassas. 

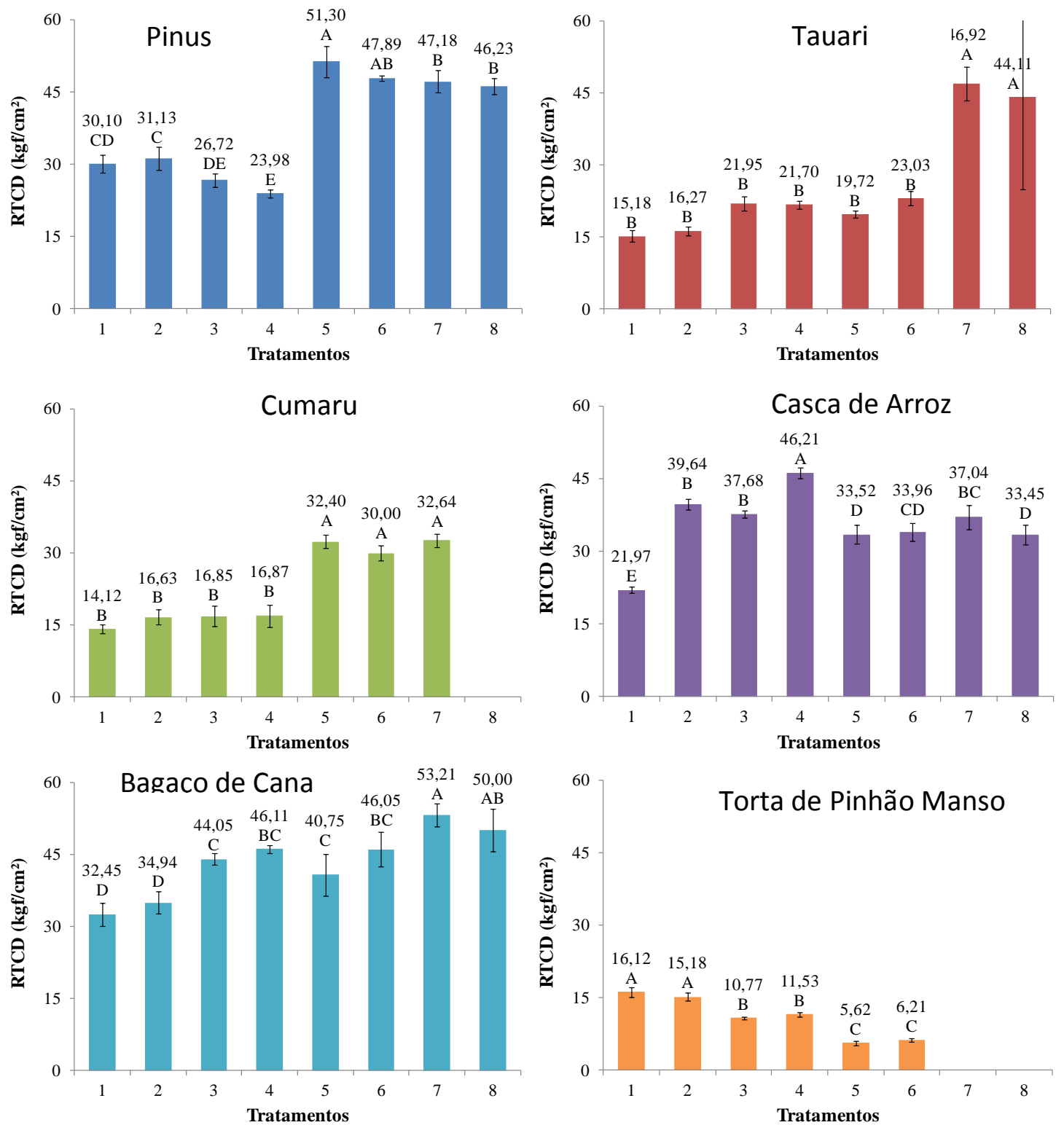

Figura 10. Valores da Resistência à Tração por Compressão Diametral (RTCD - $\mathrm{kgf} / \mathrm{cm}^{3}$ ) para os briquetes confeccionados a partir das biomassas de pinus, tauari, cumaru, casca de arroz, bagaço de cana e torta de pinhão manso; em função dos oito tratamentos propostos. Onde: Letras diferentes para a mesma biomassa representam diferenças estatisticamente significativas entre os tratamentos pelo Teste Tukey a 5\% de significância.

De uma forma geral, o comportamento das médias da RTCD foi bastante semelhante ao comportamento obtido para a força máxima de compressão descrita anteriormente, porém, levando-se em consideração, as dimensões do briquete no cálculo desta propriedade. 
Assim, o efeito da partícula foi o mais significativo a partir de uma relação diretamente proporcional com a resistência mecânica, ou seja, ao se utilizar partículas finas, maiores foram os valores observados para a RTCD. Este comportamento foi observado para os briquetes confeccionados com resíduos florestais e com o bagaço de cana.

Por outro lado, para os briquetes de pinhão manso, as partículas grossas na compactação resultaram em maiores médias da RTCD, conforme descrito para a FMC.

Souza et al. (2012) observaram esta semelhança de comportamentos entre a FMC e RTCD em briquetes confeccionados com serragem de Cupiúba (Goupia glabra). Apesar de levar em consideração as dimensões dos briquetes no cálculo da RTCD, no presente estudo as dimensões pouco variaram entre os tratamentos ou entre as biomassas. Assim, estas pequenas variações não resultaram em diferenças perceptíveis entre as duas formas de se determinar a resistência mecânica dos briquetes, sujeitos à forças aplicadas no sentido diametral.

Portanto, o efeito da pressão, temperatura e tamanho das partículas, foram semelhantes ao descrito para a FMC, nas seis biomassas estudadas.

Um estudo empregando a $\mathrm{V}_{0} \mathrm{~S}$ e a $\mathrm{V}_{0} \mathrm{U}$ em modelos de regressão linear simples para estimar os valores de RTCD foi realizado. A Tabela 11 resume os valores do coeficiente de determinação $\mathrm{R}^{2}(\%)$ para a análise de regressão entre as variáveis não destrutivas (independentes) e a destrutiva (dependente) nos briquetes com as seis biomassas estudadas. 
Tabela 11. Valores do coeficiente de determinação $-\mathrm{R}^{2}(\%)$ obtido pela análise de variância da regressão entre a avaliação não destrutiva e a resistência à tração por compressão diametral para os briquetes com as seis biomassas estudadas.

\begin{tabular}{|c|c|c|c|c|}
\hline \multirow[t]{2}{*}{ Biomassa } & \multirow[t]{2}{*}{ Eixo $x$} & \multicolumn{3}{|c|}{ Eixo y } \\
\hline & & RTCD & F de signif. & Signif. \\
\hline Pinus & & 13,53 & 0,2291 & n.s. \\
\hline Tauari & & 57,94 & 0,0000 & $* *$ \\
\hline Cumaru & & 36,07 & 0,0000 & $* *$ \\
\hline Casca de Arroz & $\mathrm{V}_{0} \mathrm{~S}$ & 3,22 & 0,2436 & n.s. \\
\hline Bagaço de Cana & & 49,43 & 0,0000 & $* *$ \\
\hline Torta de Pinhão Manso & & 85,05 & 0,0000 & $* *$ \\
\hline Pinus & & 14,55 & 0,0106 & $*$ \\
\hline Tauari & & 64,62 & 0,0000 & $* *$ \\
\hline Cumaru & & 43,13 & 0,0000 & $* *$ \\
\hline Casca de Arroz & $\mathrm{V}_{0} \mathrm{U}$ & 9,96 & 0,0369 & $*$ \\
\hline Bagaço de Cana & & 67,96 & 0,0000 & $* *$ \\
\hline Torta de Pinhão Manso & & 85,54 & 0,0000 & $* *$ \\
\hline
\end{tabular}

Onde: $\mathrm{V}_{0} \mathrm{~S}$ - velocidade de propagação da onda de tensão; $\mathrm{V}_{0} \mathrm{U}$ - velocidade de propagação da onda ultrassônica; RTCD - resistência à tração por compressão diametral; (*) significativo ao nível de 5\%; (**) - significativo ao nível de 1\%; (n.s) - não significativo.

Foi observado que, da mesma forma apresentado para a predição da FMC, a regressão não foi significativa empregando-se a $\mathrm{V}_{0} \mathrm{~S}$ na estimativa da FMC em briquetes com pinus e casca de arroz. Assim, nesta situação a $\mathrm{V}_{0} \mathrm{~S}$ não pode ser empregada para predizer a RTCD.

Observou-se também que apesar de as regressões para os briquetes com as outras biomassas terem sido significativas, os valores do $\mathrm{R}^{2}$ foram baixos para os briquetes com tauari, cumaru e bagaço de cana. Uma boa relação entre a RTCD e a avaliação não destrutiva só foi detectada para os briquetes com a torta de pinhão manso, onde o valor do $\mathrm{R}^{2}$ ultrapassou os $85 \%$, tanto quando foi empregada a $\mathrm{V}_{0} \mathrm{~S}$ como para a $\mathrm{V}_{0} \mathrm{U}$. Ainda, praticamente não houve diferença entre os $\mathrm{R}^{2}$ dos dois métodos de propagação da onda. 


\section{CONCLUSÕES}

Conforme os resultados apresentados para o presente estudo pode-se concluir que:

- A temperatura e posteriormente o tamanho da partícula foram os fatores que mais influenciaram a $\mathrm{V}_{0} \mathrm{~S}$ e $\mathrm{V}_{0} \mathrm{U}$, onde de uma forma geral, com exceção dos briquetes produzidos com a torta de pinhão manso, quanto maior a temperatura e menor a partícula, maiores velocidades de propagação foram observadas. Para os briquetes de torta de pinhão manso, a relação foi inversa;

. Com vistas à resistência mecânica, o tamanho da partícula influenciou as médias da força máxima de compressão (FMC) e da resistência à tração por compressão paralela (RTCD). Em ambos os casos houve uma tendência em se reduzir o tamanho da partícula e consequentemente aumentar a resistência mecânica, excetuando-se os briquetes de torta de pinhão manso, onde a relação foi inversa;

. Os valores médios da $\mathrm{V}_{0} \mathrm{~S}$ e $\mathrm{V}_{0} \mathrm{U}$ tiveram comportamento de forma geral, bastante semelhantes entre si, assim como os valores médios da FMC e a RTCD;

. Os parâmetros DARX e DERX não devem ser estimados pela $\mathrm{V}_{0} \mathrm{~S}$ e $\mathrm{V}_{0} \mathrm{U}$. O comportamento da velocidade de propagação da onda de tensão e ultrassônica $\left(\mathrm{V}_{0} \mathrm{~S}\right.$ e $\left.\mathrm{V}_{0} \mathrm{U}\right)$ foram mais relacionados com a densidade aparente obtida pelo método estereométrico, podendo ser estimada em alguns casos;

- $A V_{0} \mathrm{U}$ pode ser apontada como a variável mais eficiente na predição das propriedades estudadas ao apresentar 


\section{REFERÊNCIAS BIBLIOGRÁFICAS}

ASSOCIAÇÃO BRASILEIRA DE NORMAS TÉCNICAS. NBR 8112: Carvão vegetal: análise imediata, Rio de Janeiro, 1986.

ASSOCIAÇÃO BRASILEIRA DE NORMAS TÉCNICAS. NBR 8633: Carvão vegetal: determinação do poder calorífico, Rio de Janeiro, 1984.

ASSOCIAÇÃO BRASILEIRA DE NORMAS TÉCNICAS. NBR 7222: Argamassa e concreto - Determinação da resistência à tração por compressão diametral de corpos-de-prova cilíndricos, Rio de Janeiro, 1994.

AZEVEDO JÚNIOR, A. P. Avaliação não destrutiva de propriedades mecânicas de madeiras através da técnica de ultra-som: fundamentos físicos e resultados experimentais. 2002. 196f. Dissertação (Mestrado em Engenharia de Estruturas) - Universidade Federal de Minas Gerais, Belo Horizonte. 2002.

BARTHOLOMEU, A. Classificação de peças estruturais de madeira através do ultra-som. Tese (Doutorado em Engenharia Agrícola) - Universidade Estadual de Campinas, Campinas. 2001.

BODIG, J. The process of NDE research for wood and wood composites. The e-Journal of Nondestructive Testing, v.26, n.3, 2001.

BRASHAW, B. K.; WANG, X.; ROSS, R. J.; PELLERIN, R. F. Relationship between stress wave velocities of green and dry veneer. Forest Products Journal, Madison, v. 54, n. 6, p. 8589, 2004.

BRITO, J. O. Expressão da produção florestal em unidades energéticas. In Congresso Florestal Panamericano, 1, Congresso Florestal Brasileiro, 7, 1993, Curitiba, Anais...Curitiba: Sociedade Brasileira de Silvicultura, 1993, p.280-282.

BRITO, J. O.; BARRICHELO, L. E. G. Carvão vegetal de madeira de desbaste de Pinus. Circular Técnica IPEF, Piracicaba, v. 146, p. 1-12, jun. 1981.

BUCUR, V. Acoustics of Wood. Boca Raton, Florida, USA: CRC Press, Inc., 1995.

BULIGON, E.A. Características físico-mecânicas de painéis de lâminas paralelas reforçados com fibra de vidro. 2011. 96f. Dissertação (Mestrado em Engenharia Florestal) Universidade Federal de Santa Maria, Santa Maria. 2011.

CARVALHO, A.M. Caracterização de painéis LVL obtidos da madeira do híbrido de eucalipto Eucalyptus grandis x Eucalyptus urophylla do Estado de São Paulo. 2004. 80f. Tese (Doutorado em Ciência e Engenharia de Materiais) - Universidade de São Paulo, São Carlos. 2004.

GABRIEL, M. S. C. Desempenho físico-mecânico de painéis LVL de pinus tropicais da região de São Paulo. 2007, 125f. Tese (Doutorado em Agronomia - Energia na Agricultura) Universidade Estadual Paulista, Botucatu. 2007.

GOMIDE, R. Estequiometria industrial. $3^{a}$ ed. São Paulo: 1984. 423 p.

MELO, R. R. Avaliação de variáveis tecnológicas para produção de painéis LVL com a madeira de Paricá (Schizolobium amazonicum Huber ex Ducke). 2012. 164f. Tese (Doutorado em Ciências Florestais) - Universidade Federal de Brasília, Brasília/DF. 2012. 
MINÁ, A. J. S.; OLIVEIRA, F. G. R.; CALIL JR, C.; DIAS, A. A.; SALES, A. Avaliação não destrutiva de postes de madeira por meio de ultra-som. Scientia Forestalis, n. 65, p. 188196, 2004.

MORALES, E. A. M. 2006. Técnicas de propagação de ondas na estimativa de propriedades mecânicas de painéis OSB. Tese (Doutorado em Ciência e Engenharia de Materiais) Interunidades Ciência e Engenharia de Materiais da Universidade de São Paulo, São Carlos. 2006.

OLIVEIRA, F. G. R.; CAMPOS, J. A. O.; SALES, A. Ultrasonic measurements in Brazilian hardwood. Materials Research, São Carlos, v. 5, n. 1, p. 51-55, 2002.

OLIVEIRA, F. G. R.; MILLER, K. P.; CANDIAN, M.; SALES, A. Efeito do comprimento do corpo-de-prova na velocidade ultra-sônica em madeiras. Árvore, n. 1, v. 30, p. 141-145, 2006.

PELLERIN, R.F.; ROSS, J.R. Nondestructive evaluation of wood. Madison: FPS. 2002, 210p.

PINHEIRO, G. F.; RENDEIRO, G.; PINHO, J. T. Densidade energética de resíduos vegetais. Biomassa \& Energia, v. 2, n. 2, p. 113-123. 2005.

PROTÁSSIO, T. P.; ALVES, I. C. N.; TRUGILHO, P. F.; SILVA, V. O.; BALIZA, A. E. R. Compactação de biomassa vegetal visando à produção de biocombustíveis sólidos. Pesquisa Florestal Brasileira, Colombo, v. 31, n. 68, p. 273-283, 2011.

PUCCINI, C. T. Avaliação de aspectos de qualidade da madeira utilizando o ultra-som. 2002. 139f. Tese (Doutorado em Engenharia Agrícola) - Universidade Estadual de Campinas, Campinas. 2002.

QUIRINO, W. F.; PINHA, I. V. O; MOREIRA, A. C. O. M.; SOUZA, F.; TOMAZELLO FILHO, M. Densitometria de raios x na análise da qualidade de briquetes de resíduos de madeira. Scientia Forestalis, v. 40, n. 96, p. 525-536. 2012.

QUIRINO, W. F.; VALE, A. T.; ANDRADE, A. P. A.; ABREU, V. L. S. A.; AZEVEDO, A. C. S. Poder calorífico da madeira e de resíduos lignocelulósicos. Biomassa \& Energia, v. 1, n. 2, p. 173-182, 2004.

QUIRINO, W. F.; VALE, A. T.; ANDRADE, A. P. A.; ABREU, V. L. S.; AZEVEDO, A. C. S. Poder calorífico da madeira e de materiais ligno-celulósicos. Revista da Madeira, n. 89, p. 100-106, 2005.

QUIRINO, W.F.; BRITO, J.O. Características e índice de combustão de briquetes de carvão vegetal. Brasília: IBAMA / LPF- Laboratório de Produtos Florestais, 1991. (Série Técnica, n.13).

ROSS, R. J.; BRASHAW, B. K.; PELLERIN, R. F. Nondestructive evaluation of wood. Forest Products Journal, v. 48, n. 1, p. 14-19, 1998.

ROSS, R.J.; WILLITS, S.W.; SEGEN, W.N.; BLACK, T.; BRASHAW, B; PELLERIN, R.F. A stress wave based approach to nde of $\operatorname{logs}$ for assessing potential veneer quality. Part 1 . Small-diameter ponderosa pine. Forest Products Journal, v.49, n. 11/12, p.60-62, 1999.

SOUZA, F.; TELES, R. F.; RIBEIRO, P. G.; CAMARGOS, A. M.; DEL MENEZZI, C. H. S. Resistência natural e alteração da cor da madeira de Machaerium scleroxylon Tul. submetida ao ataque de fungos apodrecedores. Scientia Forestalis, v. 38, n. 87, p. 449-457, 2010a. 
SOUZA, F.; DEL MENEZZI, C. H. S., BORTOLETO JÚNIOR, G. Material properties and nondestructive evaluation of laminated veneer lumber (LVL) made from Pinus oocarpa and P. kesiya. European Journal of Wood Products, n. 69, v. 2, p. 183-192, 2011.

SOUZA, M. M.; SILVA, D. A.; ROCHADELLI, R.; SANTOS, R. C. Estimativa de poder calorífico e caracterização para uso energético de resíduos da colheita e do processamento de Pinus taeda. Floresta, v. 42, n. 2, p. 325-334. 2012a.

STANGERLIN, D. M.; GATTO, D. A.; MELO, R. R.; CALEGARI, L.; VIVIAN, M. A.; CASTELO, P. A. R.; BELTRAME, R. Uso do ultrassom para estimativa das propriedades mecânicas da madeira de Peltophorum dubium. Ciência da Madeira, v. 1, n. 2, p. 44-53, 2010.

TECHNICAL ASSOCIATION OF PULP AND PAPER - TAPPI. Sampling and preparation wood for analysis. T $257 \mathrm{om}-88$. TAPPI, test chemical, Atlanta, TAPPI press, 1996a.

TRINCA, A. J. Metodologia para determinação das constantes elásticas da madeira por ultrassom. Tese (Doutorado em Engenharia Agrícola) - Universidade Estadual de Campinas, Campinas. 2011.

VALE, A. T.; GENTIL, L. V.; GONÇALEZ, J. C.; COSTA, A. F. Caracterização energética e rendimento da carbonização de resíduos de grãos de café (Coffea arabica) e de madeira (Credrelinga catenaeformis). Cerne, Lavras. V.13, n.4, p.416-420, out./dez 2007. 


\section{CONSIDERAÇÕES FINAIS}

\section{CONCLUSÕES GERAIS}

- As biomassas utilizadas no presente estudo foram consideradas aptas à briquetagem nos determinados parâmetros de temperatura, pressão e granulometria, excetuando-se o cumaru e torta de pinhão manso para altas temperatura e pressão quando associada à partícula fina; pois estouros ou fissuras profundas inviabilizaram a formação do briquete;

. Do ponto de vista da densidade aparente, o método mais preciso foi o da densitometria de raio $\mathrm{X}$ sendo os briquetes que apresentaram melhor desempenho foram os com bagaço de cana. Aparentemente, o conteúdo mineral na biomassa da casca de arroz e da torta de pinhão manso superestimaram as médias deste parâmetro. Resultado semelhante foi o obtido para a densidade energética, sugerindo a utilização do bagaço de cana na fabricação de briquetes;

- Do ponto da resistência mecânica, os briquetes de bagaço de cana e pinus foram os que apresentaram desempenho superior à esforços no sentido diametral, sugerindo menores danos à integridade estrutural dos briquetes, como fraturas ou esmigalhamentos, durante o transporte ou quedas;

- As técnicas de avaliação não destrutiva por ondas de tensão ou ultrassônicas foram sensíveis às variações dos parâmetros de briquetagem e tem potencial para serem utilizadas na predição da densidade aparente e densidade energética em alguns casos, com destaque para o ultrassom. 


\section{RECOMENDAÇÕES}

Visando o aprofundamento do tema, recomenda-se avaliar adicionalmente os seguintes parâmetros:

- A influência dos fatores como o conteúdo de umidade e conteúdos minerais (cinzas) em biomassas agrícolas na determinação da densidade aparente pelo método de raio $\mathrm{X}$, assim como obter as extremidades dos briquetes perfeitamente planas;

- A predição da densidade aparente e da densidade energética em briquetes comerciais utilizando-se métodos não destrutivos como forma de validação dos resultados obtidos em escala laboratorial;

. A predição da resistência mecânica em briquetes comerciais por métodos não destrutivos;

. A influência de outros materiais acoplantes, diferentes do gel medicinal, na determinação da velocidade de propagação através com o equipamento de ultrassom. 